Cuadernos

de trabajo social

$\mathrm{N}^{\mathrm{o}} 17 \cdot 2010$ 




\section{ALTERNATIVAS \\ Cuadernos de Trabajo Social}

N. ${ }^{\circ} 17$. Año 2010

Estado de Bienestar y cuidados: entre el modelo familista, la institucionalización y la desnacionalización del cuidado

Belén Agrela, M. ${ }^{a}$ Teresa Martín y Delia Langa (coords.)

DEPARTAMENTO DE TRABAJO SOCIAL Y SERVICIOS SOCIALES UNIVERSIDAD DE ALICANTE 
Publicaciones de la Universidad de Alicante

Campus de San Vicente s/n

03690 San Vicente del Raspeig

Publicaciones@ua.es

http://publicaciones.ua.es

Teléfono: 965903480

Fax: 965909445

(C) de la presente edición: Universidad de Alicante

ISSN: 1133-0473

ISSN electrónico: 1989-9971

Depósito legal: M.37.152-1992

Diseño de portada: candela ink

Corrección de pruebas: M. ${ }^{a}$ Fernanda de Andrés

Composición:

E Espagrafic

Impresión:

Reservados todos los derechos. No se permite reproducir, almacenar en sistemas de recuperación de la información, ni transmitir alguna parte de esta publicación, cualquiera que sea el medio empleado -electrónico, mecánico, fotocopia, grabación, etcétera-, sin el permiso previo de los titulares de la propiedad intelectual. 


\section{ÍNDICE}

1. Modelos de provisión de cuidados: género, familias y migraciones. Nuevos retos y configuraciones para las políticas públicas

Care provision models: gender, families and migrations.

New challenges and outlines for public policy.... 9

Belén Agrela Romero, M. ${ }^{a}$ Teresa Martín Palomo

Y DELIA LANGA ROSADO

2. Familismo, asitencialismo y precariedad. La configuración del empleo en el sector de atención a las personas en España Familism, Welfarism and Precariousness. How Employment is Structured in Spain's care sector 19

Carolina Recio Cáceres

3. Fundamentos éticos para la promoción de la autonomía: hacia una ética de la interdependencia

Ethical grounds for promoting autonomy: towards an ethic of interdependence 45

Francisco GuZMÁn CASTILlo, MARIO TOBOSO MARTÍN

Y JAVIER ROMAÑACH CABRERO

4. La gestión de la crisis de los cuidados y su relación con la feminización de las migraciones. Análisis comparativo de los modelos de España y Chile Managing the crisis in care and its relationship with the feminisation of migrations. A comparative analysis of the models in Spain and Chile 63

M. ${ }^{a}$ LUISA SETIÉN SANTAMARÍA y Elaine ACOSTA GONZÁlEZ 
5. El Trabajo Social y las nuevas formas de reorganización del cuidado. Una aproximación a propósito de la Ley de Dependencia Social work and the new ways of reorganising care.

A consideration of the Dependent Care Law.... 83

VIRGINIA FUENTES GUTIÉRREZ, JESÚS MUYOR RODRÍGUEZ

Y ZAHIRA GALINDO ROMERO

6. Impacto de la Ley de Dependencia en los cuidados a la tercera edad en el ámbito rural: el caso de Enguera

The impact of the dependent care law on the elderly in rural areas:

The case of Enguera 103

CRISTINA BENLLOCH DOMÉNECH Y JOAQUín SARRIÓN ESTEVE

7. Configuraciones del trabajo de cuidados en el entorno familiar.

De la toma de decisión a la gestión del cuidado

How care work is organised in the family environment.

From decision making to managing care

ANTía PÉREZ CARAMÉS

8. Necesidades de los hombres frente a cuidados de larga duración de sus parejas con esclerosis múltiple: los casos de Finlandia, Austria y España Needs of men in front of the long-term care of their partners with Multiple Sclerosis: the cases of Finland, Austria and Spain. 141

M. ${ }^{a}$ CARMEN PÉREZ BELDA

9. Servicio doméstico y trabajo de cuidados. Hacia la privatización del cuidado familiar

Domestic service and care work. Towards the privatisation of family care

RAQUEL MARTíNEZ BUJÁN

10. El tiempo de trabajo de las cuidadoras inmigrantes de personas mayores

The working time of migrant caregivers for elderly people 181

EVA MARTín COPPOla y JESÚs ROGERO GarCía 
11. «Las otras» cuidadoras: mujeres inmigrantes en el servicio doméstico y trasvases generizados en el ámbito territorial del bienestar

"The other» carers: immigrant women in domestic service and genderised transfers in local welfare 201 M. ${ }^{a}$ JOSÉ AGUILAR IDÁÑEZ

12. Gestión de los cuidados, desnacionalización y precariedad laboral: una perspectiva comparada Care management, denationalisation and precarious employment: a comparative perspective 221 LUCÍA MARTÍNEZ VIRTO

\section{RESEÑAS}

PASTOR Seller, Enrique, Participación ciudadana y gestión de las politicas sociales municipales, Murcia, Ediciones de la Universidad de Murcia, 2009, 318 páginas. ISBN: 978-84-8371-828-5

VIVANCO, Borja, Cultura y técnicas de gestión en las ONG, Madrid, Editorial CCS, 2009, 244 páginas. ISBN: 978-849842-336-5

VV.AA. Gestión de caso (y métodos afines) en servicios sanitarios y sociales, en Revista Politicas Sociales en Europa, 25, 26, Hacer Editorial, 2009. ISBN: 978-84-96913-23-3 241

Instrucciones para los autores 245

Instructions for the authors 263

Protocolo revisores externos 279

External reviewers' protocol 285 



\title{
MODELOS DE PROVISIÓN DE CUIDADOS: GÉNERO, FAMILIAS Y MIGRACIONES. NUEVOS RETOS Y CONFIGURACIONES PARA LAS POLÍTICAS PÚBLICAS
}

\section{Care provision models: gender, families and migrations. New challenges and outlines for public policy}

\author{
BELÉN Agrela ROMERO* \\ $\mathrm{M}^{a}$ TERESA MarTín PALOMO** \\ DELIA LANGA ROSADO***
}

Este monográfico, que lleva por título Estado de Bienestar y cuidados: entre el modelo familista, la institucionalización y la desnacionalización del cuidado, surge del encuentro científico sobre esta temática celebrado en Oviedo los

\footnotetext{
* Belén Agrela Romero

Departamento de Psicología, área de Trabajo Social y Servicios Sociales Universidad de Jaén Edificio C5, despacho 119. Campus Las Lagunillas, s/n. 23071 Jaén

Teléfono: 953212963 Fax: 953211881

bagrela@ujaen.es

* $\quad$ M. ${ }^{\text {a }}$ Teresa Martín Palomo

Departamento de Ciencia Política y Sociología

Universidad Carlos III de Madrid

Despacho 9.0.10. C/ Madrid, 126-128. 28903 Madrid

Teléfono: 916249330 Fax: 916249574

mtmartin@polsoc.uc3m.es

*** Delia Langa Rosado

Departamento de Administración de Empresas, Contabilidad y Sociología

Universidad de Jaén

Despacho 180, D-3. Campus Las Lagunillas, s/n. 23071 Jaén

Teléfono: 953212993 Fax: 953211869

dlanga@ujaen.es
} 
días 5 y 6 de noviembre de 2009. ${ }^{1}$ Como directoras del panel, nos planteamos propiciar el intercambio y el debate científico y profesional entre quienes trabajamos con cuidados desde diferentes ámbitos y enfoques, en el campo de la política social, de género y de la acción social. Quisimos delimitar un lugar de estudio y análisis sobre los modos de abordar el cuidado a las personas en situación de dependencia, o con mayor vulnerabilidad, a la luz de las transformaciones que han tenido lugar recientemente a nivel social, familiar, político, económico y normativo. A partir de los retos que plantea la descrita como «crisis de los cuidados» (Hochschild, 1995; Pérez Orozco, 2005), parecía especialmente sugerente indagar sobre los actuales modelos de gestión de los cuidados en el marco de un Estado de Bienestar de corte familista como el nuestro.

En los últimos años, la incorporación de las mujeres españolas al mercado laboral y el incremento de personas en situación de dependencia y/o con dificultades para desarrollar su vida diaria con autonomía (derivado sobre todo del progresivo envejecimiento de la población), en el marco de una enorme limitación de medidas de protección social, con escasa capacidad de cobertura de las necesidades de la población desde el universo de lo público, han tenido un impacto y unas consecuencias importantes sobre cómo se resuelven los cuidados en la vida cotidiana. Así, por ejemplo, la asistencia a sus parientes enfermos y con necesidades de cuidados de distinta índole se ha caracterizado por apoyarse y casi exclusivamente en el aporte de las familias. Estas necesidades pueden derivar de diferentes momentos del ciclo vital, ser demasiado pequeños o demasiado mayores, de un proceso de deterioro físico consecuencia de una enfermedad, de un accidente, de la diversidad funcional; pero también de un modelo normativo de relaciones de género por el que buen número de hombres adultos sanos generan una enorme cantidad de trabajo de cuidados a sus familias, más concretamente, a las mujeres de sus familias (Durán, 2006). Este Estado del Bienestar familista se basa, pues, en una desigual división de género del trabajo doméstico y de cuidados, por lo que en realidad más que en las familias en quien se sustenta es en las mujeres.

Asimismo es importante destacar el componente de clase social que en esta distribución de probabilidades de aportar cuidado en las redes familiares tienen las mujeres (Langa Rosado y otros, 2009). Uno de los comportamientos

1. Panel de trabajo con el mismo título desarrollado en el marco del I Congreso Anual de la Red Española de Política Social (REPS) titulado «Treinta años de Estado de Bienestar en España. Logros y retos para el futuro». Red de estudios@s de las políticas sociales creada bajo los auspicios de ESPAnet (European Network for the Analysis of Social Policy), [en línea], <http://www.espanet.org> [consulta: 16/12/2009]. 
en que más se deja notar precisamente esta influencia es en el despliegue de estrategias de privatización y mercantilización del cuidado. Ante la ausencia de mujeres nativas que quieran o puedan realizar este tipo de actividades, el mercado de cuidados ha generado una progresiva feminización de las migraciones y las mujeres extranjeras se han convertido en un recurso para hacer frente a las carencias de atención (Agrela Romero, 2009b; Agrela Romero y Langa Rosado, 2009). La transferencia de estas actividades a mujeres inmigrantes tiene lugar en muchos casos bajo la lógica de la economía sumergida, normativas y políticas que ordenan el servicio doméstico y reclutamiento de inmigrantes, apoyándose a menudo en discursos que legitiman condiciones de servidumbre, perpetuación de la división sexual del trabajo y desigualdades de clase, nacionalidad, etnia o extranjería (Agrela Romero, 2009a). Jerarquizaciones que acaban ordenando los discursos y prácticas sobre quién y cómo ha de ejercerse el cuidado.

A la tradicional respuesta de la privatización, condicionada en gran medida por el nivel de recursos y la posición social de las familias, hemos de añadir la propuesta en el sentido de externalización pública que supone la aprobación de la Ley de Promoción de la Autonomía Personal y Atención a las Personas en Situación de Dependencia (2006). La intención que se expresa en dicha ley es la de consolidar un nuevo derecho universal de carácter subjetivo para dar cobertura a las necesidades de cuidados de las personas que se encuentran en situación de dependencia. Este importante cambio a nivel legislativo necesariamente ha de tener consecuencias en el diseño de las políticas de cuidados o, dicho de otra manera, debe consolidarse con el propósito de asentar un nuevo pilar que implica una nueva organización social del modelo de provisión de cuidados (Martín Palomo, 2009). De hecho, son numerosos los artículos de este número que más directa o más tangencialmente han abordado el análisis sobre cómo se está aplicando la denominada Ley de Dependencia y consolidando el Sistema de Autonomía y Atención a la Dependencia (SAAD), teniendo en cuenta las variaciones de hábitat, desarrollos normativos autonómicos, etc. El acceso a la categoría de «dependencia» se produce por múltiples vías: a) psicológica (autopercepción), b) social (percepción de los demás), c) médica (dictamen clínico), d) administrativa (Durán, 2006: 59). Sin embargo, tanto las agencias de las Administraciones Públicas como las compañías de seguros y otras instituciones, dedican una parte considerable de sus recursos a vigilar el acceso administrativo a la condición de «dependiente» en tanto que ello tiene implicaciones económicas considerables. Esto es especialmente relevante en el contexto de la implantación en nuestro país del sistema nacional de dependencia que prevé la nueva ley. 
El modo en el que se concibe el cuidado prestado a otras personas así como el autocuidado está íntimamente relacionado con los conceptos de independencia y autonomía. Tal como se destacó en el panel, el concepto de autonomía con el que se opera en el diseño de las políticas públicas parte de un concepto de normalidad determinado, que presupone a cada individuo como un adulto sano e independiente. Sin embargo, el universo de los cuidados hace emerger otra realidad bien distinta: la condición humana es vulnerable, y ese ideal de autonomía e independencia que ha constituido el gran anclaje de la modernidad dista mucho de lo que cada uno de los seres humanos experimentamos en nuestras vidas cotidianas. La dependencia mutua entre las personas implica una situación referencial en la que, al menos, hay dos sujetos implicados en la relación: el que necesita cuidados y el que los presta. No obstante, esta situación puede variar en el tiempo y no tiene por qué darse en una única dirección: introduciendo una dimensión temporal, diacrónica, en el análisis de los cuidados es posible identificar estos aspectos (Damamme, 2009; Martín Palomo, en prensa).

Todo ello parece ofrecer un cuadro muy dispar en el que, en todo caso, habría que destacar una insistente llamada de atención, a partir de las observaciones y análisis de los datos empíricos de las distintas investigaciones presentadas, sobre la posibilidad de que se estén evidenciando determinadas inercias de distribución sexista, e incluso clasista y étnicas, a la hora de construir y asumir el rol de cuidador/a. Se está conformando un panorama que requiere una atenta mirada, por lo que parece pertinente preguntarnos hacia dónde vamos, pues la situación, teniendo presente los datos ofrecidos por los demógrafos, no tiene visos de mejorar en el futuro más inmediato, sino todo lo contrario.

Así pues, parece oportuno detenernos a analizar y reflexionar sobre los efectos que todas estas articulaciones están teniendo. Nos interesaba explorar estos fenómenos partiendo de una amplia mirada que diera cuenta de la complejidad de situaciones y dinámicas englobadas bajo el rótulo de Estado de Bienestar y cuidados. Tal como se puso de manifiesto en las diferentes investigaciones presentadas, la diversidad y heterogeneidad desde la que abordar esta temática es muy amplia. Y no sólo en relación al ámbito académico o profesional desde el que se han enfocado, sino también a los diversos encuadres teóricos y campos disciplinares desde los que se han construido las miradas, interpretaciones y metodologías de abordaje de este campo, como son: la Sociología, el Trabajo Social, la Antropología, la Ciencia Política o el Derecho.

Al plantearnos tratar el tema de los cuidados y el Estado de Bienestar, si bien éramos conscientes de la importancia de la cuestión, nos sorprendió 
gratamente recibir tantas y tan sugerentes propuestas de comunicaciones, así como percibir entre los participantes un gran interés por intercambiar reflexiones y aportes sobre distintos aspectos de la temática «cuidados» que hasta ahora no se habían encontrado en un espacio común como el generado por dicho panel. En este monográfico se recogen algunas de las propuestas más sugerentes presentadas en la sesión de trabajo. En ellas se hace hincapié en los marcos institucionales y políticos (dirigiendo la atención hacia las Administraciones Públicas y la organización de los servicios sociales), así como en el entorno y contexto de cuidadores (sobre todo familiares, en su mayoría mujeres, pero también de hombres) y, muy especialmente, se atiende a la situación de las extranjeras. Ha habido quienes han realizado propuestas de reflexión teórica en torno a la conceptualización del cuidado, quienes han orientado su análisis hacia las personas en situación de dependencia, o hacia las que prestan cuidados habitualmente. Y dando un paso más allá, quienes han inscrito sus trabajos desde una perspectiva macro y global (comparando modelos entre varios países), quienes lo han hecho desde una perspectiva meso-nacional y quienes han dirigido su atención sobre el nivel micro-local. Evidenciando con todo ello el llamado «enfoque glocalizador», esto es, la necesaria relación entre lo global y lo local que se hace necesaria en el análisis de los modelos de cuidados.

En la heterogeneidad de trabajos presentados se recogen en gran medida los debates centrales que están emergiendo en relación a los temas que nos (pre)ocupan. Muchos son transversales y evidencian la complejidad e imbricación entre conceptos, espacios, instituciones, niveles y agentes sociales. Se pretende así proponer una mayor apertura a los debates existentes. Los textos presentados en este número pueden organizarse en tres bloques, que se corresponden con las propuestas presentadas en las sesiones que tuvieron lugar en el panel.

En primer lugar, se desarrolló una mesa en torno a nuevas aproximaciones, enfoques y debates teóricos en la que se abordaron algunas de las problemáticas que genera el cambio en el escenario de los cuidados prestados en nuestra sociedad desde diferentes perspectivas, de las que se seleccionaron dos contribuciones para este número: una, desarrollada a partir del análisis de la mercantilización de los cuidados y los problemas teóricos y empíricos que genera; y otra, realizada a partir de las propuestas filosóficas y políticas derivadas de la perspectiva de la diversidad funcional y de la responsabilidad sobre los otros. Hablar de los cuidados encierra una enorme dificultad debido a las limitaciones que conlleva el utilizar herramientas clásicas de las ciencias sociales para el estudio de un tipo de actividad que hasta tiempos muy 
recientes cargaba con altas dosis de invisibilidad, o dicho en otras palabras, un trabajo caracterizado por tener un déficit crónico de reconocimiento (Molinier, 2005). Invisibilidad que está estrechamente ligada a la naturalización de estas actividades como propias de la identidad femenina ya que en el trabajo de cuidados se entremezclan la identidad de género con la identidad profesional. Es por todo ello que incorporar en el análisis además de los aspectos materiales, los emocionales y los morales, ayuda a avanzar en la difícil tarea de desentrañar la complejidad de los cuidados, más cuando se analizan desde la perspectiva del trabajo (Martín Palomo, 2008), o se pretende incorporarlos a la agenda política (Martín Palomo, 2009).

En segundo lugar, el debate giró en torno a la profesionalización y mercantilización de los cuidados, dirigiendo la mirada especialmente hacia las cuidadoras (in)migrantes. De acuerdo con la estructura del panel, estas ponencias se corresponderían con la segunda y cuarta sesión. De entre ellas surge el grueso de este volumen, e incluye aportaciones tan diferentes, innovadoras y enriquecedoras como las reconfiguraciones del campo profesional desde la comparativa internacional (España-Chile), la aproximación desde el Trabajo Social o el análisis de los cuidados hacia las personas mayores en el ámbito rural. La atención hacia el perfil y situaciones de «las nuevas cuidadoras» viene de la mano de trabajos que contribuyen a desvelar el entendimiento de los procesos de privatización del cuidado familiar, los tiempos de trabajo de las inmigrantes, su incorporación en el servicio doméstico o la precariedad laboral que sufren, todo ello desde una perspectiva comparada. En conjunto, las aportaciones muestran, no sólo las fragilidades del sistema público de atención y las argucias de las políticas de extranjería, sino también el papel asignado a las mujeres inmigrantes como «recurso en sí mismas», utilizadas por el Estado, mercado y familias para (re)forzar el proceso de externalización y desnacionalización del cuidado (Agrela Romero,2009a). El trabajo de cuidado se inserta en la economía global, lo que presenta una doble faz. Por un lado, refleja el conocimiento de este tipo de actividad como trabajo remunerado, en tanto que está retribuido y existe un mercado que lo demanda, dando lugar a una verdadera economía de los cuidados. Sin embargo, por otro lado, se reproducen y multiplican las desigualdades de género, así como la división sexual e internacional del trabajo, y aparecen nuevas asimetrías, basadas en el origen nacional o en la etnia. Bajo estas condiciones, para las extranjeras se torna en una actividad aún más invisible que las ubica al final de la cadena de estratificación de desigualdades, encarnando así la paradoja de estar dentro de la Nación pero fuera de la ciudadanía (Macklin, 1999). 
En tercer lugar, se trabajó el tema de los cuidados en las familias: dilemas, retos y necesidades. Aquí sobre todo se han aportado estudios que se acercan empíricamente a los modos en que se construye y se le da contenido al papel de cuidador en el seno de las redes familiares, y las estrategias puestas en marcha a la hora de decidir e incluso a veces dotar de valor a esta actividad en principio tan invisibilizada. Estas estrategias se diseñan en uno u otro campo (público, familiar-privado) en el que se hacen valer unos determinados recursos, que se distribuyen de un modo desigual entre hombres y mujeres. Además algunos de estos trabajos ponen de manifiesto la existencia de otras variables que apuntan a otras formas de inequidad (actividad/inactividad, ocupación, etc.). Todos ellos, en fin, permiten reflexionar de nuevo sobre cómo los modelos de provisión de cuidados se enmarcan en unos determinados regímenes de bienestar que engarzan con una determinada estructura social, siempre mediada a su vez por una u otra cultura, donde los valores familiares, y de género, contribuyen a consolidar escenarios en los que los potenciales cuidadores tienen más o menos oportunidades reales de decisión a la hora de de elegir convertirse en proveedor de cuidados o no, así como en qué medida se asume esta responsabilidad.

A modo de resumen, los artículos que aparecen en número abordan las siguientes temáticas:

- Articulaciones entre las principales agencias de provisión de bienestar: Estado, mercado, familia y sociedad civil. El peso del Estado en la reestructuración de los actuales modelos de cuidado.

- Condiciones socio-políticas del trabajo de cuidados y las «otras dimensiones» implicadas no reconocidas: las relaciones afectivas y los usos del tiempo. El territorio transfronterizo entre lo moral y lo afectivo.

- Institucionalización de los cuidados: retos y posibilidades.

- Ley de Dependencia. Generación de nichos laborales para cuidadoras ¿profesionales? El funcionamiento del Sistema Nacional de Dependencia, la oferta y utilización de servicios públicos. Logros, vacíos y contradicciones.

- El papel de los servicios sociales y los trabajadores sociales como técnicos de gestión y evaluación de las situaciones de dependencia y provisión de prestaciones públicas.

- Articulaciones entre el sistema familiar y extrafamiliar (servicios públicos, voluntariado, empresas...) en la atención de las personas necesitadas de cuidados. Aperturas y cuestionamientos desde la perspectiva de género y feminista. 
- Políticas migratorias, feminización de las migraciones y mujeres migrantes cuidadoras. El transnacionalismo y las cadenas globales de cuidados. La desnacionalización de los cuidados.

- Mercantilización y externalización del trabajo doméstico y de cuidados.

Nos propusimos el reto de sacar a la luz los resultados de un encuentro colectivo en el que nos dimos cita tanto investigadoras/es con trayectorias consolidadas en las temáticas que nos ocupan como otras de quienes se están iniciando en el estudio de estas cuestiones (y sus posibles problematizaciones), así como profesionales con dilatada experiencia en el ámbito de la intervención. Con sus aportaciones contribuyen al debate desde muy diversos ángulos y espacios disciplinares, mostrando la persistencia de vacíos que requieren ser permanentemente observados e invitándonos a seguir en el camino de su exploración. Por todas estas razones, quienes firmamos esta presentación nos comprometimos a difundir estos trabajos mediante una publicación que permitiera compartir y divulgar estas (pre)ocupaciones, líneas de investigación, quehaceres profesionales y propuestas transformadoras. Y seleccionamos para ello una revista de Trabajo Social por lo que esta profesión y disciplina significa a nivel tanto académico como empírico: su posición visagra entre los distintos territorios y agentes implicados en el espacio relativo a los cuidados. Esto es, su ubicación estratégica entre las políticas públicas, servicios sociales de proximidad, las familias, el mercado y las personas con necesidades de cuidados en su vida cotidiana. Más allá de ser una profesión que implementa las políticas sociales es también un oficio que conoce directamente sus impactos y está en condiciones de cuestionar el modo en el que las políticas legitiman y (re)producen las desigualdades de género, clase y/o nacionalidad.

A todas y cada una de las compañeras y compañeros que participan en el volumen, gracias por su esfuerzo y generosidad.

\section{Bibliografía}

AGrela ROMERO, Belén, «De los significados de género e inmigración (re)producidos en las políticas sociales y sus consecuencias para la acción e integración social», en Lorenzo Cachón y Miguel Laparra (eds.), Inmigración y políticas sociales, Barcelona, Bellaterra, 2009, pp. 239-267.

- (dir.), Mujeres inmigrantes en los servicios de atención y cuidado en Jaén. Explorando las condiciones y subjetividades de un trabajo imprescindible e invisibilizado, investigación financiada por la Dirección General de Coordinación de Políticas Migratorias, Consejería de Empleo, Junta de Andalucía (20092010), $2009 b$. 
Agrela Romero, Belén y Delia Langa Rosado, (dirs.), Cuidadoras familiares e inmigrantes. Transformaciones en el modelo de cuidados a las/os dependientes en el nuevo marco de la Ley de Dependencia, investigación financiada por el Instituto Andaluz de la Mujer, Junta de Andalucía (2009-2010), 2009.

Anderson, Bridget, Doing the Dirty Work: The Global Politics of Domestic Labour, Zed Books, Londres, 2000.

DAmamme, Aurélie, «El cuidado en las familias: perspectiva temporal versus radiografía», en El trabajo y la ética del cuidado (en prensa), P. Molinier y L. G. Arango (coord.), en Seminario Feminismo y Cambio Social, Afectos, justicia y violencia en las relaciones interpersonales: IIF, Universidad Complutense de Madrid, 23 y 24 de abril de 2009.

DURÁn, M. a Ángeles, «Dependientes y cuidadores: el desafío de los próximos años», en Revista del Ministerio de Trabajo y Asuntos Sociales, n. 60; 2006, pp. 57-73.

Hochschild, Arlie R., «The Culture of Politics: Traditional, Post-modern, Coldmodern, and Warm-modern Ideals of Care», en Social Politics, 2 (3), 1995.

LANGA ROSADO, Delia y otros, Las cuidadoras y los cuidadores de dependientes en el seno de las redes familiares. Una mirada desde la desigualdad, Instituto de Estadística de Andalucía, Sevilla, 2009.

MACKLIN, A., «Women as migrants. Members in national and global communities», Canadian Women Studies, 19 (3), 1999, pp. 24-31.

Martín Palomo, M. ${ }^{a}$ Teresa, Los cuidados en las familias. Estudio a partir de tres generaciones de mujeres en Andalucía, (en prensa), Sevilla, Instituto de Estadística de Andalucía.

- «El care un debate abierto: de las políticas de tiempos al social care», en Cuestiones de género: de la igualdad y la diferencia, vol. 4, 2009, pp. 325-355.

- «"Domesticar" el trabajo: una reflexión a partir de los cuidados», en Cuadernos de Relaciones Laborales, 26 (2), pp. 13-44.

MOLinier, Pascale, « Le care à l'épreuve du travail. Vulnérabilités croisées et savoirfaire discrets", en Le souci des autres, éthique et politique du care, P. Paperman y S. Laugier (eds.), EHESS/Raisons Pratiques, París, 2005, pp. 299-316.

PÉrez Orozco, Amaia, Economía feminista de la ruptura. El caso de los cuidados, tesis doctoral, Universidad Complutense de Madrid, Madrid, 2005. 



\title{
FAMILISMO, ASITENCIALISMO Y PRECARIEDAD. LA CONFIGURACIÓN DEL EMPLEO EN EL SECTOR DE ATENCIÓN A LAS PERSONAS EN ESPAÑA
}

\author{
Familism, Welfarism and Precariousness. How \\ Employment is Structured in Spain's Care Sector
}

Carolina Recio Cáceres*

\begin{abstract}
Resumen
El sector de atención a las personas en España ha adquirido una mayor importancia a raíz de la aprobación de la Ley de Dependencia a finales del 2006. La ley, además de reconocer el derecho a recibir cuidados, también considera que éstos deben ser prestados con calidad. Partiendo de este contexto se propone una mirada sobre el empleo en este sector, teniendo en cuenta que las nuevas leyes y normativas hacen preveer un aumento paulatino en la ocupación. Para ello se realiza un análisis amplio que tiene en cuenta las distintas esferas sociales que intervienen en la expansión de un modelo u otro de ocupación en este sector. Se utiliza así la perspectiva sobre los modelos de empleo que analiza el empleo mediante la interacción entre distintas instituciones sociales. Bajo esta perspectiva, el artículo analiza las interacciones entre el modelo familista español, el modelo asistencialista de bienestar y un mercado laboral marcado por la precariedad. Es por ello que el texto plantea que el empleo en el ámbito de la dependencia se explica mediante la relación establecida entre familismo, asistencialismo y precariedad.
\end{abstract}

Palabras clave: cuidados, división sexual del trabajo, empleo, políticas sociales, dependencia.

\footnotetext{
* Carolina Recio Cáceres

Universitat Autònoma de Barcelona

Facultat de Ciències Polítiques i Sociologia

Edifici B. 08193 Cerdanyola del Vallès, Barcelona

Teléfono: 9358133 03/676 807682 Fax: 935812405

carolina.recio@uab.cat
} 


\begin{abstract}
The care sector in Spain has come a long way since the Dependent Care Law came into effect in late 2006. It not only recognises the right to receive public care, but also makes it clear that the care provided should be one of quality. It is in this context that this paper considers employment in the care sector, taking into account that the new laws and regulations mean that a gradual increase in job numbers is to be expected. A broad analysis is made by taking into account the various social spheres involved in expanding various sector employment models. This view of employment models is used to analyse employment by means of the interaction between social institutions - the Spanish family model, the welfare care model and a job market known for its precariousness. This paper therefore considers that employment in the dependent care sector can be explained by the relationship between familism, welfarism and precarious employment.
\end{abstract}

Keywords: care, sexual division of work, employment, social policy, dependent care.

«Lejos de constituir una imagen costumbrista de una tradición feudal y luego burguesa, el empleo de servicio aparece ahora como una necesidad pública y privada a la vista de la evolución económica y social. Paliativo de las carencias del Estado, remedio frente a la desestructuración familiar, expresión de unas nuevas relaciones entre hombres y mujeres, el empleo familiar designa el lugar de una mutación de la organización del trabajo entre la gratuidad y el salario, la intimidad y el salario, la intimidad y la publicidad, la emancipación de las mujeres y la tradición de la función femenina...» (Fraisse, 2000)

\title{
1. Introducción
}

El cuidado se está consolidando como un objeto de estudio recurrente en las Ciencias Sociales, en parte gracias a los trabajos desde la perspectiva de género, y ha ido adquiriendo una mayor atención teórica. Esta atención viene avalada por las realidades de las sociedades occidentales en las que diversos cambios sociales, económicos y culturales, han obligado a los gobiernos a plantear nuevas áreas y formas de acción para dar solución a lo que algunas autoras han bautizado como «la crisis de los cuidados» (Hochschild, 2008; Simonazzi, 2009). El cuidado ya no sólo se presta en el ámbito familiar, ahora también es posible dibujar un escenario en el que el trabajo de cuidados se dibuja como un sector específico de empleo. Este empleo debe ser estudiado desde la relación entre las distintas instituciones sociales, incluyendo elementos propios del contexto social, económico, político y cultural de los distintos países. El objetivo del texto es poner de relieve cómo se configura el empleo en el sector de atención a las personas en España, una propuesta que intenta vincular el ámbito del trabajo y del bienestar en el estudio del cuidado. No 
es sólo estudio de las condiciones de empleo, sino de las relaciones entre esferas sociales que configuran un tipo de modelo de cuidados y que tiene consecuencias sobre el bienestar de la población. Para tal objetivo, el texto se adentra en la perspectiva sobre los modelos de empleo, que pone en relación las distintas instituciones sociales en la concreción de un tipo nacional de empleo o de otro (Rubery, Bosch y Lehndorff, 2008; Bosch, Lehndorff y Rubery, 2009). Esta perspectiva no sólo explica el mercado desde el propio mercado, sino que asume que la acción política o los cambios en la división sexual del trabajo pueden ejercer una presión sobre los modelos productivos nacionales. Además, permite realizar estudios sobre sectores de ocupación concretos, relacionándolos con el modelo de empleo general de una sociedad determinada.

El texto se inicia con un breve repaso de aquellas perspectivas que han permitido visibilizar la importancia de los cuidados para el bienestar de las personas. Y que además nos recuerdan que el cuidado es trabajo. Tras este rápido viaje sobre el concepto de cuidado, nos detendremos en la propuesta de los modelos de empleo y su plasmación en el sector de atención a las personas. Para terminar echaremos una mirada sobre el caso español, y cómo éste parece definirse como un modelo familista, asistencialista y precario, aun asumiendo que se observan algunos indicios que harían pensar en un posible proceso de transición a un modelo distinto.

\section{La construcción sociológica del cuidado}

En las siguientes líneas realizaremos un breve repaso de aquellos trabajos que han contribuido al asentamiento del concepto de cuidado, y que nos va a permitir entender los apartados posteriores. Partiremos de la tesis de Teresa Torns (2008), que defiende el estudio del cuidado desde el ámbito de la sociología del trabajo, y realiza un análisis que conjugue el trabajo con el bienestar. Esta perspectiva reivindica la recuperación de aquellos estudios del cuidado desde el concepto de trabajo y la importancia de su realización para el bienestar cotidiano que permitieron, años después, avanzar en el estudio del cuidado.

\subsection{De la ruptura conceptual al social care}

Los trabajos pioneros en el ámbito del care se inscriben en la literatura científica feminista de la década de los sesenta. Desde el marxismo algunas científicas sociales iniciaron los debates acerca del papel del trabajo de las mujeres en la sociedad, y su relación con el sistema capitalista. En estos trabajos el cuidado no era el núcleo central, sino que la idea del care se incluía dentro de los debates sobre el trabajo no remunerado realizado en el seno de los hogares 
por las mujeres adultas (Letablier, 2007; Torns, 2008). Estos debates nacieron del interés de introducir la relación de explotación hombre-mujer en la teoría marxista (Astelarra, 1982). Siguieron aquellos trabajos que contribuyeron a dotar de estatuto teórico al trabajo doméstico y familiar, que engloba a su vez el trabajo de cuidado de los miembros dependientes de la familia. La revisión del significado del concepto de trabajo supuso el reconocimiento de la actividad invisible que las mujeres realizaban en el seno de los hogares y que era necesaria para la reproducción de la fuerza de trabajo (Benería, 1981; Borderías, Carrasco y Alemany, 1994). Podría situarse dentro de las teorías de la dualidad, en que se reconocen dos esferas, la pública y la privada. La primera puede definirse, grosso modo, por ser masculina, remunerada, valorada y fuente de derechos de ciudadanía. La segunda es femenina, no remunerada, invisible y está desprovista de derechos de ciudadanía (Benería, 1981; Picchio, 1994; Balbo, 1994, Borderías, Carrasco y Alemany, 1994; Rubery, 1997; Gardiner, 2000). Es el modelo de male breadwinner y female housekeeper que supone que el marido es el que mediante las rentas generadas por su trabajo remunerado sustenta económicamente al resto de miembros de la familia, y al mismo tiempo obtiene los beneficios sociales que le otorga su estatus de empleado (Rubery, 1997; Gardiner, 2000). Es importante hacer visibles estas investigaciones puesto que fueron pioneros en el estudio del trabajo, incluyendo la tarea de cuidar dentro del trabajo doméstico y familiar.

El cuidado al que se hacía referencia era el realizado dentro de los hogares, por ello, mucha de la literatura sobre el care se dedicó al estudio del cuidado informal, entendiendo por informal aquel que se realizaba mediante el trabajo no remunerado de las mujeres adultas de las familias (Finch y Groves, 1983; Graham, 1983; Ungerson, 1990; Letablier, 2007). En esta línea encontramos aquellos estudios que introducían la importancia de la emotividad y los sentimientos en el trabajo de cuidados. De hecho, el título de Finch y Groves (1983) es el que mejor resume las posturas en esta línea: A labour of love: work, care and feeling. Desde esta perspectiva consideran que hay trabajo doméstico que puede ser racionalizado y rutinizado, mientras que entienden que el cuidado es una actividad sensiblemente distinta. El cuidado requiere no sólo actividad física, sino también emociones y sentimientos. Definen el cuidado como una actividad material y una relación emotiva (Finch y Groves, 1983; Graham, 1983). Esta consideración del trabajo de cuidados, alejada en parte de la concepción del cuidado como trabajo, es la que ha marcado muchos de los debates pasados y actuales sobre la ética del cuidado, tanto en el ámbito privado del hogar como en los empleos que supuestamente contienen una alta carga emocional. 
En la década de los ochenta, y especialmente en la de los noventa, el interés por el estudio se desplaza al área de la política social. Desde Reino Unido y los países nórdicos llegan los primeros trabajos en esta línea: el estudio del trabajo de cuidados y las políticas públicas que se diseñan en esta línea. En estos países existía algún tipo de políticas públicas en relación a los cuidados de la población. De ahí que las investigadoras de ambas realidades nacionales se interesaran por la temática. Mientras que en los países nórdicos se intentaba delimitar en qué medida los servicios públicos suavizaban la carga de trabajo de las familias, en Reino Unido el traslado del cuidado a la comunidad era el foco principal de atención (Ungerson, 1990). En Reino Unido se estaba produciendo una transición hacia la promoción del care by the comunity, que en la práctica significaba una pérdida del poder público para prestar cuidado, trasladándose los costes a la comunidad. En este contexto se desarrollaron con fuerza los análisis desde la política social. El envejecimiento de la población, la mayor presencia de las mujeres en el mercado de trabajo, los cambios culturales que supuso el avance de los movimientos feministas, explican también por qué el cuidado pasa a ser un foco de interés en las Ciencias Sociales. Así, las exigencias del cuidado de las personas dependientes se hicieron visibles. También, ante la proliferación de estudios comparativos de los distintos Estados del Bienestar, las autoras feministas adoptaron una perspectiva nueva, que ponía el cuidado en el centro de los análisis. Se entiende que el cuidado es una parte inseparable del bienestar de las personas, y por ello es necesario introducirlo en los análisis de los Estados del Bienestar. Reconocen la tarea invisible que han realizado las mujeres en el seno de los hogares y su importancia capital en el estudio de los Estados del Bienestar (Carrasco et al, 1997, Sainsbury, 1996; Daly y Lewis, 2000; Letablier, 2007).

Con este trasfondo, el care obtiene estatuto teórico y aparecen propuestas consistentes para obtener una definición del concepto, siempre teniendo en cuenta su naturaleza relacional. Se intenta captar desde el cuidado informal al formal, el papel de los poderes públicos, la persistencia de la división sexual del trabajo en los hogares, etc. Carole Thomas (1993) y posteriormente Daly y Lewis (2000) son algunas de las aportaciones más destacadas y que han obtenido más reconocimiento en las Ciencias Sociales. A ambas se las debe entender como un avance definitivo en el campo de estudio del care, específicamente del social care, o lo que en castellano podríamos traducir como las formas de organizar socialmente los trabajos de cuidados. Hacen referencia pues a las relaciones entre actores e instituciones y los modelos de cuidado que de éstas se derivan (Letablier, 2007). Construyen el concepto de social care que les ha de permitir la realización de estudios comparativos entre distintas realidades 
nacionales. Las dimensiones propuestas se materializan en tres aspectos. En primer lugar reconocen que el care es trabajo, considerando todas las formas en que se realiza, lo cual significa que rompen la tendencia dicotómica en el estudio del cuidado. En segundo lugar deben considerarse los marcos normativos en los que se realiza el cuidado, es decir, se debe atender a las responsabilidades y obligaciones que marcan las distintas sociedades en relación al cuidado. Por ejemplo, hay estados que pueden reconocer la obligación a las familias a realizar trabajos de cuidados a los miembros de su familia, mientras que otros no recogen esta obligación. En tercer lugar, aseguran que el concepto del social care permite medir los costes materiales, financieros y emocionales que causa la actividad de cuidar. Reconocían además que el estudio de los regímenes de cuidado debía incluir tanto el cuidado de menores como el cuidado de adultos, pensando en el aumento imparable de la población anciana. Este cambio demográfico debía contar con estructuras conceptuales capaces de captar los cuidados que requieren los distintos colectivos de edad, que suelen esconder grandes diferencias en términos de necesidades de cuidado. Además, esta propuesta permitía no sólo avanzar en el conocimiento sobre las condiciones de vida de las mujeres, sino que también incluía los elementos necesarios para captar las necesidades sociales y personales que conducen al bienestar.

Esta construcción teórica les valió para desarrollar una nueva propuesta sobre los modelos de Estados del Bienestar, que se oponía claramente a todas las que habían omitido el género en sus análisis. Otras autoras han seguido esta línea inaugurada por las autoras anglosajonas, Bettio, Simonazzi y Villa (2006), y consideran necesario atender tanto a las políticas sociales como a la historia cultural de los países en cuestión. Todas son propuestas que ahondan en el concepto de ciudadanía que ya no sólo se fijará en la presencia pública de las personas, sino que añadirá también otras esferas de la vida. (No sólo el empleo es fuente de bienestar). Estas consideraciones se traducen en regímenes de cuidado que tratan de dilucidar cuál es el sistema de organización social de los cuidados en los distintos países. Cabe destacar que en este sentido se recoge el tipo de servicios generadas, y es precisamente lo que aquí se pretende estudiar. El tipo de empleo creado depende del lugar que ocupa el cuidado en las políticas encaminadas al bienestar de la población, especialmente porque el cuidado se convierte en derecho de ciudadanía. Esto implica reconocer la necesidad de un cuidado profesional, ya que las personas dependientes necesitan unas atenciones concretas. Si esto es lo que se desprende de estas reflexiones, veamos qué es lo que está sucediendo en la práctica, y dónde se hallan las posibilidades para lograr este objetivo. 


\section{Los modelos nacionales de empleo}

El concepto de modelo de empleo sugiere el análisis de la actividad laboral desde una perspectiva relacional, o si se prefiere desde una lógica institucional. Esto significa que los empleos bajo esta perspectiva analizan los patrones de desarrollo de los mercados de trabajo teniendo en cuenta no sólo el análisis de las variables del mercado laboral, sino las interrelaciones de éste con las políticas sociales, educativas, laborales y económicas. El modelo analítico propuesto incluye por tanto variables mercantiles y no mercantiles y relaciona la «institución» laboral con otras instituciones sociales extra-mercado que configuran la vida laboral de las personas (Bosch, Lehndorff y Rubery, 2009). En general, el estudio de los modelos de empleo plantea un análisis que interrelaciona tres espacios de la vida social: el sistema productivo, el sistema público y el sistema familiar. En otras palabras, parte del modelo «Mercado, Estado, Familia». Además, la perspectiva requiere un análisis de carácter histórico capaz de captar los cambios acaecidos en los modelos de empleo. Es decir, que los modelos nacionales de empleo son el resultado de procesos históricos que van configurando y/o transformando los sistemas en cada momento.

"It is the employment relationship embedded within this multiplicity of interlocking institutions that give rise to what we call nacional employment models. (...) This interlocking of institutional arrangments also creates the possibility of spillover effects from one sphere to another, potentially increasing the scope of change through ripple of domino effects. Thus change to the nature of the internalized employment relationship has implications for the survival of the welfare system for change within the employment model may originate in different spheres» (Bosch, Lehndorff y Rubery, 2009: 2)

El espacio mercantil hace referencia a los sistemas productivos nacionales, donde es importante tener en cuenta el papel central de las empresas capitalistas y las regulaciones específicas del mercado de trabajo. Se debe tener en cuenta tanto las influencias, a nivel local, de los procesos de integración económica mundial, como las acciones de los propios empresarios en relación con las estrategias de especialización y organización. También debe considerarse el sistema de relaciones laborales. El espacio familiar atiende a la división sexual del trabajo dentro del seno de los hogares, y al peso de las familias en la proporción de bienestar, puesto que hay realidades donde el trabajo doméstico y familiar suple en muchos casos la acción del sistema público y limita o modula la presencia de las personas en el espacio mercantil. El espacio público está definido por el conjunto de políticas públicas y, por tanto, incluye el sistema de provisión pública de bienes y servicios. Unas políticas que también 
influirán en los otros dos espacios (Bosch, Lehndorff y, Rubery, 2009; Banyuls et al, 2009).

Otro elemento importante de esta perspectiva es que permite realizar estudios comparativos entre los distintos modelos nacionales. Este planteamiento supera, en parte, otras propuestas sobre modelos comparados entre países, ya sea desde la lógica productiva -los trabajos sobre variedades de capitalismo (Coates, 2005) - como desde la lógica de los Estados del Bienestar (Esping-Andersen, 1990). En lugar de fijarse tan sólo en la acción de una de las instituciones sociales, pone en diálogo a tres espacios sociales. Y, además, tiene en cuenta tanto los factores externos (políticas europeas, procesos migratorios, entre otros) como los factores internos (envejecimiento de la población, incorporación de las mujeres al mercado laboral, etc.). En parte, los trabajos de modelos nacionales de empleo nacieron como una forma de ver hasta qué punto se podía afirmar que era posible hablar del modelo social europeo (Rubery, Bosch y Lehndorff, 2008), y de cómo los países tratan de amoldarse o no a él. En este sentido, los primeros resultados de algunas investigaciones dedicadas al estudio de estos procesos ${ }^{1}$ apuntan a que si bien hay directrices comunes, basadas en el modelo social europeo, cada país ha elaborado sus propias vías de desarrollo, en función de tradiciones económicas, políticas y sociales propias.

Finalmente, la perspectiva de los modelos nacionales de empleo permite el estudio de sectores de empleo concretos. De hecho, tomando como punto de referencia el modelo general, es posible realizar el estudio del sector concreto del cuidado. En este caso, el modelo de empleo generado en el sector remite a un entresijo de relaciones establecidas entre los distintos espacios institucionales descritos. Las distintas formas de concebir el propio trabajo, las políticas sociales y el empleo dibujan un tipo u otro de sector, es decir, se configurará un sector más o menos formal (en el sentido de mayor o menor utilización de la economía sumergida), con mayor o menor reconocimiento de las profesiones vinculadas al mismo, con mayores o menores problemas para reclutar mano de obra, etc. En definitiva, el análisis derivado de ello defiende que el sistema de cuidados de un país concreto se debe explicar por la relación entre modelo laboral, modelo familiar y modelo de Estado. Unas consideraciones que mostraremos en el siguiente apartado.

1. Véanse los resultados del proyecto «Dynamics of National Employment Models» (Dynamo), financiado por la Comision Europea (VI Programa Marco) y coordinado por el profesor Steffen Lehndorff. Algunas de las reflexiones de los hallazgos del proyecto pueden encontrarse en Bosch, Lehndorff y Rubery, 2009. 


\section{El sector de atención a las personas: regímenes de empleo y regímenes de cuidado}

El sector de atención a las personas se está desarrollando rápidamente en la gran mayoría de países europeos. Los cambios sociodemográficos han obligado a los Estados a diseñar distintas acciones en relación a la necesidad de cuidados por parte de la población dependiente. La expansión de este sector no sólo se explica por la ampliación de los servicios públicos, sino que también intervienen los tímidos cambios en la división sexual del trabajo, la incorporación de la mujer al mercado de trabajo, la necesidad de crear empleo en nuevos sectores productivos, etc. Por tanto, para poder estudiar este sector es necesario atender a los cambios sociales, económicos y culturales acontecidos en los distintos países europeos, especialmente a partir de los años noventa (Rubery, Smith y Fagan, 1999). Estos cambios están detrás de la configuración de un tipo u otro de mercado del care. Las relaciones establecidas entre uno y otro aspecto interactúan con las posibilidades y las formas en que se va a desarrollar el sector del cuidado, y el tipo de empleo que se va a generar (Simonazzi, 2009).

Los trabajos de Anna Simonazzi (2007 y 2009) suponen un avance en el campo de estudio de los sectores de ocupación relacionados con el care, partiendo de la perspectiva analítica de los modelos nacionales de empleo. Así, las tesis de Simonazzi apuntan que un tipo u otro de regímenes de care (políticas sociales destinadas a atender a la población dependiente) generan un tipo específico de mercado en este sector: "The way in which elderly care is provided and financed may entail considerable differences in the creation of formal care market» (Simonazzi, 2009: 211). El sector de empleo vinculado a la prestación de cuidados debe relacionarse tanto con las políticas públicas como con las tendencias propias de los mercados de trabajo nacionales y con la tradición familiar de los distintos países, que se encuentra definida mediante el reconocimiento formal y legal de las obligaciones de las familias en los cuidados de las personas dependientes (Anxo, Fagan, 2005; Fagan, Nixon, 2001; Simonazzi, 2009). La interacción entre estos elementos generará un tipo u otro de empleo en el sentido no sólo de la cantidad del empleo generado, sino también de su calidad. Todo ello genera unas prácticas y un modelo distinto de mercado de trabajo en el sector de atención a la dependencia. Aquellos sistemas que apuestan por la prestación de servicios públicos y/o las transferencias monetarias «bajo control» son aquellos que más posibilidades generan de crear un mercado formal en el ámbito del social care. Mientras que aquellos Estados que apuestan por transferencias económicas sin comprobación y/o trasladan a las familias un volumen más elevado de obligaciones 
también están depositando su confianza en un sistema informal de cuidados (ya sea mediante la prestación familiar o bajo contrataciones propias de la economía sumergida). Desde este conjunto de relaciones debe estudiarse el empleo en este sector. Los salarios, las condiciones de trabajo, la formación y habilidades requeridas son elementos que pueden dirigir hacia empleos de calidad o, por el contrario, delatar la precariedad de los sectores (Aragón, Cruces y Rocha, 2008). Pero en la determinación de estas condiciones debe tenerse en cuenta la acción empresarial, los procesos de relaciones laborales (espacio mercantil), el tipo de promoción pública de los servicios y el modelo de despliegue de los servicios (espacio público) y la persistencia o superación del modelo male breadwiner y female housekeeper (espacio familiar).

Los distintos países de la Unión Europea han diseñado estrategias distintas, que se relacionan con lo expuesto en el párrafo anterior (Anxo, Nyman y Fagan, 2001; Moss, 2004; Simonazzi, 2007 y 2009)². Por ejemplo, en el caso sueco, la apuesta ha sido generar ocupaciones cualificadas y con unas condiciones relativamente buenas, en parte por su inclinación por un modelo de políticas universales y de servicios públicos de atención a las personas, y una fuerte influencia de las políticas de igualdad de género (Evertsson, 2000; Anxo y Nyman, 2001; Ahmed, 2006). Otro ejemplo paradigmático podría ser el de Reino Unido. Se trata de un Estado que hace años que empezó a desarrollar los servicios de atención a las personas. También, como en el caso sueco, se han fomentado los servicios de atención a las personas, pero al contrario que el país escandinavo, la estrategia ha sido la de expansión de un sector precario, de bajos salarios y sin necesidades de formación específicas en el momento de entrada en el sector (Fagan y Nixon, 2001). El modelo anglosajón se asienta sobre un modelo de familia «ausente», en el sentido de que no existe ninguna obligación normativa que exija cuidar a los demás miembros de la familia; en un Estado que sí ha previsto distintas políticas de atención a las personas dependientes, pero que dejan mucho espacio al desarrollo de las empresas privadas y a las entidades del Tercer Sector.

Finalmente, y por citar un caso más cercano, están los países del sur de Europa, donde existe una fuerte tradición familista, unos servicios sociales escasos y una mayor tendencia a las transferencias monetarias. En ellos se observa un mercado laboral de cuidados precario, con condiciones de empleo similares a los que apuntábamos para el caso anglosajón. El resultado es un empleo caracterizado por los bajos salarios, las jornadas laborales largas y/o

2. Los resultados del proyecto «Dynamics of National Employment Models» (Dynamo) financiado por la Comision Europea (VI Programa Marco) y coordinado por el profesor Steffen Lehndorff. Son especialmente relevantes los resultados en el área del care sector. 
atípicas y las pocas posibilidades de promoción profesional, que funcionan como elementos de desmotivación. Y, en el caso de los países del sur de Europa, esta escasez se está solucionando mediante el traslado de obligaciones a las mujeres adultas de las familias o hacia la contratación de mano de obra inmigrante femenina (Bettio, Simonazzi yVilla, 2006; Simonazzi, 2009).

\section{El caso español: familismo, asistencialismo y precariedad}

La perspectiva de los modelos de empleo defiende que España se encuentra en la encrucijada, puesto que se reconocen rasgos heredados de la dictadura franquista, posteriormente moldeados durante el proceso de transición cuando se creó un sistema de servicios y beneficios sociales públicos y universales, pero que pronto recibieron la influencia de la política económica de corte neoliberal, marcando definitivamente el modelo español de empleo. También cabe resaltar una tradición familista, un peso importante de la Iglesia católica y una política social a medio camino entre el universalismo y el asistencialismo (Banyuls et al., 2009). Tras las primeras elecciones democráticas es posible distinguir distintos cambios que afectaron a la estructura económica y social, la cultura, las relaciones laborales y los roles de género. Las causas de estos procesos de cambio deben buscarse tanto en procesos externos (globalización, influencia de la política común europea) como en procesos internos (democratización del país, reestructuración territorial, demandas sociales y cambios culturales) (Banyuls et. al, 2009). En este esquema, el modelo de partida era el de una economía muy cerrada, con una intervención pública (propia de un sistema de dictadura como el franquista), con un bajo nivel de desarrollo de las prestaciones sociales y una familia tradicional, en la que la norma era la provisión del bienestar mediante el trabajo de las mujeres adultas de las familias. Los cambios en los años ochenta de dos fuerzas distintas y a la vez contradictorias son los que pueden dar cuenta del modelo español. En primer lugar, la influencia de las políticas económicas neoliberales que se pusieron de parte del capital y limitaron el gasto público; del eje contrario venían las demandas sociales para la mejora del bienestar de la población, y que ejercieron una fuerza importante para el desarrollo de servicios de bienestar, regulaciones laborales, pensiones, etc. Entre las demandas destaca la del movimiento feminista, que en parte defendió la entrada al mercado laboral como la principal vía de la emancipación de la mujer (Banyuls et al., 2009). Si bien es muy destacable el incremento de la presencia de mujeres en el mercado laboral, no parece tan claro que se haya roto con la fuerte división sexual del trabajo, y los trabajos domésticos y familiares siguen recayendo hoy en día y de forma mayoritaria en las mujeres adultas (Torns et al., 2006; Borras, 
Moreno y Recio, 2009). Unas demandas que también se han hecho oír en el ámbito de la política social. Este proceso, que ha marcado de forma definitiva el momento actual, se ha dado en una sociedad que ha cambiado sustancialmente. Hablamos de una sociedad que envejece y que ha asistido a un cambio en la presencia de las mujeres en el mercado laboral y una persistencia de la ausencia masculina en el trabajo doméstico y familiar, o el paso de ser un país emisor de población a ser un país receptor de población extranjera (Torns et al., 2009; Borras, Moreno y Recio, 2009). También, en la actualidad, nos encontramos con una expansión de los servicios que dan cuenta de estos cambios, especialmente en el campo de las necesidades de cuidado a las personas, una evidencia que recoge la aprobación de la Ley de Promoción de la Autonomía Personal y Atención a las personas en situación de Dependencia, de 14 de diciembre de 2006, o de otras normativas autonómicas como puede ser el caso catalán y la Llei de Serveis Socials. En este contexto social se configura el sector de atención a las personas, y de aquí en adelante plantearemos los tres ejes que modulan el sector.

\subsection{Familia, Estado y mercado}

\subsubsection{La persistencia de la división sexual del trabajo}

En referencia a la familia se distingue una persistencia del modelo male breadwinner, pero no tanto de la mujer dedicada al trabajo doméstico y familiar exclusivamente, sino más bien de mujeres que viven en un Estado de «doble presencia» (Balbo, 1994). Entre los cambios más destacados se deben citar las mayores tasas de actividad de las mujeres y el cambio sensible de las trayectorias laborales de las mujeres, especialmente el de las generaciones jóvenes. Éstas parecen dibujar una trayectoria laboral distinta a la de sus madres y abuelas: abandonan menos el mercado laboral en el momento del matrimonio y la maternidad (Torns et al., 2009). Aun así la división sexual del trabajo es acusada, y son ellas, con mucha diferencia, las protagonistas del trabajo doméstico y familiar (Borrás et al., 2009). Esta perpetuación de la división sexual del trabajo no sólo se expresa en las prácticas cotidianas, sino también mediante los valores e imaginarios sociales, que todavía hoy siguen basándose en un modelo de familia tradicional en el que el hombre es el cabeza de familia, y la mujer, la responsable de los cuidados. Una encuesta realizada por el IMSERSO ${ }^{3}$ en el 2004 preguntaba a personas cuidadoras acerca de sus

3. Ver IMSERSO, Cuidados a las personas en los hogares españoles. El entorno familiar, MTASIMSERSO, Madrid, 2005, [en línea], <http://www.seg-social.es/imserso/documentación/ cuidadosppmmhogares.pdf>. 
preferencias en un hipotético futuro sobre su necesidad de recibir cuidados. Los resultados sobre las preferencias de cómo recibir los cuidados indican que las personas entrevistadas preferirían mayoritariamente recibir los cuidados por parte de algún miembro de la propia familia. Un 25,7 \% expresaba el deseo de ser cuidado/a por una hija, un 19,3\% esperaba ser cuidado/a por el esposo o esposa y un 13,8 \% por un hijo o hija indistintamente. La opción de recibir los cuidados a través de un hijo sólo se consideraba en un 5,4\% de los casos. Las opciones sobre los servicios y/o cuidados externos a los recursos familiares obtenían unos porcentajes mucho más tímidos. Y, cabe destacar que las primeras opciones contempladas demuestran la preferencia de la atención prestada por el sector público en detrimento del sector privado. También desde el punto de vista de los imaginarios hay que resaltar las creencias sociales en torno al significado del trabajo de cuidados, un trabajo asociado a un trabajo servil, desprovisto de valor social, y que supone vivir en una situación de desigualdad para aquellas personas que lo realizan (Fraisse, 2000). Asimismo, la Iglesia católica ha jugado un papel muy importante en el campo ideológico, formando parte de la política nacional durante la época franquista, y que tras la transición la sociedad no supo romper definitivamente con las doctrinas que esta institución insuflaba. Su defensa acérrima de la familia tradicional avala esta tesis. Todo conlleva a una situación en que las mujeres son las principales proveedoras del trabajo de cuidados y que éste es visto, comúnmente, como «el buen cuidado». Más adelante defenderemos la idea que las nuevas políticas públicas han diseñado sobre la base de una sociedad familista (la familia sigue siendo el principal mecanismo de soporte social y de proporción de bienestar). Un modelo que tiene consecuencias claras en el ámbito del empleo y que puede entorpecer los intentos de generar un sistema profesional de atención a las personas.

5.1.2. Las políticas sociales de bienestar: entre el discurso universalista y las prácticas asistencialistas

En el área de las políticas sociales es posible distinguir una doble vía: universalista y asistencialista. Desde el área que nos interesa, diremos que se ha avanzado en materia de derechos sociales, pero como podemos ver éstos aún entrañan una fuerte dependencia con el modelo familiar español y limitan el desarrollo de un mercado de cuidado pensado desde la calidad y el bienestar. En este sentido, persisten los grandes sistemas universales como pueden ser la Sanidad, la Educación y el sistema de pensiones, pero simultáneamente han ido avanzando con una cierta lógica privatizadora, ya que en muchos casos subsisten con estructuras paralelas privadas y/o han visto introducidas 
medidas de gestión privada (Pastor, 2001 y 2006). Estas medidas se concretan en la introducción de la filosofía del management en la organización del trabajo desde la propia institución, o la externalización de alguna de las fases del servicio, especialmente en la fase de gestión del mismo (Rodríguez Cabrero, 1991 y 2002). Las justificaciones a este doble proceso de privatización-externalización nacen de las críticas neoliberales a la excesiva intervención del Estado keynesiano. Unas justificaciones que defendían que la privatización era sinónimo de eficiencia y eficacia y reducía los costes y los trámites burocráticos. Un discurso que caló rápidamente y facilitó la puesta en escena de este tipo de políticas sin generar excesivas resistencias entre el conjunto de la población (Muñoz de Bustillo, 2000; Pastor, 2006). Esto encaja con el escaso aumento del gasto público en España, que apenas ha ascendido en los últimos diez años y se ha situado por debajo de la media de la Unión Europea: el gasto social en España en 2005, y en porcentaje del PIB, fue del 20,8 \% frente al $27,2 \%$ del conjunto de la UE- 27 , o el 27,8 \% de la UE-15. También, se debe destacar la impopularidad de realizar políticas impositivas más decididas que son las que en última instancia permitirían un mayor avance del gasto dedicado a políticas de bienestar.

El sector de atención a las personas se ha desarrollado con fuerza en los últimos años, pero coincide con algunos de los aspectos generales descritos para el conjunto de políticas y servicios sociales de la sociedad española. Antes se trataba de un servicio asistencial y que apenas era conocido por la población en general. Hoy en día se ha invertido algo está realidad ya que los servicios de atención a la dependencia se piensan desde la filosofía universalista, aunque ésta permanece más a nivel político-discursivo que no a nivel de prácticas reales. Veámoslo. En primer lugar, estos servicios están sujetos a la lógica de la privatización-externalización: la titularidad es pública y la gestión del servicio está en manos de empresas privadas. Una tendencia que están aprovechando las grandes empresas para desarrollar nuevas áreas de inversión, en un negocio que entraña poco riesgo, pues estos servicios parecen estar expandiéndose. Muchas de ellas provienen de otros sectores, especialmente del de la construcción, que han podido invertir en estas actividades y que se auguran un negocio seguro en este sector (Miguélez, Lope y Olivares, 2006). Aunque no está de más apuntar que juntamente con estos grandes grupos coexiste un numeroso grupo de empresas locales y relativamente pequeñas que ofrecen este tipo de servicios. Muchas de ellas ligadas al tercer sector, que desde hace muchísimos años trabajan con gente desvalida y marginal, pero también se

4. Ver EUROSTAT. 
trata de pequeñas empresas ligadas a los ámbitos locales (Recio, 2009)5. Este sistema supone que son las Administraciones Locales las que controlan el servicio y fijan su precio público. Las políticas públicas pues juegan un papel esencial para entender la fijación de condiciones de empleo en este sector, como por ejemplo en las políticas salariales.

Si atendemos al tipo de servicios hay que reconocer los avances realizados en las últimas décadas, especialmente en los últimos tres años cuando se han aprobado las distintas normativas que han impulsado definitivamente el sistema de atención a las personas, y han facilitado la expansión y diseño de un sistema público que atiende a la necesidad de cuidados. Hoy todavía es pronto para realizar un análisis sobre el impacto de estas normativas, pero sí es posible extraer algunas reflexiones al respecto que van a tener gran influencia en la configuración del empleo en el sector. En primer lugar, y en sintonía con el resto de países europeos, el discurso político promueve la expansión de los servicios de atención domiciliaria, ya que se piensa que las personas tienen mayor calidad de vida cuanto menos separadas estén de su contexto cotidiano. Sin embargo, el hecho de que se fomente la permanencia de las personas dependientes en su entorno familiar es una forma de asegurar la persistencia de una institución familiar fuerte pues no se altera su estructura y el reparto desigual de trabajos domésticos y familiares (Bettio, Simonazzi y Villa, 2006), permitiendo además una reducción de los costes económicos que genera el mantenimiento de un recurso residencial. La Tabla 1 muestra

Tabla 1. Tasas de cobertura de los Servicios Sociales.

Población mayor de 65 años. España 2002 y 2008

\begin{tabular}{|l|c|c|c|}
\hline & 2002 & 2008 & Variación 08/02 \\
\hline Servicio de Atención Domiciliaria & 2,75 & 4,69 & $+1,94$ \\
\hline Servicio de Teleasistencia & 1,45 & 4,72 & $+3,27$ \\
\hline Centros de Día (total) & 0,26 & 0,83 & $+0,57$ \\
\hline Plazas públicas + concertadas & 0,14 & 0,53 & $+0,38$ \\
\hline Plazas privadas & 0,12 & 0,30 & $+0,19$ \\
\hline Residencias (total) & 3,34 & 4,31 & $+0,97$ \\
\hline Plazas públicas + concertadas & 1,38 & 2,04 & $+0,65$ \\
\hline Plazas privadas & 1,96 & 2,28 & $+0,32$ \\
\hline
\end{tabular}

Fuente: IMSERSO, Las personas mayores en España. Informe 2008.

5. Ver el estudio de Lope, Recio y Gibert de 1997 en el que se estudió el caso del SAD de Manlleu, y que resulta un buen ejemplo de la existencia de pequeñas empresas privadas y del Tercer Sector muy ligadas a municipios pequeños y medianos. 
que los mayores incrementos en las tasas de cobertura de los servicios públicos de atención a las personas se encuentran precisamente en los SAD y la teleasistencia. Asimismo queda claro que es en el servicio más costoso, el centro residencial, donde la presencia del sector privado es mayor. Según el Informe del IMSERSO sobre las personas mayores, el $87 \%$ de las residencias para la tercera edad son de titularidad privada, frente a un tímido $13 \%$ de titularidad pública.

Después de tres años de andadura de la Ley de Dependencia existen registros que permiten hacer alguna valoración sobre el alcance de dicha ley. Y, empezar a visualizar si éste ha contribuido a construir un Sistema Público de Atención a las Personas. Los datos ofrecidos ponen de relieve que aquellas prestaciones que más se están aprobando son, precisamente, las prestaciones económicas a los cuidados personales (ver Tabla 2), medida prevista con carácter de excepcionalidad y que se está convirtiendo en una normalidad. De este modo, más del $30 \%$ de los Planes Individuales de Atención resuelven que la prestación social a recibir es una transferencia monetaria a la cuidadora principal de la persona dependiente. Esta cuidadora recibirá un salario y será dada de alta en el régimen de la Seguridad Social, contribuyendo así a la disminución de la elevada tasa de desempleo femenino. Las personas que reciben este «salario» son consideradas «cuidadores no profesionales». Un ejemplo que hace pensar que el modelo público de cuidados sigue apoyándose en las mujeres, un elemento que limita la expansión de un sistema realmente profesionalizador.

Tabla 2. Prestaciones reconocidas en el PIA. España.

Datos del 1 de septiembre de 2009

\begin{tabular}{|l|c|c|}
\hline & N & $\%$ \\
\hline $\begin{array}{l}\text { Prevención a la dependencia y promoción A, } \\
\text { Personal }\end{array}$ & 2554 & 0,39 \\
\hline Teleasistencia & 28286 & 4,32 \\
\hline Servicio de Ayuda a Domicilio & 46509 & 7,11 \\
\hline Centros de Día/Noche & 22827 & 3,49 \\
\hline Atención Residencial & 86220 & 13,18 \\
\hline Prestación Económica Vinculada al Servicio & 28633 & 4,38 \\
\hline Prestación Económica a Cuidados Personales & 228817 & 34,99 \\
\hline Prestación para la Asistencia Personal & 630 & 0,10 \\
\hline Total & 444476 & 67,96 \\
\hline Pendientes del PIA & 209559 & 32,04 \\
\hline Total & 654035 & 100 \\
\hline
\end{tabular}

Fuente: IMSERSO/Sistema para la Autonomía y Atención a la Dependencia. 


\subsubsection{El empleo en el sector de atención a las personas}

El mercado laboral español bebería de los dos procesos descritos, de ahí que nos encontremos en un menor desarrollo del sector servicios y un mercado de trabajo muy segmentado por razones de género. En líneas generales, el mercado laboral español se caracteriza por el hiperdesarrollo de ciertos sectores, en detrimento de otros, como son los servicios públicos, que tienen un efecto clave sobre el nivel de desigualdad de una población y por ende sobre su nivel de bienestar. En general, en España se dibuja un mercado definido por estar muy segmentado, y de terminarse precisamente desde la precariedad laboral, con una presencia limitada de las organizaciones sindicales, en parte debido al gran número de pequeñas y medianas empresas que supone un freno a la sindicalización. Los expertos en mercado laboral nos dibujan el caso español como un mercado laboral precarizado, con altas tasas de temporalidad y paro, e inestable (Miguélez y Prieto, 1999; Miguélez, 2004; Banyuls et al, 2009). caracterizado, también por estar muy segmentado por razones de género. Así, las mujeres están sobrerepresentadas en los sectores menos cualificados y con salarios menores (Recio, 2001), es decir, el mercado laboral femenino se caracteriza por su segregación horizontal y su segregación vertical (Torns, 1999). Existen otros elementos a tener en cuenta para entender el mercado de trabajo español y que tienen una clara influencia sobre el sector de atención a las personas. En primer lugar, la recepción de flujos migratorios, de hecho las personas extranjeras han venido por el efecto llamada que se ha producido a raíz de las necesidades de mano de obra del mercado de trabajo español. Los hombres han venido a ocupar, principalmente, los puestos en el sector de la construcción, mientras que muchas mujeres han cubierto las necesidades en el sector de los cuidados. Otra característica que define el mercado de trabajo español y que tiene una importancia esencial en el sector que estudiamos es el modelo formativo. Un mercado que apuesta por el desarrollo de actividades no cualificadas, es decir, ha basado su expansión en actividades que requerían de una escasa formación profesional de entrada; aunque este no requerimiento de formación previa no es un aspecto neutro, sino que tiene que ver con la forma cómo se ha valorado la cualificación necesaria para desempeñar un empleo determinado. El caso del trabajo de atención a las personas es paradigmático en este sentido, ya que no es que no se trate de trabajo cualificado, sino que los sistemas de valoración de los empleos se han hecho de espaldas a los saberes de las mujeres. El cuidado es visto socialmente como una aptitud inherente al hecho de ser mujeres, y por ello es algo que se aprehende sin pasar por el sistema educativo formal (Maruani, 1993). 
Tabla 3. Características del empleo en el sector de atención a la dependencia. España, 2009*

\begin{tabular}{|l|c|}
\hline \multicolumn{1}{|c|}{ Características del empleo } & $\%$ \\
\hline \multicolumn{2}{|c|}{ Incremento del empleo 2008-2009 } \\
\hline Todos los sectores de empleo & $-7,8 \%$ \\
\hline Asistencia en establecimientos residenciales & $+6,7 \%$ \\
\hline Actividades de servicios sociales sin alojamiento & $+10,8 \%$ \\
\hline \multicolumn{2}{|c|}{ Perión del sector 2009 } \\
\hline Asistencia en establecimientos residenciales \\
\hline Actividades de servicios sociales sin alojamiento \\
\hline \multicolumn{2}{|c|}{$82,8 \%$} \\
\hline Asistencia en establecimientos residenciales en el sector privado 2009 \\
\hline Actividades de servicios sociales sin alojamiento & $75,5 \%$ \\
\hline Actividades sanitarias & $76,5 \%$ \\
\hline Educación & $34,4 \%$ \\
\hline
\end{tabular}

(*) Los datos seleccionados corresponden al segundo trimestre del año.

Fuente: Elaboración propia a partir de datos EPA.

Todo ello va a tener su expresión específica en el sector del cuidado: expansión de un sector feminizado, precario y con un nivel alto de economía sumergida. En primer lugar parece claro que es un sector en clara expansión y que el sector público tiene un papel central en el fomento de este tipo de servicios, pero que éstos, al contrario que los otros grandes sistemas del Estado del Bienestar, están siendo gestionados por el sector privado (ver Tabla 3).

El sector que nos ocupa recibe influencias de todas las lógicas mercantiles y extramercantiles descritas. Es necesario hacer referencia al proceso histórico del sector para entender algunas de las lógicas actuales. En este sentido, el primer impulso del sector no proviene de la ampliación del Estado del Bienestar, sino que se promueve como una forma de fomentar el empleo femenino y luchar con las altas tasas de paro femenino de la primera década de los años noventa (Torns,1997). De hecho, se adecuaba a la política europea que tras el Libro Blanco de Delors había intensificado su impulso de los yacimientos de empleo, que intentaban fomentar el trabajo a nivel local para luchar contra las altas tasas de desempleo. Por tanto, la noción de bienestar estuvo lejos de la consideración de la expansión de este sector de empleo. En ese contexto, se buscaron soluciones para la contratación de mujeres, y se hallaron en un sector relativamente nuevo y que ante las previsiones demográficas de envejecimiento de la población se vieron como unas soluciones óptimas. No se pensó 
ni en la calidad del empleo ni en la calidad del servicio. En parte porque eran servicios-empleos que iban a dar respuesta a las demandas de una población excluida socialmente y silenciada, y en parte porque iban a emplear a mujeres que estaban en riesgo de exclusión social. El imaginario del servicio y la profesión se situó más en el discurso de la lucha por la cohesión social que en el de la calidad del empleo y del bienestar de las personas (Torns et al., 2009).

«(...) los servicios personales y los care services son un magnífico ejemplo de esta creciente feminización de los también llamados servicios pink collar. Unos empleos poco cualificados, con bajos salarios, y con una fuerte presencia de contratos temporales y a tiempo parcial. Lo que no hace sino mostrar la persistencia de la tradición de precariedad de la relación salarial en femenino». (Carrasquer y Torns, 2007)

Desde Francia, a mediados de los años noventa, surgen estudios sobre el significado y la naturaleza de los empleos de proximidad (Fraisse, 2000; Croff, 1996; Lallement, 2000), relacionando los distintos aspectos que intervienen en la configuración de este tipo de trabajo en empleo y representando una síntesis de todos los elementos que se han ido citando y que están implicados en la configuración del modelo de empleo del sector de servicios de proximidad, que estas autoras lo entienden desde la precariedad laboral (Fraisse, 1996 y 2000; Croff, 1996; Lallement 1996 y 2000). De ahí que consideren que el servicio de proximidad es la denominación dada al trabajo doméstico asalariado, y sitúan este proceso en un contexto de crisis de empleo (en el sentido de precariedad) y en relación con el trabajo invisible (Fraisse, 1996). Por otro lado, consideran también que las relaciones de dependencia, subordinación y dominación atribuidas al trabajo doméstico (que remiten a la idea de servidumbre) impiden que estas profesiones se conciban como profesiones cualificadas, conllevando esto a que las personas empleadoras se sitúen en una posición de superioridad respecto a las personas contratadas. El imaginario social sitúa a las personas encargadas de realizar estos trabajos más como siervas/criadas que como trabajadoras asalariadas, y el tipo de trabajos asignados a estos nuevos servicios de proximidad se asemejan al trabajo doméstico no asalariado y realizado bajo condiciones de subordinación.

Estas visiones nos permiten realizar alguna consideración en este campo, aunque los datos escasean podemos destacar que estos empleos, aun con el impulso de los nuevos marcos legales, cuando están en el mercado formal, no tienen buenas condiciones de trabajo (Aragón, Cruces y Rocha, 2008). No están bien remunerados, muchas veces son inestables, y no están reconocidos. Como expresa la cita de Fraisse que encabeza este artículo, se trata de empleos demasiado cercanos a los imaginarios serviles. Sin embargo, es cierto 
que el nuevo marco legal preveé un importante incremento del sector ${ }^{6}$. Lo que se desconoce es la vía de creación de empleo y en qué categorías se va a generar. Parece ser que el discurso político apuesta por la profesionalización, una demanda que también proclaman tanto los colegios profesionales, las organizaciones sindicales, e incluso las organizaciones patronales ${ }^{7}$ (Torns et al., 2009). Y, de hecho, el debate ahora está instalado en el cuerpo de competencias y el grado de formación que debe exigirse, puesto que aún persiste un sistema no estatal de formación profesional que no es equiparable a ningún grado medio ni superior de la Formación Profesional en España. Parece ser que la vía sería acercarse al sistema sanitario, un proceso inconcluso, pero que se plantea como la vía para la mejora del empleo.

\section{Conclusiones}

La comunicación recoge algunas reflexiones en torno a la temática del trabajo de cuidados y sobre todo propone una lectura desde el vínculo entre trabajo y bienestar. En concreto se ha plasmado una propuesta teórica basada en el estudio de los modelos nacionales de empleo. Se trata de un debate inconcluso, y lo que aquí se presenta son algunas pinceladas y planteamientos iniciales de esta perspectiva.

El cuidado toma relevancia, traspasando la academia para situarse ya en la arena política y pública. Este es el proceso que hemos querido demostrar en el primer apartado. Y recoger aquellos trabajos que desde el feminismo han servido para mostrar cuán importante es el cuidado para el bienestar de la población, denunciando que a veces esta dimensión continúa silenciada. Tras este breve recorrido por aquellas perspectivas que hoy en día permiten avanzar en el conocimiento del cuidado, se ha presentado una propuesta teórica para el estudio del empleo en el sector de atención a las personas. Este enfoque parte del contexto de los modelos nacionales de empleo, que explican las transformaciones en los modelos nacionales de empleo desde una perspectiva institucional. El empleo se inscribe así en un contexto social determinado, donde instituciones extramercantiles interactúan con el mercado, y es desde esta intersección desde donde se generan unas dinámicas nacionales u otras. Esto nos ha permitido dibujar un modelo nacional de empleo caracterizado por su precariedad e inestabilidad y fuertemente segmentado por razones de

6. Las previsiones sitúan en casi 300000 los nuevos empleos que se van a generar con el despliegue de la Ley de Dependencia.

7. Éstas conclusiones derivan de una investigación finalizada recientemente y realizada por el Centre de Recerca QUIT, y sobre la cual se está trabajando para elaborar publicaciones futuras. 
género. Un modelo que depende de la persistencia de una familia tradicional y un estado asistencialista. Es en este contexto donde hemos enmarcado el estudio del sector del cuidado. En este sentido los primeros indicios apuntan precisamente a que se trata de un sector de empleo incipiente que generará nuevos empleos incluso en un momento como el actual donde las tasas de desempleo son significativamente elevadas. Pero este empleo aún parece estar pensado desde la precariedad y desde el valor social obtenido por aquellos empleos próximos al trabajo de las mujeres. El tipo y la cobertura de los servicios nos dice que todavía estamos muy cerca de un planteamiento familista de la política social española y ello revierte claramente en el tipo de ocupación. La menor apuesta por servicios no ataca las necesidades reales de cuidado de las personas, tan sólo transmite los costes del cuidado a las familias, cubriendo éstas sus necesidades, ya sea vía la propia institución familiar o con soluciones privadas, unas decisiones que dependerán de la clase social y la capacidad económica mayor o menor a hacer frente al coste económico que suponen las soluciones privadas. De esta manera, parece que se pierde el tren de una política clara que apunte hacia la profesionalización del cuidado. En definitiva, nos encontramos ante un sector que genera ocupación precaria, altamente feminizado, desarrollado gracias al impulso de las políticas públicas y la expansión del sector privado en la gestión y prestación del servicio. Unas características que comparten algunos rasgos con los otros grandes sistemas de bienestar, pero que se alejan de ellos en tanto en cuanto las condiciones de empleo y el acceso a los servicios son precarias e insuficientes y que se asientan sobre un modelo persistente de male breadwinner.

A nuestro parecer, para revertir esta situación sería necesaria una apuesta por un modelo de organización social sensiblemente distinto al actual, implicando la exigencia de cambios en el ámbito de la división sexual del trabajo y en la orientación política respecto a la importancia de los servicios de atención a las personas. También exige cambios en el mercado, por ejemplo, en el campo de la revisión de las valoraciones de los puestos de trabajo o de las grandes escalas salariales. Sólo si se piensan cambios en este sentido, que alberguen a distintas esferas de la vida social de un país, se podrá pensar en un sector de atención a las personas como una apuesta definitiva hacia el bienestar, tanto de las personas que prestan los cuidados como de las que los reciben. Existen algunos países que parecen estar más cercanos a este modelo, de ahí que se argumente que estas reflexiones lejos de ser utópicas puedan ser realmente aplicadas. 


\section{Bibliografía}

Adelantado, J., Los cambios en el estado del Bienestar, Barcelona, Icaria, 2000.

Adelantado, J., J.A. Noguera y X. RAmbla, «El marco de análisis: las relaciones complejas entre la estructura social y políticas sociales», en Cambios en el Estado del Bienestar. Políticas sociales y desigualdades en España, J. Adelantado(coord..), Barcelona, Icaria-UAB, 2000, pp. 23-61.

Ahmed, A., «the Swedish elderly care», national Report Dynamics of National Employment Models (DyNAMO) project, Växjö: CAFO, Växjo University, 2006.

ANXO, D. y C. FAGAN, «The family, the state and now the market: the organisation of employment and Working time in home care services for the elderly», en Working in the Service Sector: a tale from different worlds, G. Bosch y S. Lehndorff (ed.), New York, Routledge, 2005, pp. 133-164.

ANXO, D. y H. NyMAN, «Home care in Sweden» en New forms of employment and working time in the Service Economy, E. Mermet y S. Lehndorff, Final Report, 2001.

- «Home care in Sweden» en Country report for the New Forms of Employment and Working Time in the Service Economy (NESY) Project, E. Mermet y S. Lehndorff, 2001.

AnXo, D., H. Nyman y C. FAGAN, «The elderly home care», New forms of Employment and Working Time in the Service Economy Conference, 26-27 de Abril de 2001, Bruselas.

ARAGON, J., J. CRUCES y F. ROCHA, Las condiciones laborales en el sector de atención a la dependencia: una aproximación a la calidad en el empleo, Madrid, Fundacion Primero de Mayo, 2008.

AstelarRa, J., «Marx y Engels y el movimiento de las mujeres. ¿Es posible una lectura feminista de Marx?, A priori, no 0, 1982.

BALBO L., «La doble presencia» en Las mujeres y el trabajo: rupturas conceptuales, C. Borderías, C. Carrasco y C. Alemany, Barcelona, Icaria-Fuhem, 1994, pp. 503-513.

BANYUlS, J. et al., «The Transformation of the Employment System in Spain: Towards a Mediterranean Neoliberalism?» en European Employment Models in Flux. A comparison of Institutional Change in Nine European Countries, G. Bosch, S. Lehndorff y S. Rubery, Basingstoke, Palgrave Macmillan, 2009, pp. 247-270.

BENERIA, L., «Reproducción, producción y división sexual del trabajo», en Mientras Tanto, 6, 1981.

Bettio, F. y J. Plantenga, «Comparing care regimes in Europe», en Feminist Economics, n. ${ }^{\circ} 10$ (1), 2004, pp. 85-113. 
BetTiO, F; A. SimONAZzi y P. Villa, «Change in care regimes and female migration: the "care drain" in the Mediterranean», en Journal of European Social Policy, n. ${ }^{\circ} 16$ (3), 2006, pp. 271-285.

Borderías, C., C. CARrasco y C. Alemany, Las mujeres y el trabajo: rupturas conceptuales, Barcelona, Icaria-Fuhem, 1994.

BORRÁs, V., S. MORENO y C. RECIO, «La incorporación de los hombres en la esfera doméstica», en Sociología del Trabajo, n. ${ }^{\circ}$ 67, 2009, pp. 97-116.

Bosch, G., S. LeHndorfF y J. Rubery, (ed.), European Employment Models in Flux. A comparison of Institutional Change in Nine European Countries, Basingstoke, Palgrave Macmillan, 2009.

- «European Models in Flux: Pressures for change and Prospects for survival and Revitalisation» en European Employment Models in Flux. A comparison of Institutional Change in Nine European Countries, en G. Bosch, S. Lehndorff y S. Rubery (eds.), Basingstoke, Palgrave Macmillan, 2009, pp. 1-57.

Carrasco, C., A. Alabart, y M. Mayordomo, Mujeres, trabajos y políticas sociales: una aproximación al caso español, Madrid, Instituto de la Mujer, 1997.

CARRASQUer, P. y T. TORNS, «Cultura de la precariedad: Conceptualización, pautas y dimensiones. Una aproximación desde la perspectiva de género», en Sociedad y Utopía, n. ${ }^{\circ}$ 29, 2007, pp. 139-156.

Carrasquer, P., T. TORns, E. Tejero y A. Romero, «El trabajo reproductivo», en Papers: Revista de Sociologia, n. ${ }^{\circ}$ 55, 1998, pp. 95-144.

COATES, D. (ed.), Varieties of Capitalism, Varieties of Approaches, Basingstoke, Palgrave-Macmillan, 2005.

CROFF, B. , « Les emplois familiaux:le travail domestique réhabilité? », en Cahiers du Mage, n. ${ }^{\circ} 4,1996$, pp. 77-82.

DALY, M. y J. LEWIS, «The concept of social care and the analysis of contemporary welfare states», British Journal of Sociology, n 51, (2), 2000, pp. 281-298.

EsPing-Andersen, G., The three worlds of welfare capitalism, Cambridge, Polity Press, 1990.

EVERTSSON, L, «The Swedisch Welfare State and the emergente of Female State Occupations», en Gender, Work and Organisations, 7 (4), 2000, pp.230-241.

FAGAN, C. y D. NiXON, «Home care in the United Kingdom», Country report for the New Forms of Employment and Working Time in the Service Economy (NESY) Project, Manchester: Department o Sociology, University of Manchester, 2000.

FINCH, J., «The politics of comunity care in Britain» en Gender and caring, C. Ungerson, Hertfordshire, Harvester Wheatsheaf, 1990, pp. 34-58.

FinCH, J. y D. GROVES, A labour of love: Women, work and caring, Londres, Routdlege and Kegan Paul, 1983. 
FRAISSE, G., «Servidumbre, servicios de proximidad y democracia» en Las nuevas fronteras de la desigualdad, M. Maruani, Ch. Rogerat y T. Torns, Barcelona, Icaria, 2000, pp. 227-232.

GARDINER, J., «Rethinking self-sufficiency: employment, families and welfare», en Cambridge Journal of Economics, n. ${ }^{\circ}$ 24, 2000, pp. 671-689.

GRAHAM, H., «Caring: a labour of love» enA labour of love: women, work and caring, J. Finch y D. Groves, London, Routledge and Kegan Paul, 1983, pp.13-30.

Hochschild, A. R., La mercantilización de la vida intima. Apuntes de la casa y el trabajo, Buenos Aires, Katz Editores, 2008.

IMSERSO, Cuidados a las personas en los hogares españoles. El entorno familiar, [en línea], MTAS-IMSERSO Madrid, 2005, <http://www.imserso.es/Presentacion/ groups/imserso/documents/binario/cuidadosppmmhogares.pdf>.

LALLEMENT, M., «Familia y empleos de servicio» en Las nuevas fronteras de la desigualdad, M. Maruani, Ch. Rogerat y T. Torns, Barcelona, Icaria, 2000, pp. 249-268.

LETABLIER, M.-TH., «El trabajo de "cuidados" y su conceptualización en Europa», en Trabajo, género y tiempo social, C. Prieto, Madrid, Hacer, 2007, pp. 64-84.

LEWIS, J.(ed.), Gender, Social Care and Welfare State Restructuring in Europe, Aldershot, Ashgate, 1998.

LOPE, A., A. RECIO y F. GIBERT, La qualitat de l'ocupació i dels serveis d'assistència domiciliaria a Manlleu, Barcelona, QUIT, 2004.

LOPE, A., F. GIBERT y A. RECIO, Propostes per l'establiment d'un protocol sobre ocupació en la prestació dels serveis d'Atenció Domiciliaria de Manlleu, Barcelona, QUIT, 2005.

MARUANI, M., «La cualificación, una construcción social sexuada», en Revista de economía y sociología del trabajo, n. ${ }^{\circ} 21-22,1993$, pp. 41-49.

MiguÉlez, F., «La flexibilidad laboral», en Trabajo, n. ${ }^{\circ}$ 13, 2004, pp. 17-36.

Miguélez, F. y C. PRIETo, Las relaciones de empleo en España, Madrid, Siglo XXI, 1999.

Miguélez, F. A., Lope y I. OlivareS, «Eldery care sector in Spain», en Proyecto Dynamo, (impreso), Barcelona, QUIT, 2006.

Muñoz DE Bustillo, R., «Retos y restricciones del Estado del Bienestar en el cambio de siglo«, en El Estado del Bienestar en el cambio de siglo, R. Muñoz de Bustillo (ed.), Madrid, Alianza, pp. 50-108.

PASTOR, I., « ¿Treball públic amb lògica privada?» en Revista de l'Associació Catalana de Sociología, n. ${ }^{\circ}$ 15, 2001, pp. 154-171.

- ¿La gestión privada en la Administración Pública? El caso de los servicios hospitalarios de Cataluña, Madrid, Consejo Económico y Social, 2006.

PICCHIO, A., «El trabajo de reproducción, tema central en el análisis del mercado laboral», en Las mujeres y el trabajo. Rupturas conceptuales, C. Borderías, C. Carrasco y C. Alemany, Barcelona, Icaria-Fuhem, 1994, pp. 450-490. 
RECIO, A., «Low pay in Spain», en Transfer, 7(2), 1999, pp. 321-337.

— «Low pay in Spain», en Transfer, vol. 7, 2, 2001, pp. 321-337.

— «El negoci de la dependència» en Carrer, 111, 2009, p. 16.

Rodríguez CABrero, G. (comp.), Estado, privatización y bienestar. Un debate de la Europa Actual, Barcelona, Icaria-Fuhem, 1991.

- «Los restos de la política social en la era de la globalización» en La sociedad: Teoría e investigación empírica, AA.VV., Madrid, CIS, 2002, pp. 507-536.

RUBERY, J., «What do women want from full employment?», en Working for Full Employment, J. Philpott, Londres, Routdlege, 1997, pp. 63-80.

Rubery, J., M. SMITH y C. FAGAN, Women and European Employment. Trends and prospects, Londres, Routledge, 1999.

RUBERY, J., G. BOSCH y S. LEHNDORFF, The influence of the EU on the evolution of National Employment Models, International Labor Organization-International Institute for Labour Studies, Ginebra, 2008.

SAInSBURY, D., Gendering welfare states, Sage Londres, Publications, 1996.

SARACENO, CH., «Familismo ambivalente y clientelismo categórico en el Estado del Bienestar italiano», en El estado del Bienestar en la Europa del Sur, L. Moreno y S. Sarasa (coord.), Madrid, CSIC, 1995, pp. 261-288.

Simonazzi, A. M., "Care regimes and nacional employment models», Cambridge Journal of Economics, n. ${ }^{\circ} 33,2009$, pp. 211-232.

Thomas, C., «De-constructing concepts of care», en Sociology, n. 27 (4), 1993, pp. 649-669.

TORNS, T., «Los servicios de proximidad ¿un yacimiento de empleo?», en Revista de Treball Social, 1997, pp. 40-53.

- «Las asalariadas: un mercado con género», en Las relaciones de empleo en España, F. Miguélez y C. Prieto, Madrid, Siglo XXI, 1999, pp. 150-161.

- «El trabajo y el cuidado: cuestiones teórico-metodológicas desde la perspectiva de género», en Empiria, n. ${ }^{\circ}$ 15, 2008, pp. 53-73.

— «El futuro del empleo femenino y los yacimientos de empleo», en La mujer en el mercado de trabajo, P. Rodríguez y otros, Instituo de Desarrollo Regional, Málaga, 2000, pp. 223-243.

TORNS, T. et al., Local development and care services in Catalonia, comunicación, 27th International Labour Process Conference «Work Matters», Edimburgo 6,7 y 8 de abril de 2009.

UnGERSON, C., "The language of care. Crossing the boundaries», en Gender and caring. Work and Welfare in Britain and Scandinavia, C. Ungerson, Hertfordshire, Harever Wheatsheat, 1990, pp. 9-33. 



\title{
FUNDAMENTOS ÉTICOS PARA LA PROMOCIÓN DE LA AUTONOMÍA: HACIA UNA ÉTICA DE LA INTERDEPENDENCIA
}

\section{Ethical grounds for promoting autonomy: towards an ethic of interdependence}

\author{
FRANCISCO GUZMÁN CASTILLO* \\ MARIO TOBOSO MARTÍN** \\ JAVIER ROMAÑACH CABRERO***
}

\section{Resumen}

Las políticas sociales se fundamentan en modelos éticos, antiguos y nuevos, que se implantan paulatinamente en la sociedad. Los modelos tradicionales, además de basarse en las éticas kantianas o deontológicas y consecuencialistas, incluyen otras aportaciones, entre las que podemos reseñar las de Hans Jonas, Martha Nussbaum o Alasdair MacIntyre. Sin embargo, sólo se producen innovaciones importantes cuando un colectivo «no tradicional» hace su voz presente en el mundo de la ética. Actualmente el modelo social y el modelo de la diversidad aportan una nueva voz, que nace de las

* Francisco Guzmán Castillo

Instituto de Filosofía, Centro de Ciencias Humanas y Sociales, CSIC

C/ Albasanz, 26-28. 28037 Madrid

Teléfono: 916022300 Fax: 916022971

paco.guzman@cchs.csic.es

* Mario Toboso Martín

Instituto de Filosofía, Centro de Ciencias Humanas y Sociales, CSIC

C/ Albasanz, 26-28. 28037 Madrid

Teléfono: 916022300 Fax: 916022971

mario.toboso@cchs.csic.es

*** Javier Romañach Cabrero

Foro de Vida Independiente

C/ Raimundo Fernández Villaverde, 53, 9d. 28003 Madrid

Teléfono: 9153477 59/670 216894

jromanac@diversocracia.org 
personas discriminadas por su diversidad funcional y que tiene fuertes implicaciones en los fundamentos éticos de las políticas sociales. En este texto se abordan las novedades y críticas que esta nueva voz aporta a la ética contemporánea, con especial énfasis en la presencia o ausencia de la misma en la Ley de Promoción de la Autonomía Personal y Atención a las personas en situación de dependencia.

Palabras clave: ética de la interdependencia, ética del cuidado, ley de dependencia, diversidad funcional, modelo social, modelo de la diversidad.

\begin{abstract}
Social policy is based on both old and new ethical models that are introduced gradually into society. Traditional models are not only based on Kantian, deontological and consequentialist ethics, they also include contributions such as those by Hans Jonas, Martha Nussbaum and Alasdair MacIntyre. However, important innovations only occur when a «non-traditional» collective makes its voice heard in the world of ethics. This new voice is currently being provided by social and diversity models, and which stems from people being discriminated against due to their functional diversity, with major implications in the ethical grounding of social policy. This text considers what this new voice brings to contemporary ethics and how it is considered, with particular emphasis on the presence or absence of this voice in the Personal Autonomy and Dependent Care Law.
\end{abstract}

Keywords: ethics of interdependence, ethics of care, Dependent Care Law, functional diversity, social model, diversity model.

\title{
1. Teorías éticas clásicas
}

Hasta un momento muy reciente, el destinatario de las teorías éticas ha venido siendo un ser humano dotado de unas competencias básicas indispensables para ejercer la acción moral: la racionalidad, el carácter y el juicio en Aristóteles; la caridad, la misericordia y la beneficencia en la ética cristiano-medieval; el sentimiento de benevolencia y cierta capacidad física y mental para oponerse a una posible dominación en Hume, la autonomía moral basada en la razón en Kant, etc., todas ellas aptitudes básicas para ser considerado sujeto moral agente, es decir, aquel que actúa bien sobre otro. ${ }^{1}$

En cuanto al sujeto moral paciente, que recibe la acción del agente, sólo es incluido como miembro de pleno derecho en este intercambio ético si reúne las competencias exigidas a los agentes morales. Al carecer de alguna de estas competencias se puede ser objeto de la acción moral, pero puesto que desde un punto de vista ético-antropológico no se disfruta del mismo estatus que el

1. Véanse, por ejemplo: Aristóteles, Ética a Nicómaco, Retórica; Tomás de Aquino, Suma Teológica; Hume, Investigación sobre los principios de la moral, Tratado de la naturaleza humana; Kant, Fundamentación de la metafísica de las costumbres, Metafísica de las costumbres. 
sujeto moral agente, la relación de intercambio será asimétrica, favoreciendo comportamientos opresivos y consideraciones prejuiciosas y discriminatorias.

Los tratados de ética y filosofía se aproximan a la realidad de las personas con diversidad funcional ${ }^{2}$ a través del análisis de la inherente fragilidad del ser humano desde dos supuestos diferentes. En primer lugar se considera al ser humano frágil como un objeto de la acción ética del sujeto, alguien a quien se sitúa en un plano inferior de existencia y al que se trata de ayudar para que recupere su estatus de ser humano autónomo, autosuficiente, sano, etc. Desde este punto de vista se estudia el mejor modo de tratar a quienes padecen penalidades y las maneras de fomentar medios morales y sociales para su superación o erradicación. Todas las éticas anteriores al siglo XX (como la aristotélica, la cristiana y las de Hume y Kant, entre otras) se encuadran en este tipo y sitúan a la persona con diversidad funcional en la categoría de «objeto» sobre el que se actúa moralmente. Aunque contengan algunas ideas que se pueden rescatar para una ética de la interdependencia, todas ellas limitan sus potenciales emancipatorios al grupo de los competentes según su particular visión, apropiándose de la voz de los excluidos. En segundo lugar se considera al ser humano dependiente como un «sujeto» de la acción ética sobre otros seres humanos dependientes por otras o las mismas razones. Desde este punto de vista se critica cualquier sistema social o de conocimiento que fomente la distinción entre los necesitados y los autosuficientes, de manera que los medios sociales se orientan a desarticular esta desigualdad de partida, distribuyéndose de modo tal que contribuyan a eliminar cualquier diferencia de estatus derivada de un diseño social discriminatorio (Sutherland, 1981; Zola, 1989; MacIntyre, 2001).

\section{Contractualismo del siglo XX}

El contractualismo, que tiene sus raíces en Rousseau y Kant, establece que la sociedad es una empresa cooperativa, fruto del acuerdo o contrato entre iguales, para obtener ventajas comunes. Las teorías contractualistas clásicas se basan, generalmente, en una visión pesimista de la naturaleza humana, que se compensa gracias a un orden natural optimista que finalmente siempre se impone. Pero, ¿quiénes son los beneficiarios de este orden de bien y justicia fruto del miedo, el egoísmo y la desconfianza mutua? Precisamente quienes provocan estos mismos sentimientos.

2. Acerca de la propuesta del término «diversidad funcional» como revisión crítica del concepto de «discapacidad», véase Romañach y Lobato (2005). A lo largo del artículo asumimos esta propuesta. 
Los autores contemporáneos del contractualismo se preocupan por el proceso a través del cual se elabora el contrato de convivencia justa entre individuos o grupos con necesidades e intereses distintos. En este terreno hay dos cuestiones que afectan especialmente a las personas con diversidad funcional. La primera, definir quiénes son los sujetos que determinan cuáles van a ser los principios de justicia que regirán en la sociedad. Esto, en la teoría de Rawls (1995), se decide en la posición original que está ocupada por aquellos que tienen reconocida una mínima personalidad moral y una plena capacidad de cooperación social. Si alguien no cumple con este mínimo establecido por la teoría, no puede participar plenamente y se convierte en un sujeto pasivo del juego de la convivencia. Esto les ocurre a las personas con diversidad funcional, que se sienten discriminadas porque viven en una sociedad que ha sido diseñada sin tener en cuenta su voz.

Rawls, en su Teoría de la Justicia, reconoce sus dudas sobre una posible extensión de su concepto de la justicia social hacia las personas con diversidad funcional, que por no ser plenamente cooperantes no pueden satisfacer las condiciones mínimas de participación social igualitaria. Únicamente señala que desde sus principios de justicia pueden establecerse criterios para fomentar un servicio normal de salud (Rawls, 1995: 51); una actitud clásica (entre lo despótico y lo paternalista) con la cual se regresa al modelo médico de la discapacidad, en lugar de avanzar hacia nuevas propuestas éticas. ${ }^{3}$

En una línea diferente, Amartya Sen desarrolla su «enfoque de las capacidades» intentando ampliar y modificar los planteamientos de Rawls, en el ámbito de la economía, como una evaluación comparativa de la calidad de vida en diferentes sociedades (Sen, 1985, 1993, 1999). El concepto de «capacidad» de Sen consiste en un conjunto de seres y quehaceres valiosos a los que el individuo puede acceder libremente gracias a que vive en sociedad. El concepto de «funcionamiento» refleja esas diversas cosas que una persona puede valorar ser o hacer. Los funcionamientos valorados pueden ir desde los más elementales: estar alimentado, no padecer enfermedades evitables, la higiene, el descanso, etc., hasta otros más complejos, como participar en la vida comunal, disfrutar del ocio, de la sexualidad, viajar, formar una familia (Cejudo, 2007); todo aquello relacionado con el respeto a uno mismo y a su propio concepto de vida digna. ${ }^{4}$

3. Modelo que reduce la diversidad funcional a los aspectos biomédicos del ser humano y que ha sido ya descartado legalmente por la Convención Internacional de la ONU sobre los Derechos de las Personas con Discapacidad (diversidad funcional).

4. Los funcionamientos más complejos suelen ser guías de las preferencias y valoración que sobre los elementales tienen las personas, pero no se les suele considerar a la hora 
La labor de una sociedad justa es producir y mantener activos estos funcionamientos (Toboso y Arnau, 2008), para que la mayor diversidad posible de personas acceda a los mismos con el fin de alcanzar sus fines, y así habrá disponibles más funcionamientos para que otros los utilicen como capacidad. ${ }^{5}$

La segunda cuestión en la que el contractualismo incide en la diversidad funcional remite al análisis de qué derechos o recursos básicos debe garantizar la sociedad a los individuos para llevar a cabo su proyecto de vida. Martha Nussbaum (2007) presenta su propia versión del «enfoque de las capacidades» como una revisión mejorada del contractualismo rawlsiano, que incluye el reconocimiento del deber moral hacia aquellos miembros que puedan ser considerados no plenamente cooperantes, más allá del mero beneficio mutuo como motivo para acordar los principios de convivencia. Su noción de la persona, de raíz aristotélica, la define como una criatura social y política necesitada de una pluralidad de actividades vitales, a las que se accede a través de una serie de capacidades esenciales que la sociedad debe garantizar. Sin embargo, aunque su modelo es más solidario que el del contractualismo anterior, impone la solidaridad forzosa de un concepto de la vida buena determinado por la experiencia cultural de quien define la lista de capacidades (Nussbaum, 2007).

\section{Nuevos paradigmas éticos}

También resultan aplicables a este ámbito otras voces de filósofos contemporáneos cuyas aportaciones se salen de lo analizado anteriormente. Entre ellos podemos destacar a Hans Jonas y Alasdair MacIntyre.

En la perspectiva de Jonas, el arquetipo de la responsabilidad, que es el deber de los padres de cuidar a los hijos, se establece a partir de una relación asimétrica y no recíproca (Jonas, 1995). El ser necesitado de cuidado lleva consigo de un modo inmanente y evidente un «deber» para otros que han de atender a su cuidado. Así, recuperando el finalismo aristotélico, considera que el ser, en cuanto fin en sí mismo, está dotado ya de un valor intrínseco (Becchi, 2008: 120). Esto es importante señalarlo porque parecería que, desde esta argumentación, el ser frágil tiene como fin natural convocar en los demás

de diseñar políticas sociales. Por ejemplo, en las políticas sociales de atención a la diversidad funcional se da mayor importancia a las necesidades médicas y a la realización de actividades básicas de la vida diaria, como el aseo o la alimentación, mientras que actividades como el disfrute del ocio o de los viajes no se tienen en cuenta.

5. Esta es una de las razones por las que creemos que es interesante no excluir la diversidad funcional de la sociedad, porque abre el espacio de posibilidades a nuevas formas de estar en el mundo que pueden ser aprovechadas por todos. 
el deber moral de ser ayudado, sin reconocer, en principio, mayor alcance en su existencia, cayendo de esta manera en el mismo error que la ética cristiana, que redujo al ser frágil a objeto de caridad.

La dimensión no recíproca de la responsabilidad es clave a la hora de aplicar el paralelismo que Jonas establece entre la responsabilidad paterno filial y la responsabilidad del Estado y las instituciones sociales para que posibiliten que los ciudadanos, sobre todo aquellos que se encuentren en situación de dependencia, puedan recibir la atención que requieran para ser felices. La responsabilidad recíproca establecida entre, digamos, iguales (por ejemplo, empresas colectivas, hermanos, amigos), siendo necesaria y sólida, es sin embargo menos incondicional que la responsabilidad asimétrica, tal y como la experimentan, de modo paradigmático, los padres respecto al cuidado de los hijos (Bonete, 2009: 51). Para formarnos una opinión de la bondad del Estado social, habría que dar importancia a las oportunidades de que disfrutan las diferentes personas para alcanzar el propio bienestar, como reflejo de qué cartas ha repartido la sociedad a cada una de ellas.

Vemos, pues, que Jonas nos provee de la justificación última en la que fundar nuevos desarrollos sociales con nuevos valores éticos, ya que para él es natural este tipo de avances en la sociedad. Pese a ello, aunque señala que el supremo cumplimiento de la responsabilidad es la abdicación, la autonomía y la voz del paciente que recibe la acción moral del sujeto responsable no parece tenerse muy en cuenta a lo largo del proceso.

Por su parte, Alasdair MacIntyre, plantea la conveniencia de repensar la ética a partir de la constatación de que somos seres débiles y que, por tanto, dependemos constantemente los unos de los otros para vivir humanamente. El núcleo de la condición humana no ha sido realmente analizado en sus implicaciones éticas (MacIntyre, 2001: 15): «Los seres humanos son vulnerables a una gran cantidad de aflicciones diversas y la mayoría padece alguna enfermedad grave en uno y otro momento de su vida. La forma como cada uno se enfrenta a ello depende sólo en una pequeña parte de sí mismo. Lo más frecuente es que todo individuo dependa de los demás para su supervivencia, no digamos ya para su florecimiento, cuando se enfrenta a una enfermedad o lesión corporal, una alimentación defectuosa, deficiencias y perturbaciones mentales y la agresión o negligencia humanas. Esta dependencia de otros individuos a fin de obtener protección y sustento resulta muy evidente durante la infancia y la senectud, pero entre estas primera y última etapas en la vida del ser humano suele haber periodos más o menos largos en que se padece alguna lesión, enfermedad o discapacidad, y hay algunos casos en que se está discapacitado de por vida». 
Uno de los motivos que, según MacIntyre, impulsa a cuidar de la persona dependiente es la constatación de que uno mismo podría ser quien padece alguna inesperada enfermedad o accidente paralizante. Este autor sostiene que una comunidad se desarrolla en la medida en que la necesidad urgente de alguno de sus miembros es la que provee razones suficientes para que otros reaccionen de un modo moral ante sus padecimientos, sin recurrir a argumentos sutiles o filosóficos para impulsar la acción (Bonete, 2009: 79). El planteamiento de MacIntyre apunta directamente a la dimensión social y política del problema de la fragilidad y la dependencia humanas. Su intención es imaginar una sociedad política que, según sus propias palabras, «parte del hecho de que la discapacidad y la dependencia es algo que todos los individuos experimentan en algún momento de su vida y de manera impredecible, por lo que el interés de que las necesidades que padecen las personas discapacitadas sean adecuadamente expresadas y atendidas no es un interés particular de un grupo de individuos concretos, sino que es el interés de la sociedad política entera y esencial en su concepto del bien común» (MacIntyre, 2001: 154).

Tanto las revisiones del contractualismo clásico de Nussbaum y Sen, como los nuevos paradigmas éticos de Jonas y MacIntyre plantean la inevitable necesidad de afrontar el tema de la fragilidad y la dependencia humana en el mundo de la filosofía ética y política. No obstante, para profundizar en los nuevos valores éticos, nos parecen más interesantes las éticas surgidas de las voces nunca escuchadas y que hablan en primera persona.

\section{Nuevas voces éticas en primera persona: ética del cuidado o de la implicación}

En 1977, Carol Gilligan, psicóloga feminista estadounidense, escribía el influyente artículo: «In a Different Voice: Women's Conceptions of Self and of Morality», y en 1982 el libro In a different voice: psychological theory and women's development, en el que a través de varios casos concretos desvela la diferente aproximación a la filosofía moral que tienen los hombres y las mujeres. Siguiendo a la autora Soledad Arnau (2009): «[... Gilligan, establece una distinción que considera irrevocable. Debido fundamentalmente a los roles tradicionales de género, se establecen dos tipologías de ética: ética de la justicia, de carácter predominantemente de género masculino; y la ética del cuidado (o también, "ética de la responsabilidad"), proveniente del género femenino».

La ética del cuidado surgió, pues, a partir del trabajo de Carol Gilligan en los años ochenta, que dio importancia, desde la perspectiva del feminismo, a la manera en que las mujeres parecían abordar los problemas éticos, es decir, a través de prácticas relacionadas con el cuidado. Sin embargo, la palabra 
«cuidado» en español no abarca todos los aspectos contenidos en la noción anglosajona de care. Nel Noddings desarrolla el concepto indicando que: «Preocuparse por otra persona, en su aspecto más significativo, es ayudarle a crecer y a adaptarse» (Noddings, 1984: 9) y que «cuando nos preocupamos, consideramos el punto de vista de la otra persona y qué es lo que espera de nosotros. Nuestra atención, nuestra ocupación mental está en aquel del que nos ocupamos, no en nosotros. Nuestras razones de actuar tienen que ver con lo que la otra persona quiere ser y con los elementos objetivos de su situación problemática» (Noddings, 1984: 24). Visto lo anterior, creemos que estos aspectos de la ética quedan mejor reflejados en palabras como «implicación»o «preocupación», ya que la palabra cuidado no siempre revela una atención hacia el punto de vista del sujeto cuidado.

Esta perspectiva aporta una manera más humana y menos abstracta de establecer valores que guíen la acción ética, donde las relaciones parecen menos asimétricas, y aparece de manera natural la noción de «interdependencia», ya que establece que aquel por el que nos preocupamos (cared-for) depende del que se preocupa (one-caring), tanto como éste de aquél (Noddings, 1984: 48). Esto sienta las bases de una relación menos asimétrica que la de la relación del cuidado a la dependencia. Gracias a la ética de la implicación, pasamos a una situación de interdependencia en la que es posible una nueva construcción ética y social (Marín, 1993).

La ética de la «implicación» es una voz nueva y distinta, pero hay que tener presente que en sus premisas y reflexiones nunca tuvo en cuenta a la diversidad funcional, ni a las mujeres discriminadas por su diversidad funcional (Arnau, 2009).

\subsection{El modelo social de la «discapacidad»}

Lo que hoy se conoce como el modelo social de la «discapacidad $»^{6}$ tiene sus orígenes en el Movimiento de Vida Independiente ${ }^{7}$ de lucha por los derechos civiles de las personas con diversidad funcional, que tuvo lugar en Estados Unidos a partir de los años sesenta, en el que se establecieron importantes cambios de paradigma para aproximarse a esta realidad humana desde el punto de vista ético. El principal cambio consistió en que este modelo dio voz por primera vez, a las personas con diversidad funcional, como auténticas protagonistas de la deliberación pública de las prácticas y políticas sociales que les

6. Acerca de los dos modelos aquí resumidos, véase Palacios (2008).

7. Para profundizar en la historia del movimiento de Vida Independiente, véanse García Alonso (2003) y Maraña (2004, 2007). 
afectaban directamente. Esto fue así en buena medida gracias a que los inventores y promotores de este modelo eran personas con diversidad funcional.

Este conjunto de ideas llegó a Europa a través de Gran Bretaña y los países nórdicos y fue en este primer país donde que sus ideas fueron tamizadas para adaptarlas a la realidad europea; una realidad mucho más social que la sociedad liberal estadounidense (Palacios, 2008: 106). El modelo de Vida Independiente pasó a ser denominado modelo social, y es así como ha sido internacionalizado. En este proceso, el modelo se tornó más académico y en su desarrollo tuvo un fuerte impacto la sociología académica británica, que llegó a establecer estudios específicos sobre la diversidad funcional en universidades como la de Leeds, en donde han destacado sociólogos como Colin Barnes, Len Barton, Tom Shakespeare, etc ${ }^{8}$.

El modelo social asume la premisa de que la discapacidad es una construcción y un modo de opresión social. Asimismo, reivindica la autonomía de la persona con diversidad funcional para decidir respecto de su propia vida, y para ello se centra en la eliminación de cualquier tipo de barrera, con el fin de brindar una adecuada igualdad de oportunidades. Estas barreras incluyen inaccesibilidad en la educación, en los sistemas de comunicación e información, en los entornos de trabajo, sistemas de beneficencia inadecuados para las personas con discapacidad, servicios de apoyo social y sanitarios discriminatorios, transporte, viviendas y edificios públicos y de entretenimiento inaccesibles y la devaluación de las personas etiquetadas como discapacitadas por la imagen y su representación negativa en los medios de comunicación, películas, televisión y periódicos. Desde esta perspectiva, las personas con discapacidad son discapacitadas como consecuencia de la negación por parte de la sociedad de acomodar las necesidades individuales y colectivas dentro de la actividad general que supone la vida económica, social y cultural. (Barnes, 2000, citado en Palacios, 2008: 121).

Como podemos observar, el modelo social se alinea con el objetivo de este texto, ya que arranca del planteamiento de la interdependencia y de la gradualidad de las situaciones de «inDependencia» (Arnau, 2008).

\subsection{El modelo de la diversidad}

El modelo social tardó más de 20 años en llegar a una España en la que la mayor parte de las cuatro mil asociaciones del sector permanecían ancladas en el modelo médico, al igual que ocurre en el ámbito académico. La introducción

8. Véanse, por ejemplo, Oliver (1990), Shakespeare (1993, 1994), Barnes y Mercer (1996), Barnes $(1998,2000)$ y Barnes, Oliver y Barton (2002). 
de este modelo en nuestra sociedad fue impulsada por el Foro de Vida Independiente $(\mathrm{FVI})^{9}$, una comunidad virtual de información y discusión, creada en el 2001 por un grupo muy reducido de personas y que ahora cuenta con más de 800 miembros.

Aunque desde el punto de vista político las propuestas del modelo social parecen suficientes para conseguir legalmente la igualdad de oportunidades y la ausencia de discriminación, desde el ámbito de la ética, algunos autores, miembros del Foro, han comenzado a señalar que este modelo tiene carencias. Así, Agustina Palacios (2008: 141) señala que «toda vida humana, con independencia de la naturaleza o complejidad de la diversidad funcional que le afecte, goza de igual valor en dignidad. Debe destacarse, sin embargo, que esta afirmación resulta muy difícil de ser llevada a la práctica, dado que la misma fundamentación de la idea de dignidad humana actual parte desde un modelo de ser humano capaz. Es por ello que quizás se requiera una nueva definición de la idea de dignidad que no deje a nadie afuera, ni dé lugar a interpretaciones que supongan que determinados seres humanos pueden ser más dignos que otros». Además plantea que «Las personas con discapacidad tienen el derecho a la igualdad de oportunidades, en razón de su igual humanidad, y no por ser iguales funcionalmente. De otro modo, el contenido central del imperativo categórico kantiano estaría siendo vulnerado, ya que si valoramos a la persona en la medida de su aporte a la comunidad, estaremos considerando al ser humano como un medio y no como un fin en sí mismo» (Palacios, 2008: 164). Con estos argumentos se cuestiona la noción tradicional de dignidad humana manejada por el modelo social, basado en la capacidad de una serie de competencias, generalmente racionales, consideradas propias del ser humano funcional.

Bajo estos planteamientos nació el denominado «modelo de la diversidad», planteado en 2006 por Agustina Palacios y Javier Romañach en el libro El modelo de la diversidad: La Bioética y los Derechos Humanos como herramientas para alcanzar la plena dignidad en la diversidad funcional. El modelo fue presentado por sus autores como una extensión del modelo social, que ofrece tres propuestas: en primer lugar, el uso del término diversidad funcional (que se ha venido utilizando en este artículo) en sustitución del término discapacidad como expresión positiva de esta situación vital que es inherente a la vida humana. En segundo lugar, la aceptación de la diversidad funcional planteada como una más de las diversidades que conforman y enriquecen la humanidad (género, raza, orientación sexual, religión, nacionalidad, etc.). Y, por último,

9. Véase <http://www.forovidaindependiente.org> 
el reconocimiento de la plena dignidad en la diversidad funcional, para lo cual se establecen dos ideas o valores fundamentales: dar el mismo valor a las vidas de todos los seres humanos, sea cual sea su diversidad funcional, y garantizar los mismos derechos y oportunidades a todas las personas.

Palacios y Romañach, conscientes de la incoherente aproximación del modelo social a la dignidad, basada en las nociones tradicionales de autonomía y capacidad, decidieron utilizar un concepto «instrumental» de la dignidad. Para ello se basaron en el análisis de la aparición de dicho término en textos legales nacionales, textos bioéticos y textos de declaraciones internacionales aprobados por la inmensa mayoría de los estados (Romañach y Palacios, 2006: 135-174).

Por otro lado, el modelo apunta las potenciales consecuencias para la sociedad, en función de que decida utilizar o no dichos valores «universales». Partiendo de experiencias previas en las que la plena dignidad humana no fue respetada, con consecuencias sociales y humanas desastrosas, como fueron Esparta o la Alemania nazi, el modelo propone la aceptación de sus valores como fundamentos imprescindibles para la construcción de una sociedad justa y libre (Romañach y Palacios, 2006: 222-223): «El modelo de la diversidad propone claves para construir una sociedad en la que todas las mujeres y hombres vean preservada plenamente su dignidad. Una sociedad en la que la diversidad, y en concreto la diversidad funcional, sea vista como una diferencia con valor y no como una carga independientemente de la edad a la que se produzca. Una sociedad en la que exista la igualdad de oportunidades y nadie sea discriminado por su diferencia. En definitiva, una sociedad más justa en la que todas las personas sean bienvenidas, aceptadas y respetadas por el simple hecho de ser humanos».

\section{Reflejo en el derecho}

Las teorías éticas analizadas en este trabajo tienen su reflejo en las diferentes leyes que sucesivamente se implantan para tratar el fenómeno de la diversidad funcional (discapacidad). Es por ello que los fundamentos analizados en este artículo, referentes a la ética de la interdependencia y de la promoción de autonomía, quedarían en meras opiniones o ideas si no acabasen reflejados en los textos legales.

En la legislación española se da con frecuencia un caso de incoherencia plena, en la que, si bien en los preámbulos y en los artículos iniciales que establecen principios, parece vislumbrarse un cambio radical de postura ética, el desarrollo posterior del articulado del texto legal y de los reglamentos pertinentes acaban tirando por tierra cualquier pretensión de cambio. Tal es 
el caso, por ejemplo, de la Ley 51/2003, de Igualdad de oportunidades, no discriminación y accesibilidad universal, bastante buena en su preámbulo y articulado, pero cuyas disposiciones finales y reglamentos demoran o debilitan su plena aplicación, ya que permiten infringirla a muy bajo coste.

Creemos que aquellas teorías que dan voz y reconocen la dignidad de todos los actores implicados en la convivencia con el fenómeno de la diversidad funcional son más adecuadas que otras éticas, más anticuadas, que dan todo el protagonismo al sujeto aparentemente más capaz de la relación ética, facilitando el posible diseño de sociedades injustas que opriman a sus miembros más débiles.

La plasmación en leyes de los valores defendidos en una filosofía moral permite detectar rápidamente el grado de implantación de esos valores en el sistema legislativo y, por lo tanto, en la sociedad. Por ello, hemos analizado la presencia de estos valores en algunas de las leyes más importantes en el ámbito de la diversidad funcional, para rastrear la presencia de nuevas voces, que darían fundamento a la ley desde la nueva ética necesaria para la promoción de la autonomía y la interdependencia.

El modelo social y el de la diversidad se encuentran íntimamente relacionados con la incorporación de ciertos valores intrínsecos a los derechos humanos y aspiran a potenciar el respeto por la dignidad humana, la igualdad y la libertad personal, propiciando la inclusión social sobre la base de principios tales como la vida independiente, la no discriminación, la accesibilidad universal, la normalización de los entornos y el diálogo civil, entre otros (Romañach y Palacios, 2007).

Para conseguir este objetivo, el modelo social ofrece argumentos para promover nuevos marcos legislativos basados en sus ideas, como es el caso de la Convención Internacional sobre los Derechos de las Personas con Discapacidad de la ONU o leyes antidiscriminación específicas. Ambos tipos de leyes están ya relativamente extendidas en el mundo occidental (España con leyes como la Ley 51/2003, de Igualdad de oportunidades, no discriminación y accesibilidad universal. La Convención tiene sus raíces fundamentales en el modelo social ${ }^{10}$ y está en vigor en España desde el 3 de mayo de 2008, por lo que, la mayoría de los fundamentos éticos que en ella se establecen, disponen ahora de un apoyo legislativo en todo el Estado, al menos de manera formal. De hecho, con estas directrices podría descartarse ya, por obsoleta, discriminatoria e insuficiente, la Ley de Promoción de la Autonomía Personal

10. Para profundizar en las relaciones entre el modelo social y la Convención, véase Palacios (2008). 
y Atención a las personas en situación de dependencia, aprobada en España a finales del 2006. Esta Ley limita la libertad de las personas con diversidad funcional para participar y vivir de forma independiente incluidas en la comunidad (reconocido en el artículo 19 de la Convención), ya que ofrece una cartera de servicios que prioriza aquellos que fomentan su exclusión y aislamiento (como las residencias y la atención a domicilio) y ofrece de manera restrictiva aquellos servicios que mejor fomentan la autonomía (como la asistencia personal). ${ }^{11}$

La Convención promueve la revisión de toda normativa, esté o no dirigida a las personas con diversidad funcional, que pueda contener alguna vulneración de los derechos establecidos en ella. Por eso, con estos principios se cuestionan más de 120 leyes vigentes hoy en España (Romañach y RodriguezPicavea, 2009).

\section{Conclusiones}

A lo largo de este artículo se han analizado diferentes paradigmas morales, en busca de ideas que den fundamento a la nueva ética que precisa la nueva sociedad, en especial las nuevas situaciones de «inDependencia», y se han encontrado ideas relevantes, modelos y corrientes morales y éticas. Sin descartar las aportaciones de autores clásicos y modernos, Aristóteles, Hume, Kant, Rawls, etc., para el objetivo que nos incumbe, encontramos los principiales apoyos en voces contemporáneas como las de Jonas, MacIntyre, Sen o Nussbaum, que sientan las bases de la inevitable necesidad de afrontar este tema en el ámbito de la filosofía moral.

No obstante, para profundizar en los nuevos valores éticos, nos parecen más importantes las éticas que nacen de las voces nunca escuchadas y que hablan en primera persona: la ética del «cuidado» o de la «implicación», que surge de las voces feministas, aporta una manera más humana y menos abstracta de establecer valores. En ella aparece de manera natural la noción de interdependencia ya que establece que aquel por el que nos preocupamos depende del que se preocupa tanto como el que se ocupa depende de aquel por el que nos preocupamos.

Del modelo social se desprende la necesidad de desmedicalizar y desinstitucionalizar a las personas discriminadas por su diversidad funcional, y dotarlas de las herramientas necesarias para participar en la sociedad en igualdad de oportunidades con los demás. Para conseguir este objetivo, el modelo

11. Artículo 14.2 de la Ley 39/2006 de Promoción de la Autonomía Personal y Atención a las personas en situación de dependencia. 
social propone nuevas leyes, como es el caso de la Convención Internacional sobre los Derechos de las Personas con Discapacidad (diversidad funcional) de la ONU o leyes antidiscriminación específicas (como la Ley 51/2003 en España). El modelo de la diversidad va más allá del modelo social, y propone la aceptación de la diversidad funcional como parte de la enriquecedora diversidad humana y la consecución de la plena dignidad en la diversidad funcional. Para ello, establece dos ideas o valores fundamentales: dar el mismo valor a las vidas de todos los seres humanos y garantizar los mismos derechos y oportunidades a todas las personas. Con estas ideas se está en disposición de afrontar los retos planeadas por la sociedad moderna, entre otros la promoción de la autonomía de las personas en situaciones de discriminación y la erradicación de políticas asistenciales de dependencia. Las sociedades occidentales contemporáneas se ven ahora en una encrucijada en la que habrá que elegir entre una futura sociedad en libertad y dignidad en la diversidad, o el retorno paulatino y sutil a sociedades fracasadas, discriminatorias e injustas ya existentes en el pasado. El camino elegido dependerá de los valores éticos que se utilicen para recorrerlo.

Si imaginamos que la convivencia es un juego, lo primero que establecería una teoría ética clásica sería determinar qué competencias mínimas deben reunir los jugadores para poder participar en el juego. Si el jugador no cumple con el mínimo establecido por la teoría no podría participar plenamente, convirtiéndose en un sujeto pasivo del juego. Esto les ocurre a las personas con diversidad funcional, que se sienten discriminadas porque viven en una sociedad que ha sido diseñada sin tener en cuenta su voz. Desde el punto de vista de una ética de la interdependencia, no se trataría tanto de determinar quién puede jugar y quién no, sino más bien de determinar cómo deberían ser las reglas del juego para que cualquier jugador, fuera cual fuera su capacidad y modo de funcionar, pudiera participar en él. Es decir, se trataría de definir en qué consiste el «juego de la convivencia» siendo éste el único en el que todos podemos jugar, de lo contrario se trataría del «juego de la exclusión».

\section{Bibliografía}

ARISTóteles, Ética a Nicómaco, Madrid, Centro de Estudios Constitucionales, 1981.

- Retórica, Madrid, Instituto de Estudios Políticos, 1953.

ARNAU, S., «El "cuidado" y sus perversiones: la cultura de la violencia», en Revista Intersticios, vol. 3. n. ${ }^{\circ} 2$, 2009, [en línea] <http://www.intersticios.es/article/ view/4547/3176>. 
— «La "In-dependencia": Un nuevo Derecho de Ciudadanía. Una cuestión de Derechos Humanos», en XV Congrés Valencià de Filosofia, organizado por la Societat de Filosofia del País Valencià (Valencia, 6-8 de marzo de 2008), [en línea], <http://www.uv.es/sfpv/congressos_textos/congres17.pdf>.

BARNES, C., «Las teorías de la discapacidad y los orígenes de la opresión de las personas discapacitadas en la sociedad occidental», en Discapacidad y Sociedad, L. Barton (comp.), Madrid, Morata, S.L., 1998.

- «Disabled People in Britain and Discrimination. A case for Antidiscrimination Legislation», Hurst and Company, London in association with the British Council of Organizations of Disabled People, Third Edition, United Kingdom, 2000.

Barnes, C. y G. Mercer (eds.), Exploring the Divide: Illness and Disability, The Disability Press, Leeds, 1996.

Barnes, C., M. Oliver, y L. Barton (eds.), Disability Studies Today, Oxford, Polity Press, 2002.

BECCHI, P., «El itinerario filosófico de Hans Jonas. Etapas de un recorrido», en Isegoría, n. ${ }^{\circ}$ 39, Madrid, CSIC, 2008, pp. 101-128.

BONETE, E., Ética de la dependencia. Bases morales, debates políticos e implicaciones médicas de la Ley de Dependencia, Madrid, Tecnos, 2009.

Cejudo, R., «Capacidad y libertad. Una aproximación a la teoría de Amartya Sen», en Revista Internacional de Sociología, vol. LXV, n. ${ }^{\circ}$ 47, 2007.

García Alonso, J. V. (coord.), El movimiento de vida independiente. Experiencias Internacionales, Madrid, Fundación Luis Vives, 2003, [en línea], <http://www. asoc-ies.org/docs/mvi_exper_internac.pdf>.

HuME, D., Investigación sobre los principios de la moral, Madrid, Alianza, 1993.

- Tratado de la naturaleza humana, Madrid, Editora Nacional, 1981.

JONAS, H., El principio de la responsabilidad. Ensayo para una ética de la civilización tecnológica, Barcelona, Herder, 1995.

KANT, I., Fundamentación de la metafísica de las costumbres, Madrid, Tecnos, 2005.

- Metafisica de las costumbres, Madrid, Tecnos, 1989.

Macintyre, A., Animales racionales y dependientes, Barcelona, Paidós, 2001.

Maraña, J. J., Vida Independiente. Nuevos modelos organizativos, Santiago de Compostela, AIES, 2004, [en línea], <http://www.asoc-ies.org/docs/vinmo.pdf>.

- La experiencia de la independencia, Vedra, La Coruña, DIVERSITAS EdicionesAIES, España, 2007.

MARíN, G., «Ética de la justicia, ética del cuidado», 1993, [en línea], <http://www. nodo50.org/doneselx/assemblea/etica.htm>.

Noddings, N., Caring. A femenine Approach to Ethics \& Moral Education, University of California Press, 1984.

Nussbaum, M., Las fronteras de la justicia. Consideraciones sobre la exclusión, Barcelona, Ediciones Paidós Ibérica, 2007. 
Oliver, M., The politics of disablement, Londres, Macmillan, 1990.

ONU, «Convención sobre los Derechos de las Personas con Discapacidad y Protocolo Facultativo», 2007, [en línea], <http://www.un.org/disabilities/ documents/convention/convoptprot-s.pdf>.

Palacios, A., El modelo social de discapacidad: orígenes, caracterización y plasmación en la Convención Internacional sobre los Derechos de las Personas con Discapacidad, colección CERMI, n. ${ }^{\circ}$ 36, Madrid, Grupo editorial CINCA. octubre 2008.

RaWls, J., Teoría de la justicia, Madrid, Fondo de Cultura Económica, 1995.

ROMAÑACH, J. y M. LOBATO, «Diversidad funcional, nuevo término para la lucha por la dignidad en la diversidad del ser humano», 2005, [en línea], <http://www.minusval2000.com/relaciones/vidaIndependiente/diversidad_ funcional.html>.

ROMAÑACH, J. y PALACiOs, A. El modelo de la diversidad: La Bioética y los Derechos Humanos como herramientas para alcanzar la plena dignidad en la diversidad funcional, Valencia, Diversitas, 2006, [en línea], <http://www.asoc-ies.org/ docs/modelo\%20diversidad.pdf>.

- «El modelo de la diversidad: una nueva visión de la bioética desde la perspectiva de las personas con diversidad funcional (discapacidad)», II Encuentro Moral, Ciencia y Sociedad en la Europa del Siglo XXI: «Interdependencia: el bienestar como requisito de la dignidad», San Sebastián, 15 y 16 de marzo de 2007.

ROMAÑACH, J. y A. RODRíGUEZ-PiCAVEA, «El futuro de la autonomía personal. Análisis de la Ley de Promoción de la Autonomía y atención a las personas en situación de dependencia del Estado español bajo la perspectiva de la Convención internacional sobre los derechos de las personas con discapacidad (diversidad funcional)», 2009, [en línea], <http://www.diversocracia.org/ ideateca.htm>.

SEN, A., Commodities and capabilities, Ámsterdam, Elsevier Science, 1985.

- «Capability and Well-Being», en The Quality of Life, M. C. Nussbaum y A. Sen, (eds.), Oxford, Oxford University Press, 1993.

- Nuevo examen de la desigualdad, Madrid, Alianza, 1999.

SHAKESPEARE, T., «Disabled people's self-organisation: a new social movement?», Disability E Society, Vol. 8, n. ${ }^{\circ}$ 3, 1993, pp. 249-264.

— «Cultural Representations of Disabled People: Dustbins for Disavowal» in Disability \& Society No. 9, Vol. 3. 1994. pp. 283-301.

Sutherland, A. T., Disabled We Stand, Londres, Souvenir Press, 1981, [en línea], $<$ http://www.campusred.net/TELOS/articuloexperiencia.asp? idarticulo=1\&rev $=73>$.

TOBOSO, M. y S. ARNAU, «La discapacidad dentro del enfoque de capacidades y funcionamientos de Amartya Sen», en Araucaria. Revista Iberoamericana de 
Filosofía, Política y Humanidades, año 10, n. ${ }^{\circ}$ 20, segundo semestre de 2008, [en línea], <http://www.institucional.us.es/araucaria/nro20/ideas20_4.htm>. TOMÁs DE AQuino, Suma Teológica, Madrid, BAC, 2005.

ZOLA, I. K., "Toward the necessary universalizing of a disability policy», en The Milbank Quarterly, vol. 67, supp. 2, Pt. 2, 1989, 401-428. Reimpreso en The Milbank Quarterly, vol. 83, n. ${ }^{\circ} 4$, 2005, pp. 1-27.

\section{Nota:}

Este artículo se inscribe dentro del Proyecto «Filosofía de las tecnociencias sociales y humanas» (FFI2008-03599) del Plan Nacional de I+D+i (20082011) y del Proyecto Intramural del CSIC «Discapacidad, envejecimiento y calidad de vida». 



\title{
LA GESTIÓN DE LA CRISIS DE LOS CUIDADOS Y SU RELACIÓN CON LA FEMINIZACIÓN DE LAS MIGRACIONES. ANÁLISIS COMPARATIVO DE LOS MODELOS DE ESPAÑA Y CHILE
}

\author{
Managing the crisis in care and its relationship with the \\ feminisation of migrations. A comparative analysis of the \\ models in Spain and Chile
}

\author{
María Luisa SetiÉn SANTAMaría* \\ ElAine Acosta GONZÁLEZ**
}

\section{Resumen}

En los últimos años, España y Chile se han constituido en casos emblemáticos de países que han atravesado una profunda crisis del cuidado, y en respuesta a dicho fenómeno han comenzado a importar mano de obra inmigrante, fundamentalmente femenina, para hacerse cargo de las labores de reproducción social. La presente ponencia tiene por objetivo identificar y comparar los modelos de gestión de la crisis de los cuidados en España y Chile, conociendo cómo la política social ha dado respuesta

\footnotetext{
* María Luisa Setién Santamaría

Universidad de Deusto

Avenida de las Universidades, 24. 48007 Bilbao

Teléfono: 944139323 Fax: 944139378

mlsetien@ets.deusto.es

** Elaine Acosta González

Universidad de Deusto

Avenida de las Universidades, 24. 48007 Bilbao

Doctoranda del programa en Estudios Internacionales e Interculturales de la Univer-

sidad de Deusto

Profesora e investigadora de la Universidad Alberto Hurtado en Chile

Teléfono: 9444544 14/695 875126

elaineacosta72@gmail.com
} 
en materia de distribución de la responsabilidad social del cuidado de personas dependientes entre el Estado, el mercado, la comunidad y la familia y qué régimen de bienestar social se encuentra asociado a dicha distribución. Los resultados aquí presentados forman parte de una investigación en curso, cuya metodología aplicada ha consistido en análisis bibliográfico, análisis de la normativa y la política social y análisis estadístico de fuentes secundarias.

Palabras clave: crisis del cuidado, feminización de las migraciones, personas dependientes, organización social del cuidado.

\begin{abstract}
In recent years, Spain and Chile have become emblematic cases of countries that have gone through a major crisis in care, and which have responded by importing mainly female immigrants for this reproductive labour. This paper identifies and compares this crisis of care is managed in Spain and Chile, examining how social policy has responded in terms of spreading the responsibility for dependent care between the State, the market, the community and the family, and which social welfare regimen is linked to this spread. The results form part of an ongoing investigation, using an applied methodology involving bibliographic analysis, normative and social policy analysis, and statistical analysis of secondary sources.
\end{abstract}

Keywords: care crisis, feminisation of migrations, dependent persons, social organisation of care.

\title{
1. Introducción
}

En la actualidad, siguen siendo las mujeres quienes continúan asumiendo gran parte del trabajo de cuidado remunerado y no remunerado y, al mismo tiempo, son ellas las que crecientemente demandan servicios de cuidado, produciéndose una feminización de la dependencia y de su atención. Diversos procesos, como el envejecimiento de la población y el incremento de la participación laboral femenina, han contribuido a poner en jaque el modelo previo de organización social de los cuidados, sustentado en la división sexual del trabajo.

Como resultado, se ha producido la llamada «crisis de los cuidados» y ha sido la migración una de las estrategias de resolución de la crisis que han surgido como respuesta. Se le adjudica a esta crisis el haber influido significativamente en la feminización de los procesos migratorios contemporáneos, toda vez que se ha abierto un conjunto de oportunidades laborales para las mujeres migrantes tanto en el servicio doméstico como en el ámbito de los cuidados de personas dependientes (Perez Orozco, 2007). Lo cierto es que a nivel social, la contribución de las mujeres inmigrantes ha sido crucial en la resolución del déficit de cuidados.

España y Chile forman parte del grupo de países que han experimentado un cambio significativo en su situación en relación con los flujos migratorios, 
pasando de ser países tradicionalmente proveedores de migrantes a recibir inmigrantes. En ambos casos, una de las características distintivas de este cambio tiene relación con la feminización de los flujos migratorios hacia ambos países, hecho que está estrechamente conectado con la mayor oferta de empleos que tradicionalmente han realizado las mujeres. Esto último se explica, entre otros factores, por la menor disponibilidad de las mujeres autóctonas para ejercer las tareas de cuidado. Como resultado, tanto en España como en Chile se ha comenzado a importar, de manera significativa en los últimos años, mano de obra inmigrante, especialmente femenina, para hacerse cargo de las labores de reproducción social.

En este contexto vale la pena preguntarse, en cada uno de los países, cuál ha sido la respuesta en materia de política social para enfrentar la crisis de los cuidados y qué modelos de gestión se han aplicado. En otras palabras, cómo se está distribuyendo tanto en Chile como en España la responsabilidad social del cuidado entre el Estado, el mercado, la comunidad y la familia y qué régimen de bienestar social se encuentra asociado a dicha distribución. Tomando en consideración estos antecedentes, este artículo tiene como objetivos, en primer lugar, dar cuenta de la actual crisis del cuidado que atraviesan las sociedades española y chilena y la relación de este fenómeno con la feminización de las migraciones contemporáneas; en segundo lugar, analizar comparativamente los modelos de gestión de la crisis del cuidado en España y Chile.

\section{Los cambios sociodemográficos en España y Chile y su relación con la crisis del cuidado}

El creciente déficit de cuidado de personas dependientes -aquellas que, por razones ligadas a la falta o pérdida de capacidades físicas, psíquicas o intelectuales, tienen necesidad de asistencia y/o ayuda para la realización de actividades de la vida diaria (Tellechea, 2005)- se debe a varios factores ${ }^{1}$. Entre ellos cuenta la incorporación de las mujeres al mercado laboral (que disminuye su disponibilidad como cuidadoras del hogar), los cambios en la estructura de las familias (ha disminuido el tamaño familiar), así como el envejecimiento de la población (lo que implica una mayor necesidad de cuidado durante la vida). Todo esto obliga a las familias a buscar apoyo para la provisión de

1. Aunque usualmente el término dependencia suele asociarse a las personas mayores, en este artículo lo estamos usando en un sentido más amplio, al considerar todas aquellas personas que pueden requerir de atención y cuidados porque no pueden hacer por sí mismas las actividades de la vida cotidiana. De tal modo que a la ancianidad y a la infancia, agregamos aquellos que se encuentran en situación de discapacidad y minusvalía, enfermedad crónica. 
Tabla 1. Factores sociodemográficos que inciden en la crisis del cuidado

\begin{tabular}{|c|c|}
\hline $\begin{array}{l}\text { Factores relacionados con la } \\
\text { oferta de cuidado }\end{array}$ & $\begin{array}{c}\text { Factores relacionados con la } \\
\text { demanda de cuidado }\end{array}$ \\
\hline $\begin{array}{l}\text { Aumento de participación laboral } \\
\text { femenina } \\
\text { Cambios en estructura y dinámica } \\
\text { familiar (disminución del tamaño familiar, } \\
\text { privatización proyectos de vida). } \\
\text { Persistencia del modelo de hombre } \\
\text { proveedor-madre cuidadora }\end{array}$ & $\begin{array}{l}\text { Envejecimiento de la población } \\
\text { Aumento de la esperanza de vida } \\
\text { Elevación de los estándares de salud } \\
\text { pública }\end{array}$ \\
\hline
\end{tabular}

Fuente: Elaboración propia.

cuidado de sus integrantes más allá de lo que ellas mismas son capaces de proporcionar. La Tabla 1 resume, esquemáticamente, los aspectos más significativos que condicionan tanto la oferta como la demanda de cuidado de personas dependientes en ambos países.

En relación con la oferta de cuidado, la gran mayoría de los expertos coincide en que uno de los factores más importantes que estaría incidiendo en la crisis de los cuidados se debe al significativo cambio experimentado por las mujeres en su posición social actual a partir de su participación, cada vez más creciente, en el mercado laboral. En España comienza a registrarse a partir de los años noventa un importante incremento de la participación laboral femenina hasta sobrepasar en la actualidad el $40 \%$, mientras que la masculina se ha estabilizado. En Chile también aumentó la tasa de participación femenina sustancialmente en los últimos 20 años. Según datos de la Encuesta Nacional de Empleo, esta tasa de participación femenina era del 29,3\% en 1986 y del 40,9 \% en 2008.

Junto con el incremento de la participación laboral femenina, el modelo cultural de organización familiar predominante, que se sustenta en el rol de cuidadora de la mujer, está íntimamente relacionado con la «crisis de los cuidados». Las estadísticas muestran que la mayor parte de las mujeres españolas que trabajan lo hacen a tiempo completo y la participación de los hombres españoles en el trabajo doméstico es la menor de toda Europa (Eurostat, 1995 y Eurobarómetro, 1991, en Tobío y Díaz, 2003). En términos comparativos, Chile aparece como uno de los países que más enfatiza los costos en la vida familiar asociados al trabajo remunerado de la mujer, especialmente en el caso del cuidado de los hijos. ${ }^{2}$ Con lo antes dicho se confirma la hipótesis de que

2. Véase al respecto ver CEP. Mujer, trabajo y familia: Realidad, percepciones y desafíos. Análisis sobre la base de la encuesta CEP de diciembre 2002. Centro de Estudios Públicos. Puntos de Referencia 269, septiembre 2003. 
tanto en Chile como en España aún impera culturalmente el modelo de hombre proveedor-madre cuidadora, incluso cuando la mujer participa activamente en el mercado laboral. La presencia de nuevos modelos de división del trabajo doméstico es todavía incipiente en ambos países.

Adicionalmente, la familia ha estado sujeta a un conjunto de transformaciones que han alterado no sólo su estructura, sino también su dinámica de comportamiento. En primer lugar, hemos pasado de una familia extensa a un modelo de familia nuclear, que se ha replegado sobre sí misma y en la que la solidaridad intergeneracional no es una obligación prioritaria. En resumen, los procesos de privatización de los proyectos de vida individual han erosionado el control social para la asunción de responsabilidades familiares, generándose con ello discriminaciones y desigualdades que afectan fundamentalmente a las mujeres y personas dependientes.

En relación con los factores que explican el aumento de la demanda de cuidado aparece el envejecimiento de la población como uno de los más significativos. En España, en tan solo 20 años (1981-2002), el peso de la población mayor aumenta del 11,2\% al 17,1 \% (IMSERSO, 2005). Todavía más llamativo resulta el fenómeno conocido como el envejecimiento dentro del envejecimiento. En el mismo periodo ha crecido significativamente la población española más longeva, pasando a representar del 1,9\% al $4 \%$ de la población. En Chile, según datos del último Censo (2002), las personas mayores de 60 años constituyen el 11,4\% de la población nacional. Las estimaciones indican que de mantenerse las tendencias actuales, las proporciones de adultos mayores chilenos frente a menores de 15 años será de casi la mitad (Morales, sin año).

Junto con lo anterior, se ha registrado un incremento sin precedentes de la esperanza de vida en ambos países. En el caso de España, se ha pasado de los 40 escasos años de vida con que contaban las personas al nacer en las primeras décadas del siglo pasado, a los 83 años para las mujeres y a los 76 para los hombres en la actualidad (IMSERSO, 2005). Chile, junto a Costa Rica y Cuba, se sitúa entre los tres países con la esperanza de vida más alta de América Latina (INE, 2004). Los recién nacidos en Chile a principios del siglo XXI tienen una expectativa de vida en promedio de poco más de 77 años, casi el doble de la estimada en su momento para quienes nacieron a comienzos del siglo XX.

El incremento de la demanda de cuidado también está relacionado con el aumento de los estándares de salud pública. La elevación de la calidad de los tratamientos médicos para las personas discapacitadas y crónicamente enfermas, también alargan su esperanza de vida. En Chile, un 12,9 \% de la población padece algún tipo de discapacidad (FONADIS, 2004), mientras que en España, representa el 9 \% (Madariaga, 2008). Por último, a la demanda 
de estos grupos se suma la de la población menor de 18 años, que, si bien ha experimentado un proceso paulatino de disminución, continúa siendo responsabilidad prioritaria de las familias, especialmente en los sectores de bajos ingresos en el caso chileno (Acosta, Perticara y Ramos, 2007).

La incidencia e impacto tanto de los factores sociodemográficos como de los procesos de cambios sociales descritos anteriormente han erosionado el modelo previo de organización social de los cuidados, disminuyendo la oferta de cuidadores y aumentando la demanda de cuidado. Dicha demanda, al no poder ser satisfecha por la familia, los servicios sociales o el mercado local, está siendo crecientemente proporcionada por mujeres inmigrantes, tanto en España como en Chile.

\section{La importación de mano de obra inmigrante femenina como una respuesta a la crisis del cuidado en España y Chile}

Una de las características distintivas del aumento significativo de la participación femenina en los movimientos poblacionales está relacionada con la mayor oferta de empleos disponibles que tradicionalmente han realizado las mujeres. Al observar los flujos migratorios internacionales puede apreciarse un importante movimiento de las mujeres hacia España, como caso ilustrativo de los flujos migratorios sur-norte. En España, de cada 100 personas extranjeras residentes, esto es, con tarjeta o permiso de residencia en vigor, aproximadamente 45 son mujeres, lo cual indica que su presencia no es marginal. Este colectivo femenino ha aumentando en torno a un $162 \%$ entre 1997-20033.

Según datos del Observatorio Permanente de la Inmigración, desde 1997 los permisos de trabajo concedidos a mujeres en España aumentan anualmente un $10 \%$ y siete de cada diez permisos solicitados son para trabajar en el servicio doméstico. Por ejemplo, España es el destino preferente de las mujeres de países de Latinoamérica, especialmente por el idioma común ${ }^{4}$. En particular, se puede constatar la creciente feminización de algunas colonias de inmigrantes, particularmente provenientes de República Dominicana, Perú y Ecuador,

3. Es un crecimiento nada desdeñable, pero inferior al alcanzado en el mismo periodo por el grupo de los hombres inmigrantes (que han crecido un $200 \%$, desde 301261 a 904331), por lo que en el conjunto de España se observa un importante incremento de los flujos migratorios femeninos, aunque su peso relativo muestre una ligera tendencia descendente, rompiendo la línea evolutiva señalada a nivel mundial.

4. Es importante considerar que el mayor crecimiento de la población extranjera se ha producido en la población procedente de América -y más concretamente de Latinoamérica- que entre 2001 y 2007 ha aumentado su presencia en un $256 \%$, de modo que actualmente representa el 35 \% de la población extranjera residente en España. 
concentradas fundamentalmente en el sector de los servicios (Tobío y Díaz, 2003).

En los flujos migratorios sur-sur, Chile aparece como un país emergente de atracción de inmigrantes y los datos censales confirman la feminización cuantitativa de su inmigración. La inserción de la población activa inmigrante según ramas de actividad tiene como primeras mayorías al servicio doméstico (16\%) y al comercio minorista (13\%). El trabajo doméstico se ha convertido en la principal actividad económica desarrollada por mujeres inmigrantes, principalmente provenientes de Perús. De acuerdo con la información del Censo del 2002, el 71,5\% de las mujeres provenientes de ese país trabaja en esta actividad (Martínez, 2003). La población peruana resulta ser la que registra mayor concentración en el servicio doméstico (43\%).

Como resultado de la mencionada mayor presencia femenina en los movimientos poblacionales, no sólo se contribuye a resolver el déficit de cuidado en los lugares de destino, sino que adicionalmente se generan un conjunto de reordenamientos y transformaciones tanto en los hogares de origen. Para las mujeres migrantes se plantea tanto el problema del cuidado de su descendencia como de sus ascendientes, lo que se agrava dado el contexto de debilidad de los sistemas de protección social (Escrivá, 2005). La externalización del trabajo de cuidado, particularmente la realizada con mujeres inmigrantes, genera nuevos conflictos que se relacionan, por un lado, con la transformación de las relaciones sociales establecidas entre proveedores y receptores de cuidado, y por otro, con los sistemas que sostienen estos servicios, que generalmente reproducen estructuras de inequidad y discriminación, tanto para los trabajadores como para las personas necesitadas de cuidado. Amén de estas dificultades, lo cierto es que a nivel social, la contribución de las mujeres migrantes ha sido crucial en la resolución del déficit de cuidados.

\section{El rol del Estado y de las políticas sociales en la organización social del cuidado de personas dependientes}

El análisis sobre los regímenes de cuidado nos remite a ciertas conceptualizaciones del Estado en función del papel que éste ocupa en la distribución de dicha responsabilidad. Un régimen de cuidado refiere a las modalidades que adopta la distribución social del cuidado, o en otras palabras, a la organización

5. Dentro de los cuatro principales grupos migratorios hacia Chile (argentinos, peruanos, ecuatorianos y bolivianos) destaca Perú como el que más crecimiento ha experimentado en los últimos años, llegando a equipararse con la migración histórica hacia Chile liderada por los argentinos. 
que la provisión de cuidado tiene en un nivel macrosocial. Es de interés de este artículo conocer el rol que cumple el Estado en esta materia, ya sea adjudicándose la responsabilidad principal y directa de proveer servicios de cuidado $\mathrm{u}$ otorgando las medidas para que otros agentes -familia, comunidad o mercado- se hagan responsables y ejecutores del mismo.

Dependiendo del rol que juegue el Estado, los regímenes de cuidado, según Aguirre (2005), pueden clasificarse de dos formas: el régimen «familista» y el régimen «desfamilista». En el régimen familista, la responsabilidad principal corresponde a las familias y a las mujeres en las redes de parentesco, siendo la familia la unidad a quien se entregan los beneficios. Cuando ocurre que las mujeres trabajan además en forma remunerada, se desarrollan una serie de estrategias de conciliación entre trabajo y familia, estrategias que muchas veces tienden a reproducir, o hacen posible mantener, la división sexual del trabajo. ${ }^{6}$ Por su parte, en el modelo «desfamilista» se deriva la responsabilidad al Estado y al mercado, y es el individuo quien recibe los apoyos.

Los supuestos ideológicos que sustentan ambos regímenes de cuidado difieren. Mientras que el modelo familista supone la centralidad del matrimonio legal y la división sexual del trabajo, el desfamilista se basa en un cuestionamiento de la relación esfera pública/esfera privada y en políticas familiares activas. En resumen, el peso del Estado y la extensión de los servicios lucrativos, así como la participación de las familias y las redes informales de apoyo, están implicadas en las variaciones que se encuentran de estos regímenes.

En los últimos años, los países europeos han incrementado considerablemente las investigaciones comparativas sobre la génesis, fundamentos y situaciones de «crisis» de los sistemas de protección social. Dentro de lo que se ha denominado la «corriente dominante de investigación» sobre las políticas sociales, se destacan los aportes del sociólogo Gosta Esping-Andersen (1998) por cuanto han sido iluminadores al plantear un esquema sistemático para el análisis comparativo de los sistemas de protección social, facilitando la comprensión de las diferencias existentes entre los distintos Estados del Bienestar. Sin embargo, aún cuando ha sido muy útil la aportación del mencionado autor, desde la crítica feminista han surgido varias voces en desacuerdo con la escasa o nula consideración que la corriente dominante le ha concedido al papel que juega la familia en la estructuración de los sistemas de protección

6. Aguirre cita las estrategias propuestas por María Ángeles Durán, que consisten en: a) la reducción de objetivos tanto en el plano laboral como familiar, b) la delegación, que consiste en interrumpir la producción de un servicio para trasladarlo a otra persona y c) la secuencialización, que consiste en alternar la producción para la familia y para el mercado que es lo que buscan las excedencias y las licencias maternales. 
social $^{7}$. Por consiguiente, la tipología propuesta por Esping-Andersen ha sido ampliamente discutida y modificada ${ }^{8}$. En el debate, uno de los argumentos que a efectos de este artículo interesa destacar tiene relación con el concepto de familismo, que se propone sea definido con mayor detalle, desarrollando un dispositivo teórico sensible al género, que permita identificar las múltiples variaciones del familismo (Leitner, 2003).

$\mathrm{Al}$ aplicar la dimensión de género, pueden identificarse cuatro tipos ideales de políticas de acuerdo a la provisión del cuidado -opcionalmente familísticas, explícitamente familísticas, implícitamente familísticas y desfamilistas (Leitner, 2003)-, tal y como se muestra en la Tabla 2. El segundo eje en el que las feministas han trabajado está relacionado con el acceso a los derechos sociales de las mujeres y, en consecuencia, a la noción de ciudadanía social (Letablier, 2007). Siguiendo esta línea, Pautassi (2007) ha insistido en que la problemática del cuidado y quien lo ejerce remite necesariamente a un problema de ejercicio de derechos, reproducción de desigualdades y política pública en el que la evidencia empírica indica la perpetuación de situaciones de desigualdad en el tratamiento de una responsabilidad social ${ }^{9}$. Una de las expresiones concretas de este problema tiene que ver con los desafíos que las mujeres enfrentan para insertarse en igualdad de oportunidades en el mercado laboral y la manera en que se reparten los roles y la responsabilidad de las tareas de cuidado entre el Estado, la familia y el mercado de trabajo, quiénes asumen los costos y cómo son socialmente valoradas estas actividades. A continuación analizaremos cómo se produce esta distribución de responsabilidades de cuidado en España y Chile y qué modelos de gestión de la crisis se han implementado en cada caso.

\section{Los modelos de gestión de la crisis del cuidado de personas dependientes en España y Chile}

5.1. El modelo español de promoción de la autonomía personal y apoyo a la dependencia como un nuevo derecho social

El informe de resultados del estudio sobre Cuidado a la Dependencia e Inmigración (IMSERSO, 2005) concluye que el cuidado de personas dependientes que ejercen las mujeres en España descansa sobre un modelo familiar de reparto

7. Para más información sobre el desarrollo de esta crítica véase, Letablier, 2007.

8. El propio Esping-Andersen ha reconocido en su producción posterior la carencia de atención sistemática a la familia, como algo «dolorosamente evidente» (Esping-Andersen, 2000, citado en Añón y Miravet, 2005).

9. Letablier (2007) destaca cómo el enfoque comparativo ha sido muy útil para desvelar las distintas maneras de basar los derechos sociales y, en particular, su dimensión sexuada. 
Tabla 2. Tipos ideales de política de acuerdo a la provisión del cuidado aplicando un análisis de género

\begin{tabular}{|l|l|}
\hline \multicolumn{1}{|c|}{ Tipo de políticas } & \multicolumn{1}{c|}{ Descripción } \\
\hline Desfamiliarizadoras & $\begin{array}{l}\text { Fuerte desfamiliarización debido a la provisión de ser- } \\
\text { vicios de cuidado tanto del Estado como del mercado } \\
\text { y una débil familiarización. Los cuidadores familiares } \\
\text { están (parcialmente) descargados, pero el derecho fa- } \\
\text { miliar a cuidar no está valorado. }\end{array}$ \\
\hline $\begin{array}{l}\text { Implícitamente } \\
\text { familiarizadoras }\end{array}$ & $\begin{array}{l}\text { No ofrecen la desfamiliarización ni apoyan activamen- } \\
\text { te la función de cuidado en la familia a través de nin- } \\
\text { gún tipo de política familiarizadora. Sin embargo, la } \\
\text { familia sigue siendo el cuidador principal, dado que no } \\
\text { se ofrecen alternativas de cuidado. Es un tipo de polí- } \\
\text { tica que confía o depende implícitamente en la familia } \\
\text { cuando se trata de temas de cuidado. }\end{array}$ \\
\hline $\begin{array}{l}\text { Explícitamente } \\
\text { familiarizadoras }\end{array}$ & $\begin{array}{l}\text { Fortalecen a la familia en la función de cuidado a tra- } \\
\text { vés de políticas familiarizadoras. A través de ellas no } \\
\text { se ofrecen alternativas al cuidado familiar. Explícita- } \\
\text { mente se fortalece la función de cuidado en la familia } \\
\text { debido tanto a la carencia en la esfera pública y en el } \\
\text { mercado de provisión de cuidado como a la fuerte fa- } \\
\text { miliarización. }\end{array}$ \\
\hline $\begin{array}{l}\text { Opcionalmente } \\
\text { familiarizadoras }\end{array}$ & $\begin{array}{l}\text { Se fortalece el cuidado familiar pero, al mismo tiempo, } \\
\text { se ofrece la opción de ser (parcialmente) liberado de } \\
\text { las responsabilidades de cuidado. El «derecho» de la } \\
\text { familia a cuidar no es equiparado con la «obligación» } \\
\text { de la familia a cuidar. }\end{array}$ \\
\hline
\end{tabular}

Fuente: Elaboración propia en base a Leitner (2003).

desigual de roles, basado en el trabajo doméstico de la mujer y en su situación de inactividad económica. En España, al igual que en otros países del sur de Europa, la intervención del Estado para favorecer la compatibilidad entre la vida familiar y laboral aún es limitada, a pesar de los significativos avances que tanto en materia de normativa como de política social se han realizado en los últimos años. Estos avances han permitido colocar como un tema prioritario dentro de la política social actual y de los próximos años la atención a las necesidades de apoyos generalizados y la promoción de autonomía personal, reconociendo con el rango de derechos lo que antes eran ayudas dispersas y subsidiarias del cuidado familiar.

\subsubsection{Predominio del cuidado informal de personas dependientes}

En España, la atención y cuidados a las personas dependientes son prestados en más de un $70 \%$ de las situaciones mediante los denominados «cuidados 
Tabla 3. Cuidados en la familia de mayores dependientes, España, 2004

\begin{tabular}{|l|c|}
\hline & 2004 \\
\hline Edad cuidador & 53 años \\
\hline Hijas & $47 \%$ \\
\hline Problemas profesionales y económicos & $62 \%$ \\
\hline No pueden trabajar fuera de casa & $26 \%$ \\
\hline Ha dejado de trabajar & $11.7 \%$ \\
\hline Problemas con su pareja & $7 \%$ \\
\hline Cuidador y mayor viven juntos & $70 \%$ \\
\hline
\end{tabular}

Fuente: Torres, 2006.

informales» (Iglesias, 2006). La asistencia al dependiente está asegurada fundamentalmente por la familia, siendo en particular las mujeres (esposas e hijas, y en menor medida las nietas) las que asumen esta labor. Son los mayores dependientes, según IMSERSO, quienes de forma más marcada reciben los cuidados de parte de la familia, llegando a un $86,5 \%$.

Como se puede apreciar en la Tabla 3, el perfil social de la cuidadora que constituye, a decir de María Ángeles Durán (2006), el soporte básico del Estado de Bienestar español, es el de una mujer entre 40 y 65 años de edad, que no realiza tareas remuneradas fuera del hogar, o bien las lleva a cabo a tiempo parcial. Por lo general, dedica más de 40 horas semanales al cuidado del dependiente y asume casi en exclusiva dicha responsabilidad. Presenta, en la mayoría de los casos, dificultades económicas y le resulta difícil mantener sus relaciones sociales. Como resultado del trabajo de cuidado padece patologías múltiples, especialmente cansancio, trastornos del sueño y frecuentemente depresión.

Las necesidades de atención que en particular tienen las personas mayores dependientes implican una dedicación horaria de atención que no siempre puede ser asumida en exclusividad por la familia. A ello se agrega la complejidad de los requerimientos de cuidados que en muchas ocasiones necesitan de una formación previa o de supervisión profesional, que pocas veces se produce. En resumen, los estudios realizados han conseguido demostrar que el recurso a la ayuda informal para el cuidado de personas mayores dependientes aparece como una opción preferente, relacionada con la práctica de la autonomía residencial y el familismo típico de la sociedad española.

\subsubsection{Insuficiente cobertura de servicios de cuidado}

Los cambios producidos en la estructura social española a partir de la participación masiva de la mujeren el mercado laboral han puesto en evidencia la 
falta de estructuras de atención alternativas a los cuidados informales. Estudios recientes indican que los cuidados «formales» ${ }^{10}$-integrados por el conjunto de servicios provistos por entidades y organizaciones, tanto públicas como privadas, con y sin ánimo de lucro, y por personas que trabajan por su cuenta de manera remunerada- atienden aproximadamente a un porcentaje en torno al $27 \%$ de las necesidades (Iglesias, 2006).

De acuerdo al Libro Blanco sobre la atención a personas en situación de dependencia (IMSERSO), la oferta de servicios de cuidado es manifiestamente insuficiente, tanto para las necesidades actuales como para las que previsiblemente se demanden en el futuro. Los servicios sociales formales de atención prestados a las personas que precisan cuidados y viven en su domicilio tienen muy poca significación. El peso de los mismos se calcula en un $4,7 \%$ del total de cuidados recibidos (IMSERSO, 2005). Adicionalmente la colaboración entre los servicios formales y los cuidadores informales es muy escasa.

En el mismo estudio se consigna la escasa implantación de servicios sociosanitarios formalizados de proximidad (servicios de ayuda a domicilio, teleasistencia y centros de día). Frente a esta carencia, la llegada de mujeres inmigrantes con posibilidades de realizar tareas de cuidado a mayores dependientes y la posibilidad de residir en el propio domicilio del mayor, ha sido una estrategia crecientemente utilizada por las familias españolas. Sin embargo, esta salida a la crisis podría estar ocultando la limitación de los servicios de proximidad. Adicionalmente, las mujeres inmigrantes estarían llenando otro vacío o debilidad asociado a los servicios formales de cuidado. Se trata de las aptitudes psicosociales y de la ética del sacrificio con la que contarían estas mujeres, procedentes por lo general de una cultura tradicional de respeto y atención a las personas mayores.

A los problemas de cobertura habría que agregar los desajustes económicos generadas como consecuencia de la atención constante de una persona en situación de dependencia. Frente a esta realidad, el Estado español presenta uno de los índices más bajos en materia de gastos de protección social a la vejez, al compararlo con el conjunto de la comunidad europea. «En 2005, la media europea de gasto para los mayores fue de 2.929 euros por persona, cantidad muy superior a los 1.648 euros que se gastaron en España.» (Setién, 2009: 332)

10. La oferta formal de cuidados se integra fundamentalmente por los servicios de ayuda a domicilio, teleasistencia, plazas de estancia diurna y centros residenciales, de provisión pública y privada. 
5.1.3. Avances en materia de normativa y política social: la creación de un Sistema Nacional de Dependencia

En respuesta a estos problemas, en los últimos años ha podido constatarse una creciente preocupación en España por los fenómenos sociodemográficos asociados a la crisis del cuidado. Dicha preocupación se ha expresado en el debate público sobre la conciliación de la vida laboral y familiar, que derivó en la Ley 39/1999 para promover la conciliación de la vida familiar y laboral de las personas trabajadoras, así como en la discusión sobre la protección social de la situación de dependencia.

Como resultado se aprobó en el 2006 la Ley 39/2006 de Promoción de la Autonomía Personal y Atención a las personas en situación de dependencia (conocida como Ley de Dependencia), que actúa como principal norma reguladora de la atención a las personas en tal condición en España. Entre sus objetivos se encuentra fomentar la promoción de la autonomía, evitando al máximo la institucionalización de las personas mayores dependientes, así como la optimización de los recursos públicos y privados en la prestación de servicios de cuidado. Con la aprobación de esta ley se ha configurado un derecho subjetivo fundamentado en los principios de universalidad, equidad y accesibilidad, desarrollando un modelo de atención integral al ciudadano. Para hacer realidad su mandato se ha diseñado un Sistema para la Autonomía y Atención a la Dependencia (SAAD), constituido en el organismo encargado de canalizar y optimizar los recursos públicos y privados. Los servicios que comprende dicho sistema van desde la prevención, la teleasistencia y ayuda a domicilio hasta las prestaciones económicas que pueden obtener las personas en situación de dependencia. Dada su reciente creación, quedan pendientes de evaluación los alcances, limitaciones o vacíos que pueda estar teniendo su aplicación práctica.

\subsection{El modelo chileno de máxima responsabilidad privada}

En el modelo chileno se produce una dependencia sistemática de la familia para la provisión de trabajo de cuidado y servicios, basada en los principios de subsidiaridad. A pesar de la escasez de estudios, las estadísticas disponibles permiten extender esta afirmación al resto de los grupos de personas dependientes.

\subsubsection{Predominio del cuidado informal de personas dependientes}

En Chile existe un fuerte predominio del cuidado informal que atraviesa los distintos grupos de personas dependientes. Este predominio se refleja, en 
primer lugar, en las características de la oferta y la demanda actual de cuidado infantil, por citar el grupo más estudiado. ${ }^{11}$ En el caso de los menores, alrededor del $80 \%$ del cuidado es proporcionado por las madres o familiares. (Acosta, Perticara y Ramos, 2007). Para el caso de las personas discapacitadas, se estima que hasta en un $88 \%$ del total de cuidados prestados corresponde a cuidados de tipo informal (Herrera, 2007) y el $68,71 \%$ de los apoyos son proporcionados por un familiar (FONADIS-INE, 2004), como puede apreciarse en la Tabla 4.

En el caso de los adultos mayores, el perfil de los cuidadores de adultos mayores corresponde en más de un $80 \%$ a los familiares, en particular a las mujeres que representan entre el 75 y el $84 \%$ de quienes proveen de cuidados a ancianos (Zavala y otros, 2001). Lejos de la creencia común de que el anciano en la sociedad contemporánea ha sido abandonado por su familia, la evidencia empírica en Chile muestra una realidad muy distinta. La familia sigue siendo el principal sostén para los adultos de edad avanzada (Guzmán y Huenchuan, 2005).

\subsubsection{Escasez de servicios de cuidado coherentes con la realidad de participación laboral de la mujer}

El mencionado predominio del cuidado informal está estrechamente relacionado con las características de la oferta de servicios de cuidado para los distintos grupos de personas dependientes en Chile. En general, se trata de una oferta insuficiente en términos de cobertura y poco flexible y ajustada a la realidad de participación creciente de la mujer en el mercado laboral. Los estudios han constatado, entre otros problemas, poca disponibilidad de lugares de cuidado cercanos al domicilio, dificultades con el traslado, alto costo económico y riesgos para la salud -particularmente en el caso de los menores- como algunos de los problemas relacionados con la oferta de servicios de cuidado (Acosta, Perticara y Ramos, 2007).

El alto costo de la atención requerida por las personas dependientes, en particular, los discapacitados y ancianos enfermos, y la dificultad de los servicios asistenciales para atender las múltiples demandas de estos grupos, provoca que se traspase a los cuidadores familiares e informales prácticamente la totalidad de la responsabilidad y costo del cuidado. Éstos, no disponen muchas

11. Al respecto pueden consultarse los estudios «Oferta Laboral Femenina y Cuidado infantil» y «Modelos de Cuidado Infantil y Participación Laboral Femenina. Estrategias de conciliación entre el rol laboral y de cuidado en mujeres pertenecientes a sectores de bajos ingresos». 
Tabla 4. Discapacidad según quienes prestan apoyo.

Frecuencia y distribución porcentual, Chile 2004

\begin{tabular}{|l|r|c|}
\hline & N & $\%$ \\
\hline Amigos & 325 & 0,002 \\
\hline Cuidadora & 4978 & 0,24 \\
\hline Familiares & 1421066 & 68,71 \\
\hline Vecinos & 6282 & 0,30 \\
\hline Nadie & 635421 & 30,73 \\
\hline Total & 2068072 & 100 \\
\hline
\end{tabular}

Fuente: FONADIS, 2004.

veces del tiempo ni las competencias necesarias para brindar un cuidado de calidad. «Los cuidados de salud que se dejan de hacer en el sistema institucional público o privado son realizados en el espacio doméstico, la mayor parte por mujeres, que deben absorber los costos de la salud ahorrados por seguros públicos y privados sin ninguna visibilidad ni retribución.» (Observatorio de Equidad de Género en Salud-Chile, 2004)

Por su parte, en relación con los apoyos sociales disponibles para las personas con discapacidad, el primer estudio nacional sobre la discapacidad en Chile arroja algunos datos interesantes. El 70 \% de las personas con discapacidad cuenta con algún nivel de apoyo de una tercera persona, mientras que el $30 \%$ restante no tiene o no requiere de terceras personas que les preste apoyo (FONADIS, 2004). El $68 \%$ de las personas con discapacidad recibe apoyo de sus familiares, mientras que el resto de personas no es significativo en términos de porcentajes (amigos, cuidadores, vecinos).

5.2.3. Política social y normativa para el cuidado de personas dependientes: una tarea pendiente

Frente a la situación anterior, es evidente la necesidad de que la política social en Chile debe ajustarse a las nuevas necesidades y demandas de protección social y cuidado. En respuesta a ello se han producido avances tanto en el ámbito normativo como en el de la política, pero de manera diferenciada por grupos de personas dependientes. En el área de la infancia se han dado los pasos más significativos, creándose el Sistema de Protección Integral a la Infancia (Chile Crece Contigo) ${ }^{12}$. Se trata de un sistema que tiene como misión

12. Chile Crece Contigo forma parte además del recientemente creado Sistema de Protección Social comprometido por el Gobierno chileno hasta este año 2010. 
acompañar, proteger y apoyar integralmente, a todos los niños y sus familias, a través de acciones y servicios de carácter universal. Al mismo tiempo, focalizar apoyos especiales a aquellos que presenten alguna vulnerabilidad mayor. Quedan por evaluar, sin embargo, los avances registrados a partir de la implementación de esta política. Por el momento, sabemos que el gasto público en cuidado de menores y en la educación preescolar en Chile es de alrededor del $0,1 \%$ del PIB en 2007, cifra baja comparada con el promedio del 0,25\% que destina la OCDE.

Por su parte, la intervención estatal frente al envejecimiento está delineada en una política nacional promulgada en 1996. En ella, el Estado asume un rol subsidiario a favor del adulto mayor, tratando de superar el enfoque predominantemente asistencial que había existido hasta entonces. De esta forma, el Estado delimita responsabilidades frente al cuidado del adulto mayor, propendiendo a un papel activo por parte de la familia en primera instancia y también de la comunidad. Se pone un gran énfasis en que la responsabilidad por el adulto mayor se realice sin separarlo de su entorno habitual, promoviendo su integración activa al medio social.

Es en relación con la Seguridad Social, el campo donde con más fuerza se expresa el predominio o presencia de la economía de mercado, a través de cómo se compone el sistema de pensiones. Por tales razones, dentro de la nueva política pública en materia de protección social también se ha considerado la Reforma Previsional (Ley 20.255), que viene a cumplir la mayor promesa del gobierno de la presidenta Bachelet, al crear un nuevo sistema de pensiones que protege y cuida a todos los chilenos, desde la cuna hasta la vejez. Por su reciente creación todavía es muy pronto para poder realizar una evaluación de su impacto. Lo que sí podemos anticipar es que por sí sola esta reforma previsional no resolverá los múltiples problemas relacionados con el envejecimiento de la población y la carga de cuidado que ello representa para las familias chilenas.

\section{Reflexiones finales: hacia una política democrática del cuidado}

Al comparar los casos de España y Chile, se ha reafirmado la estrecha conexión existente entre la actual crisis del cuidado y el proceso de feminización de las migraciones. La importación de mano de obra femenina para realizar las labores de reproducción social es una estrategia crecientemente utilizada por las familias, tanto en los flujos migratorios sur-norte como en los sur-sur, siendo España y Chile casos ilustrativos de este fenómeno. Sin embargo, a nivel de política social la respuesta a la crisis de los cuidados ha tenido énfasis 
e impactos diferentes en materia de distribución social de la responsabilidad del cuidado en los dos países estudiados.

En cuanto a los modelos de gestión de la crisis del cuidado, los países estudiados comparten un modelo familista en tanto estructura normativa que modela la responsabilidad social del cuidado. Esta estructura confiere a la familia un rol central en la procura del bienestar, asociado a las asunciones ideológicas y parámetros de tipo simbólico, cultural y normativo, mencionados con anterioridad. Sin embargo, y siguiendo los aportes de Leitner, difieren en materia de política social, por cuanto en el caso español predomina una política de familiarismo implícito, mientras que el caso chileno se puede clasificar como de familiarismo explícito.

En el caso español, el Estado ha empezado a asumir crecientemente parte de las competencias cuidadoras que tradicionalmente tenían las familias y, en consecuencia, tanto el sistema de salud como los servicios sociales han liberado tiempo familiar de cuidado a las personas. En el caso chileno, en cambio, continúa predominando un modelo de máxima responsabilidad privada en relación con el cuidado de personas dependientes, siendo la familia, en particular las mujeres, la que asume la mayor parte de la carga de cuidados, sin que ésta sea debidamente reconocida a nivel público. A pesar de los recientes esfuerzos del actual gobierno en la construcción de un Sistema de Protección Social, existen importantes vacíos a nivel normativo y de la política social que permiten garantizar adecuadamente los derechos y deberes de las personas que requieren cuidados, así como de sus cuidadores.

De los casos estudiados se desprenden algunas lecciones. En primer lugar, la necesidad de estimular y consolidar el debate y reconocimiento público del cuidado de personas dependientes como un problema público, en el que el Estado tiene una gran responsabilidad. En segundo lugar, tomando en consideración los aportes de los estudios comparados sobre regímenes de protección social, se deriva la necesidad de continuar con el estudio del comportamiento de esta problemática y su relación con la feminización de las migraciones. Para ello, será imprescindible incorporar en el análisis a otros flujos migratorios y los marcos normativos que definan y garanticen los derechos y deberes de las personas que requieren cuidados, así como de sus cuidadores, en particular de las mujeres inmigrantes. 


\section{Bibliografia}

Acosta, E., M. Perticara y C. Ramos, «Oferta Laboral Femenina y Cuidado Infantil», en Desafíos al Desarrollo de Chile: Elementos para el Diálogo de Políticas, BID, Santiago de Chile, 2007.

AguirRe, R., Los cuidados familiares como problema público y objeto de políticas, reunión de expertos Políticas hacia las familias, protección e inclusión social, CEPAL, Montevideo, 2005.

AÑón, M. J. y P. Miravet, «Paradojas del familiarismo en el Estado del Bienestar: mujeres y renta básica», en Cuadernos de Relaciones Laborales, 23, n. ${ }^{\circ}$ 2, 2005, pp. 101-121.

DurÁn, M. ${ }^{a}$ Ángeles, «Dependientes y cuidadores: el desafío de los próximos años», Revista del Ministerio de Trabajo y Asuntos Sociales, n. ${ }^{\circ}$ 60, Madrid, 2006.

ESCRIVÁ, M. a Ángeles, «Peruanos en España. ¿De migrantes a ciudadanos?», en El Quinto suyo: Transnacionalidad y Formaciones Diaspóricas en la Migración Peruana, Lima, Instituto de Estudios Peruanos, 2005.

ESPING ANDERSEN, Gosta, The three worlds of welfare capitalism, New Jersey, Princeton University Press, 1998.

FONADIS (Fondo Nacional de la Discapacidad), Resultados. Primer estudio nacional de la discapacidad en Chile, Santiago de Chile, 2004.

- Apartado Género. Primer estudio nacional de la discapacidad en Chile, Santiago de Chile, 2004.

Guzmán, J. M. y S. Huenchuan, Políticas hacia las familias con adultos mayores: el desafío del derecho al cuidado en edad avanzada, Santiago de Chile, CEPALCELADE, 2005.

HERRERA, Eduardo, Cuidadoras y cuidadores de personas dependientes y enfoque de género en Chile, Santiago de Chile, FONADIS, 2007.

IGLESIAS, Pilar, "Sistema Nacional de Dependencia», en Revista del Ministerio de Trabajo y Asuntos Sociales, n. ${ }^{\circ}$ 60, Madrid, 2006.

IMSERSO, Cuidados en la vejez. El apoyo informal, Madrid, 1995.

- Cuidado a la dependencia e inmigración. Informe de Resultados, Colección de Estudios, Serie Dependencia, Madrid, 2005.

LEITNER, Sigrid, «Varieties of familialism», en European Societies, 5 (4), 2003, pp. 353-375.

LETABLIER, M. T., «El trabajo de "cuidados" y su conceptualización en Europa», en Trabajo, Género y tiempo social, C. Prieto, (ed.), Madrid, Editorial Complutense, 2007.

MADARIAGA ORTUZAR, Aurora, «Los servicios de ocio de las asociaciones de discapacidad», tesis doctoral, Bilbao, Universidad de Deusto, 2008. 
MARTínEZ, Jorge, El encanto de los datos. Sociodemografía de la inmigración en Chile según el Censo de 2002, Santiago de Chile, CEPAL, 2003.

Morales, María E., Chile envejece: Prospectiva de los impactos políticos y sociales de este fenómeno hacia el bicentenario, [en línea], <http://www.gerontologia. uchile.cl/docs/chien.htm>.

PAUTASSI, Laura, «El cuidado como cuestión social desde un enfoque de derechos», Unidad Mujer y Desarrollo, Santiago de Chile, CEPAL, 2007.

PÉrez Orozco, Amaia, «Cadenas globales de cuidado», serie Género, migración y desarrollo, documento de trabajo, 2, Naciones Unidas, INSTRAW, 2007.

SETIÉN, María Luisa, "Género y cuidados a las personas en el espacio doméstico», en Inguruak, Revista Vasca de Sociología y Ciencia Política, n. ${ }^{\circ} 22$, diciembre, 1998.

— «Gasto social en España», en Políticas Sociales, Carmen Alemán Bracho, (coord.), Pamplona, Thomson Reuters, Civitas, 2009, pp. 309-340.

TEllecheA, Lourdes, Cuidados permanentes de las personas mayores, documento de trabajo, Buenos Aires, [en línea], <www.eclac.cl>.

TOBíO, Constanza y Magdalena DíAz, Las mujeres inmigrantes y la conciliación de la vida familiar y profesional, Comunidad de Madrid, Dirección General de la Mujer, Consejería de trabajo, 2003.

TORRES, Julio Alberto, «Libro Blanco para las personas en situación de dependencia en España», en Revista del Ministerio de Trabajo y Asuntos Sociales, n. ${ }^{\circ}$ 60, Madrid, 2006.

VICENTE, Trinidad y María Luisa SETIÉN, «Modelos migratorios femeninos», en Diversidad migratoria. Distintos protagonistas, diferentes contextos, Julia González y María Luisa Setién (eds.), Bilbao, Universidad de Deusto, 2005.

Zavala y otros, Características sociodemográficas de los cuidadores de ancianos, ponencia presentada al IV Congreso Chileno de Antropología, Universidad de Chile, 2001, [en línea], <www.uchile.cl>.

\section{Nota:}

Este artículo forma parte del Proyecto FEM2009-09007 (Subprograma FE$\mathrm{ME}$ ): «Crisis del cuidado y migración. Análisis comparativo de flujos migratorios feminizados: sur-norte y sur-sur», financiado por el Ministerio de Ciencia e Innovación, España, 2009-2012. 



\title{
EL TRABAJO SOCIAL Y LAS NUEVAS FORMAS DE REORGANIZACIÓN DEL CUIDADO. UNA APROXIMACIÓN A PROPÓSITO DE LA LEY DE DEPENDENCIA
}

\author{
Social work and the new ways of reorganising care. \\ A consideration of the Dependent Care Law
}

\author{
Virginia Fuentes GUTIÉRREZ* \\ Jesús Muyor RODRÍGUEZ** \\ ZAHIRA GALINDO ROMERO***
}

\section{Resumen}

En España se está produciendo en los últimos años una reestructuración en la gestión de las responsabilidades del cuidado, influenciada, principalmente, por la aprobación de la Ley 39/2006 de Promoción de la Autonomía Personal y Atención a las personas en situación de dependencia (LAAD, en adelante) que conlleva la introducción de ¿nuevos? actores en su ejecución.

* Virginia Fuentes Gutiérrez

Universidad de Jaén

Departamento de Trabajo Social y Servicios Sociales

C/ Profesor Tierno Galván, 10. Esc. B. Bajo B. 14014 Córdoba

Teléfono: 679392003

virginiafuentesgutierrez@hotmail.com,vfuentes@ujaen.es

* * Jesús Muyor Rodríguez

MediCall® Servicios Sociosanitarios, S.L.

Avd. Mariano Hernández. Apartado de Correos n. ${ }^{\circ} 481.04740$ Almería

Teléfono: 9503264 87/692032659 Fax: 950326487

jesusmuyor@medicall.es

*** Zahira Galindo Romero

Universidad de Jaén

C/ Padre Manjón, 8. 14400 Pozoblanco (Córdoba)

Teléfono: 654201387

zahiragalindo@hotmail.com 
Con el presente texto, desde la disciplina y práctica del Trabajo Social, recogemos algunas reflexiones sobre los modos en los que está siendo acometida dicha reorganización en el actual sistema de cuidados, atendiendo especialmente al contexto andaluz. Dirigimos nuestra atención hacia la aplicación e impactos que las vigentes políticas referentes al cuidado están teniendo sobre la práctica profesional y modalidades de provisión de cuidados.

Por último, pretendemos abordar algunas de las situaciones derivadas de la implantación de la LAAD para plantear posibles controversias y dilemas que se suscitan y que inevitablemente condicionan el quehacer profesional del Trabajo Social.

Palabras clave: cuidados, Ley 39/2006 de Promoción de la Autonomía Personal y Atención a las personas en situación de dependencia (LAAD), Trabajo Social, dependencia.

\section{Abstract}

In recent years, Spain has begun to restructure how the responsibilities of care are managed, mainly as a result of the 2006 Personal Autonomy and Dependent Care Law (PADCL), with new(?) actors becoming involved in its implementation. Based on both the theory and the practice of social work, this paper reflects on how this reorganisation is being carried out in the current care system, particularly in Andalusia, examining how current care policies are applied and what effects they are having on professional practice and the ways in which care is provided. The dissertation seeks to analyse some of the situations resulting from the implementation of the PADCL, and to consider possible controversies and dilemmas that may arise that will inevitably have an affect on the social work profession.

Keywords: care, Personal Autonomy and Dependent Care Law (PADCL), Social Work, Dependent Care.

\section{Introducción}

El modo en que se viene dando respuesta a las necesidades de cuidados de las llamadas personas dependientes parece experimentar cambios (isignificativos?) en España, en sus maneras de concebirlo, legislarlo y gestionarlo, tanto a nivel institucional como familiar.

Podemos considerar que la falta de autonomía funcional que supone la situación de dependencia no constituye una situación de necesidad nueva, sin embargo lo que le añade un perfil novedoso a este fenómeno es su generalización, en cuanto al número de personas afectadas, la intensificación en efectos y tiempo y, sobre todo, la conciencia respecto de la ineficacia de las formas tradicionales de afrontarla (supeditada a la solidaridad, al apoyo familiar, y centrada sólo en los factores individuales de la persona), dejando de lado el cariz social. Esta situación de dependencia, vista también desde un plano social, implica, por otro lado, que la atención normativa no se proyecte únicamente y exclusivamente en el ámbito de la asistencia sanitaria. El objetivo 
básico de cualquier protección contra las situaciones de dependencia debe ser, en primer lugar, el hacer desaparecer, en el mayor grado posible, aquellas circunstancias sociales que pueden provocarlas o aumentarlas y, a partir de ahí, proporcionar a la persona la asistencia, ayudas y auxilios que necesita para poder realizar, adecuada y dignamente, las actividades de la vida diaria para las que requiere ayuda (De Asís y Palacios, 2007: 19-20).

En esta directriz, el sistema público español de Servicios Sociales ha sufrido, en los últimos años, una reestructuración que ha provocado la unificación del sistema de protección a las situaciones de dependencia en el marco de la LAAD. Los/as trabajadores/as sociales han sido, y continúan siendo, un actor importante en la implementación de los servicios y recursos derivados del Sistema para la Autonomía y Atención a la Dependencia (SAAD, en adelante).

Desde esta premisa es desde la que se analiza dicha implementación de la Ley que ha ido configurando una serie de desconciertos, dilemas y retos en lo que se denomina un derecho subjetivo, individual y universal a recibir atención necesaria cuando se está en situación de dependencia.

El texto de este artículo se divide en tres apartados. En primer lugar, nos preguntamos sobre el amplio campo relativo al desarrollo de la dimensión socio-política e ideológica presentado en dicha Ley y sus impactos sobre la (re)producción de las desigualdades de género, vinculadas con el mantenimiento del rol subordinado de las mujeres, la división sexual del trabajo, la generización que atraviesa el mercado de trabajo derivado del cuidado o la invisibilidad y condiciones de precariedad en la que se encuentran las mujeres inmigrantes cuidadoras. Nos interesa especialmente enmarcarlo en lo que se define como mercantilización y externalización del trabajo doméstico y de cuidados, así como detenernos en el papel que juegan los agentes sociales que parecen implicarse (Estado, mercado, Tercer Sector y familia) en la llamada reorganización del cuidado. Trataremos de hacer emerger algunas de las posibles contradicciones que se activan. En un segundo lugar, dirigiremos nuestra atención hacia la dimensión deontológica de nuestra actividad profesional, con el objetivo de cuestionarnos e interrogarnos sobre el papel desempeñado por los trabajadores sociales como meros técnicos de gestión o, por el contrario, como posibles actores implicados en el diseño de la política pública y en la evaluación de las situaciones de dependencia. Por último, nos centraremos en la trascendencia y connotaciones prácticas que la implantación de la LAAD está teniendo para el Trabajo Social y los Servicios Sociales. Aspectos como la burocratización del servicio, reajustes de las prestaciones, dilemas éticos, la (escasa) formación de los profesionales o la posible desatención de otras áreas de acción de los servicios sociales son limitaciones y retos que nos plantean el 
debate, abierto y pendiente, sobre el papel desempeñado en la actualidad por los profesionales del Trabajo Social.

Con estas tres dimensiones tenemos el propósito de recapacitar sobre la oportunidad que esta nueva reestructuración de cuidados puede dar a lugar, mostrando una imagen del Trabajo Social en concordancia con los principios propios de esta profesión.

\section{Dimensión socio-política e ideológica}

2.1. Una gestión pluralista. El papel de los agentes sociales en el proceso de reorganización de los cuidados

La LAAD surge en un momento de profundo cambio social (lo que se ha denominado también "Crisis de los cuidados $»^{1}$ ) caracterizado por políticas neoliberales que impulsan la globalización y que generan cada día mayor precariedad en el empleo, en la vivienda, en la alimentación, en las condiciones de salud, en las prestaciones sociales y en las formas de vida. La quiebra con el modelo previo de provisión de cuidados -apoyado en una estricta división sexual del trabajo y en la imposición de la familia nuclear heterosexual como norma social-, que era la base del sistema económico (Pérez de Orozco y Baeza Gómez, 2006: 24), ha propiciado que se empiece a pensar en otras formas de reorganización y modelos de cobertura del cuidado.

Podría decirse que caminamos hacia una nueva gestión del cuidado en la que siguen participando agentes tradicionales, principalmente familias, y a los que se van a incorporar otras fuentes de gestión del cuidado sustentadas principalmente a través del Estado y del mercado. La labor del cuidado se convertiría así en una responsabilidad compartida, al menos parcialmente, en la que participan a nivel macro varias esferas interconectadas entre sí y que incluso a veces intervendrían simultáneamente, precisamente por la insuficiencia de los recursos aportados por cada una de ellas.

Dicho de otro modo, dado el bajo nivel de cobertura existente de servicios sociales, a pesar del innegable crecimiento de los últimos años, sobre todo de atención y rehabilitación (Centros de día y de noche) y domiciliarios (Ayuda a domicilio), además de otros de tipo intermedio (estancias temporales y de respiro) y alternativos (viviendas tuteladas, domicilios de acogida) (Rodríguez Cabrero, 2007), son las familias, en ocasiones, las que se ven obligadas a superponer los recursos públicos y privados de manera que puedan obtener la

1. Para saber más, ver Río, 2003; Colectivo Precarias a la deriva, 2004; Pérez Orozco, 2006a, Pérez de Orozco y Baeza Gómez, 2006; Vega, 2009. 
ayuda más completa posible de cara al cuidado de la persona en situación de dependencia. Así, si a una persona en situación de dependencia se le asignan formalmente un tipo de recurso en su PIA ${ }^{2}$, la familia por otro lado, si su nivel de renta se lo permite, podrá contratar en el mercado otro servicio de proximidad complementario para así garantizar el eficaz cuidado a su familiar.

Ante esta realidad, nos preguntamos ies previsible que se consolide un modelo dual de sociedad que acentúe las desigualdades sociales, en el que el nivel de renta determine la calidad de vida de las personas en situación de dependencia? Según Amaia Pérez y Paula Baena, por un lado se situarían los segmentos de población con suficiente poder adquisitivo para satisfacer la mayor parte de sus necesidades en base a la compra de servicios en el mercado. Y, por otra parte, se localizarían aquellos segmentos de población que no tienen ese nivel de consumo y sustituyen compra en el mercado por provisión gratuita y en muchas ocasiones residual de servicios (Pérez de Orozco y Baeza Gómez, 2006: 32).

Es preciso insistir en que dichas situaciones antagónicas, basadas en el tener o no suficiente poder adquisitivo como para satisfacer la necesidad del cuidado a través de un modo u otro (Estado o mercado), no deben ser vistas como excluyentes. En la realidad, como ya adelantábamos, surgen situaciones de compensación intermedias caracterizadas por la coexistencia de múltiples formas de cubrir la necesidad de cuidados. Como mecanismos intermedios que entrañan algún riesgo en su implantación destacamos entre otros:

- Las prestaciones monetarias para el cuidado informal, que si no se utilizan con el criterio de excepcionalidad ${ }^{3}$ por el que fueron creadas, podrían hacer demorar la construcción de una red pública de servicios sociales directa y concertada suficientemente, además de una perpetuación de la ayuda prestada en el ámbito familiar.

- La provisión gratuita de servicios suministrada por las ONGs evitaría situaciones de emergencia social, pero a su vez, podría evadir la responsabilidad pública del Estado.

2. Programa Individual de Atención (PIA), realizado por los Trabajadores sociales desde los Centros de Servicios Sociales Comunitarios, determinará las modalidades de intervención más adecuadas a sus necesidades de entre los servicios y prestaciones económicas previstos en la resolución para su grado y nivel.

3. En el caso andaluz de las 169368 prestaciones concedidas en la Comunidad andaluza a 1 de diciembre de 2009, 85021 (50,20\%) fueron destinadas a prestaciones económicas a cuidadores familiares y 3201 (1,89\%) prestaciones económicas fueron vinculadas a servicios concedidos, según datos del IMSERSO, [en línea], <http://www.imserso.es/ Presentacion/groups/imserso/documents/binario/estsisaad20091201.pdf>. Extraído el 14 de diciembre de 2009. 
- La ayuda invisibilizada de empleadas del hogar, en la mayoría de los casos mujeres inmigrantes, que debido a su situación de vulnerabilidad social y jurídica se inserta en el mercado del cuidado de una forma irregularizada (Colectivo IÓE, 2001). Situación de la que se benefician los empleadores cuando el resto de recursos sociales no satisfacen sus necesidades o, si lo hacen, son demasiado costosas para su nivel de renta.

Estas opciones intermedias de reorganización del cuidado reflejan los mecanismos que tanto el Estado, mercado, organizaciones sociales y familia disparan para afrontar una situación de cuestionamiento del actual modelo de provisión de cuidados. Esto nos hace abrir algunas dudas sobre cuál es la verdadera ideología que sustenta a la LAAD y el peso que, pareciera, siguen asumiendo especialmente las familias en la legislación actual. En palabras de Rodríguez Cabrero «se podría pensar que la Ley de Dependencia parece más un reconocimiento del actual sistema social familista que una revolución social basada en la universalización de la acción protectora a través del Estado» (Rodríguez Cabrero, 2007: 74).

También nos parece importante empezar a reflexionar sobre el papel que están desempeñando los Servicios Sociales y las entidades del Tercer Sector y empresas de servicios en la construcción de este sistema de atención al cuidado que parece activarse.

\subsubsection{Servicios Sociales ${ }^{4}$}

Por un lado, vemos cómo se reconoce a los servicios sociales su papel como puerta de entrada al SAAD, delegándose, por tanto, una parte importante de la demanda de usuarios que genera la Ley de Dependencia. En contrapunto, cabe preguntarse sobre los recursos personales y materiales puestos en marcha para afrontar esta nueva competencia. En el informe «Perfeccionamiento de los Servicios Sociales en España», con motivo de la creación de la Ley de Autonomía y Dependencia se pone de manifiesto que «la red de equipos con que cuentan los servicios sociales que habrían de realizar esta labor en el área de discapacidad son insuficientes y se dedican sólo, salvo excepciones afortunadas, al reconocimiento administrativo de la discapacidad» (Casado y Fantova, 2007: 9).

Ante esta realidad, ¿cuál es el papel que están jugando los Servicios Sociales públicos en la gestión de la LAAD? ¿Realmente los recursos humanos y materiales se han aumentado como para hacer frente a esta demanda social?

4. Retoma el estudio de los Servicios Sociales en apartados posteriores, sobre todo en lo referido a la figura del trabajador social en dicha institución. 
¿La ampliación de recursos en esta área específica de lo social puede traer consigo un abandono del resto de áreas de atención? Planteamos aquí una serie de interrogantes abiertos a la reflexión, de aspectos sobre los que indagar e investigar para suscitar el debate sobre cómo se está gestionando el SAAD en el contexto público.

De otro modo, es preciso señalar que la creación de un sistema de Atención a la Dependencia, tal y como se ha configurado en nuestro país, implica no solo la participación del Estado, sino también que éste se apoye en una red concertada y privada de organizaciones del Tercer Sector por un lado y empresas dedicadas a la prestación de servicios sociales por el otro.

\subsubsection{Organizaciones del Tercer Sector}

En nuestro intento por aglutinar una serie de ideas, como resultados de plantearnos algunos interrogantes derivados de la nueva gestión del cuidado a partir de la aprobación de la LAAD, nos preguntamos en esta ocasión sobre el papel que están desempeñando las entidades del Tercer Sector en el proceso de creación del SAAD.

Concretamente se define al Tercer Sector en la LAAD como (artículo 2): «Organizaciones de carácter privado surgidas de la iniciativa ciudadana o social, bajo diferentes modalidades que responden a criterios de solidaridad, con fines de interés general y ausencia de ánimo de lucro, que impulsan el reconocimiento y el ejercicio de los derechos sociales».

Las entidades no lucrativas se caracterizan por las numerosas y diversas formas que adquieren ${ }^{5}$, surgiendo así ONGs, asociaciones, entidades voluntarias, instituciones privadas sin fines de lucro (IPSFL) y organizaciones humanitarias, entre las más comunes. Pero lo que parece de algún modo caracterizar a dichas entidades es su objeto social y carácter altruista. Dicha delimitación nos orienta y limita el campo dentro del universo asociativo, pero resulta difícil la calificación de tipologías de asociaciones, dado que existe un segmento de organizaciones e iniciativas de objeto social que se aproxima a la esfera lucrativa del mercado (Zurdo Alaguero, 2007).

Es en este debate en el que nos cuestionamos el posible acercamiento de las entidades no lucrativas a identidades cada vez más circunscritas a su papel de proveedoras de servicios sociales (principalmente servicios de ayuda a la dependencia y servicio doméstico). Como advierte Luis Enrique Alonso «las ONG muchas veces representan más intentos de profesionalización de colectivos que no pueden entrar en el mercado de trabajo, búsqueda de beneficios

5. Para saber más, véanse Zurdo Alaguero (2007) y Alonso Benito (2000). 
y de subvenciones utilizado el señuelo del bienestar social...» (Alonso Benito, 1998: 167).

En el mismo sentido, Martínez Román, Mira-Perceval Pastor y Pedero Bellido (1996: 235) observan la aparición y proliferación en los últimos años de empresas enmascaradas de ONGs [...] «constituidas, en realidad, por profesionales que, al elegir esta forma organizativa, pueden acceder a subvenciones de la Administración pública y a las correspondientes desgravaciones fiscales».

En conclusión, nos parece interesante repensar en el rol que ¿empiezan? a jugar las organizaciones del Tercer Sector, que pareciera más acercarse a la lógica del mercado en su papel como proveedoras de servicios, gestionando recursos a la sociedad, en detrimento de su papel como espacio independiente generador de reivindicación social. Nos encontramos pues ante la eclosión de un asociacionismo activo y voluntario, difícilmente descifrable usando la división tradicional entre Estado y Sociedad Civil (Alonso Benito, 2000).

\subsubsection{Empresas prestadoras de Servicios Sociales}

Las empresas sociales empezaron a proliferar en nuestro país como conocedoras de la futura demanda ${ }^{6}$ que sobre ellas recaería a partir de la aprobación de la LAAD. Recordemos que una empresa proveedora de servicios sociales responde a la lógica del beneficio empresarial, beneficio que obtienen a partir de la oferta de prestaciones y servicios sociales en pro del bienestar social, pero plenamente insertas en el mercado y por ende en la búsqueda del beneficio económico. Esta búsqueda de beneficio económico hace que las reglas del juego empresarial se asienten en la minimización de costes y ampliación de beneficios. Lógica que parecería no casar con las buenas intenciones de la LAAD al hablar de un derecho universal y de calidad para todos los ciudadanos ${ }^{7}$. Ante

6. Esa proliferación de empresas dedicadas a la prestación de servicios sociales viene fuertemente condicionada por la LAAD que promueve que "Cuando las personas en situación de dependencia no puedan acceder a un recurso público o concertado, tendrán una ayuda económica para tener acceso a un dispositivo privado, para lo que se consignarán 15,1 millones de euros», [en línea], <http://www.juntadeandalucia.es/ fundaciondeserviciossociales/es/noticias/not_071106/wfnews_view_pub>.

7. En el Artículo 3 de la LAAD se establecen los principios inspiradores que sustentan la ley, entre los cuales encontramos: «2. La universalidad en el acceso de todas las personas en situación de dependencia, en condiciones de igualdad efectiva y no discriminación, en los términos establecidos en esta Ley. 10. La calidad, sostenibilidad y accesibilidad de los servicios de atención a las personas en situación de dependencia y 13. La participación de la iniciativa privada en los servicios y prestaciones de promoción de la autonomía personal y atención a la situación de dependencia». 
esta situación cabe preguntarse si realmente la empresa privada va a asumir los costes derivados de establecer un servicio universal y de calidad aunque implique disminuir su cuantía de beneficio económico. Recordemos en este punto que las licitaciones públicas se realizan a un precio muy bajo. Esta imposición administrativa (precio del concurso público) adquiere un valor muy importante para que las empresas concursen en la gestión del servicio. De esta manera, son las empresas quienes tienen que adaptar el precio del servicio a las exigencias impuestas por la administración (precio muy bajo). Así, las empresas, en muchos casos, se ven forzadas a limitar la calidad del servicio para poder adecuarse al precio que fija la administración en el concurso público de gestión de los servicios.

Por otra parte, y enlazando con las entidades del Tercer Sector, nos planteamos lo siguiente: ¿se estrecha cada vez más la diferencia entre empresas de Servicios Sociales y Entidades del Tercer Sector? ¿Dónde queda el carácter garantista de la LAAD si la gran parte de su gestión (pública y/o privada) se encuentra mercantilizada? ¿Existen protocolos de seguimiento real, eficiente y eficaz sobre la gestión concertada?

\subsection{El papel de la familia y la mujer: ¿crisis del modelo tradicional?}

Como hemos introducido ya en el apartado anterior, en la LAAD se recogen una pluralidad de formas para cubrir la necesidad de cuidados: a través de entidades públicas, ONGs y entidades asociativas, en el sector privado con ánimo de lucro y en el ámbito familiar. Es precisamente en este último en el que ahora nos detendremos insistiendo en nuestra idea de plantear posibles contradicciones, aspectos interrogantes y dudas que parecen brotar.

Las investigaciones del IMSERSO sobre apoyo informal -realizadas en 2009- ponen de relieve que la gran mayoría de los cuidados que precisan las personas en situación de dependencia es asumida por las familias. Recordemos el dato en el caso andaluz de las 169368 prestaciones concedidas en la Comunidad andaluza a 1 de diciembre de 2009, de las que $85021(50,20 \%)$ fueron destinadas a prestaciones económicas para cuidadores familiares.

De igual modo, la feminización de la figura del denominado «cuidador principal familiar» es abrumadora en nuestro país según muestran los datos

Llegado el momento nos preguntamos: ¿Se podrían entrever en los principios inspiradores lógicas contradictoras? ¿Cómo casa el derecho universal y de calidad con el surgimiento de la iniciativa privada y empresarial cuyo objetivo, recordemos, es la búsqueda del beneficio económico? ¿Realmente es la empresa privada la que debe asumir los costes de un servicio de calidad y universal? ¿no debería ser el Estado el encargado de ofrecer estas garantías? 
del IMSERSO ${ }^{8}$, cabe destacar que si en 1994 el $83 \%$ del total de cuidadores eran mujeres, 15 años después ese porcentaje, por más que pueda resultar sorprendente, no solo no se ha modificado con el paso del tiempo, sino que llega incluso a incrementarse, ya que en 2009 el total de cuidadoras mujeres asciende a un $94 \%$ frente a un $6 \%$ de cuidadores hombres (IMSERSO).

Ante este análisis de los datos, es preciso que nos detengamos a reflexionar sobre la reproducción de la desigualdad de género que las políticas sociales y en concreto la LAAD parecen representar. Como afirman Pérez de Orozco y Baeza Gómez (2006: 14): «La Ley de dependencia se configura como una respuesta a una situación de emergencia social, derivada de la crisis de los cuidados, pero no como una herramienta para revertir injusticias históricas en el reparto de los trabajos».

La responsabilidad de cuidar, en el caso de las mujeres, se confunde con su rol principal en el mundo. Proporcionar cuidados a los demás ha sido un elemento central en la identidad femenina hasta hace bien poco. Las mujeres cuidan, se ha dicho muchas veces, incluso a costa de sí mismas, de su propia salud y bienestar (Vega Solís, 2009: 10).

La nueva legislación sobre dependencia propuesta por el Estado español parece apostar, como explicábamos, por un sistema de bienestar mixto en el que participan familia, Estado, mercado y voluntariado en distintas dosis. Pero surgen ciertas medidas como, por ejemplo, las prestaciones económicas dirigidas a retribuir a las personas cuidadoras de ámbito familiar, que nos hacen reflexionar sobre la supuesta liberación de las familias, y en especial de las mujeres, que dicha legislación promulgaba.

En este sentido, las prestaciones dirigidas a retribuir a las personas cuidadoras deberían considerarse prestaciones verdaderamente excepcionales, ya que el uso extendido de las mismas podría desincentivar el acceso y conservación del empleo de las mujeres al tiempo que contribuiría al estereotipo tradicional de asociar a los valores femeninos cuando se relacionan con la ética del cuidado (Rodríguez Rodríguez, 2005: 7).

Como podemos observar, es mucha la polémica en torno a la prestación económica por cuidados familiares, y el hecho de otorgar una cuantía económica visibiliza parcialmente la labor realizada de las familias pero ¿pudiera convertirse en un instrumento que sujete a muchas mujeres al ámbito familiar, inhibiéndolas de entrar en el mercado laboral?

8. Véase<http://www.imserso.es/Presentacion/groups/imserso/documents/binario/estsisaad 20091201.pdf>, extraído el 14 de diciembre de 2009. 
Otro aspecto sobre el que nos parece interesante reflexionar es la incorporación de las mujeres (in)migrantes al sector del cuidado (Agrela Romero, 2009a). Esta incorporación responde precisamente a esa necesidad presentada por las familias españolas como estrategia de organización en sus vidas cuando no encuentran apoyo por parte de las instituciones públicas y la esfera familiar presenta algunas circunstancias ${ }^{9}$ a partir de las cuales no puede hacerse cargo del cuidado de su familiar. Esta realidad individual/familiar y cotidiana tiene una repercusión a nivel macro, pues la demanda producida desde países como España para trabajar como empleadas de hogar implica a su vez que se produzca una oferta específica de mano de obra de mujeres en países emisores de (in)migración (Hochschild, 2001).

Unido a todo lo anterior, muchos son los factores que desestabilizan los niveles de oferta y demanda a los que tradicionalmente asistíamos. A modo de ideas: por un lado hemos presenciado la incorporación de la mujer española al mundo laboral. Además cada vez son más las mujeres con formación que eligen un empleo de mayor cualificación. De otro modo, la ocupación de empleada de hogar se presenta como una actividad laboral altamente precarizada y de escaso reconocimiento social. Las negociaciones sobre el reparto de tareas en el ámbito doméstico entre los hombres y las mujeres no se han producido de forma igualitaria, y surgen cada vez más nuevos modelos de familias, más complejos (familias monoparentales, familias reconstruidas, etc.) que requieren de nuevas estrategias de organización en el cuidado (Agrela Romero, 2009b).

La demanda de empleadas domésticas es cada vez mayor y dada su situación de precariedad del régimen laboral ${ }^{10}$ en nuestro país, es fácilmente predecible que sean las mujeres (in)migrantes las encargadas de ocupar este nicho laboral. Según el colectivo IOÉ, la ocupación del cuidado se convierte, hoy por hoy, en la principal puerta de entrada de las mujeres inmigrantes al mercado laboral español (IOÉ, 2005).

Recordemos que no sólo la demanda está ahí, sino que surge al mismo tiempo una internacionalización del mercado de trabajo acompañada de una

9. Entre ellas, destacan que la mujer esté inserta en el mercado laboral, que esté a cargo de otros miembros de la familia que también necesiten cuidados (por ejemplo, sus hijos), que no quiera encargarse de esa labor, o que la unidad familiar esté exclusivamente compuesta por varones.

10. El Real Decreto 1424/1985 de 1 de agosto por el que se regula la relación laboral de carácter especial del servicio de hogar permite, entre otras muchas cuestiones, que el pago de salario se pueda realizar en especia hasta un $45 \%$, que el tiempo de trabajo no supere las 40 horas semanales pero sin contabilizar los «tiempos de presencia» y que el contrato laboral se pueda realizar de forma oral, entre otras situaciones abusivas. 
aceleración de los flujos migratorios que hace que la inmigración femenina -fuertemente influenciada por la demanda de sus servicios- elija esta región como lugar de destino (Martínez Buján, 2009). Es en este punto donde nos preguntamos: $¿$ Es posible que aumenten las desigualdades entre mujeres según sus clases? ¿Qué papel juegan las mujeres (in)migrantes en la familia en la que ofrecen su servicio? ¿Cuáles son las condiciones en las que trabajan estas mujeres? ¿Qué repercusiones tiene la inmigración de mujeres en sus contextos de origen? ¿Qué valor se atribuye a la actividad de cuidar (laboral/ emocional)?

\section{Retos del Trabajo Social respecto a la dimensión deontológica}

En el actual paradigma ideológico de los Servicios Sociales públicos en España poco a poco entendemos que se trata de derechos universales y no de actividades o recursos especiales para colectivos vulnerables. Son áreas donde es necesaria, en general y para todo el mundo, una intervención profesional y, también, una protección pública (Fantova, 2009).

La LAAD se ha configurado bajo este modelo teórico de universalización y derechos sociales. No obstante, en el ejercicio diario del Trabajo Social, encontramos una serie de aspectos que permiten cuestionarnos el imaginario en el cual se estructura y desarrolla una ley de contenidos básicos que posiciona el quehacer del profesional del Trabajo Social, en la (re)estructuración del cuidado, bajo las órdenes técnico políticas y burocráticas.

Este debate entre una situación (cuestión política) y qué se debe hacer (cuestión ética) es una cuestión de sobra conocida en el Trabajo Social ${ }^{11}$ pero que vuelve a tomar relevancia en el tema en el cual lo encuadramos.

Como trabajadores/as sociales, transcurridos varios años desde la incorporación de esta ley, es el momento de reflexionar sobre el papel que estamos desempeñando y nuestra parte de responsabilidad en la (re)producción de las limitaciones y desconciertos que esta reestructuración del sistema de protección y reorganización del cuidado está desencadenando.

En el trámite de las situaciones de dependencia, en los Servicios Sociales comunitarios, hay tres situaciones en las que intervienen los/as trabajadores/ as sociales (Villalobos Santos, 2008): en el Servicio de Información, Valoración y Orientaciones, sobre la pertinencia, oportunidad, beneficios y trámites necesarios; en la elaboración del Informe Social y la Propuesta del Plan Individual de Atención (Propuesta PIA); y en el seguimiento de cada persona dependiente, una vez que el servicio o la prestación hayan quedado asignados

11. Para saber más, véase Moreno Pestaña, (2004). 
y, por la naturaleza de los mismos, impliquen que el dependiente continúa viviendo en su medio habitual. Partiendo de estas premisas, nuestras funciones no se están vinculando al activismo y al compromiso social que nos correspondería desempeñar. En las actuaciones de los/las trabajadores/as sociales que se derivan de la LAAD parece suscitar más «el hacer» que «el pensar», menospreciando la habilidad del Trabajo Social para desarrollar su propia identidad teórica y metodológica. Como expone Howe (1999), el pragmático se basa en el «sentido común» y suele significar una visión particular de ver las cosas. La actividad pragmática se rige por «si funciona, sirve» $\mathrm{y}$ «haz lo que pueda hacerse», sin cuestionarse que «lo que se puede hacer» no es lo mismo que «lo que se debe hacer» (Howe, 1999: 238-239).

El debate en estos términos se traduce en un Trabajo Social tecnócrata, en el que el profesional se especializa en los mecanismos institucionales frente a los modelos teóricos del Trabajo Social y la atención a los diferentes niveles de intervención (individual, familiar, grupal y comunitario):

«El reunir la documentación necesaria que viene establecida por el marco administrativo y gestionarla para solicitar un recurso en sí mismo, no es trabajo social. No obstante, pareciera que este es un tiempo en el que sin recurso no hay servicio. Pero si la función del trabajo social se redujera a esto, a gestionar la documentación para acceder a los recursos, cabe reconocer que para ello no se precisa ninguna diplomatura, sólo educación y conocer los papeles.» (Colom Masfret, 2005: 27)

En la actualidad, y en el desarrollo de la LAAD, estamos acometiendo el mismo papel pasivo que se le ha venido cuestionando históricamente al Trabajo Social. Centrado más en traducir la política social en servicio operativo que en aportar indicadores que contribuyan a la configuración de dicha política social, podríamos decir que el Trabajo Social se ha desarrollado más por la influencia del bienestar social y la política social en él que por la influencia contraria (De la Red, 1997: 100).

Precisamente, en este momento de reestructuración, en relación al sistema de protección de las situaciones de dependencia y la reorganización del cuidado, el Trabajo Social adquiere una actitud pasiva que se traduce en funciones relacionadas con la gestión de trámites y cumplimentación de formularios. Además, los Servicios Sociales continúan siendo organizaciones fuertemente jerarquizadas, burocratizadas, donde la figura profesional del trabajador social, principalmente, adquiere una función de respuesta frente a las demandas de la institución relegando, a un segundo plano, las necesidades de la ciudadanía.

Debemos recordar que el desarrollo e implementación de la LAAD se hace, principalmente, desde la base de los Servicios Sociales comunitarios. Esta 
vinculación de la política pública con la responsabilidad institucional de los Servicios Sociales recae sobre los trabajadores sociales que son los que sostienen la base del sistema y constituyen la referencia ciudadana e imagen pública de la misma. Esto sitúa a los trabajadores sociales ante el reto de perfeccionar su metodología de intervención, así como innovar, investigar y producir una creciente calidad profesional (Las Heras Pinilla, 2009: 171-172).

Por tanto, es nuestra responsabilidad visibilizar aquellas circunstancias que limitan el desarrollo efectivo, eficiente y real de un derecho subjetivo. Reconocer este papel y asumir una dimensión informadora y de crítica social trata de ser una propuesta que conecta la proyección de lo personal y lo disciplinar como poderoso argumento para modificar la situación que envuelve la profesión y enmarca la posición de los trabajadores sociales. Se trata pues de proyectar la realidad de las situaciones sociales estudiadas, de desarrollar una actividad de información y también de sensibilización que tendría como destinatarios a la sociedad en general, a los políticos y a los profesionales (Barbero, Feu y Vilbrod, 2007: 139-143).

\section{Retos del Trabajo Social respecto a la dimensión práctica}

Desde el Trabajo Social son múltiples y diversas las limitaciones que encontramos en la LAAD y que hacen necesario que el colectivo de profesionales que formamos esta disciplina profesional y científica manifieste.

En este aspecto encontramos que la práctica del Trabajo Social, en el desarrollo de la ley, se está vinculando, tal y como se ha mencionado con anterioridad, a los aspectos administrativos en la gestión de solicitud de reconocimiento del grado y nivel de dependencia, así como en la coelaboración del PIA. En ambos casos, los procedimientos y actuaciones vienen diseñadas desde un nivel técnico-político en el que el trabajador social no tiene margen de acción más allá de limitarse a rellenar los formularios y cuestionarios (pre) establecidos. Por el contrario, estos aspectos tan necesarios en la identificación de las necesidades en los cuidados se convierten en una tarea ardua de identificar, debido a las limitaciones de tiempo en los encuentros de valoración y evaluación, y difícil de reflejar en los registros cerrados que manejamos los profesionales.

Estas limitaciones administrativas se reflejan notablemente en el Informe Social y en el PIA, ya que las circunstancias que rodean a la persona en situación de dependencia (vivienda, relaciones sociales, comunidad, estructura y dinámica familiar, debilidades y puntos de apoyo...) pueden quedar incompletas en el diagnóstico técnico. 
Además de estas restricciones burocráticas que perjudican la práctica profesional de nuestra disciplina, se está produciendo, en multitud de ocasiones, un incumplimiento de los plazos previstos en los diferentes procesos administrativos. Esto puede estar proyectando una imagen de los Servicios Sociales como institución con excesivos procesos burocráticos que limita la resolución de las necesidades de la ciudadanía.

Por otra parte, cabe afirmar que estamos ante una ley de corte asistencial, enmarcada en el modelo médico-rehabilitador y con escasas referencias a la promoción de la autonomía personal. Además, podemos añadir que dicha ley «es ilegal y fuertemente discriminatoria para la mayoría del colectivo de personas con diversidad funcional (discapacidad)» (Foro de Vida Independiente, 2006), ya que sus principios no están en la línea de los establecidos por la Convención Internacional de la ONU, sobre los derechos de las personas con discapacidad, que posiciona a las personas con diversidad funcional como sujetos, ciudadanos titulares de derechos, participativos y responsables, que asumen la dirección total y completa de su vida personal y social.

Estos aspectos ideológicos condicionan la práctica profesional de nuestra profesión en la medida en que la red de servicios y equipos con que cuentan los Servicios Sociales se incrementa y expande, en buena parte, hacia servicios institucionalizados (residencias, centros de estancias diurnas...). En cambio, la buena práctica en esta área, que coincide con los deseos de las personas con discapacidad y en situación de dependencia, aconseja concentrar el esfuerzo en la ampliación de las prestaciones para la permanencia en el domicilio (Casado y Fantova, 2007).

Para evitar posibles prácticas erróneas en las asignaciones y propuestas de los recursos y prestaciones, desde nuestro colectivo profesional, debemos tener presente que no toda persona con diversidad funcional (discapacidad) debe ser considerada como una persona en situación de dependencia. Si bien, esto no significa rechazar la relación que pueda existir entre ambas. Esta relación entre diversidad funcional y la situación de dependencia se ha visto influenciada, en gran medida, porque las personas con diversidad funcional han sido discriminadas y minusvaloradas sistemáticamente a lo largo de la historia. Incluso la realidad actual es plenamente discriminatoria y está basada en un conjunto de confusiones conceptuales, muchas de las cuales están relacionadas con la escasa implantación del modelo social y de Vida Independiente en nuestro país.

De este modo, y como se ha visto, la respuesta normativa frente a la situación de dependencia no puede quedar en términos de asistencia, sino que debe ser considerada un derecho de todas las personas a ser protegidas en 
dicha situación, orientando dicho amparo hacia el logro de la autonomía (entendida tanto como el punto de partida cuanto como punto de llegada). Si la falta de autonomía se convierte en un indicio significativo de la existencia de una situación de dependencia, entonces las medidas tendentes a garantizar el mayor grado de autonomía posible serán la respuesta adecuada a ofrecer (De Asís Roig y Palacios, 2007: 56).

En relación a este último aspecto, una de las reivindicaciones más consolidadas por el movimiento de personas con diversidad funcional, y gran desconocido por el colectivo de profesionales del Trabajo Social, es la implementación real de la figura del asistente personal. La aprobación de la Ley 39/2006, de 14 de diciembre, de Promoción de la Autonomía Personal y Atención a las personas en situación de dependencia, establece una prestación económica de asistencia personal, en la que queda reflejada la figura del asistente personal como una prestación más de dicha ley ${ }^{12}$.

No obstante, a pesar de las reivindicaciones del propio colectivo de personas con diversidad funcional en pro de desarrollar una implementación mayor de la figura del asistente personal, lo cierto es que las resoluciones identificadas en el PIA son escandalosamente menores frente a recursos como las residencias ${ }^{13}$.

El enfoque, antes mencionado, de la LAAD hacia un modelo médico-rehabilitador arraigado a prácticas asistencialistas está propiciando el olvido, casi sistemático, de servicios y actuaciones que fomenten la autonomía personal en línea con la filosofía de vida independiente. Sin embargo, en el texto jurídico podemos descubrir los fundamentos específicos de la Filosofía de Vida Independiente, además de en las menciones en el propio título y en la exposición de motivos de la ley, en otras referencias específicas ${ }^{14}$.

No obstante, la implementación real de esta política pública parece estar enfocándose más a la atención de la dependencia que a la promoción de la autonomía. Y, en esta última vertiente los esfuerzos se limitan y conciben como herramientas centradas en características concretas de las personas, $y$ en ningún momento se plantea la posibilidad de que la dependencia tenga además un origen social (De Asís Roig, 2007: 9).

12. Artículo 19 y artículo 2.7.

13. En Andalucía se ha concedido esta prestación sólo en 32 casos frente a 15391 para plazas residenciales (situación a 1 de diciembre de 2009). Extraído el 14 de diciembre de 2009 de http://www.imserso.es/Presentacion/groups/imserso/documents/binario/ prestarecsaad.pdf.

14. Ver artículos 2, 3, 13 y 14. 
En otro lugar, es preciso detenerse sobre la formación adquirida por los trabajadores sociales que estamos desarrollando e implementando las actuaciones derivadas de la LAAD. No podemos negar el valor político de esta ley que ha conllevado una urgencia por incrementar el número de profesionales (aún insuficiente) para hacer frente no sólo a las necesidades de la ciudadanía, sino también a la auto exigencia y expectativas creadas. Un sistema público de estas características debe tener una estructura desarrollada bajo un entorno laboral estable que permita a los profesionales adquirir una formación continua y de calidad en el ámbito en el que se desenvuelven. Sin embargo, en muchos de ellos, se destacan las dificultades y debilidades para analizar e intervenir en los distintos aspectos relacionados con el actual sistema de protección a la dependencia y a las nuevas formas de reorganización del cuidado. Por ello, es muy importante la colaboración entre profesionales, investigadores y teóricos del Trabajo Social, que permita ampliar conocimientos, trasmitir y vincular experiencias, y convertir al Trabajo Social en una materia interesante e imprescindible para los que trabajan en el ámbito del bienestar social (Rossell Poch, 2009).

Dicho todo esto, si miramos la realidad cotidiana de los trabajadores sociales en la actualidad, en los Servicios Sociales comunitarios parece, a juzgar por el número de trámites relativos a las solicitudes para la valoración de la situación de dependencia, y posteriormente por la elaboración de Programas Individuales de Atención, que su única competencia fuera el trabajo relacionado con los trámites del actual sistema de protección social de la dependencia (Villalobos Santos, 2008). Esta situación puede ser percibida como una amenaza para las otras áreas, servicios y programas de los Servicios Sociales comunitarios. Verter todos los esfuerzos humanos, recursos materiales y presupuestarios, a la gestión de las situaciones de dependencia puede hacernos caer en el olvido de otras, y tantas, necesidades sociales que son, y deben ser, atendidas desde los Servicios Sociales comunitarios y por los profesionales del Trabajo Social.

\section{Conclusiones}

La LAAD viene a (re)estructurar la forma institucional de atención a las personas en situación de dependencia. Estas (¿nuevas?) prestaciones y servicios refuerzan, (re)organizan y reproducen, en algunos casos, como hemos visto, las formas tradicionales de provisión del cuidado. En la LAAD, las mujeres, como principales cuidadoras, siguen siendo una figura sin reconocimiento social (en lo referido a la dignificación del trabajo). Esta ley desplaza al colectivo destinatario y lo sitúa como un agente pasivo, receptor de prestaciones 
y recursos (en muchos casos inadecuados, incompletos o mal distribuidos), anulando la posibilidad de participar en su formulación.

El ejercicio profesional del Trabajo Social tiene la responsabilidad de elevar la problemática individual a un nivel social. Se trataría no sólo de implicar al conjunto de la sociedad en las respuestas ofrecidas hacia determinadas necesidades, sino de identificar y elaborar un análisis de la situación de forma holística e integrada, fruto de la sinergia entre el ciudadano (usuario) y el profesional.

Somos conscientes de que en la implementación de la ley los trabajadores sociales sólo formamos una parte de los agentes implicados. No obstante, nuestro ejercicio profesional debe estar en concordancia con los principios de la profesión (justicia social). Así, los retos del Trabajo Social deben pasar por analizar de forma crítica todos los aspectos en los que la profesión entra en contacto con las formas de reorganización del cuidado. Desde esta perspectiva reivindicamos una cohesión profesional que rompa con la excesiva burocratización en las funciones de los trabajadores sociales y que apueste, por el contrario, por el afianzamiento de una disciplina con compromiso profesional y comprometida socialmente. Esta visión puede ofrecer una oportunidad para afrontar los retos y dificultades que la gestión de los cuidados parece estar atravesando.

\section{Bibiliografía}

Agrela Romero, B. y otros, Mujeres inmigrantes en los servicios de atención y cuidado en Jaén. Explorando las condiciones y subjetividades de un trabajo imprescindible e invisibilizado, investigación financiada por la Dirección General de Coordinación de Políticas Migratorias, Jaén, Consejería de Empleo. Junta de Andalucía (2009-2010). 2009a.

Agrela Romero, B., «De los significados de género e inmigración (re)producidos en las políticas sociales y sus consecuencias para la acción e integración social», en Inmigración y Políticas Sociales, L. Cachón, y M. Laparra, (eds.), Barcelona, Bellaterra, 2009b, pp. 239-267.

BARbero, J. M, M. FeU, y A. Vilbrod, La identidad inquieta de los trabajadores sociales, Barcelona, Hacer, 2007.

Alonso Benito, L. E., Trabajo y postmodernidad: El empleo débil, Madrid, Fundamentos, 2000.

- «Los nuevos movimientos sociales en el umbral del año 2000», en Documentación Social, n. ${ }^{\circ}$ 111, Cáritas Española, Madrid, 1998, pp. 155-177.

CASADO, D. y F. FAntova (coords), Perfeccionamiento de los Servicios Sociales en España: Informe en ocasión de la Ley sobre autonomía y dependencia, Madrid, Polibea, 2007. 
Colectivo IOÉ, Mujer, Inmigración y Trabajo, colección Inmigración y Refugio, Madrid, Ministerio de Trabajo y Asuntos Sociales, IMSERSO. 2001.

- «El cuidado de personas mayores dependientes realizado por ciudadanos inmigrantes en la Comunidad de Madrid», en Cuidado a la dependencia e inmigración, Madrid, IMSERSO, 2005, pp. 233-370, [en línea], <http://www. infodisclm.com/documentos/dependencia/depedencia_inmigracion.pdf $>$.

Colectivo Precarias a la deriva, Cuidados globalizados. A la deriva por los circuitos de precariedad femenina, Madrid, Traficantes de sueños, 2004.

COlOM MASFRET, D., «La formación permanente: Retorno con camino eficiente», en Revista de Servicios Sociales y Política Social, Madrid, Consejo General de Colegios de Diplomados en Trabajo Social, 2005. n. ${ }^{\circ} 71$, pp. 23-44.

DE Asís Roig, R., «Reflexiones en torno a la Ley de promoción de autonomía personal y atención a las personas en situación de dependencia», Universitas: Revista de filosofía, derecho y política, Madrid, Instituto de Derechos Humanos «Bartolomé de las Casas», 2007. n. ${ }^{\circ}$ 5, pp. 3-21.

- Derechos Humanos y Situaciones de Dependencia, Madrid, Dykinson, S.L., 2007.

DE La ReD, N., «La formación del Trabajo Social en España», en Revista de Servicios Sociales y Política Social, Madrid, Consejo General de Colegios de Diplomados en Trabajo Social, 1997, n. ${ }^{\circ} 39$, pp. 97-105.

FANTOVA, F., «Algunas notas sobre la identidad profesional en el Trabajo Social», Congreso Estatal del Trabajo Social, Zaragoza, 6 de mayo de 2009, [en línea], <http://www.colegiotstenerife.org/ficheros/File/Congreso-Zaragoza/05_Fernando_Fantova.pdf>.

Foro de Vida Independiente, «Análisis ideológico y de coherencia del anteproyecto de Ley de la promoción de la autonomía personal y atención a las personas en situación de dependencia», 2006, [en línea], <http://www.minusval2000. com/relaciones/vidaIndependiente/lepa/index.html>.

HochSCHILD, R. A., «Las cadenas mundiales de afecto y asistencia y la plusvalía emocional», en En el límite. La vida en el capitalismo global, Anthony Giddiens y Will Hutton (eds), Barcelona, Kriterios Tusquets, 2001, pp. 187-208.

Howe, D., Dando sentido a la práctica. Una introducción a la teoría del trabajo social, Granada, Maristán. 1999.

IMSERSO, Datos sobre prestaciones reconocidas a 1 de Diciembre de 2009, extraído el 14 de diciembre del 2009, [en línea], <http://www.imserso.es/Presentacion/groups/imserso/documents/binario/estsisaad20091201.pdf>.

Las Heras Pinilla, M. P., «Mi experiencia de compromiso con el trabajo social», Servicios Sociales y Política Social, Madrid, Consejo de Colegios de Diplomados en Trabajo Social, 2009. n. ${ }^{\circ}$ 86, pp. 167-172.

Ley 39/2006, de 14 de diciembre, de Promoción de la Autonomía y Atención a las personas en situación de dependencia. 
MARTíneZ BujÁN, R., «Inmigración y envejecimiento desde una perspectiva asistencial», en Género y Empleo, J. Astelarra, (coord.), Madrid, Fundación Carolina, 2009. n. ${ }^{\text {3 } 32, ~ p p . ~ 87-95 . ~}$

Martínez Román, M. ${ }^{a}$ A., M. ${ }^{a}$ T. Mira-Perceval Pastor y H. Redero Bellido, «Sistema público de servicios sociales en España», en Administración Social: Servicios de Bienestar Social, M. ${ }^{a}$ C. Alemán Bracho y J. Garcés Ferrer, (dirs.), Madrid, Siglo XXI Editores, 1996, pp. 203-246.

Moreno Pestaña, J. L., «La demanda de ciencia. Esbozo de una sociología de los discursos epistemológicos en Trabajo Social», en Portularia, n. ${ }^{\circ} 4,2004$, Huelva, pp. 371-386.

Pérez De Orozco, A. y P. BAEZA Gómez, «Sobre -dependencia-y otros cuentos: reflexiones en torno a la ley de promoción de la autonomía personal y atención a las personas en situación de dependencia (Ley 39/2006, de 14 de diciembre, BOE de 15 de diciembre)», en Lan harremanak: Revista de relaciones laborales, n. ${ }^{\circ}$ 15, 2006, Guipuzkoa, pp. 13-40.

PÉrez Orozco, A., «Amenaza de tormenta: la crisis de los cuidados y la reorganización del sistema económico», en Revista de Economía Crítica, n. ${ }^{\circ}$ 5, 2006a, pp. 7-37.

Río, Sira del, «La crisis de los cuidados: precariedad a flor de piel», en Rescoldos, Revista de diálogo Social, n. ${ }^{\circ}$ 9, 2003, pp. 45-57.

Rodríguez Cabrero, G., «La protección social de la dependencia en España. Un modelo sui generis de desarrollo de los derechos sociales», en Política y Sociedad, vol. 44, n. ${ }^{\circ}$, Madrid, 2007, pp. 69-85.

RODRÍGUEZ RODRÍGUEZ, P., «El apoyo informal a las personas mayores en España y la protección social a la dependencia», en Revista española de geriatría y gerontología, vol. 40, extra 3, 2005, pp. 5-15.

Rossell Poch, T., «Una aproximación al Trabajo Social», en Servicios Sociales y Política Social, n. ${ }^{\circ}$ 86, Madrid, Consejo General de Colegios de Diplomados en Trabajo Social, 2009, pp. 163-166.

Vega Solís, C., Cultura del Cuidado en transición, Barcelona, Uoc Editorial, 2009

Villalobos SANTOS, J., «Impacto de la ley de promoción de la autonomía personal y atención a personas en situación de dependencia en los servicios sociales comunitarios», en Documentos de trabajo social: Revista de trabajo y acción social, n. ${ }^{\circ}$ 43-44, 2008, Málaga, pp. 9-28.

Zurdo Alaguero A., «La Dimensión Corporativa del Tercer Sector. Los tipos organizativos del voluntariado», en Revista Internacional de sociología, Vol. LXV, n. ${ }^{\circ} 47,2007$, pp. 117-143. 


\title{
IMPACTO DE LA LEY DE DEPENDENCIA EN LOS CUIDADOS A LA TERCERA EDAD EN EL ÁMBITO RURAL: EL CASO DE ENGUERA \\ The impact of the dependent care law on the elderly in rural areas: The case of Enguera
}

\author{
CRISTINA BENLlOCH DOMÉNECH* \\ JOAQUÍN SARRIÓN ESTEVE**
}

\section{Resumen}

En ocasiones, desde las Ciencias Sociales se nos olvida que la realidad se desarrolla en el espacio microsocial, y elaboramos proyectos de gran alcance sin tener en cuenta los contextos locales. Es esta premisa bajo la que se justifica nuestra investigación, porque entendemos que los estudios de caso, como el que nos atañe, son necesarios no sólo para conocer la realidad en los contextos más reducidos, sino también porque las políticas públicas y la legislación no se aplican en abstracto, sino que es en estos emplazamientos «microsociales» donde producen sus efectos directos.

La segunda justificación para el análisis de este municipio en concreto, ha sido el entendimiento de que la realidad de los municipios pequeños de ámbito rural de nuestro país es bien diferente de la dinámica de las grandes zonas urbanas. Esta discre-

\footnotetext{
* Cristina Benlloch Doménech

Universidad de Valencia

Departamento de Trabajo Social y Servicios Sociales

Campus de Tarongers, edif. Occidental. Avd. Tarongers, s/n. 46022 Valencia

Teléfono: 647698376

cristina.benlloch@uv.es

** Joaquín Sarrión Esteve

UNED Facultad de Derecho

Departamento de Derecho Constitucional

C/ Obispo Trejo, s/n. 28040 Madrid

Teléfono: 637967690

joaqsarrion@gmail.com
} 
pancia se da no sólo en cuanto a estructuras demográficas y productivas, sino también en cuanto a las relaciones sociales.

El objeto de nuestro estudio es el análisis de las relaciones de cuidado a la tercera edad generadas a partir de las ayudas de la Ley 39/2006 en este municipio de cinco mil habitantes. Emplazamiento local cuya pirámide de población podemos considerar envejecida pues es ancha por la cúspide.

Palabras clave: cuidados a la tercera edad, Ley 39/2006, ruralidad, estudio de caso, relaciones de género.

\begin{abstract}
Those working in the social sciences can sometimes forget that reality occurs in a micro-social setting, and grand far-reaching projects are designed without taking local contexts into account. Our research is based on this premise, and that case studies such as this are necessary not only to determine the situation in the very smallest contexts, but also because public policies and legislation are not applied in the abstract, but rather it is in very «micro-social» settings where these direct effects occur. The second reason for analysing this town in particular is that small rural towns in Spain have a very different dynamic to large urban areas, a discrepancy that occurs not only in terms of demographics and production, but also with regard to social relations. It is our understanding, therefore, that public policies, particularly those linked to dependent care, exert different influences in rural and urban contexts. The purpose of this study is to analyse the relationships that are created in the care of the elderly as a result of Law 39/2006, in the town of Enguera, with five thousand inhabitants and an ageing population.
\end{abstract}

Keywords: care of the elderly, Law 39/2006, ruralism, case study, gender relations.

\title{
1. Introducción
}

Los estudios de caso como el de Enguera, municipio del ámbito rural de Valencia, son necesarios para el análisis de las políticas públicas porque en este territorio tan micro se puede medir de una forma más cercana el impacto las acciones púbicas sobre la vida de las personas.

Pero además, la realidad de los municipios contextualizados en el ámbito rural de nuestro país es bien diferente de la dinámica de las grandes zonas urbanas y por esto se necesita de diversas políticas de desarrollo (Esparcia y Noguera, 1995)ํ. Las políticas públicas, y en especial las políticas vinculadas con el cuidado y la dependencia, tienen dispares consecuencias según el contexto de referencia y en el ámbito rural las consecuencias de las políticas son diferentes y requieren de especial atención (Esteban, 2007).

1. Por estas necesidades existen ayudas diferenciadas, como las de las escuelas agrupadas o las de dotaciones especiales (Santamaría, 2006). 
El proyecto que se presenta tenía como objetivo analizar el impacto sobre las relaciones de cuidado generadas a partir de las ayudas que ofrece la Ley sobre las relaciones de género en un municipio de cinco mil habitantes en el interior de la Comunidad Valenciana, Enguera. Es relevante ya que de esta forma conoceremos qué ocurre con la Ley de Autonomía y Dependencia en los espacios en los que es más necesaria, atendiendo a la pirámide de edad del contexto rural, que además está escorado hacia las mujeres, que son las que más cuidan y las que más cuidados requieren por su mayor esperanza de vida (Esteban, 2007).

También veremos cómo es la aplicación de la ley en el contexto valenciano, pues en estos casos no se pueden entender los resultados, sino se mira desde la óptica de las autonomías. Esto hay que tenerlo claro, hemos de contextualizar el municipio como parte de la comunidad autónoma y con todas las particularidades señaladas.

\section{Objetivos de la investigación}

La aproximación empírica de la localidad de Enguera se hizo desde una serie de objetivos fundamentales para la investigación, atendiendo a que el centro del análisis era la ayuda económica para el cuidado que está previsto en la Ley 39/2006: 1) Comprender la dinámica y funcionamiento de la Ley de Promoción de la Autonomía Personal y Atención a las personas en situación de dependencia en el contexto de la Comunidad Valenciana, a fin de poder realizar el trabajo de campo de una forma correcta, así como comprender todo el proceso de solicitud y aprobación de la ayuda, con los respectivos trámites y los detalles de la Ley y las ayudas que prevé; 2) analizar la aplicación de la Ley de la Autonomía Personal y Atención a las personas en situación de dependencia en un municipio de la Comunidad Valenciana de ámbito rural, Enguera. Con ello entendemos los plazos, así como la satisfacción y la efectividad de la acción, atendiendo al texto de la ley; 3 ) descubrir el tipo de relaciones de cuidado generadas a partir de las ayudas recibidas en el marco de las ayudas a cuidadores y cuidadoras no profesionales; 4) comprender el proceso que va desde que se solicita la ayuda por parte de la persona hasta que se recibe, y cómo modifica las condiciones de vida de las personas que ejercen el rol de cuidadoras; y 5) evaluar el impacto de la conocida como Ley de Dependencia sobre las relaciones de género, centrándonos en las personas que ejercen de cuidadoras y en el rol asumido con esta tarea. 


\section{Metodología}

La metodología de la investigación ha sido fundamentalmente de tipo cualitativo, con el soporte de datos municipales de tipo cuantitativo. La aproximación se realizó cualitativamente materializada en forma de entrevistas por la característica de los datos sobre las ayudas, y porque necesitábamos conocer los discursos de los sujetos implicados. Debíamos conocer la opinión de las personas que son «beneficiarias» como cuidadoras en la Ley de Promoción de la Autonomía Personal y Atención a las personas en situación de Dependencia a través de su propio discurso, y no a través de datos estadísticos, que por otra parte son inexistentes a nivel municipal ${ }^{2}$.

De todas las técnicas de tipo cualitativo, la herramienta fundamental para el desarrollo de la investigación ha estado formado por las entrevistas semiestructuradas, de las que se han conseguido los datos para el análisis y evaluación de la Ley de Dependencia en el municipio de Enguera.

La población de análisis: 1) Por un lado, aquellas personas que han recibido la ayuda en calidad de cuidadoras. A las personas que requerían asistencia no se las entrevistó por cuestiones del estado de la salud de los mismos. Con estas entrevistas, conseguimos analizar y descubrir el grado de satisfacción con la prestación, así como el proceso por el cual han de pasar los usuarios para recibir la ayuda y las relaciones de género que se establecen en los cuidados; y 2) por otro lado, se realizaron entrevistas a personas que habían solicitado la ayuda pero se la denegaron porque el «paciente» no se encontraba en una situación de dependencia. Éstos fueron los dos grupos de partida para el análisis de la realidad en Enguera, sin embargo, durante la investigación surgió un tercer grupo. Éste estaba compuesto por algunas personas a las que no se les pudo llegar a evaluar el grado de dependencia porque durante el tiempo de espera desde la solicitud a la evaluación, la persona en cuestión había fallecido.

Para la recogida de testimonios para la investigación se optó por el método de selección de los informantes a través de la muestra por efecto «bola de nieve».

Cabe decir que las entrevistadas fueron todas mujeres, ya que no conocimos a ningún hombre durante el proceso que se encargara del cuidado. Lo que nos queda claro es que una de las Instituciones que lleva la gestión de las ayudas en Enguera es la Oficina AMICS, que había registrado en su sede más de 150 solicitudes desde el momento de la entrada en vigor de la ley, pero éstos son los únicos datos de dicha entidad local.

2. Con el tiempo, si los datos se centralizan sería interesante pasar una entrevista en cuenta de satisfacción a las personas beneficiarias de las ayudas de la dependencia. 
Gráfico 1. Evolución de la población de Enguera por sexo y nacionalidad (2001-2008)

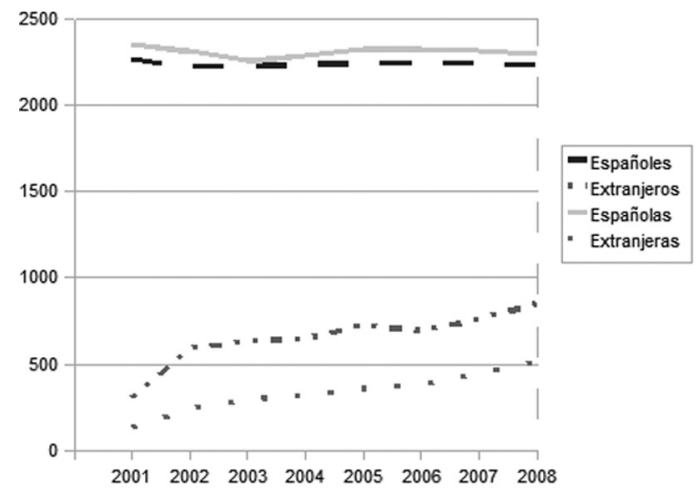

Gráfico 2. Pirámide de población de Enguera a 1 de enero de 2008 Pirámide de Población de Enguera a 1 de Enero de 2008

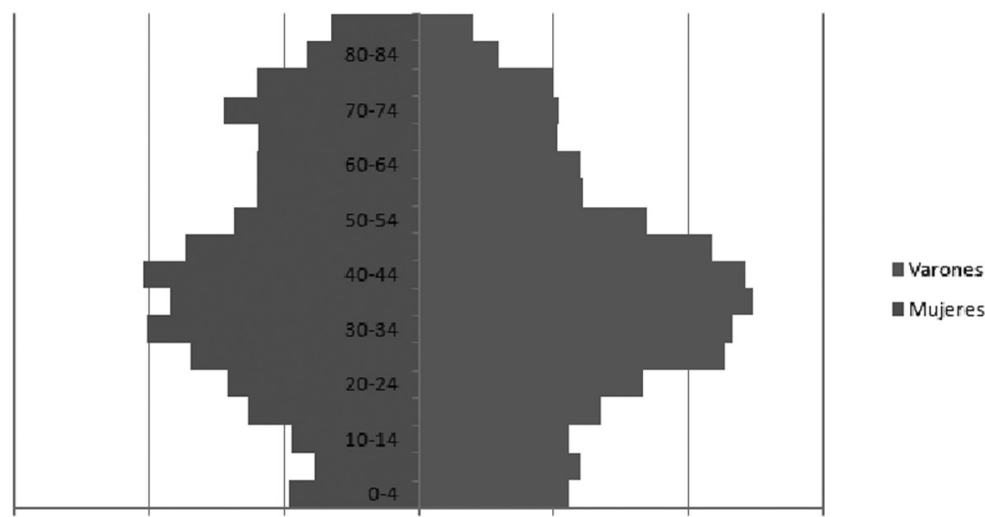

Fuente: Elaboración propia a partir de datos del Padrón Municipal.

\section{Breve referencia al municipio de Enguera}

En cuanto a los datos de población, a 1 de enero de 2008, Enguera tiene empadronados, según el padrón municipal, 5900 habitantes. Tal como observamos en la gráfica siguiente, la población «autóctona» se mantiene estable, casi no crece en los cinco años de referencia si no es por los vecinos que han 
llegado de otros países ${ }^{3}$. Se descubre que las mujeres están sobrerrepresentadas en las edades avanzadas, por lo tanto vemos que se cumple la descripción de Esteban (2007) del medio rural como un espacio en el que las mujeres en edad avanzada son un número mayor que hombres (2007).

La pirámide del gráfico 2 muestra la distribución por edades de la población de Enguera a 1 de enero de 2008. Si recordamos la evolución por años de la población, vemos que el $25 \%$ de la población residente es de nacionalidad extranjera y que, si no cambia la tendencia, crece año a año su volumen y porcentaje sobre la población total.

\section{Aspectos jurídicos de la Ley de Dependencia}

Ahora sí, tal como explicamos, el primero de nuestros objetivos era comprender el funcionamiento y la dinámica de la Ley 39/2006, de 14 de diciembre, de Promoción de la Autonomía Personal y Atención a las personas en situación de dependencia, para comprender la aplicabilidad sobre la Comunidad Valenciana.

La ley pretende configurar un sistema para la Autonomía y Atención a la Dependencia, cuya finalidad es garantizar las condiciones básicas y el contenido común de la atención a la dependencia, sirviendo de cauce para la colaboración y participación de las Administraciones Públicas, en materia de promoción de la autonomía personal y la atención y protección a las personas en situación de dependencia (artículo 6.1 de dicha ley). Dicho sistema puede calificarse como complejo, derivando esta complejidad de la distribución competencial entre el Estado central y las Comunidades Autónomas, puesto que si bien el sistema se ha diseñado como único en el territorio del Estado, cada Comunidad Autónoma puede dar un servicio distinto en función de sus prioridades o de sus recursos económicos, así pues podríamos considerar esta ley como una lista de prioridades a cumplir por las Comunidades Autónomas. Con la intervención estatal se garantizaría una igualdad en la prestación básica, que sería mejorable por las Comunidades Autónomas que estarían encargadas de perfilar las peculiaridades de las prestaciones de la ley, es decir, que el Estado delimita las bases sobre las que tienen que actuar las Comunidades Autónomas.

Debemos acudir al artículo 5 para verificar los requisitos para ser titular de los derechos previstos por la ley: encontrarse en situación de dependencia; residir en territorio español y haberlo hecho durante cinco años, de los cuales

3. Según los datos del Padrón, el 85 \% de estas personas es de nacionalidad búlgara (Ayuntamiento de Enguera). 
dos deberán ser inmediatamente anteriores a la fecha de presentación de la solicitud.

Otra de las cuestiones importantes es la tipología de las prestaciones, pues éstas no se reducen a las de naturaleza económica. En el supuesto de que la prestación recibida sea de naturaleza económica, debemos tener en cuenta la posibilidad de que se solape con otra de naturaleza análoga del régimen público de Seguridad Social, en cuyo caso se deduciría el importe procedente, por ejemplo: el complemento de gran invalidez (regulado en el artículo 139.4 de la Ley General de la Seguridad Social); el complemento de asignación económica por hijo a cargo mayor de 18 años con un grado de minusvalía igual o superior al $75 \%$; o el subsidio de ayuda a tercera persona previsto en la Ley 13/1982 de Integración Social de los Minusválidos. Así, las prestaciones económicas serían: 1) Prestación vinculada al servicio (artículos 14.3 y 17 de dicha ley). 2) Prestación para cuidados en el entorno familiar y apoyo a cuidadores no profesionales (artículos 14.4 y 18 de dicha ley). Y 3) Prestación económica de asistencia personal (artículos 14.5 y 19 de dicha ley).

Se ha considerado más positiva la prestación económica que se realiza en el cuidado familiar y no profesional, puesto que será una prestación hecha por una persona de confianza del beneficiario, asegurando que el beneficiario permanecería en su entorno familiar habitual, dentro de la convivencia en familia (Roqueta Bruj, 2007). Lógicamente habría que tener en cuenta la capacidad económica del beneficiario, pero no la de la unidad familiar (artículos 33.2 y 18.2 de dicha ley), lo que también coadyuva a apoyar este tipo de prestaciones frente a las de carácter profesional.

Este tipo de prestación parece que es el que está teniendo un mayor éxito social. Sin embargo, es curioso que atendiendo a la ley estamos ante una prestación que podría ser cartacterizada como «excepcional», puesto que con tal carácter aparece en artículo 14.4. Es cuestionable y criticable la caracterización excepcional de esta prestación, no tanto por el éxito social que se pueda llegar o no a tener, sino fundamentalmente por razones teleológicas de la norma. Y es que la Ley de Dependencia tiene como objetivo mantener a la persona dependiente en su entorno habitual, para lo que es esencial esta prestación económica. Si bien es cierto que existen otras prestaciones en especie que pueden contribuir a que la persona dependiente permanezca en el hogar familiar, como la ayuda a domicilio, la teleasistencia, los centros de día o de noche puestos a su disposición, la verdad es que parece que la prestación económica puede ser determinante de la permanencia de la persona dependiente en su hogar familiar. El artículo 18.1 dispone que excepcionalmente «cuando el beneficiario esté siendo atendido por su entorno familiar, y se 
reúnan las condiciones establecidas en el artículo 14.4, se reconocerá una prestación económica para cuidados familiares». El artículo 14.4 especifica que «El beneficiario podrá, excepcionalmente, recibir una prestación económica para ser atendido por cuidadores no profesionales, siempre que se den condiciones adecuadas de convivencia y de habilidad de la vivienda y así lo establezca su Programa Individual de Atención». Por tanto, esta prestación está supeditada a que se cumplan dos requisitos: 1) que se den condiciones adecuadas de convivencia y de habilidad de la vivienda y 2) que así lo establezca su Programa Individual de Atención. El primer requisito es previsible que se cumpla si el entorno familiar es adecuado, el segundo plantea más interrogantes al referirse al «Programa Individual de Atención» Dicho programa lo encontramos perfilado en el artículo 29 de dicha ley. Así, en el apartado primero se especifica que «En el marco del procedimiento de reconocimiento de la situación de dependencia y las prestaciones correspondientes, los servicios sociales correspondientes del sistema público establecerán un Programa Individual de Atención en el que se determinarán las modalidades de intervención más adecuadas a sus necesidades de entre los servicios y prestaciones económicas previstos en la resolución para su grado y nivel, con la participación previa consulta y, en su caso, elección entre las alternativas propuestas del beneficiario y, en su caso, de su familia o entidades tutelares que le represente».

No se pretende que el programa sea de carácter definitivo, sino que las necesidades de servicios o de tipos de prestación puede variar lógicamente. Por eso se prevé que este programa de atención sea revisado a instancia del interesado o de su representante legal -de oficio, en la forma prevista en la normativa autonómica- en caso de cambio de residencia a otra Comunidad Autónoma.

\subsection{El nivel de los cuidadores no profesionales}

Quizá un tema pendiente es el de la adecuada formación de los cuidadores no profesionales. Si bien es verdad que debe potenciarse más el cuidado en familia, y por tanto a los cuidadores no profesionales, hemos visto esta prestación que se configuraba como excepcional frente a la opción de servicios en especie o la prestación económica para un cuidado profesional. Esto es así debido a la calidad atribuida al cuidado profesional frente al familiar. Sin embargo, cuando se habla de calidad, ésta parece que se está reduciendo a la calidad formativa de los prestadores del cuidado, y esto sucede porque la calidad en sentido amplio incluye también una serie de atenciones que no están relacionados con la formación, sino más bien con el afecto que pueden prestar los familiares, pero difícilmente lo pueden hacer profesionales, 
por muy bien que hagan su trabajo. Y es aquí donde es relevante el reciente acuerdo del Consejo Territorial de Dependencia, que ha aprobado impulsar la formación de las personas no profesionales, diseñando e impartiendo cursos, tanto presenciales como a distancias, que mejoren los conocimientos de estas personas en aspectos tales como los cuidados básicos (cambios posturales, higiene, nutrición), la prevención de lesiones, estrés y riesgos para el cuidador, la información de recursos para el cuidador y el dependiente y el papel del cuidador. Estos cursos se contemplan con una duración de 15 horas en las fases iniciales, y de 10 horas en la fase de formación específica.

También debemos tener presente que la ley prevé acertadamente que el Consejo Territorial del SAAD promoverá acciones de apoyo a cuidadores no profesionales. Esto hay que ponerlo en relación con el Libro Blanco de la Dependencia, puesto que nos recuerda que la complementariedad entre el apoyo informal y los servicios formales o profesionales es una garantía de que las personas dependientes puedan permanecer más tiempo en la familia. Es verdad que las Comunidades Autónomas también contemplan diferentes servicios de apoyos a las familias y cuidadores familiares, aunque a veces son demasiado especializados. En el caso de la Comunidad Valenciana destaca su Programa de Formación de Cuidadores Informales de personas con enfermedad de Alzheimer y otras demencias. Sí es más genérico el programa de respiro familiar («Bon Respiro», para posibilitar el descanso de los cuidadores familiares no profesionales, previsto en la Orden de 27 de diciembre de 2005 de la Conselleria de Bienestar Social, que pretende posibilitar que la persona dependiente se quede en una residencia o centro durante un día o un periodo corto de tiempo, para que el cuidador no profesional pueda ausentarse por razones laborales o de descanso.

Debemos advertir que no hay que confundir esta prestación, cuyo beneficiario es la persona dependiente, con las ayudas económicas autonómicas para familias con personas mayores dependientes cuyos beneficiarios son las familias que atienden en su domicilio a personas mayores en situación de dependencia, como hace efectivamente la Comunidad Valenciana, aunque también otras comunidades como Cataluña, las Islas Baleares, Madrid, Murcia y La Rioja. Estas ayudas específicas pretenden apoyar a las familias cuidadoras para enfrentar los gastos derivados de la atención a la persona dependiente, facilitando su permanencia en la familia. En la Comunidad Valenciana se exige en concreto acreditar por parte del beneficiario una convivencia continuada y estable con la persona asistida, o manifestación de llevarla a cabo; y una acreditación de la capacidad para hacerse cargo de la persona dependiente y un compromiso de realizarlo. 


\subsection{Procedimiento}

El procedimiento para el reconocimiento de la situación de dependencia y del derecho a las prestaciones está regulado en el artículo 28 de dicha ley. Este artículo especifica que se iniciará a instancia de la persona afectada por algún grado de dependencia o de quien ostente su representación, y la tramitación se ajustará a las previsiones de la Ley 30/1992 (artículo 28.1 de dicha ley).

Previa tramitación de la solicitud, que en el caso de la Comunidad Valenciana se puede canalizar a través de las oficinas de las Agencias de Mediación para la Integración y la Convivencia Social (AMICS), o través de los Servicios Sociales municipales, o bien dirigirlas a la Conselleria de Bienestar Social por los medios previstos en la Ley 30/1992.

El reconocimiento de la situación de dependencia se efectúa mediante resolución de la Administración autonómica de la residencia del solicitante, teniendo validez en todo el territorio nacional (artículo 28.2 de dicha ley). Esta resolución determina los servicios o prestaciones correspondientes al solicitante, según el grado y nivel de dependencia (artículo 28.3 de dicha ley).

\subsection{Participación de las entidades locales y oficinas de la AMICS}

Es muy relevante para el caso que nos ocupa la participación de las entidades locales. Conforme al artículo 12 de dicha ley, las entidades locales participarán en la gestión de los servicios de atención a las personas en situación de dependencia, pudiendo participar en el Consejo Territorial del Sistema para la Autonomía y Atención a la Dependencia en la forma y condiciones que el propio Consejo disponga.

La participación de Enguera, como entidad local o municipal, se ha canalizado a través de la inclusión de los servicios sociales municipales en la oficina de la AMICS en el municipio. Esta oficina fue inaugurada por el secretario autonómico de Prestaciones Socio-Sanitarias, el 27 de julio de 2006. Se trata de una iniciativa de la Dirección General de Inmigración de la Generalitat Valenciana, que en origen pretendía facilitar el acceso de los servicios de información, orientación y mediación en materia educativa, sanitaria, laboral, cultural y social tanto para los ciudadanos valencianos como para la población inmigrante residente en la Comunidad Valenciana.

\section{La Ley de Dependencia sobre el municipio de Enguera \\ 6.1. Tramitaciones de la ayuda}

Tal como se ha explicado en los apartados anteriores, la tramitación de la ayuda se puede realizar a través de diversos trámites administrativos. Por esta 
difuminación en los datos, no podemos calcular a fecha de hoy cuántas ayudas se han solicitado en el municipio de Enguera, pero sí sabemos que se han tramitado alrededor de 150 solicitudes a través de la oficina AMICS. . La totalidad de las ayudas solicitadas, en materia de prestación económica, era para cuidadores no profesionales. Las otras dos opciones facilitadas por la ley (prestación vinculada al servicio y asitencia personal) no fueron solicitadas por ninguna de las personas que tramitó su solicitud en la AMICS ${ }^{4}$.

Por otro lado, en el trabajo de campo, se ha descubierto que la mayoría de personas que solicitan la ayuda se ha enterado de la existencia de las mismas a través de alguna persona conocida que disfrutaba de la prestación a cuidadores no profesionales, y eso les ha impulsado a solicitar la ayuda. Por los datos recogidos en las entrevistas, podemos pensar que no existen muchos casos que hayan tramitado la ayuda a través de otro tipo de canal, pues se van derivando unas a otras a la oficina. Y la primera vez que acuden es para enterarse de si la pueden pedir y qué tienen que hacer, sintiendo que AMICS ofrece un servicio personal y próximo:

«A mí me lo dijo una vecina que lo había solicitado, y me comentó que ahí abajo me lo explicarían (se refiere a la oficina de la AMCS)» (Entrevista n. ${ }^{\circ}$ 6)

\subsection{Personas para las que se solicitó la ayuda}

Si ya hemos visto que la totalidad de solicitudes registradas, tanto en el estudio cualitativo como en el cuantitativo (anotación de solicitudes en la oficina de la AMICS), reclamaban la prestación para cuidadores no profesionales, la mayoría de personas que se han considerado como dependientes, y por tanto se les ha otorgado la ayuda para que sean atendidos por un cuidador no profesional, según los parámetros de la ley, son ancianos de sexo masculino. El porcentaje de varones sobre el total de personas encontradas que solicitaban la ayuda es casi del $80 \%$ según la investigación llevada a cabo.

En esto encontramos la primera paradoja de nuestro trabajo de campo, y es que es para los varones para los que más se han solicitado las ayudas, a pesar de que la pirámide poblacional del municipio está feminizada en la cúspide de la edad, las mujeres tienen el doble de peso relativo que los varones, tal como observamos en la gráfica 2. Aunque debe hacerse una pequeña matización en cuanto a las condiciones de salud de las personas de la tercera edad para las que se solicita la ayuda, ya que cabe decir que existe igualdad en

4. Aunque no podemos saber qué es lo que se solicitaba por las otras vías administrativas, en el trabajo de campo etnográfico no hemos detectado tampoco ninguno de los otros dos casos. 
los porcentajes cuando se solicita para personas que sufren Alzeheimer ${ }^{5}$. Así pues, a pesar de que las mujeres superan a los varones, para ellas se requieren menos ayudas. Y la segunda paradoja de esta disparidad de porcentajes es que las mujeres tienen peor salud percibida que los varones, que siempre se autositúan con mejor salud que las mujeres (Bosch, 1998) ${ }^{6}$ Ante estos datos no podemos dar otra explicación que no sea la de la clara implicación los roles de género, esto se debe las mujeres han sido las encargadas del cuidado, y convertirse en objeto de cuidado les supone perder su autodefinición social (tal como lo demuestran los estudios sobre cuidados) ${ }^{7}$. Estas mujeres, tal como vemos, son fundamentales también en el mantenimiento del bienestar y del cuidado de las familias. Por ello, ha sido más fácil encontrar a mujeres que recibieran las ayudas en calidad de beneficiaras de la prestación, es decir, como cuidadoras que no como usuarias del servicio. Autoras como Durán sostienen que si las «abuelas» se pusieran en huelga se paralizaría el país ${ }^{8}$. La feminización del envejecimiento tiene consecuencias también consecuencias sobre el sistema de Bienestar. Tenemos un Estado de Bienestar que no cubre todas las necesidades de las personas que requieren asistencia, el modelo español, aunque no es familista puro se aproxima al modelo Alemán (Flaquer, 2004). En el municipio que nos ocupa sólo existe una residencia de atención a la tercera edad para un municipio en el que la población está claramente envejecida.

\subsection{Los «beneficiarios» de la ayuda en calidad de cuidadoras}

Ya hemos mencionado en el apartado anterior que la mayoría de personas para las que se solicita la ayuda son varones, pero, ¿qué ocurre con las personas que ejercen como ciudadoras?, ¿quiénes son? Del mismo modo que se ha definido para el estudio, los beneficiaros de la ayuda son aquellas personas que reciben el dinero de la prestación para realizar el cuidado, sobre las personas que las necesitan, y son personas que ejercen como cuidadoras no profesio-

5. Aunque la salud de las mujeres que cuidan de enfermos con Alzeheimer es peor que la salud de las mujeres que cuidan de otro tipo de enfermos (Badia, Lara y Roset, 2004), como veremos en las entrevistas de las mujeres que atienden a las personas que padecen este mal.

6. Se pueden consultar las estadísticas de salud subjetiva en la página del INE <http:// www.ine.es>.

7. Véanse Antonín (2003), Pérez (2007) y Siles y Solano (2007).

8. Se puede consultar la entrevista a Durán en la edición digital de El País (03.07.2006) en la que sostiene que una huelga de abuela sería peor que una de autobuseros, en el País Digital, ella sostiene que una huelga de abuela sería peor que una de autobuseros. 
nales, y sobre las que hemos dicho que sufren en su propia salud la carga del cuidado sin haber recibido la formación?

En el caso de Enguera, las personas beneficiarias son en su totalidad mujeres familiares por vía directa del usuario para el que se requiere cuidado, esto es esposas, hijas, nietas o hermanas de las personas dependientes. Esta selección de la cuidadora se toma de una forma racional por parte de las personas de la familia, o al menos así lo hemos detectado entre nuestras informantes:

«Cuando fuimos a solicitar la ayuda, entre todas nos encargábamos de mi padre, pero teníamos que ver a quién poníamos para cuidadora, todas no podíamos ser» (Entrevista n. ${ }^{\circ}$ 9)

Dentro de las mujeres que ejercen como cuidadoras, el grupo mayoritario de receptoras del dinero son las hijas de las personas para las que se solicita la prestación, y tienen como media alrededor de unos 50 años. En segunda posición encontramos a las hermanas de la personas, o bien a la mujer, que conserva mejor salud que su marido. Aunque también hay alguna nieta que, al no encontrar trabajo, se dedica al cuidado del abuelo hasta que le "salga algo mejor», y hermanas del usuario. En el estudio de caso no hemos encontrado ninguna beneficiaria que sea familia política de la persona que requiere la ayuda.

Sin embargo, no todas las situaciones sociales de las mujeres que se «prestan» como cuidadoras es la misma. Destacan tres grandes grupos: 1) mujeres que perdieron su trabajo remunerado, que se consideran demasiado mayores para buscar un nuevo empleo en un contexto social reducido, y que ven en la ayuda la posibilidad de un ingreso extra. Pueden acceder a trabajos esporádicos o por horas, de limpieza o del sector servicios, así como economía sumergida; 2) mujeres que se dedican a jornada completa al mantenimiento del hogar, dedicadas al cuidado. A ellas les darán el dinero por una atención que ya realizaban previamente a la Ley de la Dependencia y 3) mujeres que trabajaban en la economía sumergida y que conseguían más dinero de la prestación que del propio trabajo, por lo que han abandonado el trabajo fuera del hogar para dedicarse de nuevo al cuidado.

En cuanto a las particularidades de cada grupo, las del primer grupo son aquellas que perdieron su trabajo y vieron una oportunidad en la ayuda de dicha ley. Estas mujeres ya estaban al cuidado de sus mayores -eran de las que tienen doble jornada-, tratándose en este caso de las hijas de las personas con necesidad de asistencia en casa (Torns y Carrasquer, 2002).

9. Ver las referencias citadas. 
El segundo grupo de mujeres se encargaba de la realización de las tareas del cuidado sin recibir la prestación, y ahora recibe un «salario» por el trabajo que ya había realizado, que ahora media un papel en el que se le categoriza como cuidadora no profesional:

«Pues mira, de todas formas lo cuidábamos. Si un día yo no podía se encargaba mi madre, pero él solo no puede estar, porque ya se nos ha escapado dos veces. No te puedes descuidar. Ahora tenemos una ayuda que siempre viene bien, porque son muchos gastos» (Entrevista n. $\left.{ }^{\circ} 1\right)$.

En el tercer grupo encontramos aquellas mujeres que trabajaban en la economía sumergida, es decir, que tenían trabajos por horas o recibían su salario al margen de la Seguridad Social. Entre los trabajos que realizaban destaca el de coser en casa o el de limpiar escaleras o el de hacer alguna hora en otras casas. Estas mujeres ahora reciben la ayuda como un sobresueldo y no constan como pluriempleadas, pues su otro trabajo está en la economía formal:

«Mientras coso, pues cuido de mi padre, estamos los dos en casa, y además nos hacemos compañía. Hay veces que hay más trabajo, y otras menos, por lo menos ahora tenemos una ayuda todos los meses» (Entrevista n. $\left.{ }^{\circ} 11\right)$.

\subsection{El proceso para conseguir la ayuda}

Después de ver la ayuda solicitada, y a cargo de quién corre el cuidado, ahora tenemos que ver si las ayudas llegan a tiempo, y cómo es el proceso por el cual las personas se convierten en beneficiarias de las mismas. Según los testimonios de nuestro estudio de caso en Enguera, en la mayoría de las solicitudes, se tardó mucho tiempo en recibir la ayuda, y en ocasiones ésta nunca llegó por fallecimiento de la persona a cuidar ${ }^{10}$.

«Cuando vinieron a hacer la entrevista mi padre ya había muerto, fíjate lo que tardaron.» (Entrevista n. ${ }^{\circ}$ 3)

«Mientras no me salga nada mejor me voy a poner aquí, en cuanto tenga un trabajo mejor lo dejaré, ya que no sé si podemos tener las dos cosas, no lo sé.» (Entrevista n. $\left.{ }^{\circ} 1\right)$

«Yo, de vez en cuando, hago una limpieza de cara o lo que me sale, y a la vez me dedico a cuidar, aunque eso es lo más pesado, pero como lo tengo que hacer igual, ¡qué más da!» (Entrevista n. ${ }^{\circ}$ 5).

\subsection{Evaluación de los servicios de la Ley de Dependencia}

Existe la opinión generalizada en el municipio de Enguera, no sólo por parte de las beneficiarias, sino también de los Servicios Sociales, que hay poca

10. El fallecimiento de la persona se ha producido en los tres casos de solicitantes. 
información sobre las prestaciones de esta ley. Por un lado, las beneficiarias se quejan de los tiempos de espera hasta que se recibe la ayuda, además de la falta de interés por parte de las autoridades una vez concedida la prestación. Las esperas son de un año de duración como mínimo, y a veces las personas para las que se solicita han fallecido cuando llega la entrevista:

«Tardamos un año y pico en recibir la ayuda, y ahora llevamos cuatro meses cobrando, no te creas que mucho tiempo» (Entrevista n. ${ }^{\circ} 4$ ).

En el lado de la atención social, la encargada de la oficina de la AMICS manifiesta que la falta de centralización del servicio hace que desde su institución no sean capaces de controlar quién tiene la ayuda, y no sabe si se están duplicando servicios de asistencia. es decir, si se reciben a la vez ayudas del ayuntamiento y del Ministerio. En la oficina se consiguen datos de solicitudes pero no de resoluciones, por ello no es posible el seguimiento de los casos por parte de la asistencia social de municipio, pues dependen de observadores del Ministerio.

El último punto a considerar es que esta ley preveía que se dieran cursos de formación para los cuidadores no profesionales, que en su momento se consideraba que sería una vía de formación para las personas que cuidasen de forma informal, y que podrían sacar de esto una profesión. Sin embargo, nada más lejos de la realidad, yaque durante todo el tiempo que llevan ejerciendo de cuidadoras, nuestras mujeres no han recibido ningún tipo de ayuda, ni curso para mejorar la atención. Ellas veían con muy buenos ojos esta medida, porque así entendían que sabrían cómo enfrentarse a los problemas derivados de determinadas enfermedades como, por elemplo, el Alzheimer:

«A mí me dijeron que nos darían un curso, que haríamos algo (...) es que yo no sé que hacer con mi padre, porque se escapa, y mira que lo cerramos todo. De comer no se acuerda, pero de abrir la puerta sí. Es un misterio» (Entrevista . $^{\circ}$ 1).

Por último, el seguimiento. Según las mujeres entrevistadas, no se sabe nada de las personas encargadas de la gestión de la ayuda hasta que no toca ver si el paciente ha mejorado, o, en el peor de los casos, si ha fallecido:

«Pues, mira, no supimos nada de ellas hasta que tocó ver si nos quitaban el dinero. Aunque estamos más tranquilas sin que nos molesten» (Entrevista n. $\left.{ }^{\circ} 1\right)$.

\subsection{El impacto de la Ley de Dependencia en las relaciones de género}

Hemos comprobado que las mujeres son al final las que se están encargando del cuidado, y que el hecho de que se introduzca dinero en las tareas del 
cuidado, no hace que se modifiquen los roles de género y que otras personas del entorno familiar estén dispuestas a ejercer tareas del cuidado. Hemos comprobado también que se cumple lo citado en los textos referenciados, y es que las mujeres son provisoras de bienestar y soportan dobles jornadas. A la postre, las ayudas las reciben mujeres que ya realizaban los cuidados de la persona dependiente.

Por otro lado, ninguna de las entrevistadas ha dejado su trabajo para cuidar a nadie. Y la razón es que la ayuda no les permite dejar el trabajo remunerado, aunque sea en el sector informal, pues no es sustitutivo de ningún sueldo. Este hecho no hace más que reforzar la doble jornada de las mujeres de las que hablan autoras como Durán, o Carrasco (2004), que incluso afirma que el sistema es mantenido por las mujeres. Lo cierto es que los hombres no se han acogido a las ayudas, y el cuidado en el caso de Enguera parece seguir siendo un "asunto de mujeres», y consideramos que esto mismo es lo que propicia que las mujeres solicitemos en menor medida las ayudas para que nos cuiden, porque nosotras hemos sido educadas para ser sujetos activos del cuidado, y no pasivos.

Para finalizar, estas mujeres residentes en Enguera, siguen cuidando de sus mayores o enfermos, pero ahora lo hacen con una pequeña retribución. Para valorar esto debemos pensar en qué es lo que consideramos mejor: profesionalizar o igualar a hombres y mujeres en las tareas del cuidado. Lo cierto es que la ley no ha conseguido ninguna de las dos opciones, al menos en nuestro objeto de estudio.

\section{Conclusiones}

La Ley de Dependencia es sin duda una ley celebrada, sin embargo, a la luz de las entrevistas y del caso de estudio, aunque es cierto que las personas que cuidan muchas veces se harían responsables del «bienestar» de los usuarios, éstas suelen hacer referencia en las entrevistas a que la falta de experiencia formal en el cuidado de personas dependientes les hace más difícil sobrellevar la situación, y se quejan de que no reciben cursos ni formación para poder sobrellevar el cuidado.

Respecto al análisis jurídico realizado de la ley, cabe decir que su complejidad exigiría una atención mucho más extensa, y teniendo en consideración de forma comparativa la normativa autonómica existente. El hecho de que estemos ante un sistema dependiente en un alto grado de las disposiciones autonómicas hace que si nos quedamos con la ley no lleguemos a tener una buena perspectiva de la realidad normativa de la dependencia. 
También parece necesaria una mayor potenciación de la formación de los cuidadores familiares, y en este sentido parece ir el último acuerdo del Consejo Territorial de Dependencia. Además de la implementación de talleres que promuevan que los hombres se impliquen más en este tipo de tareas y sean también beneficiarios de la ayuda.

En resumen, las mujeres siguen siendo sujetos activos del cuidado y no receptoras del mismo. Situación que parece estar más clara en el medio rural que en el urbano. Así pues, desde nuestra propuesta consideramos que es necesario tener en cuenta las diferentes necesidades, las estructuras sociales y demográficas que caracterizan por un lado el espacio rural, y que no son las mismas en el espacio urbano.

\section{Bibliografía}

Antonín, M, J. TOMÁs-SÁBAdo y P. Flor, «Mujer y cuidados: ¿historia de una relación natural?», en Cultura de los cuidados: Revista de enfermería y humanidades, n. ${ }^{\circ}$ 13, 2003, pp. 36-39.

Badia, X, N. LARA y M. Roset, "Calidad de vida, tiempo de dedicación y carga percibida por el cuidador principal informal del enfermo de Alzheimer», en Atención primaria: Publicación oficial de la Sociedad Española de Familia y Comunitaria, vol. 34, n. ${ }^{\circ}$ 4, 2004, pp. 170-177.

BOSCH, E, M. GILI y V. FERRERA, «Aspectos diferenciales en salud entre las mujeres que trabajan fuera del hogar y las amas de casa», en Psicothema, vol. 10, n. ${ }^{\circ}$ 1, 1998, pp. 53-63.

CARrasco. C., «La sostenibilidad de la vida humana: ¿un asunto de mujeres?», en «Mientras Tanto», n. ${ }^{\circ}$ 82, otoño-invierno 2001.

CONDE, J. I., C. OCAÑA y G. PÉREZ, «Análisis cuantitativo del estado de bienestar en Europa: Modelos y resultados», en Documentos de trabajo (FEDEA), n. ${ }^{\circ}$, 2007, págs. 1-36.

EstebAn, A. I., «Un derecho con rostro de mujer: la Ley de dependencia y su impacto en el medio rural», en Actualidad Leader: Revista de desarrollo rural, n. ${ }^{\circ}$ 35, 2007, pp. 30-31.

FlaQUeR, L., «La articulación entre familia y Estado de Bienestar en los países de la Europa del Sur», en Papers de Sociologia, n. ${ }^{\circ}$ 73, 2004, pp. 27-58.

LÓPEZ CUMBRE, L., «Fisuras de una ley histórica en materia de protección social: el proyecto de ley de dependencia», en RGDTSS, n. ${ }^{\circ} 11$, mayo 2006.

Noguera, J. y J. ESPARCIA, «Las políticas de desarrollo rural en la Comunidad Valenciana», en Cuadernos de geografía, n. ${ }^{\circ}$ 58, 1995, pp. 307-336.

PÉREZ, A. et al. (coords.), Vejez, autonomía o dependencia, pero con calidad de vida Madrid, Dikinson, 2007. 
ROQUETA BRUJ, R., La protección de la dependencia, Valencia, Tirant lo Blanch, 2007.

SANTAMARÍA, R. S., «La escuela rural: organización de los centros rurales agrupados», en Revista de ciencias de la educación: Organo del Instituto Calasanz de Ciencias de la Educación, n. ${ }^{\circ}$ 208, 2006, pp. 499-518.

Siles GonzÁlez, J y M. ${ }^{a}$ CARMEn SOlano RuIz, «Estructuras sociales, división sexual del trabajo y enfoques metodológicos: La estructura familiar y la función socio-sanitaria de la mujer», en Investigación y educación en enfermería, vol. 25, n. $^{\circ} 1,2007$, pp. 66-73.

TORnS, M. T. y P. CARRASQUER, «La doble presència femenina i les necessitats de conciliació», en Diàlegs: revista d'estudis polítics i socials, vol. 5, n. ${ }^{\circ}$ 15, 2002, pp. 23-32. 


\title{
CONFIGURACIONES DEL TRABAJO DE CUIDADOS EN EL ENTORNO FAMILIAR. DE LA TOMA DE DECISIÓN A LA GESTIÓN DEL CUIDADO
}

\section{Care arrangements within the family environment. From decision making to managing care}

ANTÍA PÉREZ CARAMÉS*

\begin{abstract}
Resumen
En este artículo trataremos la cuestión de la organización del trabajo de cuidados a mayores dependientes, analizando tanto las variables que influyen en las diferentes configuraciones de cuidados resultantes y su interrelación, como el carácter diacrónico de la toma de decisión y la articulación del trabajo de cuidado, centrando el estudio en el caso de Galicia. El objetivo es estudiar la variabilidad de articulaciones de cuidado registradas en la realidad gallega, proponiendo una tipología y arrojando pautas de explicación de los factores que entran en juego. Se aplicará una perspectiva de género en el análisis del discurso emitido por distintos miembros de las familias a la hora de tomar decisiones y organizar el trabajo de cuidados a sus familiares faltos de autonomía, entendiéndose las configuraciones de cuidados derivadas de estos procesos como articulaciones estratégicas, dinámicas y flexibles, atravesadas por relaciones de poder y lógicas de género que operan en las familias. La metodología empleada en este estudio forma parte del material recolectado por la autora para su tesis doctoral y consiste en el análisis de datos secundarios de carácter sociodemográfico y sobre políticas de atención a la dependencia, así como en entrevistas en profundidad semiestructuradas.
\end{abstract}

Palabras clave: configuraciones de cuidado, mayores dependientes, envejecimiento, género, estrategias familiares.

\footnotetext{
* Antía Pérez Caramés

Universidad de A Coruña

Facultad de Sociología

Campus de Elviña, s/n. A 15071 La Coruña

Teléfono: 981167000 (extensión: 4851) Fax: 981167103

antia.perez@udc.es
} 


\begin{abstract}
This paper considers the issue of how care for elderly people is organised, analysing the variables that influence the various ways in which care is configured and how they interrelate, as well as the diachronic nature of decision making and how care work is co-ordinated in Galicia. The aim is to study how variable the co-ordination of care is in Galicia, and to describe and explain the factors involved. A gender perspective is applied in the analysis of the discourse by various family members when making decisions and organising care for relatives lacking in autonomy, in which the configurations of care resulting from these processes are seen as strategic, dynamic and flexible forms of co-ordination combined with the power relationships and gender differences that operate in families. The methodology used in this study forms part of the material gathered by the author for her doctoral thesis and consists of an analysis of secondary socio-demographic data and dependent care policies, as well as in-depth semi-structured interviews.
\end{abstract}

Keywords: organisation of care, care-dependent elderly persons, ageing, gender, family strategies.

\title{
1. Introducción y contextualización: la «crisis de cuidados» y el pertinaz familismo en los Estados de Bienestar del sur de Europa
}

La reciente intensificación sobre el debate en relación a las políticas de atención a la dependencia en España viene enmarcada en un contexto que ha sido bautizado como la «crisis de los cuidados» (Pérez de Orozco, 2006), expresión que resume la convergencia de varios procesos sociales y demográficos que desembocan en una menor disponibilidad de cuidadores informales para hacer frente a una creciente demanda de asistencia. Por una parte, y dentro del espectro demográfico, el creciente aumento de la población mayor de 65 años, así como de su proporción sobre el conjunto de la población, han colocado a España en la órbita de los países más envejecidos de Europa. Por otra parte, el cambio en las expectativas personales y profesionales de las mujeres ha conllevado a una progresivamente mayor incorporación de éstas al trabajo formal y una menor disponibilidad para las ocupaciones vinculadas con las necesidades de reproducción social, fenómeno relacionado también con una transición tranquila en la tipología predominante de estructuras familiares en España (Jurado, 2005) que ha debilitado las redes sociales con las que contaban los mayores.

A continuación, analizaremos, a continuación, cuáles han sido la intensidad y magnitud de estos procesos en los últimos quince años a la luz de diversa información estadística. 
Gráfico 1. Evolución del peso de la tercera edad y de la esperanza de vida al nacer para hombres y mujeres en el periodo 1991-2005

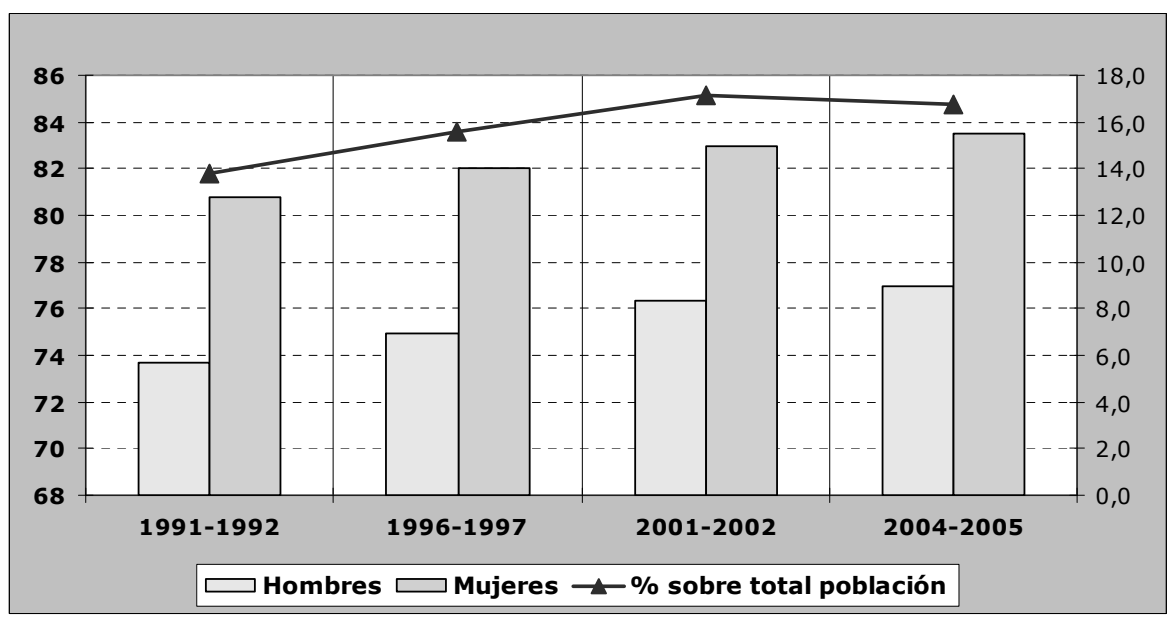

Fuente: Padrón Municipal de Habitantes, años 1996, 2001 y 2006. Censo de Población y Viviendas, año 2001. Tablas de Mortalidad, años 1991-1992, 1996-1997, 2001-2002 y 2004-2005. Instituto Nacional de Estadística (INE), <http://www.ine.es>.

Nota: la esperanza de vida se expresa en años en el eje de la izquierda y el peso de la tercera edad en años en el eje de la derecha.

En el Gráfico 1 se observa de manera comparada la evolución del indicador relativo al peso de la tercera edad ${ }^{1}$ en España, así como de la esperanza de vida al nacer de hombres y mujeres durante el periodo que media entre 1991-2006. En una franja temporal de sólo quince años, el peso de los mayores sobre el conjunto de la población española ha aumentado en tres puntos porcentuales, pasando de más de cinco millones de personas con más de 65 años a prácticamente siete millones y medio ${ }^{2}$. Paralelamente, la esperanza de vida al nacer, tanto de hombres como de mujeres, ha aumentado, en ambos casos, en casi tres años.

1. Este indicador ha sido calculado dividiendo la población total de 65 años o más entre el total de la población de España a una fecha dada y expresando el resultado en términos porcentuales.

2. Según los datos del Censo de Población y Viviendas del INE para 1991, el número de personas de edad igual o superior a los 65 años de edad era de 5370252 , mientras que los datos del Padrón Municipal de Habitantes (INE) a principios de enero de 2006 arrojan una cifra de 7484392 personas de 65 años o más. 
Gráfico 2. Tasas de actividad de las mujeres españolas por grupos de edad entre 1999-2005

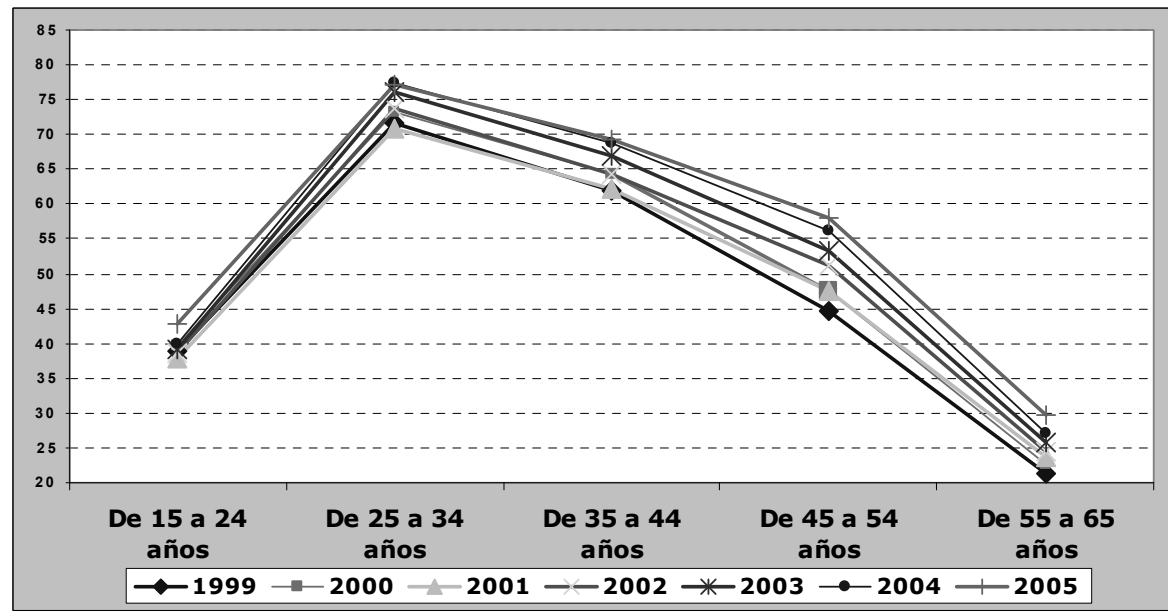

Fuente: Encuesta de Fuerza de Trabajo de la UE (EU Labour Force Survey) 1999-2005. Instituto Nacional de Estadística (INE).

En segundo lugar, nos concentraremos en el análisis de la evolución de las tasas de actividad de las mujeres en España en función de su edad (ordenada en grandes grupos) en un periodo de tiempo reciente, entre 1999-2006. A la luz del Gráfico 2 podemos comprobar cómo las tasas de participación en el mercado laboral de las mujeres en nuestro país han crecido en todos los grupos de edad considerados, pudiendo constatarse, además, que el mayor crecimiento en términos porcentuales lo experimentan las mujeres situadas entre los 45 y los 54 años de edad, que registran una participación en el mercado laboral del 58,1 \% en el 2005, frente al 44,6 \% de 1999; esto es, un aumento de más de trece puntos porcentuales. En suma, vemos, pues, que las nuevas generaciones de mujeres están aumentando notablemente la participación laboral de sus predecesoras a todas las edades, especialmente en aquellas de mayor edad. La disponibilidad de cuidadoras informales familiares es, en consecuencia, claramente decreciente, por lo que es urgente la necesidad de optar por modelos políticos de atención a la dependencia que resulten eficientes para evitar y/o aminorar las consecuencias que el desempeño del cuidado tiene para el trabajo de las mujeres (Sarasa, 2008), y que no contemplen la díada trabajo-cuidados como una relación de suma cero (Bussemaker, 1998).

Si bien es cierto que el fenómeno de la «crisis de los cuidados» ha desatado las alarmas en buena parte de los países industrializados, no deja de 
ser menos evidente que el contexto de bienestar en que se registren estos fenómenos influirá en buena medida en la capacidad de unos y otros estados para hacer frente a esta crisis. Para proporcionar el marco general, así como las principales características del Estado de Bienestar español en relación con la protección de los mayores dependientes, realizaremos un repaso teórico a las principales contribuciones a este respecto.

La publicación de la obra de Esping-Andersen en la que se hace un recorrido por los diferentes sistemas de bienestar, relacionándolos con los niveles de desigualdad social, para concluir con la proposición de una tipología de Estados de Bienestar (Esping-Andersen, 1993), ha desencadenado ríos de tinta en dos vertientes diferenciadas pero concluyentes en su trayectoria. Por una parte, los estudiosos del Estado de Bienestar de los países del sur de Europa centraron su crítica en la existencia de un conglomerado de países, agrupado bajo el calificativo de "conservadores», que no respondían a las mismas características en sus esquemas de protección social. Si bien compartían el hecho de ser sistemas que basaban los derechos de ciudadanía en el elemento contributivo, países como España, Italia, Portugal y Grecia poseían como rasgo diferenciador respecto de Estados como Francia o Alemania el papel preeminente otorgado a la familia en el desempeño de la protección social (Sarasa y Moreno, 1995; Rhodes, 1997; Moreno, 2006). Este carácter familista de los Estados de Bienestar del sur de Europa se correlacionaba, además, con otros indicadores como la baja participación femenina en el trabajo remunerado -con la única excepción de Portugal-, así como con unas tasas de fecundidad extremadamente reducidas (Flaquer, 2004). A juicio de estos investigadores, la tipología de Esping-Andersen debía ser remozada e incluir una nueva categoría, la de los Estados de Bienestar mediterráneos o los Estados de Bienestar del sur de Europa, para dar cuenta de la heterogeneidad existente dentro del grupo de los Estados de Bienestar conservadores.

Por otra parte, un buen aluvión de críticas llovieron al esquema propuesto por Esping-Andersen por parte de las investigadoras en materia de género y políticas públicas (Lewis, 1998). Nancy Fraser critica el concepto de desfamiliarización empleado por Esping-Andersen, al aducir que no necesariamente se deben concebir las políticas relacionadas con el cuidado y la conciliación de la vida laboral y familiar con las posibilidades de remercantilización de las mujeres, ya que se puede también incitar a los hombres a realizar el «trabajo invisible de las mujeres» (Fraser, 1996). Por otra parte, Diane Sainsbury indica que la variable género atraviesa y fragmenta los diferentes regímenes del Estado de Bienestar, siendo necesario evaluar la relación dinámica existente entre las lógicas políticas de los regímenes de género y los regímenes del 
Estado de Bienestar. Las políticas y la distribución del trabajo de cuidado a familiares dependientes se convierten, dentro de esta perspectiva, en un elemento fundamental para evaluar la estructura de las desigualdades de género en los diferentes regímenes de bienestar (Sainsbury, 1999).

Así, se ha señalado que los regímenes de bienestar mediterráneos comportan el máximo de desigualdad de género, al considerar primordialmente a las mujeres, en función de sus roles familiares, como reproductoras y cuidadoras y desprotegerlas del mercado en caso de necesidad económica al no promover la reconciliación entre los roles familiares y los laborales ${ }^{3}$ (Trifiletti, 1999).

El familismo, en tanto que instrumento conceptual para caracterizar a los Estados de Bienestar de la Europa Meridional, se vuelve un arma de doble filo al invisibilizar la estructura completamente desigualitaria de las relaciones de género en los regímenes de bienestar del sur de Europa, ya que afirmar que es la familia sobre quien recae el peso de la protección social supone hacer tabla rasa de la profunda inequidad existente en la distribución de los roles familiares entre hombres y mujeres en estos países (Leitner, 2003). S. Leitner, tras realizar un análisis de las políticas de apoyo a las familias en las funciones de cuidado, llega a la conclusión de que las políticas de los regímenes de bienestar de la Europa del sur -a las que atribuye un familismo explícito generizado- se caracterizan, no sólo por mantener a la familia dentro de su función cuidadora, sino que además refuerzan el rol cuidador de las mujeres, perpetuando, de este modo, la división generizada del cuidado familiar.

En su clasificación de regímenes de cuidado, las autoras F. Bettio y J. Plantenga, partiendo de indicadores tales como el tiempo que se espera sea dedicado al cuidado (de niños y/o mayores dependientes), la provisión de servicios disponibles para el cuidado y la inactividad laboral vinculada al desempeño de trabajos de cuidado, concluyen con la afirmación de que países como España delegan toda la gestión del cuidado a la familia (Bettio y Plantenga, 2004).

Otras autoras han vinculado la caracterización de los regímenes de bienestar con la expansión de la atención informal familiar y el trabajo informal de las inmigrantes en los sectores del servicio doméstico a hogares y de cuidado de niños y mayores dependientes (Woods, 2007; Kofman, 2006). Así, Eleanore Kofman, empleando el concepto de cuidado social (social care) que postulan las investigadoras Mary Daly y Jane Lewis (Daly y Lewis, 2000), caracteriza a los regímenes migratorios y de bienestar de la Europa del sur como aquellos que proveen escasos servicios de cuidado (tanto para niños como para mayores), que cuentan con una reducida tasa de participación laboral de

3. Como sí promueven, en cambio, los modelos de bienestar basados en el hombre ganapán. 
las mujeres nativas y que emplean abundante mano de obra inmigrante en el servicio doméstico a hogares y no, en cambio, en los servicios sociales.

España se encuentra, pues, en la peor de las situaciones posibles para enfrentarse a la "crisis de los cuidados». Y es que si la recientemente aprobada Ley de Promoción de la Autonomía Personal y Atención a las personas en situación de dependencia ha recibido el calificativo de «cuarto pilar» del Estado de Bienestar en España, desde luego las familias y, más concretamente, las mujeres en el seno de las familias, deberían consecuente y justamente ser apodadas como el «cimiento» del bienestar español.

\section{El apoyo formal e informal a los mayores en situación de dependencia en España: una interacción contraproductiva para las mujeres}

Según diversos trabajos del investigador Gregorio Rodríguez Cabrero, podríamos estimar que en España contamos con una población mayor en situación de dependencia de entre 1583234 y 1444750 personas (Rodríguez Cabrero, $2005 a, b$ y 2007$)^{4}$. Si tomamos los datos relativos al conjunto de la población española a comienzos del 2005 que nos proporciona el Padrón Municipal de Habitantes ${ }^{5}$, nos encontramos con que los mayores dependientes representan entre un 3,6 \% y un 3,3\% del total de la población.

Por otra parte, el investigador Rodríguez Cabrero apunta, además, que el modelo de protección social a la dependencia existente en España se define como un modelo dual, con un componente mayoritariamente informal, basado en la centralidad del trabajo no remunerado de las mujeres y su consecuente disponibilidad para prestar cuidados informales y subsidiariamente asistencial (Rodríguez Cabrero, 2005a). Este modelo aparece, por ende, refrendado por la Ley 9/1998, de 15 de julio, que hace a las familias responsables del cuidado de sus mayores ${ }^{6}$, responsabilidad familiar fijada por ley que España comparte con otros países de la órbita del bienestar mediterráneo (Naldini, 2002).

4. De entre las distintas estimaciones que el profesor Rodríguez Cabrero recoge en sus obras, hemos escogido aquella basada en la Encuesta sobre Discapacidades, Deficiencias y Estado de Salud (EDDES) -realizada en el 2005 por el Instituto Nacional de Estadística- por ser una cifra reciente (año 2005) y por estar estimada empleando los indicadores relativos a las Actividades Básicas de la Vida Diaria (ABVD) y a las Actividades Instrumentales de la Vida Diaria (AIVD), frecuentemente utilizados en Gerontología para la evaluación de la dependencia funcional de los individuos.

5. Hemos utilizado la población a esta fecha, ya que el número estimado de mayores dependientes es para el 2005. La población de España a 01-01-2005 era de 44108560 personas según el Padrón Municipal de Habitantes (INE).

6. Se trata de la Ley 9/1998, de 15 de julio, del Código de Familia. 
Tabla 1. Comparativa de los índices de cobertura de distintos servicios de atención a la dependencia en 1999 y 2008

\begin{tabular}{|c|c|c|c|c|}
\hline AÑO & SAD & Teleasistencia & $\begin{array}{c}\text { Centros de } \\
\text { día }\end{array}$ & $\begin{array}{c}\text { Residencias (plazas } \\
\text { públicas privadas y } \\
\text { concertadas }\end{array}$ \\
\hline 1999 & 1,67 & 0,72 & 0,11 & 2,95 \\
\hline 2008 & 4,69 & 4,72 & 0,83 & 4,44 \\
\hline
\end{tabular}

Fuente: Informe 2006 y 2008 sobre las Personas Mayores en España.

IMSERSO, <http://www.seg.social.es/imserso/>.

Así, si analizamos los índices de cobertura de los diferentes servicios sociales destinados a las personas mayores con algún grado de dependencia, nos encontramos con que, pese a la progresión experimentada desde 1999, la capacidad de asumir públicamente la gestión del cuidado a los mayores dependientes resulta todavía claramente deficiente.

De entre aquellos servicios con mayor cobertura, destacan precisamente los residenciales, herencia del tardofranquismo en que la pauta predominante en la atención a los mayores faltos de autonomía se basaba en el principio de la institucionalización. Sin embargo, desde comienzos de los años ochenta, el paradigma de la desinstitucionalización y la defensa del cuidado comunitario entra con fuerza en los discursos de la política social española (Bazo, 1998). El primer Plan Gerontológico Nacional, aprobado en 1992, hace suyo el lema de «envejecer en casa» y busca promover toda una serie de iniciativas conducentes a promover la permanencia del mayor en su entorno el máximo tiempo posible. Se argumenta que esta fórmula es menos costosa humana y económicamente, pero esto es únicamente desde la perspectiva del mayor dependiente, y no de su cuidadora informal en el seno de la familia (Escuredo, 2007). Esta política de mantenimiento en el domicilio del mayor no ha ido aparejada, sin embargo, de un aumento sustancial del gasto social en los años siguientes a la aprobación de este plan, por lo que las mujeres han tenido que hacer frente a una sobrecarga de trabajo en un contexto, tal y como hemos indicado, de aumento de la participación laboral femenina, escasez de oferta de empleo a tiempo parcial y cicatería de recursos sociales para el cuidado de los familiares en situación de dependencia (Guillén, 1997).

Por otra parte, los cuidadores informales han sido considerados como recursos (según la tipología de cuidadores informales formulada por Twigg, 1990) al servicio del Estado para garantizar la atención a los mayores dependientes, ya que las medidas de ayuda al cuidador (tales como el denominado 
«respiro familiar» a través de estancias temporales en residencias y centros de día) y los permisos laborales por razones de atención a un familiar dependiente desarrollados a través de la Ley de Conciliación de la Vida Laboral y Familiar ${ }^{7}$ son claramente insuficientes (Escuredo, 2007) y, en ocasiones, desincentivan la participación laboral de las mujeres (Pérez de Orozco y Baeza Gómez, 2006).

\section{Objetivos y metodología}

En primer lugar y, de modo general, el presente trabajo se propone identificar, describir y analizar, a partir de contextos concretos de investigación, el proceso de construcción social a través del que emerge la figura de la cuidadora informal en el seno de las familias, y cómo ésta se configura en "gestora del cuidado» de su pariente dependiente. En este proceso de emergencia de la cuidadora informal familiar, se hará especial hincapié en el análisis de los procesos de toma de decisión realizados en el seno de las familias ante la entrada en situación de dependencia de uno de sus miembros, o el agravamiento de esta situación. Por lo tanto, el segundo de los objetivos definidos en este estudio es determinar la influencia de la socialización diferencial por género de los miembros de la familia, y cómo esta asunción de roles diferenciados genera lógicas de género que moldean las actitudes, opiniones y estrategias de los distintos miembros frente a la necesidad de asistencia a un familiar dependiente, creando, de este modo, una normatividad refrendada en el entorno social y familiar más próximo y apoyada en la socialización diferencial por género. Partimos de la premisa de que los juicios sobre «lo que es correcto hacer» son variados y complejos y muchas personas no responden al mismo patrón de obligaciones filiales (Finch y Mason, 1993). Las investigaciones de Simon Duncan y Rosalind Edwards, así como la obra de Janet Finch, han resaltado el papel de las normas sociales y las lógicas de género a la hora de moldear las actitudes de los actores sociales en la toma de decisiones relativas al cuidado, como un patrón normativo incorporado socialmente que se utiliza para dar sentido a los comportamientos (Duncan y Edwards, 1999; Finch, 1987).

Por último, se evalúa el papel de distintos factores estructurales en las estrategias y lógicas de género derivadas de los procesos decisionales ante las necesidades asistenciales de un miembro de la familia. Entre estas variables, hemos considerado, por su importancia contrastada en otros estudios sobre los determinantes del cuidado informal en el seno de las familias, el tipo y

7. Hablamos de la Ley 39/1999, de 5 de noviembre, de Conciliación de la Vida Laboral y Familiar. 
tamaño del hogar en el que reside el mayor dependiente, la posición relativa de las mujeres en el mercado de trabajo en el contexto más amplio del hogar, la relación de parentesco del cuidador con la persona asistida, así como las posibilidades económicas del hogar de cara a evaluar las posibilidades de externalización del trabajo de cuidado. Así, los estudios de Claudine AttiasDonfut han puesto de relieve las diferencias en cuanto a la percepción de las obligaciones sociales en función de la clase social de pertenencia (AttiasDonfut, 1995). Sobre la influencia de los hijos en los procesos de toma de decisión relativa a los cuidados, afirmando que estas decisiones no pertenecen ni se gestan en exclusiva por parte de las personas mayores carentes de autonomía, resultan de especial interés para nuestro trabajo las aportaciones de Clara Pratt y sus colegas, así como las de T. Brubaker (Pratty y otros, 1989; Brubaker, 1987; Pratt, Jones y Pennington, 1993). En torno al factor de corresidencia en relación a las decisiones relativas a la provisión de cuidados, Liliana Pezzin, R. A. Pollak y B. Schone han mostrado la reducción de la capacidad de negociación en caso de corresidencia de los hijos con los mayores dependientes (Pezzin, Pollak y Schone, 2005).

En cuanto a la metodología, su carácter es cualitativo. El trabajo de campo ha consistido en la realización de 20 entrevistas en profundidad a mujeres responsables del cuidado de un familiar en situación de dependencia, así como a otros miembros del entorno familiar del mayor dependiente -principalmente hijos varones de la persona necesitada de cuidados. En lo referido a la observación participante, ésta se ha realizado en el seno de dos familias que contaban con una persona mayor que no podía valerse por sí misma.

\section{La toma de decisión ante situaciones de dependencia: roles, estrategias y lógicas de género}

Dado que uno de los objetivos principales ha sido analizar cómo se gestan los procesos de decisión relativa a la provisión de cuidados que necesita un familiar dependiente, la primera de las constataciones derivadas del análisis del trabajo de campo realizado es que parece desprenderse a primera vista la inexistencia de un proceso o momento en el que se toma el acuerdo acerca de quién y cómo provee el cuidado al familiar necesitado, pareciera tratarse de un mecanismo de toma de decisión que no implica la reunión voluntaria de la familia (Engers y Stern, 1998; Stern, 1995; Hiedemann y Stern, 1999). Muchas de las entrevistadas llegaban incluso a aludir al destino para explicar por qué ellas, y no otro familiar, se hicieron cargo en su momento de la asistencia al mayor: 
«Fue como un castigo divino. Ya cuando era mayor yo decía: “¿A que me va a tocar a mí esto de cuidar de mi madre?" " (Hija cuidadora de su madre con Alzheimer).

Tirando del hilo de la aparente fatalidad, enseguida constatamos que la toma de decisión acerca de la gestión familiar del cuidado no puede cifrarse en un momento concreto del tiempo, ni siquiera puede circunscribirse al hecho aislado de la entrada en situación de dependencia de un miembro de la familia; se trata, más bien, de un proceso decisional subrepticio y subyacente, que en no pocas ocasiones se retrotrae hasta la etapa de socialización adolescente de la cuidadora, que, a menudo, no es consciente de los pactos intergeneracionales que lleva implícita una determinada decisión en un momento dado.

«Ella, no sé, quizás por su carácter, porque pasó muchos trabajos con los niños (yo estaba todo el día fuera de casa) se involucró mucho, de lleno con los críos. (...) Ahora, cualquier cosa que le hagas ya te dice: "Lo tienes que hacer porque yo esto ya lo hice por tus hijos". Mi madre tiene la actitud de "Mira, yo lo hice por ti, fastídiate, que ahora tú lo tienes que hacer".» (Hija cuidadora de su madre y de su padre).

Así pues, la responsabilidad del cuidado de un mayor dependiente entra dentro de un contrato de género más amplio, que, si bien en un momento facilita la inserción laboral de las mujeres de la familia -al ser los mayores los que se encargan de las tareas de cuidado de los más pequeños de la casa-, posteriormente puede ejercer el efecto contrario, el de desmercantilización obligada de las mujeres que entenderán el trabajo de cuidar de sus mayores como la reciprocidad normativa inherente al contrato intergeneracional y de género o, como lo define Constanza Tobío, la «doble lógica de consanguinidad y de género» (Tobío, 2002), implícitamente suscrito.

En hogares intergeneracionales en los que la cuidadora es hija de la persona atendida y existe corresidencia entre ambos, es frecuente además que la decisión del cuidado sea un eslabón más de un conjunto de intercambios, no solamente del trabajo de cuidado, sino también económicos entre generaciones que restringen todavía más la capacidad de la cuidadora a la hora de formular estrategias para enfrentarse a la problemática de la dependencia sin considerar el abandono del trabajo formal remunerado. La «hija de la casa», beneficiada económicamente con respecto a sus hermanos y sus otras hermanas, y que tiene, además, garantizado el cuidado de sus hijos y, consecuentemente, el poder trabajar fuera de casa ya que convive con sus padres, es perfectamente consciente de que puede llegar un momento en el que tenga que desempeñar su parte del contrato, y expresa, en estas circunstancias, un sentimiento de resignación para el que ya estaba preparada y, en ocasiones, 
abandona el trabajo remunerado porque, de todas formas, ya sabía que su situación laboral podía ser temporal.

«Sabes lo típico de las herencias, también. Mis padres eran muy burros, pero para eso fueron muy listos. Mi padre tuvo muchos problemas, y de hecho su herencia quedó sin repartir entre sus hermanos. Entonces ellos, lo que era de ellos se lo dejaron a cada hijo, pero ellos -en referencia a los hermanos de la entrevistada- piensan que me dejaron más, y sí es verdad que a mí me dejaron más, pero ellos piensan que como a mí me dejaron más, pues tengo más obligación. (...) También al estar viviendo aquí, algo vas aportando, y no vas a aportar toda la vida para que al final sea para las siete partes igual. (...) Ya cuando mi padre vivía, me metieron en la misma cuenta que ellos, para que yo pudiese igualmente que ellos hacer de su dinero.» (Hija cuidadora de su madre con Alzheimer).

«También ella cuidó de mis hijos para que yo trabajase, si ahora yo tengo que dejar de trabajar para cuidarla a ella, es lo mínimo que puedo hacer.» (Hija cuidadora de su madre con Alzheimer).

Si no estamos ante el caso de hogares intergeneracionales, la influencia normativa del contrato de género se diluye, y el espectro de estrategias posibles que pueden adoptar las mujeres responsables del cuidado familiar se amplía. Aquí, el proceso de decisión y la emergencia de la cuidadora informal familiar se gestan en la transición del care about («preocuparse por») al care for («cuidar de») (Hooyman y Gonyea, 1995).

«Al principio de morir mi padre, ella lo que sí hizo desde el primer momento fue venir a dormir a mi casa, porque como que le daba así un poco de..., sentía la soledad y esas cosas.»

(...) Yo se lo comenté a mis hermanos. Ella tenía miedo a perderse, el miedo se apoderó de ella y yo la ayudé a tranquilizarse.

(...) Hasta que no le empezó el proceso nada, que ella era completamente autónoma, pero al ir empezando este proceso, empecé a tener que irme encargando yo de las cosas. (...) Luego empezaron las movilizaciones de médicos, se pasó en el hospital como un mes y medio; ella no me lo pidió, pero yo me quedé en su casa.» (Hija cuidadora de su madre con Alzheimer).

La transición aparentemente tranquila del «preocuparse por» al «cuidar de» se rebela contra la propia cuidadora cuando ésta se vuelve consciente de que realmente ha pasado de preocuparse a trabajar intensamente en tareas de cuidado. Esta transición suele ser un momento de crisis, y en ella son partícipes otros familiares directamente relacionados con la persona asistida de la necesidad de «tomar una decisión» - por primera vez, las entrevistadas hacen referencia a esta expresión- respecto del desempeño del cuidado de su pariente. Es en este momento, y no antes, cuando el factor de clase social entra en juego para determinar y posibilitar la externalización del cuidado o no. 
«Cuando estallé con mis hermanos y les dije que yo ya no aguantaba más esa situación, empecé a relatarles la cantidad de cosas que yo tenía que hacer con mi madre; ellos no eran para nada conscientes. (...) Hice una relación de cosas que hacía para decirles por qué estaba tan cansada, porque me tenía que justificar ante ellos. Les dije que estaba destrozando mi vida, que yo no tenía vida personal, que estaba deseando que la Consellería me trasladase a Ávila porque así yo no tenía que cuidarla. (...) Lo de ellos era comodidad, como tenían su coartada, se sentían liberados en ese sentido, tampoco llegaban a darse cuenta de lo implicada que estaba yo en esa situación hasta que vieron toda la lista de cosas que tenía que hacer. (...) Les dije que había que tomar una decisión. (...)». (Hija cuidadora de su madre con Alzheimer).

La utilización de las palabras «justificar»y «coartada» por parte de la entrevistada en este extracto de su entrevista, para referirse respectivamente a la expresión de la sobrecarga del trabajo de cuidado y a la exclusión de la participación de otros miembros de la familia en el desempeño de estas tareas, nos remite inmediatamente al vocabulario jurídico. La entrevistada no puede expresar la carga del trabajo emocional más que a través de la justificación y la aportación de pruebas (elaboración de un listado de tareas realizadas); expresión que realiza ante sus hermanos y ante ella misma, en un proceso de toma de conciencia ante sí misma y ante sus hermanos del componente de trabajo que subyacía en lo que ella veía como la extensión emocional de una preocupación inicial. La coartada se resume en un pretexto justificante que, según la racionalidad de género expresada por la entrevistada, exime a sus hermanos de dispensar cuidados a su madre. Los hermanos devienen inculpables porque disponen de una coartada de género, que los sitúa frente al escenario social de la dependencia, en otro lugar y otra posición social.

Si la cuidadora es hija única, es muy probable que el sentimiento de obligación moral de cuidar por parte de otros familiares tenga contornos borrosos -salvo en algún caso, por parte de hermanos/as de la persona dependiente-, por lo que, ante la carencia de recursos económicos elevados, la prácticamente única estrategia viable de mantener su empleo actual a la vez que garantizar el cuidado de su padre/madre es la fragmentación del cuidado en pequeñas unidades de tarea a asignar a todo miembro de la red familiar y social del dependiente con que se cuente. Sería, pues, aplicar la técnica de cadena de montaje fordista al trabajo emocional; reproducción social en cadena que exige, al igual que el taylorismo, una férrea disciplina del trabajo emocional y la búsqueda del control de los tiempos y los procesos.

«Por la tarde tengo a una chica que es amiga de ella y viene, juegan a las cartas, ven la telenovela. Y viene siempre una tía mía, y entonces van las tres a pasear. O sea, que si no tuviera a esta chica y a mi tía tendría que tener a al- 
guien porque no puede estar sola todo el tiempo. (...) La ducha se la hago yo, aunque con la nieta se entiende muy bien.» (Hija cuidadora de sus padres).

Si la cuidadora tiene hermanos, la posibilidad de contar con recursos económicos es mayor; y, además, si entre los hermanos hay un varón, es probable que su sentido de la obligación filial esté más connotado con la provisión de recursos económicos para el desempeño del cuidado que con el autosacrificio (Gilligan, 1993), por lo que la estrategia de externalización es una vía muy probable, y la hija cuidadora verá salvaguardada su posición en el mercado laboral, aunque nada evita, tal y como veremos en el siguiente apartado, que, durante el proceso de toma de decisión conjuntamente con sus hermanos, ella se instituya en la máxima responsable de la supervisión del trabajo de cuidado, esto es, en la gestora del cuidado.

«Mi hermano, cuando vio aquello -en referencia a la lista de tareas-, dijo que se pagaba lo que fuese. (...) Y contratamos a una chica. (...) Empecé a encargarme yo, o sea, le pusimos una mujer por horas. La contraté y yo le dije: "Tú tienes que acompañarla a ella, no dejarla nunca sola, tienes que hacerle la comida, y en casa sola no quiero nunca que esté." (Hija cuidadora de su madre con Alzheimer).

\section{Construcción social y emergencia de las «gestoras del cuidado»}

Según Barbara Da Roit, una de las estrategias empleadas parar reducir la sobrecarga de la cuidadora informal familiar consiste en la externalización al mercado privado del trabajo de cuidado mediante la contratación de una persona, generalmente inmigrante, para la realización de las correspondientes tareas (Da Roit, 2007), estrategia que ha sido analizada y desarrollada con profusión para el caso de España por la investigadora Raquel Martínez Buján (Martínez Buján, 2005 y 2007). Sin embargo, ésta es una decisión que, tal y como hemos señalado anteriormente, no se produce siempre que existe sobrecarga de la cuidadora informal familiar, sino que existen un proceso previo que sienta las condiciones normativas para que el contrato intergeneracional y de género se diluya, así como unos requisitos materiales y económicos para poder hacer frente a la externalización del cuidado. No sólo la clase social importa, sino también la presencia de hijos varones en la familia, más dispuestos a aportar en moneda que en especies.

Para Martínez Buján, la externalización de las tareas de cuidado no agota la responsabilidad de las cuidadoras informales familiares, al devenir estas «gestoras del cuidado» o cuidadoras secundarias directas del pariente dependiente (Finley, 1989). Este proceso ha sido constatado también en nuestro trabajo de campo, y consiste en una cesión del trabajo físico con el mayor 
dependiente y una supervisión muy estricta sobre el trabajo emocional delegado que, en ocasiones, es compartido, ya que el trabajo desempeñado por la cuidadora contratada no colma las expectativas de la gestora del cuidado, tal y como se desprende del extracto de la última entrevista mencionada en el punto anterior.

Sin embargo, el papel de las gestoras del cuidado va más allá de la mera supervisión y responsabilidad constante sobre las atenciones dispensadas a su pariente. El rol de supervisión que se arrogan las gestoras del cuidado, antes cuidadoras informales familiares en régimen intensivo, resalta el potencial valor de mercado que este trabajo tiene y desemboca en lo que Nancy R. Hooyman y Judith Gonyea denominan extensión del cuidado (extended care), y que definen como la traslación del apoyo a la comunidad más cercana en situaciones semejantes de contar con un familiar falto de autonomía para la realización de las tareas de la vida diaria (Hooyman y Gonyea, 1995). Con ciertos matices, este proceso ha sido constatado en varias de las cuidadoras informales familiares entrevistadas, especialmente en aquellas que han abandonado su trabajo formal para dedicarse al trabajo de cuidado de algún familiar dependiente. Así, estas personas se convierten en algo así como «cuidadoras profesionales» para su familia y su entorno más próximo, y se muestran dispuestas a cuidar de otro familiar más en caso de que esta persona caiga en situación de dependencia, e incluso realizan trabajos de cuidado remunerado fuera del hogar para compensar la pérdida de recursos generada por la desmercantilización.

«Yo ahora mismo voy aquí, a la casa de al lado, la que está pegada, que también tienen una señora dependiente y les hago las cosas de la casa, y saco a pasear a la señora. Este señor con el que estoy trabajando me está pagando el seguro de hogar -se refiere a la cotización a la Seguridad Social a través del Régimen Especial de Empleados Domésticos-, me paga el seguro de ocho horas, sólo voy dos, pero en vez de pagar, cotiza por mí.

(...) Yo le dije a mi marido -en referencia a los suegros de ella- si quieren venir para aquí, sí que los cuido, porque una vez que cuidas a uno, también cuidas a otro.» (Hija cuidadora de su madre con Alzheimer).

En la experiencia de estas mujeres, el trabajo de cuidado da el salto de la reproducción social a la producción social, haciéndose visible como trabajo formal lo que se invisibilizaba, bajo las lógicas de género, en un deber familiar.

\section{Conclusiones}

Hemos tratado de exponer cómo se articula y arregla la asistencia informal familiar a los mayores dependientes en el seno de las familias, atendiendo a 
aspectos que se han demostrado cruciales para el entendimiento de los procesos de toma de decisión relativa al cuidado, tales como la socialización temprana en roles de género, las lógicas y normativas de género interiorizadas por nuestras informantes; $y$ hemos definido el abanico de posibilidades estratégicas en torno a las decisiones de cuidado, teniendo en cuenta la especial incidencia de variables como la composición y el tamaño del hogar, la relación de parentesco de la cuidadora informal con el mayor dependiente, la posición laboral de la cuidadora informal en el contexto inmediato del hogar y el estatus socioeconómico del hogar.

No quisiéramos finalizar este trabajo, sin hacer un breve comentario crítico acerca del cambio más reciente y de mayor calado de la política social española en relación a la atención a la dependencia, que viene dado por la aprobación, a finales del 2006, de la Ley de Promoción de la Autonomía Personal y Atención a las personas en situación de dependencia, así como de la creación del Sistema Nacional de Dependencia (SND). Esta ley parte de un concepto de dependencia doblemente restringido. En primer lugar, restringido a la dependencia permanente, por lo que deja a las puertas de la protección a todas aquellas personas que temporalmente experimenten una situación de falta de autonomía (Hernando, 2006); y, en segundo lugar, restringido a la dependencia funcional, excluyendo toda aquella necesidad de cuidados que tienen las personas a lo largo de su ciclo vital y de su vida cotidiana, siguiendo el concepto más amplio que de dependencia y cuidados plantea S. Sevenhuijsen (1998) y que quedan, nuevamente, invisibilizados (Bosch, Carrasco y Grau, 2006).

Por otra parte, se trata de una ley reguladora del derecho a recibir una prestación de dependencia de difícil encaje, tanto en el sistema de Seguridad Social como en el Sistema Nacional de Salud, por lo que el encaje de esta prestación resulta algo ambiguo (López Cumbre, 2006; Berrocal Vela, 2006). Como sugiere también Lourdes López Cumbre, así como la investigadora Bibiana Escuredo, esta ley hace más hincapié en la promoción de la autonomía que en la protección de la dependencia y, sin embargo, de entre los servicios que enumera, considera únicamente la teleasistencia como recurso para la promoción de la autonomía personal (López Cumbre, 2006; Escuredo, 2007).

En relación a los cuidadores informales de las personas dependientes, y pese al énfasis político puesto en la visibilización del cuidado informal que se lograba a través de la aprobación y puesta en marcha de las medidas contempladas por esta ley, lo cierto es que esta normativa tiene como objetivo a los dependientes, y trata a sus cuidadores informales nuevamente como recurso al servicio del desarrollo del sistema de protección a la dependencia en ella 
contemplado. No se mejoran y amplían las medidas recogidas en la Ley de Conciliación de la Vida Laboral y Familiar, ni se cuestiona la obligatoriedad de las familias a la hora de prestar atención y cuidados a sus dependientes, tal y como afirma Bibiana Escuredo. Además, la fórmula propuesta para la figura de los cuidadores informales incide nuevamente en la consideración del trabajo de cuidados como un «no-trabajo», al estar obligadas las cuidadoras informales a darse de alta y cotizar en la Seguridad Social para recibir la prestación (que no salario), sin, no obstante, contar con derechos laborales (Hernando, 2006). Por otra parte, si se tratase en el caso de la figura del cuidador familiar, tal y como se recoge en el texto de dicha ley, de una figura de carácter excepcional, no se entiende por qué se prevé que en el 2015 vaya a haber entre 300000 y 400000 cuidadoras familiares.

En conclusión, se trata de una ley que resulta continuista en cuanto al tratamiento de la problemática de la atención informal a la dependencia y que no resuelve la cuestión de la obligatoriedad legal y moral de las familias a prestar cuidados a sus familiares dependientes de una manera provechosa para las mujeres.

\section{Bibliografía}

Attias-Donfut, C., «Le Double Circuit de Transmission», en Les solidarités entre générations, C. Attias Donfut (ed.), París, Nathan, 1995.

Bazo, M. T., «Vejez dependiente, políticas y calidad de vida», Papers, n. ${ }^{\circ}$ 56, 1998 , pp. 143-161.

BerRoCal Vela, M. A., «Consideraciones críticas sobre el anteproyecto de Ley de Promoción de la Autonomía Personal y Atención a las Personas en Situación de Dependencia», Revista Jurídica de les Illes Balears, n. ${ }^{\circ}$ 4, 2006, pp. 153-169.

Bettio F. y J. Plantenga, «Comparing Care Regimes in Europe», en Feminist Economics, 10 (1), 2004, pp. 85-113.

Bosch, A., C. Carrasco y E. Grau, «La Ley de Dependencia y el Mito del Homo Economicus», en Revista de Economía Crítica, n. ${ }^{\circ}$ 5, 2006, pp. 105-107.

BRUBAKER, T., «The long-term care triad: the elderly, their families and bureaucracies», en Aging, Health and Family: Long-term Care, T. H. Brubaker (ed.), Beverly Hills, Sage, 1987, pp. 12-22.

BussemakeR, J., «Rationales of Care in Contemporary Welfare States: The Case of Childcare in the Netherlands», en Social Politics, 5 (1), 1998, pp. 70-96.

DA RoIT, B., "Changing Intergenerational Solidarities within Families in a Mediterranean Welfare State: Elderly Care in Italy», en Current Sociology, 55 (2), 2007, pp. 251-270.

DalY, M. y J. LEWIS, «The Concept of Social Care and the Análisis of Contemporary Welfare States», en British Journal of Sociology, 52 (2), 2000, pp. 281-298. 
DUNCAN, S. y R. EDWARDS, Lone mothers, paid work and gendered moral rationalities, Londres, Macmillan, 1999.

ENGERS, M. y S. STERN, «Long-Term Care and Family Bargaining», en Virginia Economics Online Papers, n. ${ }^{\circ} 320$, Universidad de Virginia, [en línea], 1998, <http://www.virginia.edu/economics/RePEc/vir/virpap/papers/virpap320. pdf>. [Consulta: 13/03/2008].

ESCUREDO, B., «Las políticas sociales de dependencia en España: contribuciones y consecuencias para los ancianos y sus cuidadores informales», en Revista Española de Investigaciones Sociológicas (REIS), n. ${ }^{\circ} 119,2007$, pp. 65-89.

EsPING-ANDERSEN, G., Los tres mundos del Estado del Bienestar, Valencia, Alfons el Magnánim, 1993.

FINCH, J., «Family obligations and the life course», en Rethinking the Life Cycle A. Bryman, P. Allatt y T. Keil (eds.), Londres, Macmillan, 1987, pp. 155-169.

FINCH, J. y J. MASON, Negotiating Family Responsibilities, Londres, Tavistock/ Routledge, 1993.

FINLEY, N. J., «Theories of Family Labor as applied to Gender Differences in Caregiving for Elderly Parents», en Journal of Marriage and the Family, 51 (1), 1989, pp. 79-86.

FLAQUER, L., «La articulación entre familia y Estado del Bienestar en los países de la Europa del Sur», en Papers, n. ${ }^{\circ}$ 73, 2004, pp. 27-58.

Fraser, N., «Gender Equity and the Welfare State: A Postindustrial Thought Experiment», en Democracy and Difference: contesting the Boundaries of the Political, S. Benhabib, Princeton, Princeton University Press, 1996, pp. 219-241

Gilligan, C., In a Different Voice. Psychological Theory and Women's Development, Cambridge:, Harvard University Press, 1993.

GuillÉn, A. M., «Regímenes de bienestar y roles familiares: un análisis del caso

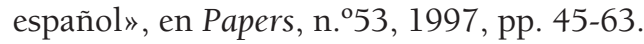

Hernando, A., «Una crítica feminista a la Ley de Dependencia», en Viento Sur, n. ${ }^{\circ} 88,2006$, pp. 89-95.

Hiedemann, B. y S. Stern, «Strategic Play Among Family Members When Making Long-Term Care Decisions», en Virginia Economics Online Papers, n. ${ }^{\circ}$ 321, Universidad de Virginia, [en línea], 1999, <http://www.virginia.edu/ economics/RePEc/vir/virpap/papers/virpap321.pdf>. [Consulta: 13/03/2008].

Hooyman, N. y J. Gonyea, Feminist Perspectives on Family Care. Policies for Gender Justice, Londres, SAGE, 1995.

IMSERSO, Informe 2006 sobre las personas mayores en España, Madrid, MTAS/ IMSERSO, 2006.

JURADO, T., «Las nuevas familias españolas», en Tres décadas de cambio social en España, J. J. González Rodríguez y M. Requena Díez de Revenga (coords.), Madrid, Alianza, 2005, pp. 51-80. 
Kofman, E., «Gendered Migrations, Social Reproduction and Welfare Regimes: New Dialogues and Directions», [en línea], 2006, <http://www2.iisg.nl/esshc/ programme9606.asp? selyear $=8 \&$ pap $=4596>$. [Consulta: $13 / 03 / 2008$ ] .

LEITNER, S., "Varities of Familialism: the Caring Function of the Family in Comparative Perspective», en European Societies, 5 (4), 2003, pp. 353-375.

LEWIS, J. , Gender, Social Care and Welfare State Restructuring in Europe, Aldershot, Ashgate, 1998.

LÓPEZ Cumbre, L., «Fisuras de una ley histórica en materia de protección social: el proyecto de ley de dependencia», en Revista General de Derecho del Trabajo y Seguridad Social, n. ${ }^{\circ}$ 11, 2006, pp. 1-17.

MARTínEZ BUJÁN, R., «El cuidado de ancianos: un vínculo entre la inmigración y el envejecimiento», en Panorama Social, n. ${ }^{\circ}$ 2, 2005, pp. 86-97.

- Bienestar y Cuidados: el Oficio del Cariño. Mujeres Inmigrantes y Mayores Nativos, tesis doctoral, Universidad de La Coruña, 2007.

MORENO, L., España y el bienestar mediterráneo, documento de trabajo 06-10 de la Unidad de Políticas Comparadas (CSIC), [en línea], 2006, <http://www. iesam.csic.es/doctrab2/dt-0610.pdf>. [Consulta: 11/03/2008].

Naldini, M., The Family in the Mediterranean Welfare States, Londres, Frank Cass, 2002.

Pérez de Orozco, A. y P. BAEZA GÓmeZ, «Sobre "dependencia” y otros cuentos. Reflexiones en torno a la Ley de Promoción de la Autonomía Personal y Atención a las Personas en Situación de Dependencia», en Revista de Relaciones Laborales / Lan Harremanak, n. ${ }^{\circ}$ 2, 2006, pp. 13-40.

PÉrez Orozco, A., «Amenaza tormenta: la crisis de los cuidados y la reorganización del sistema económico», en Revista de economía crítica, n. ${ }^{\circ}$ 5, 2006, pp. 7-37.

Pezzin, L. E., R. A. Pollak y B. Schone, «Efficiency in Family Bargaining: Living Arrangements and Caregiving Decisions of Adult Children and Disabled Elderly Parents», en NBER Working Paper, n. ${ }^{\circ}$ 12358, [en línea], 2005, <http:// www.nber.org/papers/w12358.pdf>. [Consulta: 10/03/2008].

Pratt, C., A. JoneS, y D. PenNington, «Decisión-Making Influence Strategies of Caregiving Daughters and their Elderly Mothers», en Family Relations, n. ${ }^{\circ} 42$, 1993, pp. 376-382.

PRATT, C. y otros, «Autonomy and decision-making among single women and their caregiving daughters», en The Gerontologist, n. ${ }^{\circ}$ 29, 1989, pp. 792-797.

RHodes, M., Southern European Welfare Status. Between Crisis and Reform, Londres, Routledge, 1997.

Rodríguez CABrero, G., «La protección social de las personas dependientes como desarrollo del Estado de Bienestar en España», en Panorama Social, n. ${ }^{\circ} 2$, 2005a, pp. 21-33. 
- «Conocimientos sociográficos sobre la dependencia funcional en España y su dimensión aplicada» en Avances en bienestar basados en el conocimiento, D. Casado (dir.), Madrid, CC2, 2005b, pp. 151-178.

- «Población en situación de dependencia y cuidados informales», en Temas Laborales, n. ${ }^{\circ} 89,2007$, pp. 47-62.

SAinsburY, D., Gender and Welfare State Regimes, Oxford, Oxford University Press, 1999.

SARASA, S., «Do Welfare Benefits Affect Women's Choices of Adult Care Living?», en European Sociological Review, 24 (1), 2008, pp. 37-51.

SARASA, S. y L. MORENO, (comps.), «El Estado de Bienestar en la Europa del Sur», Madrid, CSIC, 1995.

Sevenhuijsen, S., Citizenship and the Ethics of Care: Feminist Considerations on Justice, Morality and Politics, Londres, Routledge, 1998.

Stern, S., "Estimating Family Long-Term Care Decisions in the Presence of Endogenous Child Characteristics», en Journal of Human Resources, 20 (3), 1995, pp. 551-580.

ToBío, C., «Conciliación o contradicción: cómo hacen las madres trabajadoras para conciliar la vida», en Tiempos y servicios para la igualdad, C. Tobío, Madrid, Dirección General de la Mujer, 2002, pp. 15-43.

TRIFILETTI, R., «Southern European Welfare States and the Worsening Position of Women», en Journal of European Social Policy, 9 (1), 1999, pp. 49-64.

TwIGG, J., "Cuidadores de los ancianos: modelos para un análisis», en Comparación de políticas europeas de atención a las personas ancianas. A. Jamieson y R. Illsey (eds.), Madrid, SG/Fundación Caja de Madrid, 1990.

Woods, D. R., «Focusing on Care: Family Policy and Problems of Analysis», en Working Paper, $\mathrm{n}^{\circ}$ 30-2006 del Institut für Politikwissenschaft, [en línea], 2006, <http://tobias-lib.ub.uni-tuebingen.de/volltexte/2006/2309/pdf/ WIP_30.pdf>. [Consulta: 13/03/2008].

— «Shadow Worlds of the Welfare State: Examining the European Informal Domestic Sector», Gender, Work and Organization Conference, Keele 27-29 Junio, (paper). 


\title{
NECESIDADES DE LOS HOMBRES FRENTE A CUIDADOS DE LARGA DURACIÓN DE SUS PAREJAS CON ESCLEROSIS MULTIPLE: LOS CASOS DE FINLANDIA, AUSTRIA Y ESPAÑA
}

\author{
Needs of men in front of the long-term care of their \\ partners with Multiple Sclerosis: the cases of Finland, \\ Austria and Spain
}

M. ${ }^{a}$ CARMEN PÉREZ BELDA*

\section{Resumen}

El papel de los hombres como cuidadores de personas dependientes ha estado omitido o relegado a un segundo plano en el cuerpo de la investigación dedicada al cuidado. La mujer ha sido la gran protagonista dentro de la provisión del cuidado en el ámbito familiar. Aunque durante los últimos años también se han realizado estudios sobre la participación de los hombres en el cuidado y en tareas tradicionalmente realizadas por mujeres.

Este artículo profundiza en las experiencias de los hombres de Laponia, en Finlandia; de Vorarlberg, en Austria; y de Alicante, en España, cuando sus esposas necesitan cuidados de larga duración debido a la enfermedad de Esclerosis Múltiple. Éstas han sido analizadas bajo la perspectiva de género, prestando atención a la influencia de factores contextuales en cada caso. Las relaciones de género, tales como poder, emoción, simbolismo y producción (Connell, 2002), y de las perspectivas interaccional, individual e institucional (Stoller, 2002), han sido la referencia teórica para este análisis. Los resultados de este estudio nos ofrecen la posibilidad de acercarnos

\footnotetext{
* M. ${ }^{a}$ Carmen Pérez Belda Universidad de Alicante Ctra. San Vicente, s/n. 03690 San Vicente del Raspeig (Alicante) Departamento de Trabajo Social y Servicios Sociales Teléfono: +34 965903400 (extensión. 2153) mc.perez@ua.es
} 
a las experiencias que viven los hombres envueltos en el cuidado de larga duración, mostrando la influencia de factores contextuales, tales como los diferentes sistemas de protección social que tienen, así como de factores de género.

Palabras clave: Hombre, cuidados de larga duración, género, Esclerosis Múltiple.

\begin{abstract}
The role of men as carers of dependent people has been omitted or relegated to second place in the body of research devoted to care. Women have been the main protagonist in the provision of care in the family. In the recent years, studies on male involvement in care and tasks traditionally performed by women have also conducted.

This article explores the men's experiences from Lapland in Finland, Vorarlberg in Austria and Alicante in Spain, when their wives need long term care due to Multiple Sclerosis disease. These experiences have been analyzed under the gender perspective, with attention to the influence of contextual factors in each case. Gender relations, such as power, emotion, symbolism and production (Connell, 2002) and interactional individual and institutional perspectives (Stoller, 2002) have been used as reference for the analysis. The results of this study offer the possibility of approaching the experiences that men live with the long-term care situations of their wives, showing the influence of contextual factors, such as the different social protection systems that they since a gender perspective.
\end{abstract}

Keywords: Man, long-term care, gender, Multiple Sclerosis.

\title{
1. Introducción
}

El estudio sobre los hombres como cuidadores ha venido ocupando un segundo plano en el cuerpo de la investigación dedicado al cuidado. Gran parte de estudios previos se ha centrado en la mujer como cuidadora principal en las familias, tales como Durán (2002), La Parra (2002). Sin embargo, en los últimos años se han realizado también diferentes estudios sobre la participación de los hombres en el cuidado desde diversos enfoques, algunos relacionados con el bienestar y la protección social desde una perspectiva de género, feminista o pro-feminista (Pease y Pringle, 2002).

Giddens (2006: 135-163) apunta que Europa vive nuevos retos conectados directamente con la globalización, pero ésta no puede ser vista únicamente como un fenómeno económico. La globalización, de un modo más amplio, debe ser vista más que la integración de actividades económicas, ya que la competitividad en el mercado global es esencial para el futuro de Europa y para la supervivencia del modelo social. Dentro de este modelo social, los cambios y la diversidad de las estructuras familiares traen consigo nuevos retos en el ámbito del cuidado, y con ello una mayor evidencia de la participación de los hombres en este campo tradicionalmente relegado a las mujeres. La 
transformación de la estructura familiar es uno de esos cambios. Las nuevas tendencias son complejas pero tienen una fuerte influencia en el cuidado y en los roles desarrollados por las familias. Kramer (2002: 3) sugiere que se producirá un incremento del número de hombres cuidadores durante o a través del curso de la vida debido al aumento de la longevidad de la población, por lo tanto necesitamos un mejor entendimiento de esas tendencias desde el punto de vista de todos los profesionales y disciplinas para ofrecer respuestas efectivas.

Las necesidades que los hombres experimentan cuando se ven envueltos en situaciones familiares de cuidados de larga duración, especialmente cuando la persona enferma es su pareja, son muy diversas y están influenciadas en gran medida tanto por factores contextuales, culturales, políticos, económicos etc., como por factores personales. Estos factores personales tienen relación con el grado de adaptación que sufren frente a los cambios, dependiendo del contexto en el que viven. Algunos de estos esposos o parejas comienzan a realizar prácticas que hasta ese momento eran desarrolladas únicamente por sus esposas, además, también encuentran dificultades en el desarrollo del cuidado personal (bañar, asear, llevar al baño, etc.). Por lo tanto, las vivencias varían dependiendo del grado de aceptación/resignación o negación de la situación, así como del apoyo recibido.

De esta manera, y basándome en el estudio realizado en mi tesis doctoral sobre las experiencias de los hombres, esposos o parejas, con mujeres en situación de cuidados de larga duración debido a la enfermedad de Esclerosis Múltiple, en Finlandia, Austria y España, pretendo profundizar y explorar en las necesidades experimentadas por estos hombres y sus familias, algunas comunes a todos los casos independientemente de su procedencia según apuntan los resultados. De forma preliminar, los resultados indican que la participación de los hombres en las tareas tradicionalmente realizadas por mujeres viene influenciada por las relaciones de género y el contexto en el que viven. Del mismo modo, las necesidades experimentadas estos hombres pueden diferir dependiendo de factores contextuales, relacionados directamente no sólo con la cultura o con las prácticas, sino también con el apoyo institucional que puedan percibir, y con el objetivo de facilitar o fomentar su rol como cuidador formal o informal. Estas necesidades influirán a su vez en otras necesidades que señalo en este artículo como personales y que van relacionadas con los sentimientos y cambios experimentados por los hombres.

El objetivo de este artículo es alcanzar un mayor entendimiento de las experiencias de estos hombres, prestando atención a qué hacen y a cómo se sienten envueltos en la situación de cuidado cuando sus mujeres necesitan 
cuidados permanentes. Se pretende detectar las necesidades experimentadas por los casos estudiados en estos tres países, cada uno con un sistema de protección social diferente, porque para comprender y alcanzar igualdad en el cuidado a dependientes es necesario abrir un debate sobre las prácticas que los hombres realizan en este campo y el apoyo que reciben ante los nuevos cambios que la sociedad presenta. Para ello, se intenta encontrar respuesta a lo largo de esta investigación a dos cuestiones importantes: ¿cuáles son las necesidades institucionales o de apoyo formal detectadas por los esposos entrevistados en Laponia, Vorarlberg y Alicante durante el proceso de la enfermedad? y ¿cuáles son las necesidades personales que los hombres y esposos o parejas expresan de manera implícita o explícita durante el proceso de la enfermedad?

\section{Conceptualización de cuidado y aspectos generales del hombre como cuidador}

Para comenzar este punto es necesario mencionar la importancia y derecho que tienen las personas y las familias de enfermos con enfermedades crónicas a una calidad de vida, así como a las oportunidades para su desarrollo humano, como bien indica Martínez Román (2002: 145).

Tradicionalmente, la labor de los hombres ha estado relacionada con la esfera pública de la vida, ocupándose del sostenimiento económico del núcleo familiar, mientras que la labor de las mujeres ha estado relacionada con las responsabilidades del cuidado de la familia de manera no remunerada, incluyendo el cuidado a mayores, miembros con discapacidad, hijas/os. Además, cuando de mujeres incluidas en el mercado laboral hablamos, el trabajo a tiempo parcial ha sido la modalidad de empleo en la que las mujeres aparecen con mayor incidencia que los hombres. Esto ha significado que la mayoría de los estudios realizados acerca de personas que se ocupan del cuidado de dependientes se centrará en resaltar la feminización de esta labor, omitiendo el trabajo y las experiencias que algunos hombres realizan, aunque ésta fuera minoritaria. Sin embargo, considero que es importante prestar atención al papel desarrollado por algunos hombres como cuidadores con el fin de mostrar y abrir debate sobre las prácticas que realizan, puesto que para lograr la igualdad en materia de cuidado, que no de conciliación, sino de corresponsabilidad, es necesario observar las necesidades de cambio que la sociedad va experimentando, así como explorando y delimitando el cuidado, su tipología, pero también su calidad, cuestiones que dependerán en gran medida de la propia construcción de género. 
Pero para poder comprender mejor las experiencias de los hombres con mujeres en situación de cuidado definiré en un primer lugar qué entendemos por cuidado. La autora finlandesa Zechner (2008: 33) indica que el cuidado abarca trabajos concretos de cuidados, desde la observación para detectar las necesidades del cuidado, a la responsabilidad de iniciar y mantener actividades de cuidado, para lo que son necesarios los recursos y el tiempo suficiente, sin olvidar tampoco las actividades de cuidado referidas al cuidado mental y emocional de la persona. Pero hablar de cuidado de forma genérica no es suficiente cuando hablamos de la enfermedad de Esclerosis Múltiple. En estos casos el cuidado es requerido durante décadas, por lo tanto, sería más preciso si hablamos de cuidados de larga duración. A este respecto, Stone (2001: 97) lo define como un tipo de cuidado que abarca un amplio rango de asistencia que las personas con algún tipo de discapacidad crónica necesitan durante un periodo de tiempo prolongado, debido a la pérdida de su funcionamiento físico o mental.

La Parra (2002: 34-88) apuntó que la manera en que una sociedad organiza la respuesta informal del cuidado, depende del proceso de construcción de género, de la organización del mercado laboral y del Estado de Bienestar. Por lo tanto, las necesidades que los esposos objeto de este estudio puedan experimentar depende del apoyo que puedan recibir en relación al tipo de Estado de Bienestar que disfruten, perteneciendo cada uno de los países a un modelo de Estado de Bienestar diferente, así como del rol que juegue en ello la organización del mercado laboral. Este contexto influirá a su vez en las prácticas que los hombres realizan influenciadas por las relaciones de género en todos los niveles, porque como bien indica Connell (2002), el concepto de género no es algo estanco, sino que cambia y se va creando día a día con las prácticas que realizamos.

Una vez definido el concepto de género es necesario mencionar brevemente varios aspectos destacables de los estudios de los hombres como cuidadores principales. En primer lugar, Parker y Seymour (1998: 187-191) destacan que las mujeres se involucraban de una manera más intensa en el cuidado que los hombres en la misma situación y que los hombres están menos dispuestos a proporcionar cuidado personal que las mujeres, entendiendo por cuidado personal a la ayuda necesaria para bañarse, vestirse o ir al baño, entre otras tareas de la vida diaria, considerando que un cuidador del mismo sexo sería más apropiado para realizar dichas tareas. Además, en los resultados se destaca también que la edad y el matrimonio como estado civil son las principales variables para que los hombres se conviertan en cuidadores, más concretamente que el estado marital, la combinación de la convivencia y las 
relaciones íntimas previenen a los hombres de escaparse de las responsabilidades de cuidado.

Por otro lado, Detinberg y Clarkberg (2002: 873-874) coinciden en la importancia de la relación de la pareja para la participación de los hombres en el cuidado, es decir, destacan que la naturaleza de la experiencia del cuidado depende en gran medida del grado de la naturaleza de la relación entre el cuidador y la persona cuidada, particularmente en el caso de una pareja o matrimonio. De este modo, mientras unos hombres se involucran más en el cuidado, otros eluden las necesidades de cuidado de las esposas o persona enferma como, por ejemplo, a través del retraso de su jubilación, y se centran en las necesidades económicas de la familia con el fin de huir o escapar de la situación de cuidado, proyectando la lealtad a la vida laboral, lo que paradójicamente les conlleva a una menor satisfacción de su rol como trabajador.

\section{Metodología}

\subsection{Selección de casos con Esclerosis Múltiple}

La Esclerosis Múltiple (EM) es una enfermedad del sistema nervioso central impredecible que se desarrolla durante un largo periodo de la vida. Concretamente, es una condición inflamatoria y de «desmielinización». La mielina es un material que cubre y aísla los nervios, permitiendo la transmisión de los impulsos de forma rápida. La Esclerosis Múltiple afecta a una población comprendida entre los 15-55 años, aunque en la mayoría de los casos aparece entre los 25-30, y afecta en un $60 \%$ a las mujeres. La esperanza de vida es de al menos 25 años desde la aparición de la enfermedad y la mayoría de los pacientes mueren por causas no relacionadas con la misma (Fernández y Fernández, 2004: 13-38).

El motivo de la elección de estudiar los casos en los que la pareja sufre Esclerosis Múltiple ha permitido encontrar más fácilmente casos donde los hombres son cuidadores, ya que según estudios como Parker y Seymour (1998) el hombre participa más en el cuidado cuando la persona enferma es la esposa o pareja. Además, estos hombres se encuentran todavía en edad activa por lo que su participación y experiencias en el cuidado a sus parejas o esposas conllevan muchos cambios, tanto económicos como emocionales, en la vida familiar y de pareja. Otros autores, como Fink (2004: 7), remarcan que no es posible presumir que la participación de los hombres en el cuidado de sus parejas ocurra en todos los casos, y que los esposos o parejas participan en el cuidado del otro de igual manera y con las mismas habilidades, especialmente en lo referente al cuidado personal. Parker y Seymour (1998: 187) apuntaron 
los problemas que los hombres experimentaban en las relaciones con sus parejas a la hora de realizar el cuidado personal, entendiendo este relacional con tocamientos para el aseo, desnudez o contacto con excrementos, entre otros.

El curso de esta enfermedad varía en cada caso. Las personas afectadas pueden sufrir periodos de ataques y otros de remisión. La recuperación de esos ataques también difiere en cada caso pudiendo ser parcial o total. Sin embargo, otros pacientes pueden sufrir un deterioro gradual, o experimentar uno o dos ataques o momentos de crisis en el momento del diagnóstico y no volver a sufrir más síntomas durante años, aunque cuando aparezca después de ese tiempo sea de modo gradual. Por lo tanto, el curso tan diferente de la enfermedad en cada persona ha hecho que el estudio se base, independientemente del tipo de EM que se pueda padecer, en el grado de independencia que tenga la persona afectada, puesto que no todas las personas diagnosticadas pueden tener las mismas necesidades de cuidado. Para ello, se ha realizado una simple división de los casos objeto de estudio, caracterizándolos como independiente, cuando no necesita ayuda para las actividades cotidianas, pero sin embargo no puede trabajar debido a otros síntomas como, por ejemplo, el cansancio; semiindependiente, cuando necesita cierto cuidado o ayuda para las tareas cotidianas, pero no necesita el cuidado de una persona permanentemente; y dependiente, cuando necesita ayuda constantemente.

\subsection{Recogida de información}

La decisión de elegir los países de Finlandia, Austria y España se debe a los diferentes sistemas de protección social y bienestar social que tienen. En este estudio de caso múltiple he entrevistado a tres parejas en Finlandia, Austria y España, concretamente en las regiones de Laponia, Vorarlberg y Alicante. Para estudiar y recabar información sobre las prácticas de los hombres y sus experiencias en las situaciones de cuidado de larga duración de sus esposas, se ha utilizado la entrevista cualitativa semiestructurada. Las entrevistas han sido conducidas y realizadas en la lengua materna de los entrevistados (finés, alemán y español). La colaboración de intérpretes ha sido necesaria para la realización de las entrevistas en Finlandia y Austria. La mayoría de los hombres entrevistados estaban casados, y todos vivían junto a sus parejas en el hogar familiar, requisito imprescindible para poder participar en el estudio. Todos los hombres se encuentran en una edad activa, y la mayoría trabaja fuera del hogar, aunque este hecho cambia de un país a otro, ya que en Finlandia, los hombres pueden recibir una prestación económica por cuidar a la persona enferma y convertirse en cuidadores formales de sus esposas. 
Las diferentes asociaciones o grupos de autoayuda han sido esenciales para encontrar casos dispuestos a participar en esta investigación. Primordialmente, los primeros contactos se hicieron a través de las presidentas de estos grupos de autoayuda, en los casos de Finlandia y Austria, y a través de la trabajadora social de la Asociación de enfermos de Esclerosis Múltiples de Alicante, en España. La ayuda de traductores a la hora de realizar las entrevistas fue totalmente necesaria, con el fin de que las personas entrevistadas pudieran expresarse en su propia lengua materna. Además, también se requirió ayuda para las transcripciones y traducciones de las mismas, ayuda que fue ofrecida por los departamentos de Trabajo Social de la Universidad de Laponia y la Universidad de Ciencias Aplicadas de Vorarlberg. Pero para el estudio de las necesidades y experiencias de los hombres entrevistados, el análisis de contenido ha sido el método utilizado.

\section{Resultados}

\subsection{Las necesidades institucionales detectadas por los hombres en las situaciones de cuidados de larga duración}

Los resultados de este estudio apuntan diferentes necesidades que se han catalogado como institucionales, y son referidas a la responsabilidad institucional que cada uno de los sistemas de protección social tienen en los casos entrevistados. En primer lugar, los resultados apuntan una falta de información en el momento del diagnóstico en los tres países o regiones, tanto de la propia enfermedad como de los servicios accesibles a las mujeres enfermas de Esclerosis Múltiple y a sus familiares. Otro de los aspectos importantes es la falta de coordinación entre los servicios sociales y los sanitarios, concretamente en los casos de Austria y España. Justamente en estos países es donde aparece una menor presencia de la participación de los hombres en el cuidado de sus esposas. En el caso español, los esposos no participan en el cuidado de los casos independiente y dependiente, y en el caso austriaco tampoco lo hace el esposo del caso semiindependiente.

Los tres entrevistados en Vorarlberg (Austria) muestran cómo una vez diagnosticada la enfermedad y percibida la prestación por cuidados de larga duración, no existe un seguimiento ni coordinación entre los servicios sanitarios y sociales, a pesar de las posteriores visitas al hospital debido a las recaídas. La falta de seguimiento y coordinación cuando los pacientes abandonan el hospital entre los servicios de salud y los municipales se hace visible en los casos entrevistados. Además, esto influye en la calidad de los cuidados, la cual no puede asegurarse como tampoco la sobrecarga que los familiares a cargo 
de la persona enferma encuentran. Esto es debido a que, en la mayoría de casos, el dinero obtenido por la prestación de cuidados de larga duración que percibe la persona enferma, cuya cuantía depende del grado de dependencia y que tiene por objeto cubrir los gastos de los cuidados necesarios, es guardado por la familia, y es esta la que se ocupa de la atención de las mujeres enfermas. Por consecuente, la percepción de esta prestación económica no asegura una calidad del cuidado ni tampoco un seguimiento.

Un ejemplo de la falta de calidad en el cuidado se observó en el caso dependiente austriaco en el que la mujer dependiente no recibía ningún tipo de aseo personal, baño o ducha, permaneciendo sola toda la mañana sentada en su silla de ruedas mientras el esposo estaba en el trabajo, es decir, durante un periodo de tiempo aproximado de tres horas en el que ella se intentaba asear. Además, la respuesta de la mujer a la pregunta sobre quién le ayuda a bañarse fue que no sudaba y por lo tanto no necesitaba bañarse, sólo en verano su esposo la metía en la piscina del jardín cuando sudaba y hacía mucho calor. Este claro ejemplo muestra la falta de calidad de los cuidados, ya que aunque el esposo era su cuidador principal, ella no percibía ningún tipo de ayuda para el aseo personal, cuando apenas tenía equilibrio para permanecer sentada. Pero la cuestión no era únicamente que no recibiera ese tipo de cuidado, sino que tampoco existía ningún tipo de seguimiento por parte de los servicios sanitarios o sociales ni apoyo para formar al hombre, con el objeto de que pudiera proporcionarle los cuidados necesarios de forma adecuada.

Sin embargo, los casos españoles habría que explicarlos clarificando que las entrevistas se realizaron en el 2005, cuando todavía no se había aprobado la Ley 39/2006, del 14 de diciembre, de la Promoción de la Autonomía Personal y Atención a las personas en situación de dependencia, por lo tanto, de los entrevistados ninguna mujer recibía ningún tipo de servicio o ayuda debido a su grado de dependencia. Solamente una de ellas esperaba percibir el servicio de ayuda a domicilio tras separarse ficticiamente de su marido, quien se había empadronado en la ciudad y domicilio donde vivía un hijo de la pareja, con el fin de obtener así una mayor prestación. La falta de coordinación entre el servicio sanitario, así como la accesibilidad a los servicios y prestaciones en las situaciones de cuidados de larga duración, evidenciaba la forzada responsabilidad de la familia, y con ello, de las mujeres de la familia principalmente. Porque aunque si bien es cierto que en el caso semiindependiente el esposo era el cuidador principal, también es importante mencionar que no tenían ningún pariente o familiar que viviera cerca y además tenían dos hijos y ninguna hija.

De este modo, puede observarse cómo cuando la responsabilidad del cuidado recae en la familia, bien sea de forma forzosa (ejemplo español), como 
de forma «voluntaria» (ejemplo austriaco), en los sistemas de protección social promovían la importancia de las familias en el cuidado, de una manera u otra, reproduciendo así los roles tradicionales. Porque incluso en el caso austriaco, incluso cuando se utiliza el dinero para contratar ayuda externa al núcleo familiar, ésta suele ser femenina. En ambos casos, la falta de coordinación entre el sistema sanitario y social se hace latente repercutiendo en la calidad del cuidado ofrecida, apuntándose una necesidad en el seguimiento de los casos.

Sin embargo, los resultados apuntan la existencia de coordinación entre los Servicios Sociales y Sanitarios en Finlandia, puesto que tras el diagnóstico se elabora un plan personalizado utilizando todos los servicios y recursos disponibles para proporcionar los cuidados necesarios y de calidad a la persona enferma. Además, a través de los profesionales que atienden los casos se realiza un seguimiento de la situación, con visitas periódicas por parte de la trabajadora social del centro de rehabilitación de la provincia. Otro aspecto importante en el sistema de protección social finlandés es la prestación familiar en la que un pariente o amigo puede pasar a ser el cuidador principal y percibir un salario por ello, convirtiéndose en un cuidador formal.

Otra de las necesidades que aparece únicamente en los casos españoles, es la económica, consecuencia del sistema de protección social existente en los casos de cuidados de larga duración, en los que las familias aparecen, según los resultados preliminares, como las responsables en primera instancia de ofrecer los cuidados necesarios. El carácter de prueba de medios que tenían los servicios y prestaciones dificulta el acceso a la mayoría de los casos, además, si tenemos en cuenta que según la estructura familiar los hijos adultos permanecen en el hogar familiar hasta edades mucho más avanzadas que en otros países como Finlandia o Austria, esto empeora la accesibilidad a los mismos.

En Laponia, la falta de oferta de empleo era un factor a tener en cuenta en la opción que algunos maridos realizaban al convertirse en cuidadores formales de sus esposas a través de la prestación familiar. Por ello, y aunque la enfermedad no suponía un problema económico, la falta de trabajo en la región más despoblada del país podía vivirse como una preocupación económica y la prestación económica de cuidar a la esposa enferma una alternativa al empleo, y no una elección libre, por lo tanto, también forzada de algún modo por el contexto en el que viven. 
4.2. Las necesidades personales de los maridos o parejas de mujeres en situación de cuidados de larga duración

Las necesidades personales son entendidas en este punto como aquellas que experimentan los hombres objeto de estudio a lo largo del proceso de la enfermedad de sus esposas. Dichas necesidades no se refieren exclusivamente a los recursos necesarios para ofrecer un cuidado de calidad o para poder implicarse en el cuidado sin que de ellos dependa todo el sustento económico de la familia, sino que se refiere a las necesidades surgidas a raíz de los cambios experimentados, tanto a nivel de sentimientos y emociones como a actividades de la vida cotidiana que han tenido que modificar. Las necesidades son, en primer lugar, de vida social y tiempo libre, necesidades íntimas-sexuales, necesidad de compartir y hablar de las vivencias y sentimientos que la situación les genera, así como también necesidades de apoyo.

Las necesidades de vida social y tiempo libre han sido expresadas por todos los esposos, inclusive por aquellos que no participaban en el cuidado de sus esposas, ya que todos han experimentado cambios debido a las consecuencias de la enfermedad sufrida por sus esposas. Esta necesidad va unida al sentimiento de pérdida, como por ejemplo, por las dificultades que algunos hombres experimentan a la hora de recibir invitaciones espontáneas, así como por las dificultades por parte de algunos amigos para relacionarse con la esposa enferma. Neufeld (1998: 961-963) también mencionó en su estudio la enorme dificultad existente para los maridos cuidadores a la hora preservar su vida social, por lo que consecuentemente viven sentimiento de pérdida. Este sentimiento también va unido a los cambios producidos en la intimidad de la pareja y a la actividad sexual de la misma. Se produce una pérdida en la relación además de cambios de su amor y de la imagen que ellos tenían de sus esposas, lo que influye en sus relaciones íntimas. Las necesidades de vida íntima-sexual con sus parejas han sido estudiadas previamente por Parker y Seymour (1998: 187-191), quienes señalaron los problemas que aparecen entre los esposos cuando son cuidadores, apuntando que estos problemas se dan más entre las mujeres que entre los hombres. Sin embargo, en las entrevistas realizadas se apunta a que los problemas son más latentes entre los hombres, puesto que no se sienten cómodos teniendo relaciones sexuales con sus mujeres debido a la condición de su salud y su falta de movilidad.

También aparecen necesidades de apoyo, así como de compartir las vivencias y cambios que se están produciendo en la vida de sus familias. Sin embargo, se muestra de forma común en todos los países, pero especialmente en Finlandia y Austria, la falta de comunicación por parte de los hombres para compartir e intercambiar experiencias, y con ello recibir apoyo. Esto va unido 
a un sentimiento de resignación. McKeown, Porter-Amstrong y Baxter (2004: 223-227) señalaron que los hombres que mostraban resistencia para pedir ayuda, iban adquiriendo más y más responsabilidades del cuidado sin darse cuenta, día a día, al mismo tiempo que la enfermedad iba progresando, pero sin sentir o percibir ningún tipo de gratificación por ello, sintiéndose orgullosos del trabajo que estaban haciendo, lo que de algún modo ayudaba a que no huyeran de la situación. En este punto aparece también una preocupación acerca del destino de sus esposas en el caso de que ellos cayeran enfermos.

Junto con los sentimientos de resignación y pérdida podemos encontrar diferentes preocupaciones a lo largo del curso de la enfermedad. Un aspecto común, cuando hablamos de preocupaciones, ha sido el hecho de vivir día a día tal y como muestran otros estudios acerca del cuidado a enfermos crónicos o terminales (Lililrank, 1998). El futuro es implícitamente la preocupación principal debido al miedo de cómo adaptarse a la condición de salud de sus esposas conforme vayan empeorando, por el carácter tan impredecible de la misma. El miedo al uso de la silla de ruedas se hace patente también en la mayoría de los maridos.

La necesidad de huir se ha hecho latente en algunos de los esposos quienes han mostrado sentimientos de rechazo, sin embargo, aparece en las primeras etapas de la enfermedad por parte de algunos maridos, tal y como mencionaban McKeown, Porter-Amstrong y Baxter (2004) en su estudio, principalmente de aquellos que no participan en el cuidado de sus mujeres, como ocurre en los casos dependiente e independiente español, o en el caso semiindependiente austriaco. El sentimiento de culpa brota en los maridos que no participan en el cuidado, tal y como ocurre en el caso independiente, donde el marido no acepta la realidad ni la enfermedad de su esposa ni tampoco los cambios que ello ha significado en su vida, intentando mantener así la normalidad y evitando incluso el recibir información de la enfermedad y sus consecuencias.

El estatus marital ha sido tradicionalmente uno de los factores principales para los hombres a la hora de convertirse en cuidadores (Detinberg y Clarkberg, 2002: 873-874). Las diferencias se muestran en lo referente a los sentimientos de obligación, vinculados también al matrimonio. En Finlandia, esos sentimientos fueron expresados por los maridos, concretamente de los casos semiindependiente y dependiente, quienes expresaron que ellos se casaron delante del cura e hicieron la promesa de respetarse. De forma similar, el sentido religioso del matrimonio y la creencia del destino fue señalada por el esposo del caso semiindependiente austriaco, que remarcó que la enfermedad de su esposa es una prueba que Dios ha puesto en su camino. Sin embargo, más allá del matrimonio, la importancia de una buena relación previa entre 
las parejas, junto con la influencia de los factores de contexto, tales como los recursos y servicios accesibles de apoyo en las situaciones de cuidado de larga duración, son algunos de los factores que más influyen en la participación de los hombres en el cuidado.

\section{Conclusión}

Este estudio dispone del material necesario para abrir debate y discusión acerca de las necesidades que las personas enfermas de Esclerosis Múltiple y sus cuidadores disponen y necesitan., así como de los diferentes recursos accesibles que pueden ayudar a la mayor participación de los hombres en el cuidado, lo que viene siendo una necesidad cada vez más latente debido a los cambios que nuestra sociedad está sufriendo. Además, también abre debate sobre las necesidades personales de los hombres a la hora de desempeñar trabajos tradicionalmente relacionados con las mujeres y la influencia que las dimensiones del género pueden afectar, tanto a nivel emocional y simbólico desde el modo en que ellos viven la situación, como a nivel de poder y producción, viendo el trabajo que desarrollan influenciados por el sistema de producción social de su contexto y las relaciones de poder del mismo, fomentando la participación del hombre en el cuidado de dependientes o el hecho de que sea la mujer quien todavía se siga ocupando de esas cuestiones, relegadas al ámbito privado de la vida.

Diferentes necesidades aparecen como resultado preliminar de este estudio. En primer lugar, la falta de información en el momento del diagnóstico, lo que resulta de vital importancia para afrontar la situación y buscar los apoyos necesarios con el fin de organizar el cuidado que la mujer enferma pueda necesitar. En segundo lugar, la necesidad de que exista una coordinación entre los servicios sociales y sanitarios, primordialmente en Austria y en España, sobre todo la necesidad de un protocolo de seguimiento de los casos, que puede llegar a tener efectos para asegurar la calidad del cuidado ofrecido por los hombres, así como la formación necesaria para que la desempeñen. Y, por último, la disminución de vida social, bien sea por ser el esposo-cuidador principal, bien percibiendo una prestación económica por ello como es el caso de Finlandia, o bien porque además de participar en el cuidado de sus esposas tienen que trabajar en sus empleos habituales, lo que reduce considerablemente la vida social de los hombres, sin contar con la disminución de visitas que reciben una vez diagnosticada la enfermedad. Además, la disminución o ausencia de actividad sexual con sus parejas, siendo todavía hombres adultos y activos, es otra de las necesidades con las que tienen que lidiar los esposos. Por lo tanto, el sentimiento de pérdida es constante en sus vidas. La necesidad 
de apoyo, tanto físico como moral, también es expresada por los hombres entrevistados, quienes aprenden a vivir con resignación la vida que les ha tocado vivir, basándose para ello en creencias religiosas o en un sentimiento de obligación o culpa que les obliga a hacerlo. También, otros mencionan el amor y el cariño como la principal razón para cuidar a sus esposas. Por otro lado, muchos se van involucrando casi sin darse cuenta en las labores de cuidado que se incrementan con el tiempo, sintiéndose orgullosos de lo bien que cuidan a sus esposas pensando que nadie lo puede hacer mejor que ellos, y viviendo en una preocupación constante por el futuro cuando piensan qué sería de sus esposas si ellos cayeran enfermos. De este modo, la enfermedad de sus esposas pasa a ser el centro de sus vidas, tal y como ocurre en los casos dependiente y semiindependiente finlandés y el caso dependiente austriaco.

En consecuencia, cabe concluir diciendo que el apoyo institucional es necesario para poder ofrecer la ayuda requerida a las personas con Esclerosis Múltiple pero también a sus cuidadores, que son en muchos casos sus maridos, y que a pesar de ser minoritarios cuando hablamos de cuidados, es importante tener en cuenta que los recursos ofrecidos no deben ir encaminados a una conciliación de la vida familiar y laboral de las mujeres, sino a una corresponsabilidad de ambos. Así, son necesarios e importantes el apoyo institucional y una suficiente información y coordinación en la evolución de una enfermedad crónica para poder ofrecer cuidados de calidad. Sin embargo, no podemos olvidar las necesidades de los hombres cuidadores, que también vienen desarrollando un papel importante en situaciones de dependencia, aunque menos numeroso que las mujeres. Estas prácticas están muy influenciadas por razón de género, sin embargo se encuentran en un proceso de cambio, y es necesario prestar atención a las necesidades surgidas a este respecto. Este estudio pretende acercar las experiencias de hombres de diferentes contextos con diversos apoyos y necesidades institucionales y personales.

\section{Bibliografía}

Connell, R. W., Gender, Cambridge, Polity Press, 2002.

Detinberg, E. y M. ClarkberG, «Informal caregiving and retirement timing among men and women: gender and caregiving Relationships in late midlife», en Journal of family Issues, n. ${ }^{\circ}$ 23, 2002, pp. 857-879.

Durán Heras, M. A., Los costes invisibles de la enfermedad, Bilbao, Fundación BBVA, 2002.

EsPing-Andersen, G., The three worlds of welfare capitalism, Cambridge, Polity Press, 1990. 
FernándeZ, O. y V. E. Fernández, Esclerosis Múltiple, Málaga, Fundación Española de Esclerosis Múltiple, 2004, pp. 13-38.

FERRERA, M., Welfare State Reform in Southern Europe. Fighting poverty and social exclusion in Italy, Spain, Portugal and Greece, Londres, Reoutledge, 2005.

FInk, J., Care. Personal lives and Social Policies, Bristo, Ed. Janet Fink, 2004.

Giddens, A., Europe in the global Age, Cambridge, Polity Press, 2006, pp. 135-166.

HEARN, J., Theorizing men and men's theorizing: Varieties of discursive practices in men's theorizing of men, 1998.

KRAMER, B. J. y E. H. ThOMPSON, Men as caregivers. Theory, research and service implications, Nueva York, Springer, 2002.

KRÖGER, T. y J. SIPILÄ, Overstretched. European Families up against the demands of work and care, Oxford, Blackwell, 2005.

La PARRA CASADO, D., La atención a la salud en el hogar: Desigualdades y Tendencias, Alicante, Universidad de Alicante, 2002.

Lililrank, A., Living One Day at time. Parental Dilemmas of Managing the Experience and Care of Childhood Cancer, Stakes, National Research and Development Centre for Welfare and Health, Research Report 89, 1998.

Martínez Román, M. A., «Las familias ya no podemos más». Riesgos de exclusión social de las familias que cuidan enfermos crónicos graves», en Revista del Ministerio de Trabajo y Asuntos Sociales, n. ${ }^{\circ}$ 35, 2002 pp. 145-165.

McKeown L.P., A. P. Porter-Amstrong y G. D. BaXter, «Pressures on State Welfare in Post-industrial societies: Is more or less Better», en Making a Euroepan Welfare State? Convergences and Conflicts over European Social Policy?, Taylor \& Gooby (eds.), 2004, pp. 17-35.

NeUfELD, A., «Men as caregivers: reciprocal relationships or obligation?», Journal of Advanced Nursing, 28(5), 1998, pp. 959-968.

PARKER, G. y J. SEYMOUR, "Male carers in marriage», en Re-examining feminist analysis of informal care, J. Popay, J. Hearn y J. Edwards, Routledge, Men Gender Divisions and Welfare, 1998.

PeAse, B. y K. Pringle, «Introduction: Studying Men's Practices and Gener Relations in a Global Context» En A man's world? Changing men's practices in a globalized world, B. Pease y K. Pringle (eds.), Reino Unido y Londres, Zed Bools Ltd., 2001, pp. 1-17.

Sanders, S., C. Morano, y S. C. Corley, «The expressions of Loss and Grief among Male Caregivers of individuals with Alzheimer's Disease», en Journal of Gerontological Social Work, 39 (4), 2002.

StOller, E. P., «Theoretical Perspectives on Caregiving men» en Men as Caregivers: Theory, research and service implications, Thompson y Kramer, Nueva York, Springer, 2002, pp. 51-68. 
StONE, R. I., «Long-Term Care Workforce Shortages: Impact on Families», en Family Caregiver Alliance, Policy Brief, 3, [en línea], 2001, <http://www.bjbc. org/content/docs/LTC_Workforce_Shortages.odf>. [Consulta: 20/11/2007].

ZECHNER, M., "Care of Older Person in Transnational Settings», en Journal of Aging Studies, 22, 2008, pp. 32-44. 


\title{
SERVICIO DOMÉSTICO Y TRABAJO DE CUIDADOS. HACIA LA PRIVATIZACIÓN DEL CUIDADO FAMILIAR
}

\author{
Domestic service and care work. \\ Towards the privatisation of family care
}

RAQUEL MARTÍNEZ BUJÁN*

\begin{abstract}
Resumen
Este artículo se inscribe en el estudio de la inmigración y el envejecimiento de la población desde una perspectiva asistencial que estudia a la población inmigrante como un recurso para cuidar a personas mayores. Desde esta aproximación, la migración internacional en España (y en los países de Europa del sur) es utilizada para cubrir las debilidades de la protección social a la dependencia y llenar los huecos que la incorporación laboral de las mujeres nativas ha dejado en sus hogares. Este mercado laboral de cuidados encuadrado, en la mayor parte de los casos, en el interior del servicio doméstico se ha llegado a convertir en nuestro país en un verdadero nicho laboral para las mujeres inmigrantes (fundamentalmente latinoamericanas) y, en la actualidad, se ha configurado como la principal vía de externalización y mercantilización del trabajo familiar de cuidados. Mediante un análisis del modelo migratorio, de la política social y del panorama laboral en Galicia y Navarra, se estudian de manera comparativa las causas del surgimiento de este sector de cuidados, el papel que desempeñan las mujeres inmigrantes en su aparición, la ubicación de esta actividad en el servicio doméstico, la incidencia de las nuevas tendencias privatizadoras de la política social y las implicaciones de algunos cambios sociales y demográficos como el envejecimiento de la población y la inserción de la mujer nativa al mercado laboral formal.
\end{abstract}

\footnotetext{
* Raquel Martínez Buján Universidade da Coruña

Facultad de Sociología

Campus de Elviña, s/n. 15071 La Coruña

Teléfono: 629358513

rmbujan@udc.es
} 
Palabras clave: inmigración, servicio doméstico, mujeres, personas mayores, cuidados.

\begin{abstract}
This paper studies immigration and the ageing of the population in terms of immigration as a resource to care for elderly persons. In this regard, international migration in Spain and other Southern European countries is used to cover care-related shortfalls in social protection, filling the gap left at home by native women entering the workforce. In Spain, this job market of care, which in most cases forms part of domestic service, has become a veritable niche for immigrant women (mainly from Latin America) and is currently the main way in which family care is outsourced and commodified. The migratory model, social policy and the employment situation in Galicia and Navarre are analysed in a comparative study of the causes of this growth in the care sector, the role that immigrant women play in it, how this activity fits within domestic service, the impact of the new trend towards privatising social policy, and the implications of certain social and demographic changes, such as the ageing of the population and native women joining the formal labour market.
\end{abstract}

Keywords: immigration, domestic service, women, elderly persons, care.

\title{
1. Introducción
}

«De nada han servido los reproches de la Iglesia, el rechazo de sindicatos y oposición, las preocupaciones del presidente italiano, el ex comunista Giorgio Napolitano, y las dudas de muchos juristas sobre su constitucionalidad: para los 650000 inmigrantes indocumentados, que se estima residen en Italia, su presencia en el país a partir de ahora basta para convertirlos en criminales. Ayer mismo se producían las primeras detenciones en varias ciudades.

La medida, contenida en el paquete de seguridad impulsado por el ministro del Interior, Roberto Maroni -miembro destacado de la Liga Norte, el partido que ha hecho de la lucha contra la inmigración el pilar de su proyecto político-, cumple la promesa que el Gobierno de Silvio Berlusconi realizó hace un año en su primer Consejo de Ministros.

Pero se trata de un cumplimiento sólo a medias. El Ejecutivo acaba de aprobar un decreto que, según cálculos oficiales, permitirá la regularización de al menos 300000 sin papeles. Y lo ha hecho a petición de miembros de la coalición en el poder que, en vísperas de la entrada en vigor de la ley antiinmigración, han puesto encima de la mesa el problema que supondría la criminalización de decenas de miles de badanti: personas que cuidan de mayores y enfermos y atienden a miles de familias italianas en sus hogares.

“¿Qué les decimos a las familias?”, se preguntó el viceministro de origen democristiano Carlo Giovanardi, quien propuso por primera vez esta regularización. Giovanardi suscitó recelos entre sus correligionarios del Pueblo de la Libertad, el partido de Berlusconi, y la ira de sus socios de la Liga Norte. Pero al final, la regularización masiva de cuidadores y personal doméstico ha sido aprobada por decreto esta misma semana. A partir del 1 de septiembre, estos trabajadores podrán 
ver legalizada su situación laboral tras el pago de una tasa, como cotizaciones atrasadas a la Seguridad Social, que espera ingresar unos 1300 millones de euros.

Se repite ahora en Italia lo ocurrido en 2002, cuando antes de que entrara en vigor una restrictiva Ley de Extranjería, el Gobierno de Berlusconi regularizó a 650000 sin papeles. "Fue la mayor regularización aprobada en Italia", recuerda Tito Boeri, economista y profesor de la Universidad Bocconi de Milán, quien subraya que el Ejecutivo ha tenido que responder de nuevo con una medida de emergencia. Porque el colectivo de badanti "representa para muchas familias el único recurso para tapar los huecos del sistema de protección social".

Pero aun con esta regularización selectiva, los problemas no parecen haberse resuelto. Porque la criminalización de los inmigrantes indocumentados también afecta a otros sectores productivos, como la construcción o la agricultura. Así lo aseguraban muchos representantes de los partidos integrados en el Gobierno, encabezados por el ministro para el Desarrollo, Claudio Scajola, quien, en el Corriere della Sera, se ha mostrado a favor de "solucionar las situaciones más delicadas, que no tienen nada que ver con la criminalidad". Sus palabras han levantado una polvareda política en Italia. La Liga Norte ha replicado "que no hay ninguna posibilidad de [aprobar] otras regularizaciones". Mientras, dirigentes del partido de Berlusconi han insistido en que se trata de una necesidad vital para las empresas. Ayer fue Fini, desde Bélgica, quien recordó a sus aliados políticos "que hay que respetar a los trabajadores aunque no tengan papeles".

"El debate abierto y la decisión de regularizar a las cuidadoras es la demostración de que las políticas del Gobierno sobre la inmigración han fallado y están destinadas a fallar", argumenta el profesor Boeri, "ya que las empresas del noroeste de Italia [el feudo político de la Liga Norte] necesitan mano de obra que las leyes sobre la inmigración hacen inaccesible".

El cupo de entrada de inmigrantes extracomunitarios ofreció 170000 puestos de trabajo en 2007. Se recibieron casi 700000 solicitudes. "Según la ley, son los empresarios quienes tienen que presentar una demanda [de permiso de trabajo] para inmigrantes que supuestamente están en el extranjero. Pero la realidad es que ya se encuentran aquí", explica el jurista de la Universidad de Palermo Fulvio Vassallo Paleologo. Para este especialista de legislación de extranjería, el Gobierno "criminaliza a los inmigrantes" con las nuevas normas y abre además "una situación imposible de sostener por los atascados tribunales italianos".

Pero es también una medida para obviar las limitaciones a las expulsiones previstas en la normativa de la Unión Europea. "La llamada directiva de la vergüenza, la directiva de retorno aprobada en diciembre de 2008, con todos sus defectos prevé garantías para los inmigrantes frente a la expulsión. Salvo que se haya cometido un delito", dice Vassallo. Pero en Italia ya es delito vivir sin papeles.

El País, 9 de agosto de 2009

En un contexto de crisis económica se convierten en ruidosas voces los rumores que ya desde hace tiempo solicitaban un endurecimiento del control migratorio, de la regulación de los flujos y de la deportación de inmigrantes clandestinos. Este discurso ha estado muy presente en el ambiente político, 
mediático y social, que achaca la inestabilidad económica y el aumento del desempleo al asentamiento de población extranjera. El debate ha cobrado un cariz especial en los países de Europa del sur cuyos regímenes migratorios se han caracterizado por la recepción de una elevada migración irregular «tolerada», combinada con un sistema de control fronterizo ineficaz que traduce su incompetencia en repetidos programas de regularización.

España ha experimentado uno de los procesos migratorios más intensos de los países desarrollados. Las fuentes de información demográfica tanto internacional (Organización de Naciones Unidas, OECD, Eurostat) como nacional (Instituto Nacional de Estadística) señalan que es el segundo país del mundo receptor de inmigrantes en términos absolutos (Laparra, 2008). Tal es así que si en el año 2000 el número de población extranjera se situaba en las 637085 personas, en la actualidad la cifra alcanza 5268764 personas $^{1}$, es decir, se ha multiplicado por diez en tan sólo ocho años. Este espectacular vigor de los flujos migratorios se ha producido también en Italia, Portugal, Grecia, Chipre o Malta (países con un saldo migratorio superior al de la media europea) y está relacionado con un ciclo económico positivo y con una necesidad laboral. Esta paradoja entre el mercado como demandante de mano de obra y el Estado como instrumento de control (Finotelli, 2008) se representa claramente en la actividad del sector doméstico de cuidados.

El servicio doméstico es, según la Encuesta de Población Activa (ofrecida por el Instituto Nacional de Estadística), la actividad laboral en la que se ha producido una mayor extranjerización. La incidencia de la población inmigrante en esta actividad es nueve veces mayor que entre la población nativa ${ }^{2}$. El enclaustramiento del colectivo foráneo en unas determinadas actividades minimiza la competencia laboral con respecto a la población autóctona. De ahí que la tasa de desempleo de los nativos haya descendido incluso en los años de mayor afluencia migratoria: pasó de un 13,7 \% en el año 2000 a un $10,8 \%$ en el $2004^{3}$. España es un país atractivo de inmigración (al igual que

1. Cifra del 1 de enero de 2008 del Padrón Municipal de Habitantes.

2. La incidencia se ha calculado dividiendo el porcentaje de población nativa entre el porcentaje de población inmigrante ocupada en una serie de actividades. Entre las que se encuentra una distancia más elevada, es decir, en las que existe una sobrerrepresentación de la población inmigrante son: la agricultura (incidencia $=1,5$ ), la construcción (incidencia $=1,9$ ), la restauración (incidencia $=2,4$ ) y el servicio doméstico (incidencia= $8,6)$.

3. Además, tanto en épocas de crisis como de bonanza, el desempleo afecta en mayor medida al colectivo extranjero que al autóctono. Mientras que la media de la tasa de paro en el periodo 2003-2007 se situó en un 9,2 \% para la población nativa, entre el colectivo inmigrante alcanzó la cifra de un 13,3\%. 
otros países de Europa del sur) pero no por su capacidad de acogida ni por su Estado de Bienestar, sino porque es bien sabido que se trata de una región en la que es fácil acceder a un empleo, con un importante sector de economía sumergida, fundamental para encontrar un trabajo en el comienzo del ciclo migratorio.

El sector doméstico de cuidados se ha configurado precisamente como una de esas actividades en las que la población extranjera, principalmente femenina y latinoamericana, pueden insertarse al cabo de pocos meses de su llegada a España. De hecho, una de las principales características de la composición de los actuales flujos migratorios que llegan a nuestro país es su tendencia a la feminización y a la latinoamericanización (Izquierdo et al., 2003). A 1 de enero de 2008, según los datos del Padrón Municipal de Habitantes, residen en España alrededor de 2500000 de mujeres extranjeras, siendo el colectivo latinoamericano el de mayor presencia de mujeres. Este número cuadruplica la cifra de seis años atrás. En el 2001, la presencia del colectivo femenino foráneo alcanzaba las 650000 personas. Esta elevada necesidad de mano de obra femenina en el mercado laboral español va a estar determinada por la demanda de trabajadores dedicados a servicios orientados a las familias. Esto es, empleadas de hogar transformadas en niñeras y cuidadoras de personas mayores.

Según los últimos datos de afiliación a la Seguridad Social ofrecidos por el Ministerio de Trabajo (diciembre 2008), el 56,6 \% de las personas incluidas en el Régimen Especial de Servicio Doméstico es extranjero. La aparición de esta extranjerización en el servicio doméstico ha estado vinculada al envejecimiento de la población y a la incorporación de la mujer nativa al mercado laboral formal. El cuidado de personas dependientes, principalmente ancianos, por parte de empleadas de hogar inmigrantes se ha convertido en el primer trabajo que han encontrado a su llegada a España.

Este artículo tiene como objetivo principal analizar las características del sector de cuidados relacionado con la asistencia a personas mayores y delegado a las mujeres inmigrantes en el ámbito doméstico, haciendo especial hincapié en cómo se ha procedido a privatizar el trabajo familiar de cuidados y cuáles son las características e implicaciones de este sector de actividad tanto para las cuidadoras como para las personas mayores.

La metodología utilizada es cualitativa y forma parte de la elaborada para la redacción de mi tesis doctoral («Bienestar y cuidados: El Oficio del Cariño. Mujeres inmigrantes y mayores nativos»). El trabajo de campo efectuado está basado en entrevistas en profundidad dirigidas a tres colectivos: mujeres inmigrantes cuidadoras de ancianos (30 entrevistas), familias empleadoras 
(20 entrevistas) y técnicos de asociaciones, ONGs y otras instituciones con una bolsa de empleo para el trabajo de cuidados ofertado a extranjeros (20 entrevistas). El espacio geográfico de la investigación se circunscribe a la ciudades de La Coruña y Pamplona, lugares en los que se ha realizado el trabajo de campo.

\section{El incumplimiento de la protección social}

Con un 16,5 \% de personas que sobrepasan los 65 años, España se ha convertido en un país envejecido. La asociación entre edad y ausencia de autonomía repercute en una elevada presencia de población dependiente. La «Encuesta sobre Discapacidades, Autonomía Personal y Situaciones de Dependencia» de 2008 indica que existen 3,8 millones de personas con alguna discapacidad, lo que supone el 8,5\% de la población. Remitiéndonos al colectivo de más de 65 años, las cifras indican que el 30,5\% de las personas mayores poseen algún tipo de discapacidad que está asociada a una dependencia en un 21,6\%. Es decir, al menos un cuarto de las personas de más de 65 años son dependientes y necesitan de la ayuda de una tercera persona para realizar las actividades básicas de la vida diaria ${ }^{4}$.

Si ponemos estos datos en relación con la oferta pública de servicios sociales destinados a cubrir las situaciones de dependencia, encontramos una auténtica escasez de cobertura en la protección social. Las principales fórmulas de asistencia personal desarrolladas desde la Administración (es decir, las residencias gerontológicas, el servicio de ayuda a domicilio, la teleasistencia y los centros de día) presentan un índice de cobertura de un 12,1 \% (Sancho, 2007). Es decir, tan solo doce de cada cien mayores son usuarios de un servicio público.

Con estas cifras ya se intuye que la familia se convierte en la institución protagonista en la provisión de cuidado y asistencia de las personas de edad. En unos casos es la única proveedora de la atención, y en aquellos en los que existe un apoyo de los poderes públicos, éstos tienen un papel

4. Estas actividades están consideradas en todas las tablas que se presentan en este apartado son: lavarse, cuidados de las partes del cuerpo, higiene personal relacionada con la micción, higiene personal relacionada con la defecación, higiene personal relacionada con la menstruación, vestirse y desvestirse, comer y beber, cuidado de la propia salud: cumplir las prescripciones médicas, cuidado de la propia salud: evitar situaciones de peligro, adquisición de bienes y servicios, preparar comidas, realizar las tareas del hogar, cambiar las posturas corporales básicas, mantener la posición del cuerpo, desplazarse dentro del hogar, desplazarse fuera del hogar, uso intencionado de los sentidos (mirar, escuchar ...) y realizar tareas sencillas. 
complementario. El respaldo familiar es el colchón que amortigua las incontingencias de nuestros mayores. Aún en el caso de las personas que poseen ayuda de algún servicio social para afrontar la merma de sus capacidades, éste siempre necesita de una red de apoyo informal que permita el desarrollo adecuado de los programas de rehabilitación y mantenimiento (excepto en el caso de las residencias en donde acuden los mayores que no tienen familiares que los cuiden).

Legislativamente la Constitución reconoce el papel fundamental que deben cumplir las familias en la asistencia a personas dependientes, a pesar, de que también tiene que desarrollarse una red de servicios sociales que permitan el adecuado cuidado de este colectivo (artículos 41 y 50). Actualmente el conflicto de las familias con este aparato legislativo surge desde el momento en que se producen transformaciones familiares que han repercutido en la estructura del «trabajo de cuidados» dentro del hogar. El progresivo envejecimiento de la población, la incorporación de la mujer al mercado laboral y el paso de las familias extensas a las nucleares, ha generado que dentro de los hogares confluyan nuevas expectativas y roles que son incompatibles con los desempeñados antaño.

La escasez de un mercado privado de cuidados profesionales que sea flexible y económico ha repercutido en que las familias españolas hayan decidido externalizar la atención de los mayores hacia el servicio doméstico. Este sector proporciona tanto cuidados personales como ayuda para el mantenimiento del hogar, de tal manera que, en los últimos años esta opción se ha convertido en la principal vía de privatización. Los datos del IMSERSO (2004) confirman que, si bien, el 83,5\% de las familias cuidan sin ninguna ayuda adicional ni pública ni privada de sus mayores, lo cierto, es que cuando deciden subcontratar este trabajo familiar, la principal vía es emplear a una trabajadora domestica, que en la mayoría de los casos es una mujer inmigrante.

«¿Por qué? Porque las dos hermanas que estábamos aquí en Pamplona estábamos trabajando y entonces no disponíamos de tiempo suficiente para cuidar a nuestro padre que no se podía quedar solo. Estaba todo el día ya que se le iba un poco la cabeza. Aunque se manejaba él pero... solo no podía estar. Entonces era para cubrir las horas que nosotras no podíamos estar y bueno...» (Mujer contratadora de una cuidadora inmigrante, Pamplona, 2004) «Bueno, pues porque mi madre estaba muy bien y ella sola en el pueblo, y la encontramos muy mal. Una mañana que no la veía ni la encontraba y bueno, [...] decidimos que al vivir sola tenía que haber alguien con ella. Resulta que le había dado una trombo y se encontraba ya muy mal, en un estado muy crítico. ¿Cómo decidimos? Pues ninguno vivíamos en el pueblo. Todos estábamos fuera, todos trabajando, todos con hijos.» (Mujer contratadora de una cuidadora inmigrante, Pamplona, 2004) 
«Contratamos a una persona extranjera para cuidar de mi madre porque yo no podía atenderla durante el día. Me dijeron que no había españolas para hacer el trabajo. Tengo una librería y estoy todo el día fuera de casa. Ya sabes que una librería es muy atado porque tengo que abrir todos los días de la semana, sábados y domingos. Mi marido también trabaja y mis hijos, cada uno tiene su trabajo. Cuando mi madre empeoró y me la traje a mi casa se me echó el mundo encima. No era capaz de hacer todo el trabajo. Al final decidí contratar a alguien y las únicas personas dispuestas eran inmigrantes.» (Mujer contratadora de una cuidadora inmigrante, La Coruña, 2003)

Esta decisión, todavía minoritaria entre la población nativa, ha repercutido ampliamente en el mercado laboral del colectivo extranjero, llegando incluso a convertirse en el primer trabajo que encuentran las mujeres inmigrantes recién llegadas (Martínez Buján, 2008). La mayor vulnerabilidad de este colectivo, en muchos casos irregular, provoca que puedan acentuarse las situaciones de abuso y de explotación. Sólo adentrándonos en las características laborales de este sector de asistencia podremos deducir las verdaderas implicaciones de esta actividad sobre las cuidadoras y los receptores del cuidado.

\section{Los beneficios de las cuidadoras domésticas}

La preferencia de las familias por la contratación de cuidadoras en el seno del servicio doméstico está en gran parte determinada por las características laborales de este sector, que permiten una mayor flexibilización de horarios, una adecuación entre el tiempo de atención y el desarrollo de las tareas domésticas y la presencia, mediante la «modalidad de interna», de una cuidadora permanente que esté pendiente de las necesidades del mayor durante las 24 horas diarias. La oferta de provisión de cuidados por empresas privadas tiene un coste económico tan elevado que pocos presupuestos familiares pueden soportarlo. Además, la frecuencia y el tiempo de asistencia que ofrecen no alcanzan a cubrir las necesidades de la población dependiente.

El tiempo medio de atención diario suministrado por las familias es de once horas y la duración del cuidado tiene una media de seis años (INE, 2000). Teniendo en cuenta estas cifras, es lógico pensar que la familia necesite una cuidadora que dispense una asistencia continuada incluso durante la noche. Las familias empleadoras requieren una persona que realice tareas que van más allá de la atención personal al mayor: desde un «trabajo físico» como es la limpieza del hogar y los cuidados personales a un «trabajo emocional» que supone la presencia continúa de una persona que ofrezca con su compañía bienestar y cariño. Y esta tarea no es realizada desde las empresas privadas, cuyas cuidadoras únicamente se dedican a tareas específicas de asistencia personal. 
«Yo las cogía (se refiere a las cuidadoras) a través de agencia y ellas se dedican al cuidado de personas mayores y entonces: "No se preocupe porque nunca le va a faltar una persona". Al principio por eso decidí hacerlo por agencia. El salario pues se notaba, es más gravoso, pero era parecido el salario porque era el mismo, lo que pasaba que una me cubría siete horas y la otra todo el día. Y yo por el salario siempre me he regido por las normas de la asociación que eran las mismas para el empleo doméstico en España.» (Mujer contratadora de una cuidadora inmigrante, Pamplona, 2004)

«Una persona de aquí que te haga ese trabajo no hay nadie. Sé que hay algunas empresas que hacen unos turnos de mañana, tarde y noche pero eso es carísimo. Estábamos hablando de 400000 ó 500000 pesetas todos los meses. Y no hay quien mantenga eso. Y entonces a partir de eso con lo que había ya en ese momento ya se planteó coger a una persona de fuera.» (Mujer contratadora de una cuidadora inmigrante, Pamplona, 2004)

«Es que las de aquí -la entrevistada se refiere a las mujeres españolas- cobran carísimo. Nosotros pagamos a esta chica, 570 euros. Está mantenida y asegurada. Y aquí te dicen, 600 euros de día y 750 de noche. O sea, que te salen carísimas.» (Mujer contratadora de un cuidadora inmigrante, La Coruña, 2003)

La tesis doctoral de Sonia Parèlla Rubio (2003) en la que se realiza un análisis de las empresas de proximidad dedicadas a prestar servicios de atención personal y domésticos (dirigidos a personas dependientes) representa una útil fuente de datos a partir de la cual se pueden comparar las experiencias empresariales y las de empleadas de hogar en torno a este ámbito. La autora refleja cómo las familias que han decidido contratar el trabajo de cuidados a través del mercado formal privado lo han hecho como una segunda opción frente a experiencias negativas anteriores con una empleada doméstica. Otro de los motivos aducidos es la ausencia de una red de «contactos personales» que permita contratar a una persona «de confianza» en el hogar. Además, en estos casos, «el cliente o usuario contrata un servicio y no una persona (es la empresa y no el particular quien posee la condición jurídica de empleador)» siendo ésta otra de las ventajas «por cuanto ello ofrece al cliente la garantía de que siempre va a contar con alguien que cubra el servicio, con independencia de las circunstancias personales de la trabajadora» (Parèlla, 2003: 313).

Incluso así, la mayoría de las familias españolas que deciden externalizar el trabajo de cuidados lo hacen principalmente hacia empleadas domésticas debido a las elevadas ventajas económicas, al mayor tiempo de atención dispensado y a que el tipo de tareas que estas personas ofrecen no se limitan únicamente a los cuidados personales, sino que también engloba actividades relacionadas con el mantenimiento doméstico. Por un lado, las relaciones de dominación y explotación que pueden realizarse dentro del dominio privado representan, sin duda, una ventaja (Ungerson, 1999; Stefoni, 2002). Y por 
otro, la garantía que ofrece el ámbito empresarial en la realización de un seguimiento y evaluación de la trabajadora no está ausente en el caso de la contratación individual de una empleada de hogar, principalmente, si ésta se ha realizado por medio de una asociación. Aquellas instituciones con bolsa de empleo para cuidadoras actúan como verdaderos agentes responsables de la relación contractual tanto hacia la empleada como hacia la familia empleadora intentando ejercer de mediadores en caso de conflicto o descontento por alguna de las partes (Martínez Buján, 2006).

Estos beneficios en la contratación de empleadas de hogar para el trabajo de cuidados son vistos por algunos gerentes, siguiendo el trabajo de Parèlla, como una «competencia desleal» por los bajos precios que pueden llegar a ofrecer las familias empleadoras y por la creciente internacionalización del trabajo que ha puesto un ejército de reserva formado por mujeres inmigrantes capaces de aceptar condiciones laborales que rozan el «servilismo». El incumplimiento de la Administración en las tareas de asistencia personal fomenta la extensión del sector de cuidados privado. Este mercado de asistencia se ha modelado en nuestro país a partir del servicio doméstico y, en el actual contexto de migración internacional, se ha convertido en un nicho laboral para las mujeres inmigrantes. La flexibilidad de las condiciones de trabajo, la irregularidad y los bajos salarios determinan la necesidad de que un colectivo vulnerable se incorpore a esta actividad, requiriendo este trabajo una empleada que pueda ofrecer bienestar y asistencia.

\section{Actividades desempeñadas por las cuidadoras en los hogares}

En el sector doméstico de cuidados es común que la atención personal de los ancianos se combine con las actividades de limpieza y mantenimiento del hogar. Al ser un trabajo realizado en el interior del domicilio, las cuidadoras de ancianos, no son solamente eso, sino que se convierten en "chicas para todo». Esta situación es especialmente importante en el régimen de interna. El 89,4\% de las cuidadoras entrevistadas en el estudio «Empleados de Hogar. Apoyo a Mayores» (IMSERSO, 2004) asegura que la realización de las tareas domésticas (limpiar, planchar, cocinar...) forma parte de su trabajo junto con la asistencia y cuidados. Ello repercute en la invisibilización de su trabajo como cuidadoras, en la escasa valoración del mismo y en la asimilación del acto de cuidado como una mera actividad doméstica más. La limpieza y la toma de contacto con el anciano se hacen al mismo tiempo. Bañar al mayor, responsabilizarse de las medicinas, acompañarlo al médico e ir con él a dar un paseo para que recupere algo de su movilidad, son las actividades más sencillas que ha de realizar una cuidadora. La incontinencia fecal y urinaria y la vigilancia 
nocturna del anciano, son los aspectos más duros que se tienen que afrontar en este empleo.

«En Colombia tú trabajas de enfermera y es solamente para cuidar a la persona. Solamente tú te dedicas al paciente. Si hay que ponerle unas inyecciones, si hay que ponerle suero, si hay que estar pendiente de las medicinas, solamente del paciente. Aquí viene una chica, una señora que es la que hace el aseo general, pero yo a diario me levanto a las 9:00 de la mañana, aspiro, luego le hago un jugo de naranja a ella, luego ella se levanta, la visto, ella ya camina un poco, pero está muy mal.» (Cuidadora colombiana, La Coruña, 2003)

«También limpio la casa. Porque aquí va incluido eso también. En el momento en que no estás cuidando a la persona estás haciendo algo.» (Cuidadora brasileña, La Coruña, 2003)

«Les ayudo a bañarse, les baño, pero con la una, con la mayor, es la más ágil, está mucho mejor en sus facultades mentales, es más cuerda, está más lúcida... Ella se da cuenta de todo, ella no necesita otra persona más que, por ejemplo, lo que yo le hago. La comida, le ayudo al aseo, la ropa limpia, la ropa planchada, a la otra sí tengo que bañarle todos los días, tengo que cambiarle la ropa, usa pañal a la noche, bueno, las dos las tengo con pañal, porque si no es terrible. La casa, cuando llegué, es fatal. Está terrible. Tuve que empezar a limpiar, a hacer todo. Las cosas de casa también. Es un trabajo bastante fuerte.» (E7, cuidadora ecuatoriana, La Coruña, 2003)

«Y claro, dirán: "Esta señora no va a venir a cuidar solo a mi padre" y entonces también les limpio la casa.» (Cuidadora venezolana, La Coruña, 2003)

El cuidado de personas mayores es una actividad con unas características propias que difieren de las encontradas en las tareas relacionadas con la limpieza del hogar e incluso también divergen de las tareas de atención a niños. El «cuidado de ancianos» amplía y extiende las actividades que clásicamente desempeñaban las «sirvientas». A la limpieza del hogar se suman las de vigilancia y asistencia de los miembros más mayores. Ello supone tener bajo control la vida de personas a las que es necesario atender no únicamente desde el punto de vista físico. La asistencia pasa por la comprensión, el cariño y la compañía. A las duras tareas de atención personal relacionadas con el aseo, la movilidad, el suministro de medicamentos y la vigilancia nocturna también se añaden actividades emocionales conducentes a mantener el bienestar psicológico del enfermo anciano.

«Tienes que tener mucha humanidad. Hoy no he dormido, porque hay noches que quiere ir al baño y no quiere la cuña, quería ir al baño y en el baño me tuvo media hora sentada, media hora. Y otros dirán, que fatal, no se duerme, que mal. Pero yo digo, éste es mi trabajo y qué le voy a hacer.» (E8, cuidadora ecuatoriana, La Coruña, 2003)

«Arrimamos la cama al ropero, y nos acostamos nosotros, por ejemplo, en el suelo. Nos acostamos al lado de ella para ver... si rueda, rueda, y si cae lo hace 
encima de nosotros pero nos damos cuenta de que cae. A veces, quiere levantarse y yo estoy ahí y le digo: "Duerme, duerme, no te preocupes". Dormimos así más tranquilos, a pesar de que se levanta y nos llama...» (Cuidadora ecuatoriana, La Coruña, 2003)

«Era psicópata depresiva. Era terrible, terrible. Pensaba en suicidio, suicidio, suicidio, está en un cuarto oscuro y estuve tres meses para levantarla de la cama y que fuera a la calle, para pasear, para andar. Tres meses, pero hacía tres años que estaba en la cama en un cuarto oscuro. Tenía asistente social, psiquiatra, todos trabajando juntos, un día tiró ella de la cama, y un día me llama: "María, estoy fatal", "¿Qué fue?", "Sale un poquito". Y ella se anima y sale. Tiene manía ahora conmigo. Para mí fue terrible. Yo tenía miedo de salir un día de aquí, llegar allí y encontrarla muerta. Fue terrible (...). Ella sigue aún con tratamiento.» (Cuidadora brasileña, La Coruña, 2003)»

«Pero la señora desvariaba un poco de la depresión y después tuvo una trombosis, siempre se caía. La casa era pequeña y había poco que limpiar y la señora no era difícil, sólo había que cocinar unas verduras y pasar, hacer unas papas con leche y un poco de café y galletas y la ayudaba a sentar y a comer sola. Ella misma comía sola. Y darle la medicina. La responsabilidad era darle la medicina, el horario era a las diez de la mañana... Siempre buscaba alguna cosa para que hiciese ella misma, peinarse los cabellos, pintarse... Ella no podía salir de casa porque se caía. No tenía una silla de ruedas. Ella sólo salía de la cama y se sentaba en el sillón. Tomaba muchísimos medicamentos para la depresión: siete comprimidos por la mañana, siete al mediodía, por la noche no sé si era menos, eran cinco.» (Cuidadora brasileña, La Coruña, 2003)

En el cuidado de niños la tarea emocional se considera más ligera psicológicamente, ya que se trata de personas con vitalidad y fuerza dinámica, de la cual carecen los mayores.

«Con niños es más gratificante trabajar. Es mucho más gratificante. Con ellos vives cada día. Con los ancianos tienes que tener una paciencia enorme. Tienes que tener una paciencia increíble. Tú ves que a diario van a menos. Un niño va a más. Porque van enseñando y todo toman, todo cogen. Entonces eso para ti es un estímulo y le enseñé esto... En cambio, el anciano va a menos. Cada día va a menos, tienes que ayudarle más, ves que va perdiendo las facultades, le ves que te necesita.» (Cuidadora ecuatoriana, La Coruña, 2003)

La trabajadora debe mantener una posición conversadora, de comprensión y de ánimo ante personas que quizá pierdan la vida en poco tiempo. Las cuidadoras entrevistadas afirman que uno de los mayores problemas de las personas receptoras de asistencia es el grado de depresión en el se encuentran, originado no únicamente por motivos de salud, sino también personales, que en muchos casos son agudizados por ciertos medicamentos. Las enfermedades, las patologías irreversibles, los medicamentos, influyen en el estado de ánimo de los mayores y en sus alteraciones de carácter. 
«Pero que una persona también que está muy malita, y ya uno tiene que ver con eso, que aunque tengan caprichos, uno sabe que es a través de su enfermedad o de sus cosas porque las personas enfermas siempre se aburren. Hay días que están muy a gusto, pero hay días que también... bueno, hay momentos en que están enfermas, pero dices, como fastidian... Cuando uno está malo no quiere ni que les toquen ni que les vayan a hablar, que le vayas a decir nada, pero...» (Cuidadora dominicana, La Coruña, 2003)

«Necesita, esa señora, necesita de mucho cariño, porque los hijos no pueden estar todo el tiempo con ella y ella lo que necesita es estar acompañada, no tanto los cuidados. Ella me llama y me dice que soy su ángel, que soy su... me dice que le toque con la mano en el lado izquierdo, y yo ojalá que con tocarla fuera suficiente, que le pase el dolor.» (Cuidadora ecuatoriana, La Coruña, 2003)

El esfuerzo físico y la implicación que suponen la custodia continua del mayor repercuten en el estado anímico de la cuidadora, sobre todo, si trabaja de interna. Como es bien conocido, y otros estudios han recalcado, el cansancio psicológico es un referente continúo en las mujeres que trabajan como internas en el servicio doméstico (Oso, 1998). Pero este agotamiento psicológico se agrava aún más cuando se añade el cuidado de una persona mayor, debido, precisamente, al mayor esfuerzo y dedicación que tienen que prestar.

«Y el otro ya te digo, se cuidaba prácticamente solo, pero a él había que darle más atención de... había que estar conversando con él... Claro, estás cansada, no te levantas con ánimos de nada, yo tenía que estar preguntándole: "Y cómo está, y cómo no sé qué". Y a veces ni me daban ganas de hablar y ya me ponía mala y: "Qué te pasa. Por qué estás así, por qué no me dices nada..." de verdad necesitas un poco de tiempo para relajarte y afrontar el día.» (Cuidadora ecuatoriana, Pamplona, 2004)

«Es que no puedo contar con mi tiempo para nada. Para nada. No soy dueña de mi tiempo, no puedo decir, hoy cojo y me voy, que me apetece hacer esto. No, no. Es imposible, no puedo [...] Sí, es terrible. Estoy empezando con un problema de varices, porque paso mucho tiempo de pie, y no duermo tranquila. Porque me da miedo[...]El cuidar a una señora no solamente implica emplear tu trabajo físico, implica psicológico... Claro, no es lo mismo que trabajar ocho horas y llegues a casa y te olvides de tu trabajo. No. Me importa mi trabajo. Cuentas con tu privacidad. Aquí no pasa eso, no puedes decir, estoy cansada de hacer esto. No puedes decir, bueno, estoy cansada y me acuesto. Todo el tiempo tienes que hacer algo, todo el tiempo que tienes que estar ahí, ahí y ahí. Hay gente mayor en el edificio que dicen: "es que si vienen acá tienen que trabajar, tienen que trabajar".» (Cuidadora ecuatoriana, La Coruña, 2003)

«Sí, es que uno se siente bien deprimida, psicológicamente se siente acabada. Se pasa todo el día sin poder decir nada, sin poder conversar, que si entra, que si sale, pero está cohibida de todas las cosas que dentro de la casa están. Si quieres poner música a un volumen más alto, no se puede. Ver a los 
programas de televisión que uno quiere, no se puede porque se tiene que ver lo que ella ve, lo que ella hace. Igual en la comida, tienes que comer lo que ella come y una está acostumbrada a otra comida.» (Cuidadora ecuatoriana, Pamplona, 2004)

La falta de espacio privado, de tiempo libre para relajarse y pensar en ella misma, la ausencia de un lugar propio que pueda «definir como suyo» agravan las circunstancias en las que se encuentra la inmigrante. El desarrollo vital y el trabajo pertenecen al mismo ámbito. No es posible separar lo que pertenece a tu propia vida de lo que es específico de tu ocupación. Ambos conceptos permanecen juntos, inseparables. No existe una definición del tiempo de tu jornada laboral, porque es todo el día. Estas horas no se pueden catalogar como extraordinarias, sino que es lo que la legislación denomina como «tiempo de presencia»: «Se trata de tiempos acordados entre el empleador y la trabajadora y que no se dedican a la realización de tareas domésticas habituales, sino de tareas que exijan poco esfuerzo, como abrir la puerta, coger el teléfono, etc.»(Martínez Veiga, 2004). Pero estas tareas no pueden ser definidas como de «poco esfuerzo» en la actividad del cuidado de ancianos. Levantarse por la noche, cuidar al anciano desvelado, suministrarle sus medicinas en horarios no «laborales», formarían parte del tiempo de presencia.

«A mí, a veces, cuando se me pone así... Todas las noches, por ejemplo, te llama. Y te llama, te llama, constantemente. Y no quiere nada, tan sólo verte. Ella por el día tampoco duerme. Tú estás cansada de la noche de no haber dormido, otro día atenderla más, porque se pone pesada... y es muy cansado.» (Cuidadora ecuatoriana, La Coruña, 2003)

«Entonces, al cuidar ancianos al principio mal porque la abuela se tiene que levantar todas las noches cada hora, o cada hora y media para ir al baño.» (Cuidadora colombiana, La Coruña, 2003)

«Las acuesto, las dejo, pero en la madrugada siempre me despierto a ver si respiran o no respiran. Porque como están viejitas, al menos ver si les pasa algo, o si puedes ayudarles o... llamar al médico o hacer algo. Unas dos veces me levanto a verles.» (Cuidadora ecuatoriana, La Coruña, 2003)

«No me dejaba dormir por las noches y me levantaba tres y cuatro veces a ver si se había orinado... Una vez me cansé: "Me hace levantar cada rato, así que si usted se orina le tendremos que poner pañales y yo me levantaré a las ocho de la mañana a darle el desayuno". De igual manera todo el día: arreglar la casa, hacer la comida, las cosas... Todo. La lavadora y todo. Entonces, se puso a llorar y me decía: "Eres una mala, chica mala, me tratas mal". Y le dije: "Usted verá". Porque era un suplicio levantarme, me acostaba a veces a las once de la noche, porque ella se acostaba a las nueve y yo arreglaba, estaba un rato despejada, pero a las once, once y media... A las dos de la mañana me llamaba, a las cuatro de la mañana me llamaba, a las seis, otra vez. Y a las ocho ya quería que le diese de desayunar porque la estoy matando del hambre. Entonces yo me levantaba cansadísima. O sea, es que para mí la noche, todo 
el día puedes estar sacando el aire como burro, pero por la noche yo tengo que descansar. Por suerte, se tranquilizó y no me molestaba a las noches.» (Cuidadora ecuatoriana, Pamplona, 2004)

En general, las cuidadoras han hecho un esfuerzo enorme por adaptarse a la situación laboral que les ha tocado desempeñar. En la encuesta del IMSERSO sobre empleadas de hogar cuidadoras de personas mayores (IMSERSO, 2004) se pidió a las personas entrevistadas (tanto españolas como extranjeras) que

Tabla 1. Tareas identificadas por las empleadas de hogar que cuidan mayores como las más costosas a realizar, 2004

\begin{tabular}{|l|c|}
\hline & $\begin{array}{c}\text { \% de personas que consideran } \\
\text { el desempeño de esa actividad } \\
\text { como más molesta* }\end{array}$ \\
\hline Acostarse/levantarse & 26,6 \\
\hline Cambiar pañales heces & 26,5 \\
\hline Utilizar el baño & 22,8 \\
\hline Bañarse/ducharse & 22,5 \\
\hline Moverse & 21 \\
\hline Andar por casa & 20, \\
\hline Administración dinero & 19,2 \\
\hline Salir/desplazarse & 18,9 \\
\hline Vestirse/desvertirse & 18,2 \\
\hline Ir al médico & 17,1 \\
\hline Asearse/arreglarse & 16,8 \\
\hline Otras tareas domésticas & 16,3 \\
\hline Utilizar el teléfono & 16,3 \\
\hline Gestiones & 16,3 \\
\hline Utilizar transporte público & 16,2 \\
\hline Abrochar los zapatos & 15,6 \\
\hline Cambiar pañales orina & 15,5 \\
\hline Dar medicación & 15,2 \\
\hline Preparar comidas & 14 \\
\hline Comer & 13,6 \\
\hline Hacer compras & 12,9 \\
\hline
\end{tabular}

Fuente: Elaboración propia a partir de IMSERSO, Empleados de Hogar. Apoyo a Mayores, Madrid, IMSERSO, 2004. Pregunta: «¿Podría indicarme, ahora, de todas las tareas que me ha dicho que realiza, cuáles son las que le resultan menos molestas?»

* La pregunta original de la encuesta estaba relacionada con indicar las actividades menos molestas. Sin embargo, por diferencia, teniendo en cuenta la base de respuestas, he calculado las personas a las que les resultaba la actividad más molesta. 
identificasen de entre una lista de actividades aquellas que considerasen más engorrosas de realizar. Las tareas que alcanzaron las puntuaciones más altas no han sobrepasado el $26 \%$ de las respuestas, lo que significa que el descontento no ha superado a un cuarto de la muestra. Las funciones menos agradecidas son las relacionadas con el cuidado personal del dependiente, principalmente, las vinculadas a aspectos que suponen un esfuerzo físico y/o asociadas a los elementos de intimidad personal del mayor. Destaca la dificultad que entraña el contacto íntimo que requieren algunos tipos de atención como el cambio de pañales en caso de incontinencia fecal o algunas actividades de movilidad como «acostarse/levantarse».

Por lo tanto, hacer la limpieza de la casa, la compra y todas aquellas tareas relacionadas con el mantenimiento del hogar y con la gestión, no se identifican como aspectos molestos a reseñar. La asistencia personal representa el trabajo más intenso de su jornada laboral y, por lo tanto, el más costoso a realizar.

Las entrevistas en profundidad realizadas a las cuidadoras inmigrantes recogen también situaciones de elevada carga laboral y escaso salario. En la Tabla 2 se resume cuál es el nivel de dependencia que sufren las personas de edad a las que cuidan las entrevistadas y qué tipo de enfermedades presentan. Los casos que más llaman la atención por el alto grado de vulnerabilidad son de aquellas cuidadoras (que estando trabajando como internas) tienen que hacer frente a la asistencia de más de un anciano. En general, se trata de casos de matrimonios mayores que han perdido la autonomía a causa de su avanzada edad (suelen sobrepasar los 80 años). Sin embargo, la mayor carga de cuidar a dos mayores no se traduce en un mejor salario mensual. Es el caso, por ejemplo, de Laura (E1), que con 410 euros se ocupa de la realización de la limpieza del hogar junto con la atención diaria de un matrimonio en en que el marido, de 86 años, padece Alzheimer, y la mujer, de 84, tiene un cáncer terminal. En la misma situación se encuentra E6, que hace frente al cuidado de una pareja de ancianos, ambos con dependencia severa, por un sueldo de 480 euros mensuales.

\section{Conclusiones}

La principal vía de privatización de la asistencia dirigida a personas mayores es el servicio doméstico. La empleada de hogar se erige como la figura principal en la dispensación de cuidados mercantilizados. Las ventajas que ofrece este recurso en cuanto a disponibilidad horaria y condiciones laborales son dos aspectos que inciden en su demanda junto con las deficiencias del sistema público de protección social. 


\begin{tabular}{|c|c|c|c|c|c|}
\hline 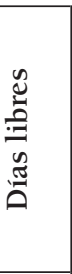 & 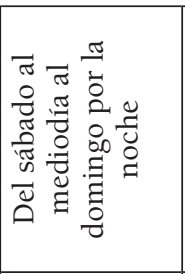 & 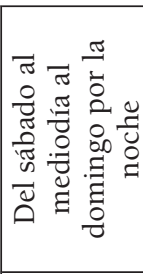 & 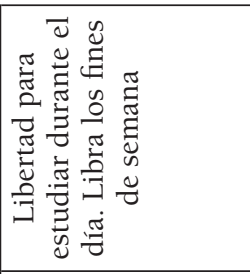 & & 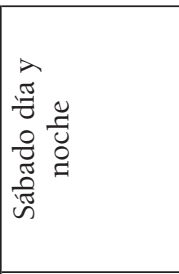 \\
\hline 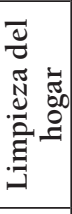 & is & in & 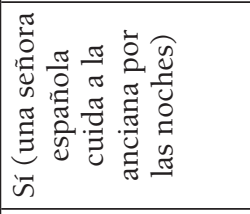 & $i n$ & 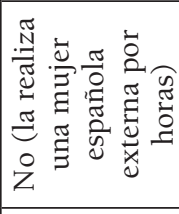 \\
\hline 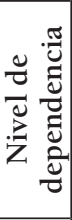 & 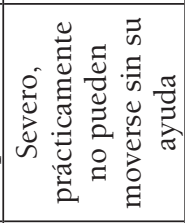 & 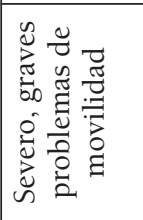 & 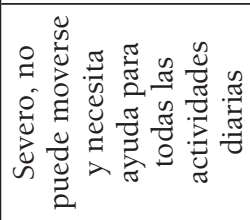 & 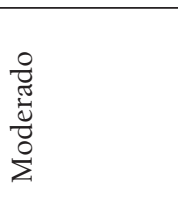 & 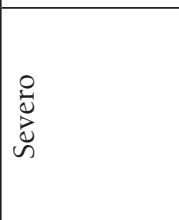 \\
\hline 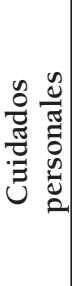 & 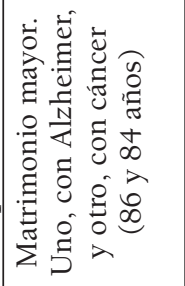 & 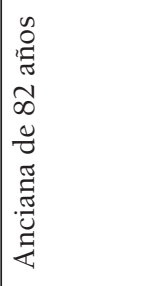 & 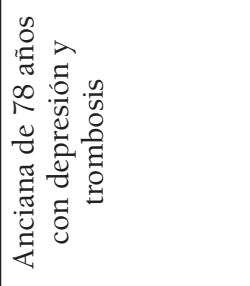 & 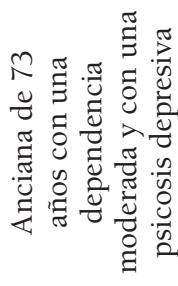 & 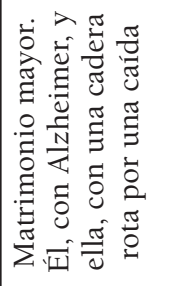 \\
\hline 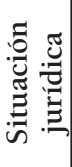 & 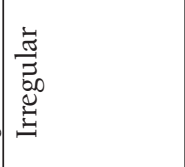 & 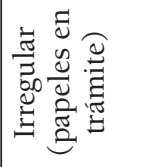 & 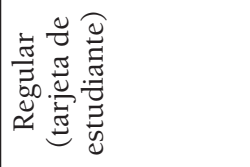 & 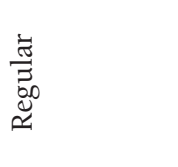 & 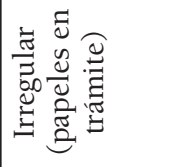 \\
\hline 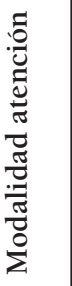 & $\begin{array}{l}\stackrel{\Xi}{\Xi} \\
\stackrel{\Xi}{\Xi}\end{array}$ & 蚫 & 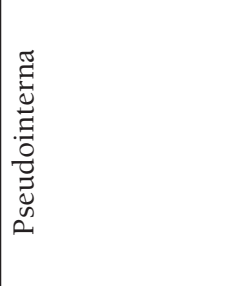 & 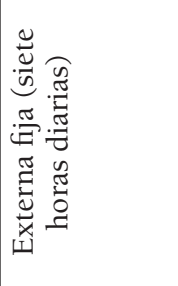 & 蚫 \\
\hline$\frac{O}{\sqrt[3]{\pi}}$ & 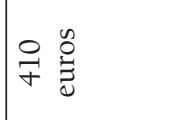 & $\begin{array}{ll}0 & 0 \\
\text { in } & 0 \\
0\end{array}$ & 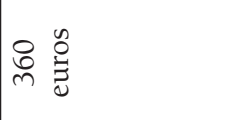 & I & 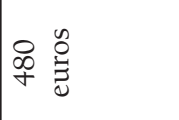 \\
\hline 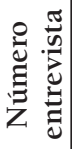 & 可 & 出 & 怘 & II & $\mid \begin{array}{l}0 \\
\end{array}$ \\
\hline
\end{tabular}

Alternativas, 17, 2010, pp. 157-179 - ISSN 1133-0473 


\begin{tabular}{|c|c|c|c|c|c|c|}
\hline 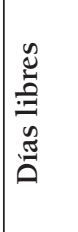 & 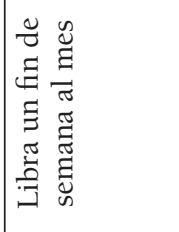 & 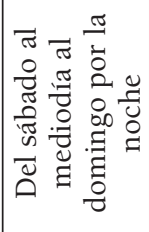 & 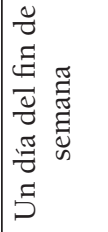 & 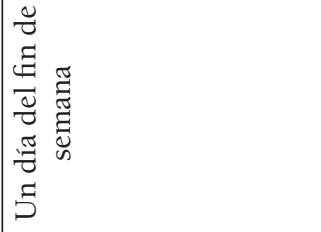 & 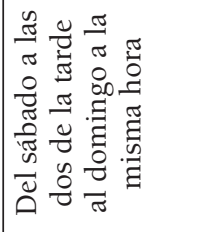 & \\
\hline 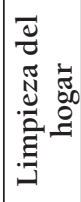 & in & in & is & $\stackrel{0}{z}$ & 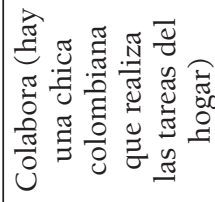 & $i n$ \\
\hline 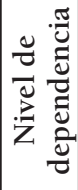 & 过 & 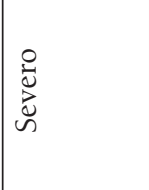 & 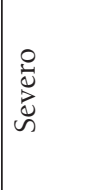 & 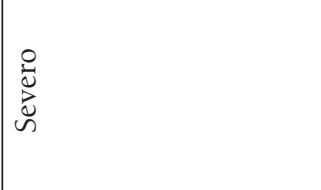 & $\begin{array}{l}\text { Oेँ } \\
\grave{J} \\
\tilde{N}\end{array}$ & $\begin{array}{l}0 \\
\frac{\pi}{\pi} \\
\frac{\pi}{\tilde{U}} \\
0 \\
\Sigma\end{array}$ \\
\hline 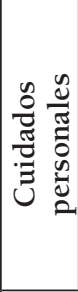 & 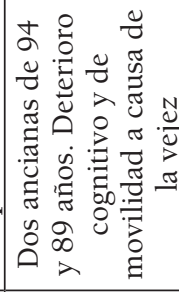 & 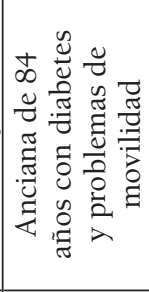 & 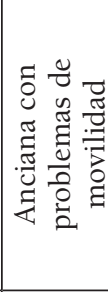 & 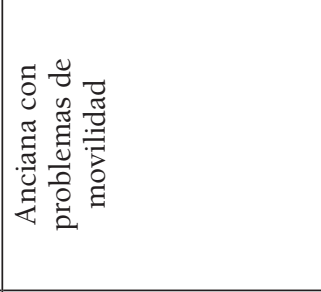 & 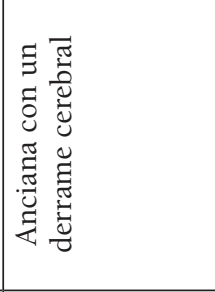 & 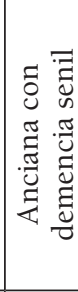 \\
\hline 总 & 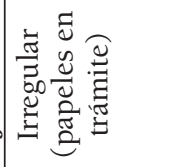 & 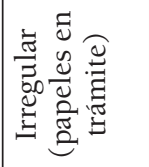 & 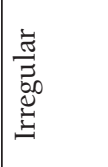 & 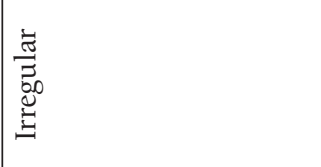 & 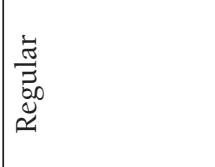 & 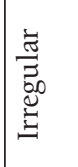 \\
\hline 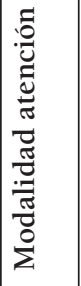 & 苞 & 苞 & 苞 & き & 苞 & 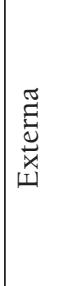 \\
\hline$\frac{0}{\sqrt[3]{\pi}}$ & 옹 & 옹 & $\stackrel{\overbrace{}}{\stackrel{0}{F}}$ & 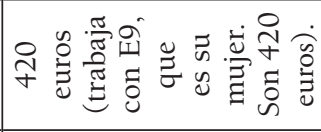 & 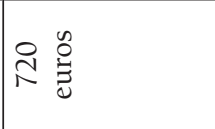 & \\
\hline 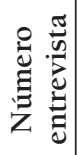 & 吉 & $\begin{array}{l}\infty \\
\amalg\end{array}$ & II & 号 & $\vec{I}$ & $\underset{\sim}{\tilde{I}}$ \\
\hline
\end{tabular}

Alternativas, 17, 2010, pp. 157-179 - ISSN 1133-0473 


\begin{tabular}{|c|c|c|c|c|c|c|}
\hline 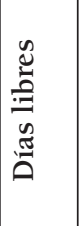 & 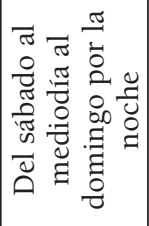 & 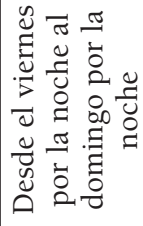 & & & 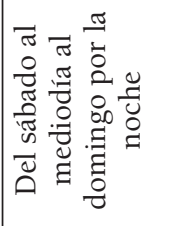 & \\
\hline 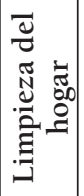 & in & in & in & 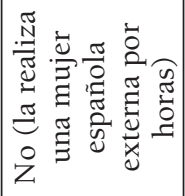 & 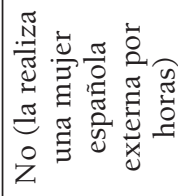 & \\
\hline 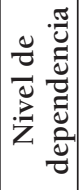 & $\begin{array}{l}0 \\
\dot{0} \\
\dot{U} \\
\omega\end{array}$ & 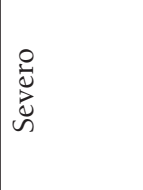 & $\begin{array}{l}\frac{0}{0} \\
\frac{\pi}{0} \\
\frac{0}{0} \\
\dot{\Sigma}\end{array}$ & $\begin{array}{l}0 \\
\stackrel{0}{0} \\
\stackrel{0}{u}\end{array}$ & & $\begin{array}{l}0 \\
\frac{\pi}{0} \\
\frac{0}{0} \\
\frac{0}{0} \\
\sum\end{array}$ \\
\hline 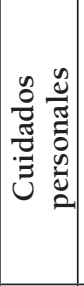 & 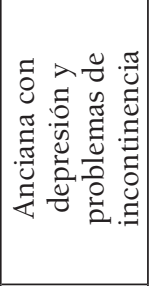 & 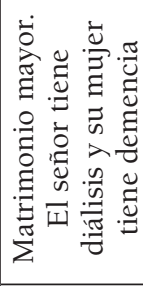 & 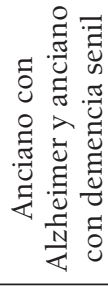 & 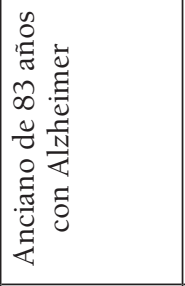 & 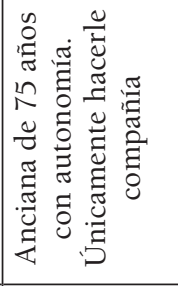 & 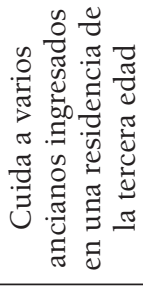 \\
\hline 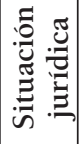 & 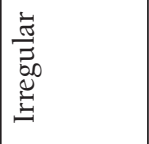 & 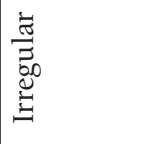 & 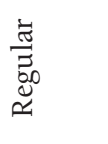 & 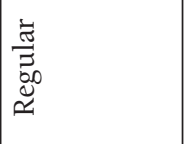 & 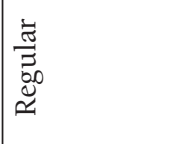 & 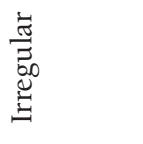 \\
\hline 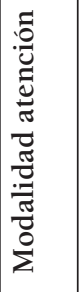 & 蚫 & 蚫 & 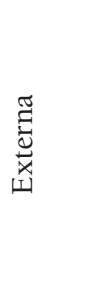 & 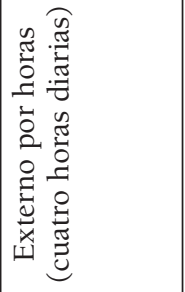 & 莺 & 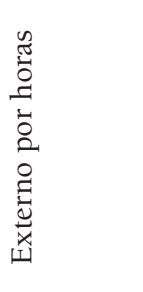 \\
\hline | & 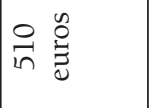 & î: & $\overbrace{0}^{0} \stackrel{n}{0}$ & 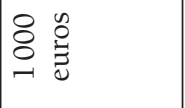 & 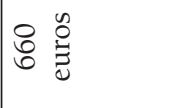 & \\
\hline 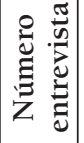 & $\stackrel{m}{\mu}$ & $\underset{\mid 山}{ \pm}$ & $\frac{10}{1 \pm}$ & $\frac{0}{I-1}$ & 武 & $\stackrel{\infty}{\underset{I}{\mid}}$ \\
\hline
\end{tabular}




\begin{tabular}{|c|c|c|c|c|c|c|}
\hline 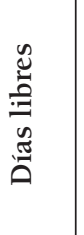 & 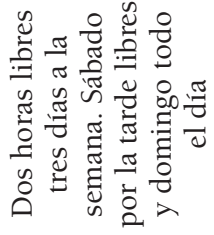 & 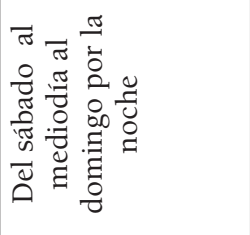 & 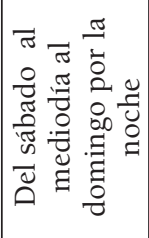 & 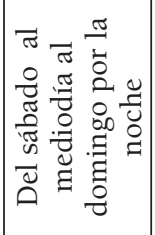 & 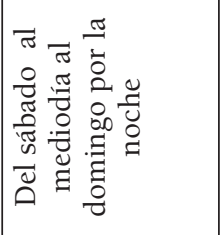 & ' \\
\hline 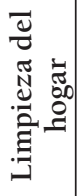 & in & in & in & is & in & $\stackrel{0}{z}$ \\
\hline 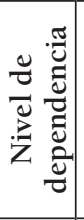 & 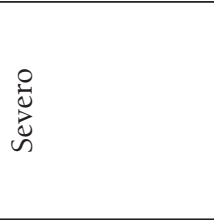 & 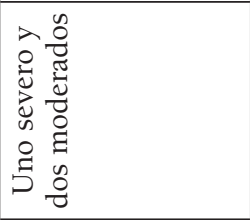 & 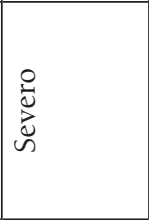 & 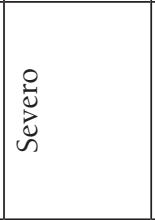 & 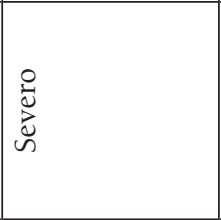 & 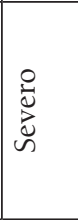 \\
\hline 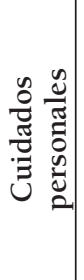 & 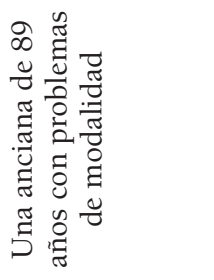 & 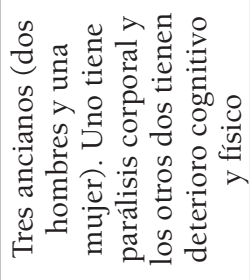 & 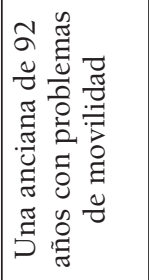 & 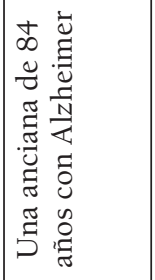 & 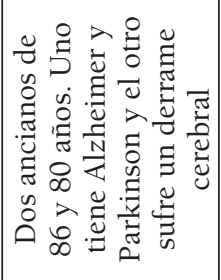 & 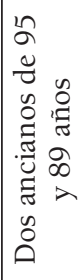 \\
\hline 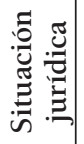 & 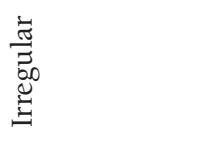 & 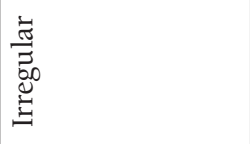 & 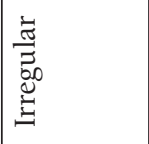 & 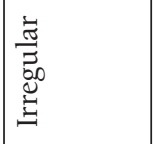 & 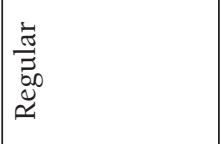 & 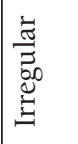 \\
\hline 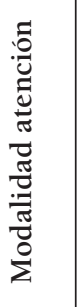 & 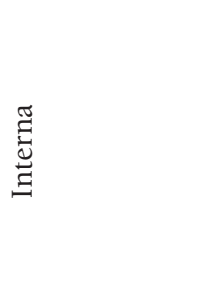 & 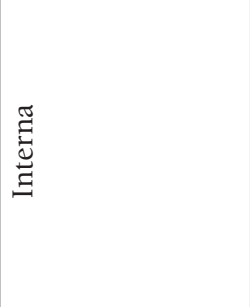 & 莺 & 苞 & 祃 & 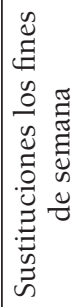 \\
\hline$\frac{0}{\sqrt[J]{\pi}}$ & $\overbrace{0}^{0}$ & ঃ & ஓ & ஓ & ஓ & ' \\
\hline 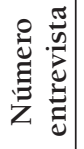 & $\stackrel{9}{\overrightarrow{1}}$ & 吕 & $\vec{\sim}$ & సี & 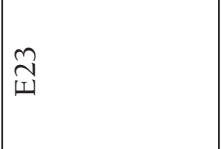 & 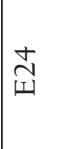 \\
\hline
\end{tabular}

Alternativas, 17,2010 , pp. 157-179 - ISSN 1133-0473 


\begin{tabular}{|c|c|c|c|c|c|c|}
\hline 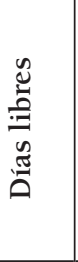 & 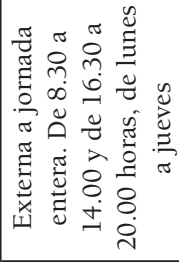 & 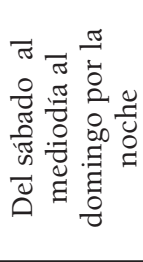 & 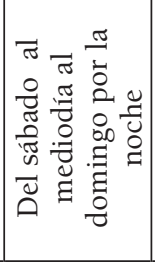 & 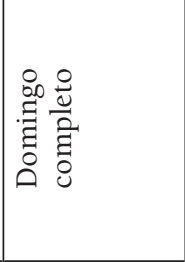 & 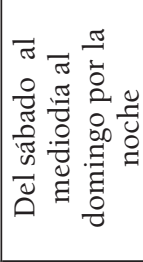 & 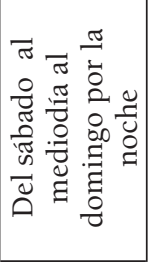 \\
\hline 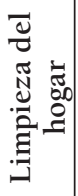 & in & $i n$ & in & 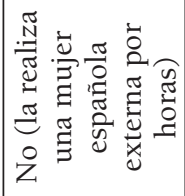 & in & $i n$ \\
\hline 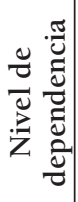 & 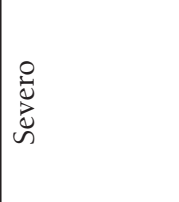 & 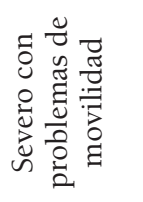 & 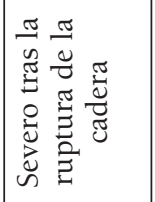 & 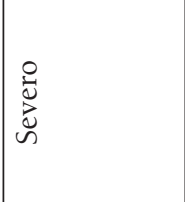 & 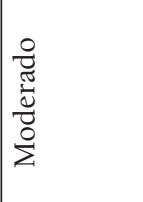 & 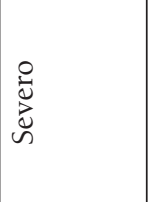 \\
\hline 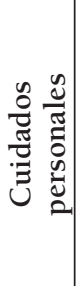 & 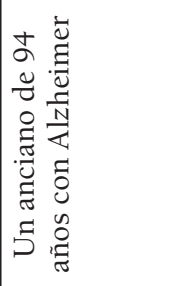 & 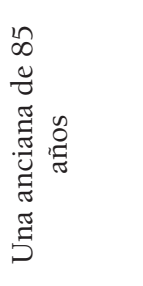 & 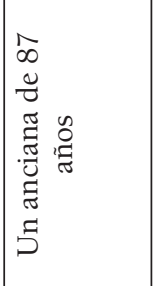 & 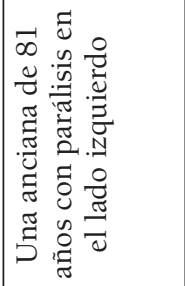 & 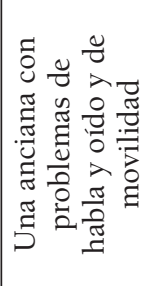 & 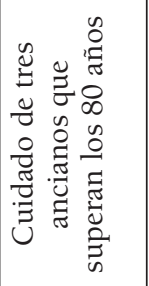 \\
\hline 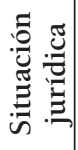 & 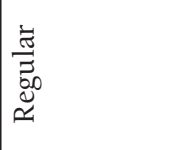 & $\begin{array}{l}\frac{\tilde{\sigma}}{J} \\
\tilde{\sigma}_{0} \\
\stackrel{\Xi}{\Xi}\end{array}$ & 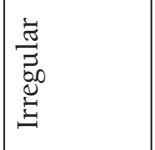 & 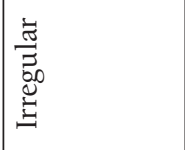 & 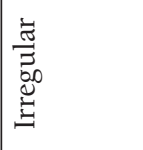 & 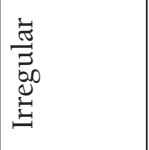 \\
\hline 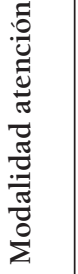 & 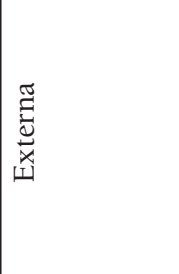 & 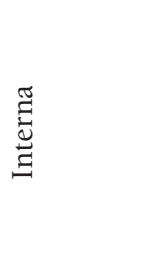 & 荧 & 丞 & 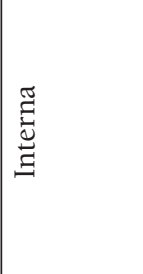 & 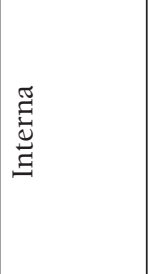 \\
\hline$\frac{\stackrel{\circ}{\pi}}{\stackrel{\pi}{\pi}}$ & $\overbrace{\infty} \stackrel{n}{\Xi}$ & ஓ & ஓ & in & 呆 & 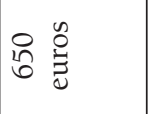 \\
\hline 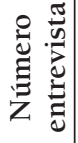 & 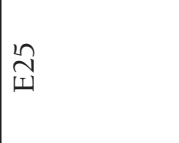 & $\stackrel{\text { I }}{\text { I }}$ & $\stackrel{N}{\tilde{I}}$ & 离 & స్తు & ભ̊ \\
\hline
\end{tabular}


El proceso de internacionalización que está experimentando el mercado laboral español ha convertido este empleo en un verdadero nicho laboral para las personas inmigrantes. Este servicio de hogar destinado al cuidado de personas mayores se ha configurado para la mayoría de las mujeres extranjeras en el inicio de su trayectoria laboral en nuestro país. Consideradas como trabajadoras domésticas, la mayoría de ellas sin estabilidad jurídica, las necesidades asistenciales de las familias empleadoras se invisibilizan ante la ausencia de una red adecuada de servicios sociales. Al mismo tiempo se oculta la vulnerabilidad de estas trabajadoras bajo la frontera que marca la privacidad del hogar.

Los beneficios que estas cuidadoras ofrecen tanto para las familias españolas (promueven la conciliación laboral y familiar) como para la protección social (rellenan las debilidades de un sistema ineficaz de servicios sociales) desafían las políticas de control migratorio y muestran la clara incoherencia surgida entre las necesidades laborales de mano de obra flexible y la filosofía migratoria restrictiva de los países occidentales.

\section{Bibliografía}

FinOtelli, C., «Migration policy between restrictive purposes and structural demand: the case of the domestic sector in Germany and Italy», en Migration and Mobility in an enlarged Europe. A gender perspective, S. Metz-Göeckl, et al. (eds.), Opladen, Barbara Publishers, 2008.

IMSERSO, Empleados de Hogar. Apoyo a Mayores, [en línea], 2004, <http://www. imsersomayores.csic.es/estadisticas/ encuestas)>. Consulta: 30/09/2005].

INE, Encuesta de Discapacidades, Deficiencias y Estados de Salud, Madrid, INE, 2000.

- Encuesta de Discapacidades, Autonomía Personal y Situación de Dependencia 2008, Madrid, INE, 2009.

IZQUIERDO, A. et al., «The Favourites of the Twenty-First Century: Latin American Immigration in Spain», en Studi Emigrazione, n. ${ }^{\circ}$ 149, 2003, pp. 98-124.

LAPARRA, M., «Inmigración y política social en Europa», en Italian Journal of Social Policy (en prensa), 2008.

MARTíneZ BujÁN, R., «El cuidado de ancianos: un nicho laboral para mujeres inmigrantes y un reto de gestión para las entidades del Tercer Sector», en Revista Española del Tercer Sector, n. ${ }^{\circ} 4,2006$, pp. 145-173.

- «Envejecimiento, Mercado Laboral e Inmigración», en Revista del Instituto de Estudios Económicos, 2 y 3, 2008, pp. 65-85.

Martínez Veiga, U., Trabajadores invisibles. Precariedad, rotación y pobreza de la inmigración en España, Madrid, Catarata, 2004. 
Oso, L., La migración hacia España de mujeres jefas de hogar, Madrid, Instituto de la Mujer, 1998.

PARÉlla, S., Mujer, inmigrante y trabajadora: la triple discriminación, Barcelona, Anthropos, 2003.

SANCHO, M. et al., Informe 2006. Las personas mayores en España, Madrid, IMSERSO, 2007.

Stefoni, C., «Mujeres inmigrantes peruanas en Chile», en Papeles de Población, n. ${ }^{\circ} 33,2002$, pp. 118-145.

Ungerson, C., «Personal Assistants and Disabled People: an Examination of a Hybrid Form of Work and Care», en Work, Employment E Society, 13 (4), 1999 , pp. 583-600. 



\title{
EL TIEMPO DE TRABAJO DE LAS CUIDADORAS INMIGRANTES DE PERSONAS MAYORES
}

\section{The working time of migrant caregivers for elderly people}

\author{
EVA MARTíN COPPOLA* \\ JESÚS ROGERO GARCÍA**
}

\section{Resumen}

Este artículo realiza una aproximación a las condiciones laborales de las trabajadoras inmigrantes que cuidan personas mayores en su domicilio, a través de su dimensión temporal: tiempo de trabajo y horarios. Se aplicó una encuesta piloto sobre uso del tiempo $(\mathrm{N}=24)$ y se realizaron 60 entrevistas en profundidad a cuidadoras inmigrantes en la Comunidad de Madrid (España) en 2008. Los resultados reflejan que la jornada laboral de las cuidadoras se sitúa muy por encima de la jornada ordinaria, con 75 horas semanales, que alcanzan las 131 horas en el caso de las internas. Se distinguen dos tipos de cuidadoras en función de las actividades que realizan: la «acompañanteama de casa», que desarrolla fundamentalmente actividades domésticas y de acompañamiento, y la «enfermera-ama de casa», cuyo núcleo diferenciador son los cuidados sociosanitarios y las ayudas personales en el hogar. Asimismo, se constata que el uso del tiempo semanal de las cuidadoras varía sustancialmente según régimen de trabajo. El trabajo concluye con una reflexión crítica sobre las condiciones laborales de este colectivo, que se pone en contraste con la regulación laboral española.

Palabras clave: cuidados domiciliarios, inmigración, uso del tiempo, dependencia.

\footnotetext{
* Eva Martín Coppola

Centro de Ciencias Humanas y Sociales

Consejo Superior de Investigaciones Científicas (CSIC)

C/ Albasanz 26-28. Despacho 3F6. 28037 Madrid

Teléfono: 916022781 Fax: 916022971

* Jesús Rogero García

Centro de Ciencias Humanas y Sociales

Consejo Superior de Investigaciones Científicas (CSIC)

C/ Albasanz 26-28. Despacho 3E10. 28037 Madrid

Teléfono: 916022753 Fax: 916022971

jesus.rogero@cchs.csic.es, jrogero@gmail.com
} 


\begin{abstract}
This article addresses the working conditions of migrants who care for elderly people in their own homes through a temporal dimension: working time and working schedule. We applied a pilot survey on time use $(\mathrm{N}=24)$ and conducted interviews with 60 immigrant caregivers in Madrid (Spain) in 2008. The main results indicate that the working hours of the caregivers are well above the average working day, with around 75 hours a week and even reaching the 131 hours in the case of the live-in caregivers. There are two types of caregivers in terms of their working activities: those who only carry out domestic activities and accompanying duties, and those who also provide nursing care and personal help at home. The weekly time use varies substantially depending on carers' employment status. The paper concludes with a critical reflection on the working conditions of this group and contrasts them with the Spanish labour regulations.
\end{abstract}

Keywords: Home care services, immigration, time use, dependency.

\title{
1. Introducción
}

La rápida expansión del cuidado a mayores por inmigrantes y sus múltiples derivaciones han generado recientemente un buen número de investigaciones en España, que reflejan la complejidad de la confluencia de problemáticas propias de la migración y de la dependencia. A pesar de estos avances, hay algunos elementos que dificultan el conocimiento sobre la situación de vida y trabajo de quienes provienen de otros países y se dedican a cuidar personas mayores. En concreto, este fenómeno está sujeto a una doble opacidad: por una parte, la derivada de una relación laboral informal que no pasa por el mercado y por otra, la que resulta de la privacidad del ámbito familiar.

Aunque no son abundantes, en los últimos años se han desarrollado en España algunas fuentes de datos que contienen información sobre cuidadores de origen extranjero. El módulo de empleados de hogar de la Encuesta de Apoyo a Mayores en España (IMSERSO, 2005b) es la fuente de representación nacional más reciente realizada en nuestro país con datos sobre cuidadoras remuneradas en el hogar. Tiene una muestra de 72 empleadas de hogar de nacionalidad no española y recoge información sobre frecuencia semanal, tiempo dedicado al cuidado, momento del día en que se desarrolla y actividades realizadas. Por su parte, la reciente aparición de la Encuesta Nacional de Inmigrantes 2008, aunque contiene abundante información sobre condiciones de vida y trabajo de este colectivo, no incluye entre sus categorías de ocupación el trabajo de cuidado a personas dependientes.

A pesar de la escasez de información estadística, en los últimos años se han realizado estudios monográficos de gran interés sobre el colectivo de trabajadoras inmigrantes en el sector de cuidados (Pérez Orozco et al., 2008; 
IMSERSO, 2005a, Martínez Buján, 2005 y 2006; Pla Julián, 2004; y Colectivo IOÉ, 2003, entre otros). Estos esfuerzos constituyen un indudable avance en la comprensión de este fenómeno. Entre otras cuestiones, estos estudios han aportado información sobre las actividades que realizan los inmigrantes en la atención a personas mayores. El cuidado implica un conjunto de tareas muy heterogéneo, que comprende la ayuda en actividades básicas de la vida diaria (ir al baño, comer, asearse, desplazarse en el hogar, etc.), actividades instrumentales de la vida diaria (limpiar la casa, cocinar, etc.) y actividades avanzadas de la vida diaria (participar en actividades de ocio, etc.). Sin embargo, hay cuestiones sobre el trabajo y la vida cotidiana de los cuidadores inmigrantes que merecen especial atención y que, hasta la fecha, no han sido abordadas por ninguna investigación de manera específica. Por ejemplo, ningún estudio aporta datos precisos sobre el uso del tiempo de las cuidadoras durante un ciclo semanal completo, y tampoco se ha analizado con precisión el tiempo que se dedica diariamente a cada una de las diferentes tareas que componen el cuidado.

Este artículo pretende contribuir al conocimiento de la realidad de estas trabajadoras a través de una nueva mirada, la proporcionada la información sobre uso del tiempo. Su objetivo es realizar un conocimiento exploratorio de las condiciones de vida y trabajo de los inmigrantes que cuidan a personas mayores en la Comunidad de Madrid, prestando especial atención a su dimensión temporal: tiempo de trabajo remunerado y relación trabajo remunerado-vida privada.

\section{Metodología}

Este trabajo analiza de manera complementaria información procedente de la Encuesta Piloto sobre Uso del Tiempo a Cuidadoras de Origen Extranjero en la Comunidad de Madrid 2008 (EPUTC, 2008) -un instrumento metodológico construido ad hoc para conocer el uso del tiempo de los cuidadores inmigrantes-y de 60 entrevistas en profundidad. La perspectiva cuantitativa tiene como antecedentes estudios previos sobre el uso del tiempo de cuidadores informales (Bittman et al., 2004; Pedrero, 2008) y permite visibilizar el tiempo dedicado por las cuidadoras a diferentes actividades, tanto durante su tiempo de trabajo como fuera del mismo. El objetivo del análisis cualitativo es conocer cómo estas trabajadoras experimentan su tiempo cotidiano, le atribuyen significado y diseñan estrategias para su organización.

El diseño muestral de ambas fuentes tiene representatividad cualitativa o intencional, es decir, trata de incluir la diversidad de situaciones o prácticas del objeto de estudio que han sido puestas de manifiesto por anteriores 
investigaciones. Se seleccionaron cuidadoras de origen extranjero en la Comunidad de Madrid que trabajaban en hogares privados y que cuidaban personas mayores de 64 años. Dado que no existe un censo ni directorio de esta población que permita seguir un muestreo convencional, el procedimiento de muestreo fue de bola de nieve a través de asociaciones de inmigrantes, ONGs y parroquias. La muestra se diseñó en función de la nacionalidad, el régimen de cuidado y el estado civil de las cuidadoras, tomando como principal referencia la Encuesta a Empleados de Hogar de Apoyo a Mayores (IMSERSO 2005b).

En el caso de la encuesta, se seleccionaron trabajadoras que cuidaban sólo a una persona mayor. Este criterio era imprescindible para establecer relaciones consistentes entre las características de la cuidadora y de la persona cuidada. La muestra final de la encuesta fue de 24 mujeres. El cuestionario incluyó dos instrumentos de recogida de información para captar diferentes aspectos del uso del tiempo: la encuesta de actividades, en la que las entrevistadas indicaron la frecuencia de realización y el tiempo dedicado a una serie de actividades durante el último día de trabajo (Tabla 1), y el diario de empleo del tiempo, que recogió secuencialmente información sobre las actividades desarrolladas durante una semana completa en intervalos de 15 minutos. El diario es la metodología de investigación sobre uso del tiempo con mayor aceptación internacional entre los expertos (Eurostat, 2008; ONU, 2006; INE, 2003). La elección de uno u otro instrumento para estimar el tiempo de trabajo de cuidado depende del criterio utilizado para definir trabajo. La estimación realizada a través del diario considera trabajo todo el tiempo que, por acuerdo con la persona dependiente o la familia, las cuidadoras deben permanecer en el hogar, incluidos los tiempos de presencia ${ }^{1}$. Parte del trabajo de cuidado consiste en estar disponible para proveer el servicio en el momento en que sea necesario. Profesionales como bomberos, enfermeras o vigilantes de seguridad tienen tiempos de trabajo similares a los de las cuidadoras: deben estar preparados para una posible intervención, cuya planificación no es posible por su carácter imprevisible. Por su parte, la estimación a través de la encuesta de actividades contabiliza únicamente los tiempos activos de trabajo, es decir, aquellos en los que se desarrolla una actividad concreta y que van más allá de la mera presencia en el hogar.

1. A este respecto, el Real Decreto que regula el Régimen Especial de Empleo de Hogar indica lo siguiente: «el/la empleador/a y el/la empleado/a podrá acordar tiempos de presencia de éste/a en situación de disponibilidad sin realizar un trabajo concreto, así como la correspondiente retribución [...]» (RD 1424/85) 
Tabla 1. Lista de actividades precodificadas realizadas durante el trabajo de cuidado. EUTPC, 2008

\begin{tabular}{|c|l|}
\hline \multicolumn{2}{|c|}{ Cuidados socio-sanitarios } \\
\hline 1 & $\begin{array}{l}\text { Ayudar en la preparación y provisión de medicamentos (pastillas, supositorios, } \\
\text { etc.) }\end{array}$ \\
\hline 2 & Curas, cambio de vendajes, limpiar heridas, administrar enemas, etc. \\
\hline 3 & Cambiar pañales \\
\hline 4 & Ayudar a hacer ejercicios mentales o físicos \\
\hline \multicolumn{2}{|c|}{ Ayudas personales en el hogar } \\
\hline 5 & Ayudar a comer/beber \\
\hline 6 & Ayudar a vestirse/desvestirse \\
\hline 7 & $\begin{array}{l}\text { Ayudar a asearse/arreglarse (lavar cara y manos, peinar, afeitar, maquillar, cortar } \\
\text { uñas de pies y manos, etc.) }\end{array}$ \\
\hline 8 & Ayudar a andar por la casa o moverse \\
\hline 9 & Ayudar a acostarse/levantarse de la cama \\
\hline 10 & $\begin{array}{l}\text { Ayudar a utilizar el retrete (llevar y sentar en el váter, quitar y poner la ropa, } \\
\text { limpiar tras la deposición, evitar que se manche) }\end{array}$ \\
\hline 11 & Ayudar a ducharse o bañarse (todo el cuerpo) \\
\hline \multicolumn{2}{|c|}{ Actividades domésticas } \\
\hline 12 & Hacer compras \\
\hline 13 & Preparar comidas \\
\hline 14 & Limpiar la casa/cocina \\
\hline 15 & Cuidados a niños \\
\hline 16 & Arreglos/mascotas/jardín \\
\hline 17 & Administrar el dinero/gestiones \\
\hline & \multicolumn{2}{c}{ Acompañamiento dentro y fuera del hogar } \\
\hline 18 & Estar con él/ella en casa sin hacer nada/viendo la televisión \\
\hline 19 & $\begin{array}{l}\text { Estar con él/ella en casa jugando a las cartas, juegos de mesa, leyéndole periódicos, } \\
\text { revistas o libros, etc. }\end{array}$ \\
\hline 20 & Dar un paseo con él/ella \\
\hline 21 & Utilizar el transporte público con él/ella \\
\hline 22 & $\begin{array}{l}\text { Acompañar en actividades de ocio fuera de casa (ir a la cafetería, cine, teatro, de } \\
\text { compras, etc.) }\end{array}$ \\
\hline
\end{tabular}

\section{Resultados}

\subsection{El tiempo de cuidado}

Investigaciones precedentes han diferenciado a las cuidadoras de personas dependientes según su régimen de trabajo: internas, externas o por horas (IMSERSO, 2005a). A estos perfiles, esta investigación añade una figura 
complementaria: la de quienes atienden en régimen de interna exclusivamente durante los fines de semana. El régimen de trabajo determina la cantidad de tiempo que estas trabajadoras invierten en cuidado y condiciona intensamente el resto de actividades de su vida cotidiana (tiempo libre, transporte, tiempo dedicado a otros trabajos, etc.).

Las cuidadoras internas viven (duermen y reciben manutención) en el domicilio de la persona a la que cuidan y le proveen atención en una franja horaria indeterminada. A pesar de que la normativa básica estipula un descanso para las internas de dos horas para las comidas y de ocho horas de sueño entre una jornada y otra, el hecho de residir en la misma vivienda donde trabajan hace que, en muchas ocasiones, esta frontera temporal para el descanso no exista. En muchos casos, no es su jornada de trabajo la que se ajusta a su tiempo de descanso, sino a la inversa:

«Como interna... ¿sabe lo que pasó? La familia era muy buena, pero se necesitaba mucho cariño, mucho amor, mucho cuidado, mucha responsabilidad... Yo trabajaba allí todo el día, estaba pendiente de la señora 24 horas.» Rumana, 46 años.

Existe un grupo de cuidadoras internas que atienden a personas mayores durante los fines de semana y/o días festivos. Su tiempo de trabajo coincide con los días libres de los cuidadores principales, ya sean internos, externos o cuidadores familiares, con el fin de cubrir su tiempo de descanso. El trabajo de las internas de fin de semana se desarrolla en jornadas de 12 a 24 horas de atención continuada y cumple una función de bisagra para la consecución del tiempo libre del resto de cuidadores.

Las cuidadoras externas se caracterizan por no residir en su lugar de trabajo. Son cuidadoras externas a tiempo completo quienes realizan jornadas entre 7 y 12 horas, frecuentemente repartidas entre la mañana y la tarde. Cuando los horarios se prolongan en exceso es posible hablar de falsas externas (Martínez Veiga, 2000: 91): trabajadoras con un régimen de externa, puesto que viven fuera de la casa del empleador, pero que experimentan el resto de condiciones de un trabajo interno. Si a una jornada media de más de 12 horas se suma el tiempo de desplazamiento, el resultado es que estas trabajadoras están en su domicilio unas pocas horas para descansar entre una jornada laboral y la siguiente:

«Me dijeron "este es el horario de trabajo y lo que tienes que hacer", y el problema es que vivo muy lejos y necesitaría salir a las 6 de la mañana de mi casa para llegar a las 8 allí, luego termino sobre las 5 o 6 , pero ahora quiere que trabaje de 8 a 8 . Pero si salgo a las 8 , llego a las 10 a mi casa y ya no tengo espacio para nada...» (Mujer boliviana, 44 años) 
Tabla 2. Tiempo de cuidado según tipo de estimación y régimen de cuidado (horas y centésimas de hora)

\begin{tabular}{|l|c|c|c|c|c|}
\hline & \multicolumn{2}{|c|}{ Diario } & \multicolumn{2}{c|}{ Encuesta de actividades } & \multirow{2}{*}{ N } \\
\cline { 2 - 5 } & Al día $^{1}$ & Semanal & Al día & Semanal & \\
\hline Externas por horas & 4,09 & 20,45 & 4,39 & 21,95 & 8 \\
\hline $\begin{array}{l}\text { Externas a jornada } \\
\text { completa }\end{array}$ & 10,53 & 63,18 & 8,39 & 50,34 & 3 \\
\hline Internas de fin de semana & 22,25 & 44,50 & 9,25 & 18,50 & 3 \\
\hline Internas & 21,90 & 131,40 & 10,23 & 61,38 & 10 \\
\hline Total & 14,59 & 75,03 & 7,93 & 41,50 & 24 \\
\hline
\end{tabular}

1. La estimación corresponde al tiempo semanal de cuidado y supervisión dividido por 5 en «externa por horas», por 6 en «externas a jornada completa»e «internas» y por 2 en "internas de fin de semana".

2. La estimación corresponde al último día que trabajó la entrevistada.

Fuente: Encuesta piloto sobre «Uso del tiempo de los cuidadores de origen extranjero en la Comunidad de Madrid 2008»

Son externas por horas aquellas cuidadoras que trabajan entre una y 6 horas diarias en un mismo hogar. La labor de estas trabajadoras se asemeja a la que desarrollada por el Servicio Público de Atención a Domicilio (SAD)2. Frente a los límites horarios de los recursos formales del SAD, las trabajadoras por horas cuidan en aquellos espacios de tiempo que no pueden ser cubiertos por la familia o por los recursos formales. Este servicio es asequible para hogares que no pueden pagar a una interna o a una externa fija, y su uso se ha incrementado en toda Europa (IMSERSO, 2005c). La flexibilidad de horarios y actividades es un rasgo común de estas cuidadoras:

«Trabajo por horas. Familias de personas mayores... Trabajo en dos casas con personas mayores. Los lunes, miércoles y viernes, entre las 9 y las 12 en una casa, y los martes y jueves, en otra casa.» (Mujer rumana, 46 años)

A través del tiempo invertido en cuidado y en las diferentes actividades que lo componen, es posible inferir su cantidad e intensidad y aproximarse a sus efectos en los cuidadores, las personas cuidadas y su entorno social. De acuerdo con el diario, el tiempo medio de cuidado asciende a 14,6 horas diarias

2. El SAD se define como «un programa individualizado, de carácter preventivo y rehabilitador, en el que se articulan un conjunto de servicios y técnicas de intervención profesional consistentes en atención personal, doméstica, de apoyo psicosocial y familiar y relaciones con el entorno, prestados en el domicilio de una persona en situación de dependencia con el objetivo básico de favorecer la autonomía personal en su medio habitual de vida». (Deloitte, 2008: 9) 
(Tabla 2). La dedicación difiere sustancialmente según elrégimen de trabajo. Las externas por horas dedican un promedio de 4,1 horas diarias, las externas a jornada completa, 10,5 horas; y las internas, en torno a las 22 horas. Según la encuesta de actividades, que no contabiliza los tiempos de presencia, las externas por horas dedican un promedio de 4,4 horas diarias, las externas a jornada completa, 8,4 horas; las internas de fin de semana, 9,3 horas al día; y las internas, un promedio de 10,2 horas.

El cuidado, como actividad general, se descompone en tareas concretas, que se desarrollan sobre todo en función a las necesidades de la persona que demanda la atención. Se trata de actividades frecuentemente imprevisibles que resultan difíciles de planificar, tal y como refleja el discurso de las cuidadoras:

«Sí, entre las seis menos cuarto y seis y media... pero esto depende de su estado de nervios, tengo que darle agua y llevarle al servicio. A las siete y media, de nuevo, tengo que darle el yogur, el agua... Con lo cual, a las diez y media le doy de nuevo la leche y la magdalena, le baño... todo, todo, todo, le acuesto, decimos el Padre Nuestro, hasta que se duerme. Si se levanta por la noche, me despierto, porque hay noches cuando no duerme. Lleva como tres semanas sin dormir...se hace caca encima, le tengo que lavar de noche...» (Mujer rumana, 51 años)

Las actividades de cuidado pueden ser agrupadas en cuatro grandes categorías: servicio doméstico y gestión del hogar, acompañamiento (dentro y fuera del hogar), ayudas relativas al cuidado personal y cuidados socio-sanitarios (Tabla 1). El tiempo dedicado a cada una de estas categorías varía según el régimen de trabajo de las cuidadoras y el nivel de dependencia de la persona mayor. Se puede establecer una tipología de cuidadoras en función de las tareas concretas en que se traduce su tiempo de trabajo. Con este objetivo, se ha realizado un análisis de conglomerados (o análisis cluster) en base al tiempo dedicado a diferentes actividades, del que han resultado dos tipos de cuidadoras $^{3}$. La Tabla 3 muestra el tiempo promedio dedicado a diferentes actividades según tipo.

El tipo 1, «acompañante-ama de casa», realiza fundamentalmente AIVD, es decir, actividades domésticas (hacer la compra, preparar comidas y limpiar) y de acompañamiento. Se caracteriza por cuidar a una persona con un nivel de autonomía relativamente alto y con menores necesidades de apoyo directo, por lo que no suelen proveer cuidados socio-sanitarios ni ayudas personales. Dos de cada tres cuidadoras responden a este perfil.

3. El análisis de conglomerados de k medias estableció dos tipos, aunque una muestra más amplia podría dar lugar a un número mayor. 
Tabla 3. Promedio de horas y centésimas de hora dedicadas a diferentes actividades según tipo de cuidadora

\begin{tabular}{|l|c|c|c|}
\hline & $\begin{array}{c}\text { Acompañante- } \\
\text { ama de casa } \\
(\mathrm{N}=16)\end{array}$ & $\begin{array}{c}\text { Enfermera- } \\
\text { ama de casa } \\
(\mathrm{N}=8)\end{array}$ & Sig. \\
\hline $\begin{array}{l}\text { Ayudar en la preparación y provisión } \\
\text { de medicamentos }\end{array}$ & 0,06 & 0,25 & $* * 0,033$ \\
\hline $\begin{array}{l}\text { Curas, cambio de vendajes, limpiar } \\
\text { heridas, administrar enemas, etc. }\end{array}$ & 0,00 & 0,03 & 0,162 \\
\hline Cambiar pañales & 0,00 & 0,78 & $* * * 0,003$ \\
\hline $\begin{array}{l}\text { Ayudar a hacer ejercicios mentales o } \\
\text { físicos }\end{array}$ & 0,13 & 0,35 & 0,122 \\
\hline Ayudar a comer, beber & 0,00 & 0,99 & $* * * 0,002$ \\
\hline Ayudar a vestirse, desvestirse & 0,12 & 0,65 & $* * * 0,001$ \\
\hline Ayudar a asearse, arreglarse & 0,06 & 0,35 & $* * * 0,002$ \\
\hline Ayudar a andar por la casa o moverse & 0,04 & 0,19 & $* * 0,018$ \\
\hline $\begin{array}{l}\text { Ayudar a levantarse, acostarse en la } \\
\text { cama }\end{array}$ & 0,02 & 0,17 & $* * * 0,001$ \\
\hline Ayudar a utilizar el retrete & 0,03 & 0,48 & $* * * 0,000$ \\
\hline Ayudar a ducharse o bañarse & 0,16 & 0,21 & 0,681 \\
\hline Hacer compras & 0,63 & 0,13 & $* * 0,020$ \\
\hline Preparar comidas & 1,16 & 1,18 & 0,972 \\
\hline Limpiar la casa, cocina & 2,20 & 1,04 & 0,072 \\
\hline Cuidados a niños & 0,00 & 0,01 & 0,162 \\
\hline Arreglos, mascotas, jardín & 0,26 & 0,33 & 0,774 \\
\hline Administrar el dinero, gestiones & 0,00 & 0,13 & 0,162 \\
\hline $\begin{array}{l}\text { Estar con él/ella en casa sin hacer nada } \\
\text { o viendo la tele }\end{array}$ & 1,12 & 0,95 & 0,746 \\
\hline $\begin{array}{l}\text { Estar con él/ella en casa jugando a las } \\
\text { cartas, juegos de mesa, leyéndole, etc. }\end{array}$ & 0,53 & 0,14 & 0,280 \\
\hline Dar un paseo con él/ella & 0,60 & 1,06 & 0,135 \\
\hline $\begin{array}{l}\text { Utilizar el transporte público con él o } \\
\text { ella }\end{array}$ & 0,05 & 0,00 & 0,345 \\
\hline $\begin{array}{l}\text { Acompañar en actividades de ocio } \\
\text { fuera de casa }\end{array}$ & 0,00 & 0,06 & 0,162 \\
\hline & & & \\
\hline
\end{tabular}

$* * \mathrm{p}<0,05 * * * \mathrm{p}<0,01$.

Fuente: Encuesta piloto sobre «Uso del tiempo de los cuidadores de origen extranjero en

la Comunidad de Madrid 2008» 
El tipo 2, «enfermera-ama de casa», se caracteriza por realizar un amplio abanico de actividades, cuyo núcleo diferenciador lo forman los cuidados socio-sanitarios (provisión de medicamentos, cambiar pañales, etc.) y las ayudas personales en el hogar (ayudar a comer/beber, desplazarse, vestirse, etc.). También suelen realizar actividades domésticas y dedicar tiempo a acompañamiento. Estas cuidadoras atienden a personas con peor estado de salud y mayor nivel de dependencia. Generalmente, este tipo de atención coincide con la etapa previa o inmediatamente posterior al ingreso en un hospital o residencia. Una de cada tres cuidadoras se encuadra en el este tipo.

\subsection{La articulación entre trabajo y vida privada}

Los resultados que se presentan a continuación analizan, con información procedente del diario, el modo en que el trabajo de cuidado está presente en la vida cotidiana de estas mujeres. En concreto, responden a dos cuestiones: qué proporción de tiempo ocupa el cuidado en relación con su tiempo total disponible y cómo se distribuye el cuidado a lo largo de la semana. Tanto la distribución del tiempo de cuidado semanal como su presencia con respecto al resto de actividades muestran las diferentes posibilidades de articulación entre la vida laboral y personal de las cuidadoras. El principal elemento de diferenciación entre estas trabajadoras es el régimen laboral, que tiene un intenso impacto en la distribución del tiempo semanal en actividades (figura 1).

Figura 1. Distribución del tiempo semanal en actividades de las cuidadoras, según el régimen de cuidado (\%)

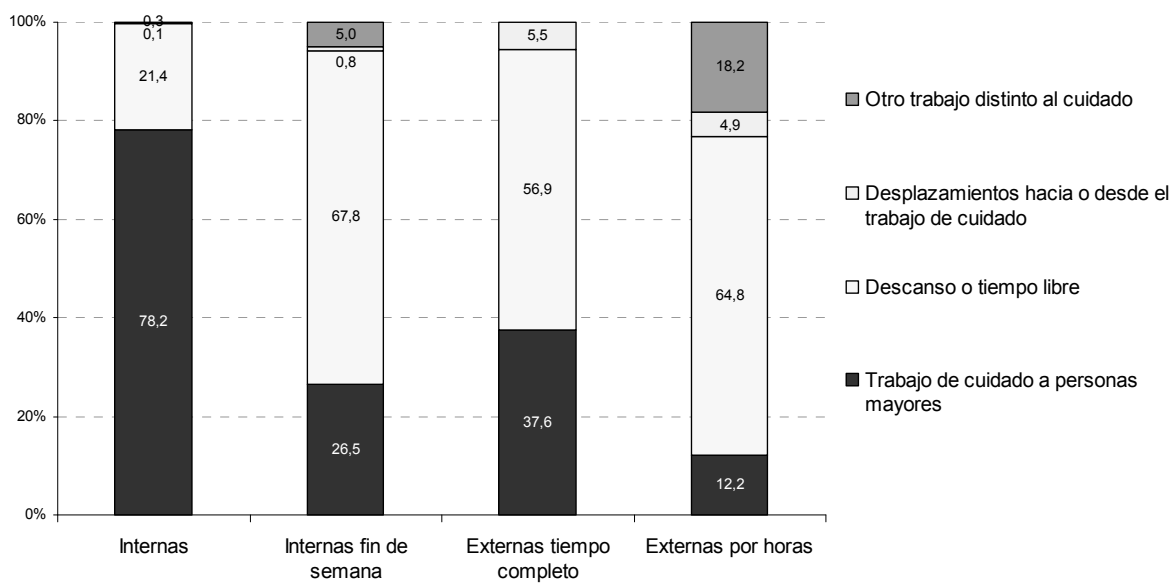

Fuente: Encuesta piloto sobre «Uso del tiempo de los cuidadores de origen extranjero en la Comunidad de Madrid 2008» 
Figura 2. La distribución de las actividades según el momento de la semana Cuidadoras internas

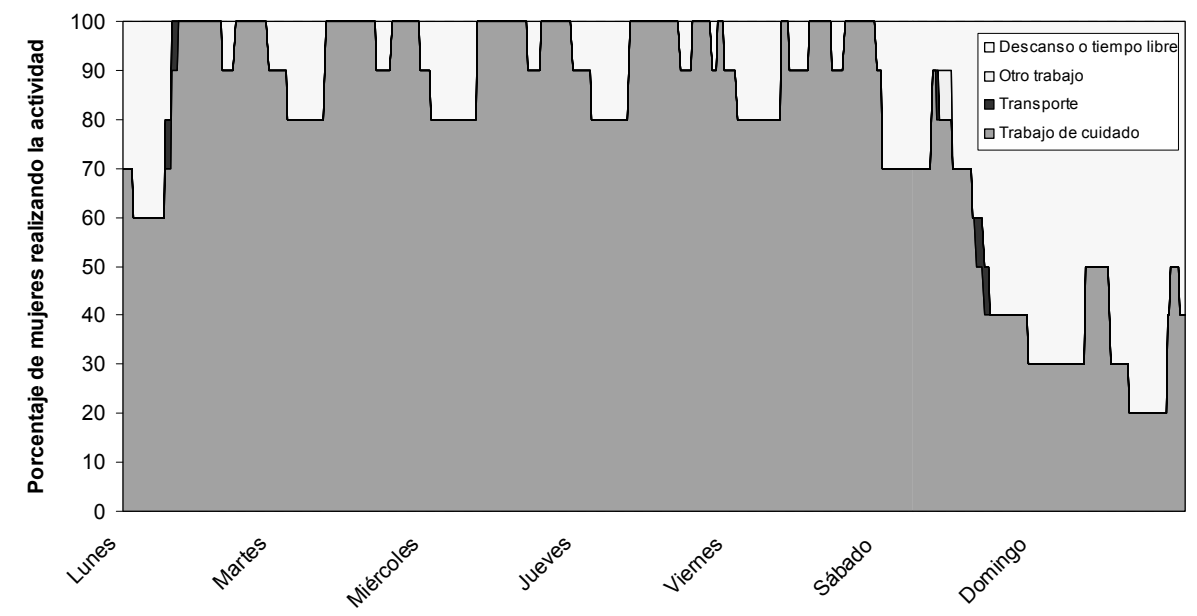

Fuente: Encuesta piloto sobre «Uso del tiempo de los cuidadores de origen extranjero en la Comunidad de Madrid 2008»

El grupo con rasgos más diferenciados es el de las cuidadoras internas. En este caso, el tiempo cotidiano está intensamente desequilibrado hacia el trabajo remunerado, con jornadas laborales muy largas y una dedicación a las necesidades propias (descanso, ocio y relaciones sociales) muy reducida. Este grupo dedica 131,4 horas semanales al trabajo (el $78 \%$ de su tiempo) y 35,9 horas a descanso y tiempo libre (el $21 \%$ ) (Figura 1). El poco tiempo libre que tienen se concentra en los fines de semana y, como se observa en la Figura 2, en torno a la mitad de las cuidadoras pasan las noches del sábado al domingo y del domingo al lunes fuera del hogar de cuidado.

Las propias cuidadoras internas consideran la escasez de tiempo libre como uno de sus principales problemas, que relacionan con la falta de independencia y autonomía. Son conscientes de que sus largas jornadas limitan las posibilidades de realización de otras actividades y, por tanto, de establecer y mantener relaciones sociales estrechas fuera del ámbito de su empleo. Perciben que buena parte de su tiempo no les pertenece porque les ha sido arrebatado:

«No, para mí, sobre todo, sería la falta de, podría decir, independencia, porque uno no es dueño de su tiempo, ya, claro, si tú trabajas no eres en este momento dueño de tu tiempo, pero después de que tú termines tu trabajo ya tú eres dueño de tu tiempo, ya tu tiempo tú lo planificas, puedes decidir estudiar, o puedes decidir salir, o puedes ir donde una amiga, o sea, puedes decidir, pero si trabajas de interna no es así.» (Mujer dominicana, 47 años) 
Las trabajadoras externas de jornada completa reflejan un uso del tiempo con un mayor equilibrio entre las distintas actividades, en el que el tiempo libre supera al tiempo de trabajo: dedican 63,2 horas al trabajo (un $38 \%$ de su tiempo semanal), a lo que hay que agregar 9,3 horas de transporte hacia o desde el hogar de trabajo (un $6 \%$ del tiempo) (Figura 1). Disponen de 95,6 horas de tiempo libre (un $55 \%$ ). A pesar de ello, su jornada laboral es especialmente extensa si se compara con las 40 horas (el $24 \%$ del tiempo semanal) que establece la normativa básica del personal al servicio del hogar familiar. Este colectivo cuenta, sin embargo, con situaciones heterogéneas que se corresponden con lo que se ha calificado de falsas externas, entre quienes la necesidad de cubrir sus gastos de manutención y los bajos salarios característicos del sector les llevan a prolongar su jornada laboral por encima de las 10 horas diarias.

La Figura 3 muestra la distribución del tiempo de las externas a jornada completa a lo largo de la semana. Sus horas libres coinciden con el final de la tarde y la noche, a excepción de los domingos por la tarde, cuando todas las trabajadoras entrevistadas reportaron disponer de tiempo libre. Esta distribución del tiempo es muy similar a la de la mayoría de trabajadores de otros sectores (INE, 2007).

Muchas externas a jornada completa se enfrentan a una difícil articulación entre su vida laboral y personal, pues al no residir en el domicilio de la

Figura 3. La distribución de las actividades según el momento de la semana Cuidadoras externas a jornada completa de 7 a 12 horas diarias

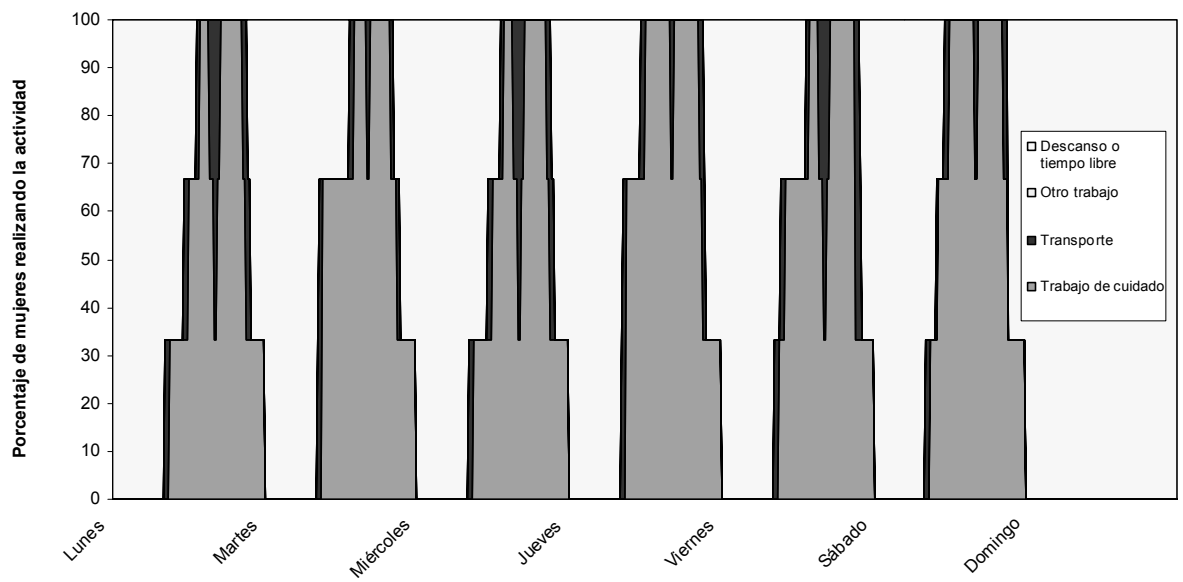

Fuente: Encuesta piloto sobre «Uso del tiempo de los cuidadores de origen extranjero en la Comunidad de Madrid 2008» 
persona mayor han de afrontar la doble atención que supone su actividad laboral y sus obligaciones domésticas. Su carga global de trabajo (García Sainz, 1998) -agregado de trabajo remunerado y no remunerado- es muy elevada y, en muchas ocasiones, genera estrés y una percepción del tiempo como recurso escaso, tal y como se refleja en el siguiente fragmento de entrevista:

«Estoy deseando descansar porque siempre me falta algo, si no es barrer, es recoger y si no es una cosa es la otra, pero siempre ando con algo que me falta, ya voy poniendo lavadoras que digo bueno luego tengo que acabar de hacer la comida, luego tengo que dar una vuelta ir a dejar el ordenador, luego tengo que ir al trabajo, antes de eso tengo que ir donde la Seguridad Social a dejar un papel, bueno, tengo todas las horas ocupadas a veces no llego a una o a la otra.» (Mujer ecuatoriana, 31 años)

Las externas por horas son el grupo que cuenta con la jornada de cuidado más reducida, aunque la complementan con otro tipo de trabajo (Figura 1). Dedican al cuidado 20,4 horas (el $12 \%$ ) y 30,6 horas a otros trabajos que no son cuidado (el $18 \%$ ). Buena parte de su tiempo libre o de descanso es reinvertido en otras actividades laborales. Según la EPUTC 2008, la mitad de las externas por horas realiza otro trabajo. Al igual que extender la jornada laboral es, para las externas con jornada completa, una estrategia para aumentar sus ingresos, las externas por horas recurren al pluriempleo como mecanismo para reunir el salario necesario. El tiempo libre constituye el $65 \%$, con 108,8 horas a la semana, y dedican a transporte 8,2 horas semanales, el $5 \%$ de su tiempo semanal.

El trabajo de cuidado de las externas por horas se distribuye fundamentalmente en las horas de la mañana (Figura 4). Los trabajos complementarios al cuidado se desarrollan también durante esos periodos, aunque en algunos casos ocupan noches y fines de semana. El resultado es que la totalidad de estas mujeres trabaja en algún momento de las mañanas de los días laborables, ya sea cuidando o realizando otras actividades. Durante las tardes y los fines de semana disponen de más tiempo libre. Los relatos de estas trabajadoras reflejan las principales motivaciones para afrontar este tipo de trabajo. En primer lugar, plantean como razón la necesidad económica:

«Estoy cuidando dos personas. Una, durante el día y otra aquí, en el hospital durante la noche. Lo que pasa es que el sueldo no es... lo que dicen según las bolsas o el mínimo que se debería pagarnos es 600 euros. Pero si calculamos que una habitación son 300 euros, el transporte el abono de metro son 50 o 55, más 150 para comer mínimamente, y luego están las cosas personales, detergentes, champús... no te alcanza con los 600 euros.» (Mujer boliviana, 44 años)

En segundo lugar, conciben este tipo de trabajo como un medio para conciliar vida familiar y laboral: 
«Ahora trabajo por horas. Tengo varios trabajos, porque al venir mi hijo, necesito cuidar de él un poco, aunque él se hace solo la comida y sabe poner la lavadora...» (Mujer rumana, 38 años)

Y en tercer lugar, algunas cuidadoras se plantean el objetivo de disfrutar de su tiempo libre reinvirtiéndolo en otro tipo de actividades formativas o de ocio:

«Mira, ahorita el trabajo que me gusta con la empresa, es bueno porque es por horas, entonces claro yo trabajo las noches, que las pagan muy bien, trabajo como cuidadora de personas mayores tanto en casas como convalecientes, enfermos, y ese trabajo lo pagan muy bien, o no lo pagan bien, o es sobre todo por la disponibilidad de tiempo, como a mí me gusta hacer cosas, entonces claro, las noches para mí, aunque trabaje diez horas no me importa porque tengo disponibilidad para hacer cosas de día, hacer cursos, he hecho cursos en la EMSI con la Comunidad de Madrid, hago voluntariado en la Cruz Roja, entonces me gusta hacer muchas cosas.» (Mujer venezolana, 34 años)

Las internas de fin de semana conforman el grupo con una distribución del tiempo más atípica. Disponen de 113,8 horas de tiempo libre o descanso a la semana (el $68 \%$ de su tiempo), frente a las 52,8 horas de trabajo remunerado (el $32 \%$ ). A pesar de dedicar parte de su tiempo libre a otros trabajos, éstos apenas representan el $6 \%$ de su tiempo semanal (Figura 1). Su uso del tiempo sigue una lógica inversa al resto de trabajadores: concentran la práctica totalidad de su trabajo de cuidado durante el fin de semana (44,5 horas), y es en

Figura 4. La distribución de las actividades según momento de la semana

Cuidadoras externas por horas

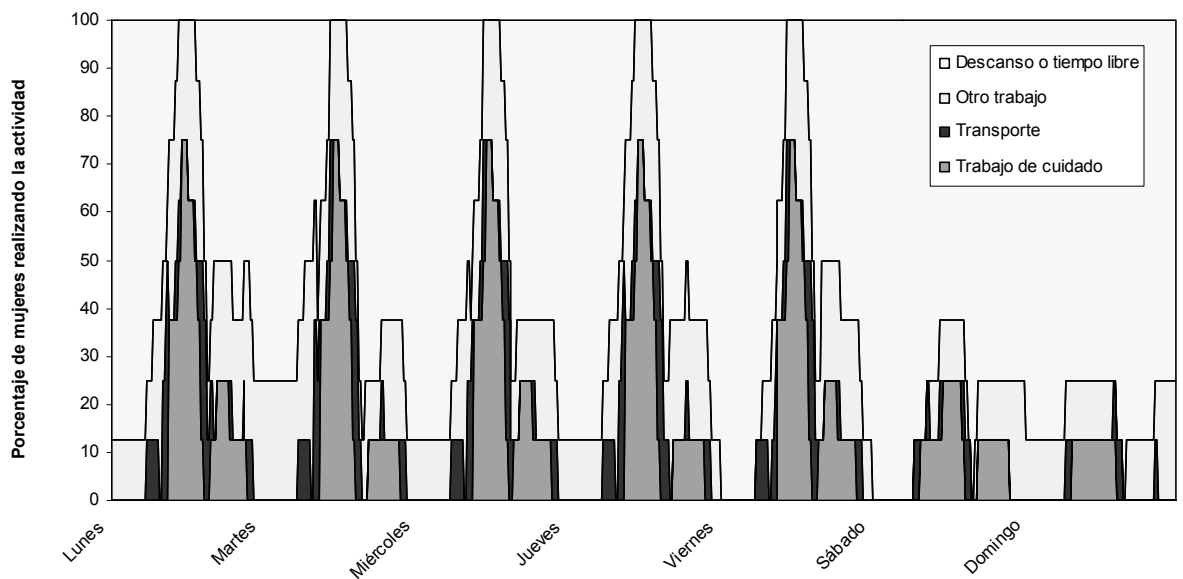

Fuente: Encuesta piloto sobre «Uso del tiempo de los cuidadores de origen extranjero en la Comunidad de Madrid 2008» 
Figura 5. La distribución de las actividades según el momento de la semana

Cuidadoras externas fin de semana (Más de 12 horas diarias en fin de semana)

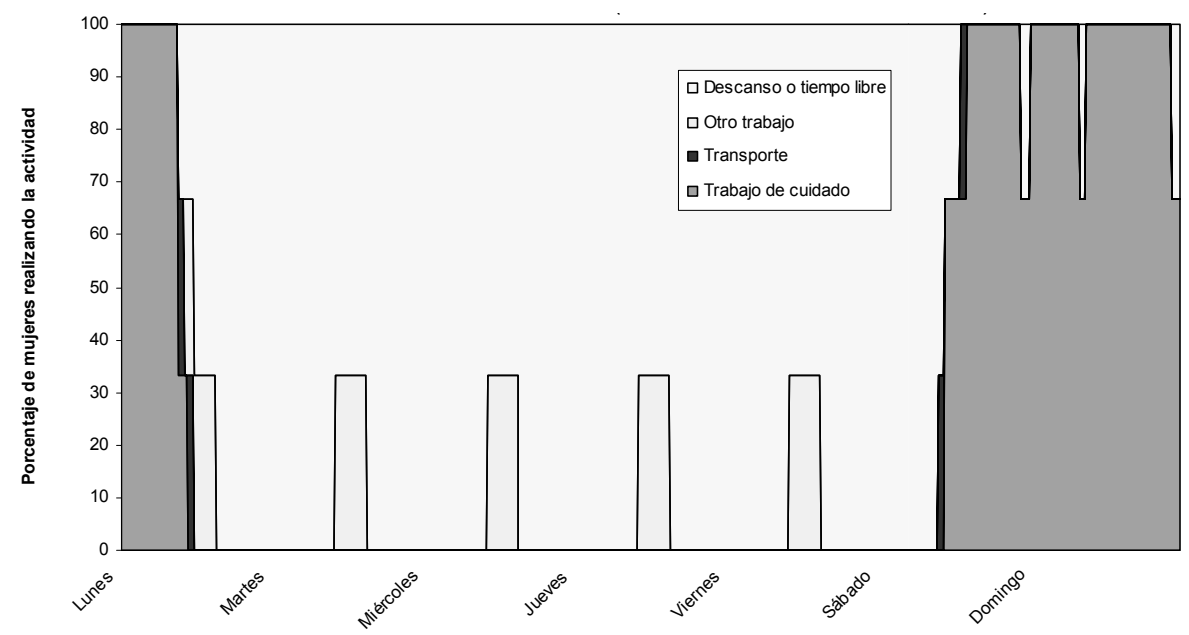

Fuente: Encuesta piloto sobre «Uso del tiempo de los cuidadores de origen extranjero en la Comunidad de Madrid 2008»

los días de diario cuando disponen de abundante tiempo libre o de descanso (Figura 5). Esto les confiere una importante distinción, no sólo respecto al resto de trabajadoras del sector, sino también respecto al ritmo del grueso de los trabajadores.

Generalmente, las internas de fin de semana conciben el cuidado como un trabajo esporádico mientras encuentran algo que ofrezca mayores ingresos, o bien son estudiantes que necesitan dinero extra y que no tienen el objetivo de incrementar su tiempo de trabajo. Estas trabajadoras suelen reemplazar a las cuidadoras fijas durante su tiempo libre. Se podría decir, utilizando la expresión empleada por los servicios formales, que es una figura que facilita el respiro familiar de los cuidadores principales, ofreciéndoles un apoyo indirecto para que puedan hacer compatible su vida laboral y su vida personal.

\section{Conclusiones}

Este trabajo aporta nueva información sobre las condiciones de vida y de trabajo de las cuidadoras inmigrantes de personas mayores en los hogares, un colectivo con una importancia social y económica creciente en España. En concreto, se han ofrecido datos sobre el uso del tiempo de estas cuidadoras en la Comunidad de Madrid, desde una perspectiva cuantitativa (tiempo 
dedicado a cuidado y a otras actividades y ciclo semanal del trabajo de cuidado) y cualitativa (discursos de las cuidadoras sobre su tiempo de trabajo). Los resultados obtenidos profundizan sobre las diferencias internas de este colectivo en relación con su régimen laboral.

Con respecto al tiempo de trabajo de las cuidadoras, los resultados de la EPUTC 2008 son similares a los hallados por el Colectivo IOÉ para las trabajadoras inmigrantes internas del sector doméstico (Colectivo IOÉ, 2003). Según su estudio, estas mujeres dedicaban en el año 2000 un promedio semanal de 60 horas al trabajo, muy cerca de las 61,4 horas calculadas a partir de la EPUTC 2008 cuando no se contabilizan los tiempos de presencia. Sin embargo, dado que la Organización Internacional del Trabajo establece que las horas efectivamente trabajadas deben incluir «el tiempo transcurrido en el lugar de trabajo esperando, o inactivo por razones tales como la falta ocasional de trabajo [...]» (OIT, 2008: 7), las horas de presencia deben ser computadas. La metodología adecuada para ello es el diario, que con la inclusión de los tiempos de presencia estima que el tiempo semanal de trabajo de las internas asciende a 131,4 horas.

Independientemente de la metodología utilizada, tanto las internas como buena parte de las externas superan con amplitud la jornada semanal ordinaria de 40 horas. En el caso de las externas, el análisis de la jornada semanal de trabajo ha revelado que, en muchos casos, no se cumple la normativa vigente que estipula un máximo de 9 horas diarias de trabajo efectivo y un descanso de por lo menos 10 horas entre una jornada laboral y otra (BOE 13/08/1985). A la generalizada vulneración de la legislación laboral española se añade la percepción negativa de las propias cuidadoras sobre sus condiciones laborales. El análisis de su discurso pone de manifiesto que aquellas que tienen largas jornadas se encuentran insatisfechas con su uso del tiempo, lo que coincide con investigaciones precedentes que indican que la falta de tiempo libre de las cuidadoras incrementa su estrés (Gallart, 2007). Es conveniente, por tanto, articular mecanismos que garanticen a este colectivo los derechos laborales del resto de trabajadores y contribuyan a mejorar su calidad de vida ${ }^{4}$.

En cuanto al tipo de actividades que se desarrollan, la presencia mayoritaria de trabajadoras que apenas proveen cuidados socio-sanitarios y/o ayudas

\footnotetext{
4. Naciones Unidas INSTRAW promovió a finales del 2009 la apertura de un proceso de diálogo entre las asociaciones de mujeres trabajadoras del hogar, el movimiento feminista, el Gobierno y los sindicatos, con el fin de avanzar en la toma de decisiones respecto a la situación de las empleadas de hogar migrantes. Las conclusiones de los encuentros y otros documentos de interés pueden descargarse en: http://www.un-instraw.org/es/md/ md-homepage/migration-and-development.html.
} 
en el hogar (categorizadas como acompañantes-amas de casa) expresa que las familias demandan más ayuda para realizar las tareas domésticas y que la mayoría de las cuidadoras se ocupa de personas con un cierto nivel de autonomía, aunque con necesidades puntuales y que requieren supervisión (Rogero García y Martín Coppola, 2010). La importante presencia de tareas que no son propiamente cuidados socio-sanitarios lleva a cuestionarse dónde reside la especificidad del trabajo de cuidado.

A pesar de que, en la práctica, los cuidados directos y las actividades domésticas suelen alternarse e incluso superponerse, ambos tipos de trabajo son sustantivamente diferentes: tienen distinta consideración social, implican un esfuerzo y formación diferentes y su valoración en el mercado no es la misma. La definición del trabajo de cuidado, de este modo, debe residir no tanto en las actividades en sí como en para quién se realizan. Debe hablarse de cuidado sólo en aquellos casos en que las tareas se realizan para personas que no pueden desarrollarlas por ellas mismas. La función de las cuidadoras es, además de proporcionar ayudas físicas directas, estar disponibles para proveer apoyos puntuales cuando sea necesario. Como se ha indicado, muchas de las ayudas personales en el hogar y de los cuidados socio sanitarios tienen un carácter imprevisible, que requiere de una supervisión constante, como por ejemplo cambiar pañales o acompañar al baño.

Los resultados de este trabajo confirman también las grandes diferencias en las condiciones de trabajo de las cuidadoras según su régimen laboral. Las internas son, debido a su extensa dedicación a cuidado y a sus grandes limitaciones temporales para desarrollar otras actividades, las trabajadoras más vulnerables del sector. Mientras las internas circunscriben su horizonte de preocupaciones al ámbito de su actividad laboral, como reflejo de su posición dentro de un sector que tiende a aislarlas del conjunto de la vida social, entre las externas los discursos hacen referencia a un mayor desempeño de papeles en la sociedad (en tanto que mujeres, trabajadoras, inmigrantes, esposas, madres, etc.), lo que remite a una mayor libertad para desarrollarse como ciudadanas y para integrarse en los modos de vida generalizados.

Las principales limitaciones de este trabajo residen en el número de casos de la encuesta. La EPUTC 2008 tiene un carácter exploratorio y la capacidad de su muestra para representar estadísticamente al colectivo inmigrante que cuida mayores en la Comunidad de Madrid es limitada. No obstante, esta fuente tiene una representatividad intencional basada en estudios precedentes y un elevado nivel de detalle y se complementa con una extensa muestra de entrevistas cualitativas. Estas características y la escasez de información cuantitativa sobre este colectivo concede a los resultados de este trabajo un valor 
especial. De cara a futuros estudios, se recomienda la utilización de muestras más amplias. Sería positivo, en este aspecto, crear un registro público de estas trabajadoras que permitiera cuantificar de manera básica este fenómeno, ofreciendo a las Administraciones Públicas información sobre su presencia en los hogares españoles.

\section{Bibliografía}

BITTMAn, M., J. FAST, K. FisHER, y C. THOMSON, «Making the invisible visible: the life and time(s) of informal caregivers», en Family Time: The Social Organisation of Care, N. Folbre y M. Bittman (Eds.), Londres y Nueva York, Routledge, 2004.

Boletín Oficial del Estado (13/08/1985). Real Decreto 1424/1985, de 1 de agosto, por el que se regula la relación laboral de carácter especial del servicio del hogar familiar.

Colectivo IOÉ, «Situación laboral de las mujeres inmigrantes no comunitarias», en Los inmigrantes y el mundo del trabajo, Tornos Cubillos, Madrid, Universidad Pontificia de Madrid, 2003.

Deloitte, Perspectivas de futuro de los servicios de atención a la dependencia. El Servicio de Atención a Domicilio (SAD). Estudio del marco conceptual, oferta, demanda y modelo de costes, 2008.

Eurostat, Harmonised European Time Use Surveys, Luxemburgo, Eurostat Methodologies and Working Papers. Eurostat, 2008.

Gallart Fernández-PUebla, A., Sobrecarga del cuidador inmigrante no profesional formal en Barcelona, tesis doctoral, Facultad de Humanidades, Universitat Internacional de Catalunya, San Cugat, 2007.

GARCía SAINZ, C., La carga global de trabajo. Un análisis sociológico, tesis doctoral, Departamento de Cambio Social (Sociología I), Universidad Complutense de Madrid, Madrid, 1998.

IMSERSO, Cuidado a la dependencia e inmigración, Madrid, Ministerio de Trabajo y Asuntos Sociales, 2005a.

- Cuidados a las personas mayores en los hogares españoles. El entorno familiar, Madrid, Instituto de Mayores y Servicios Sociales, 2005b.

- Libro Blanco de la Dependencia, Madrid, Ministerio de Trabajo y Asuntos Sociales, 2005c.

- Las Personas Mayores en España, Informe 2006, Madrid, Ministerio de Trabajo y Asuntos Sociales, 2006.

INE, Encuesta de Empleo del Tiempo. Qué hacemos y durante cuánto tiempo, Cifras INE, Boletín Informativo del Instituto Nacional de Estadística, Madrid, INE, 2007. 
-Proyecto metodológico de la Encuesta de Empleo del Tiempo 2002-2003, INE, Madrid, 2003.

MARTínEZ BujÁN, R., «El cuidado de ancianos: un vínculo entre la inmigración y el envejecimiento», en Panorama social, n. ${ }^{\circ}$ 2, 2005, pp. 86-97.

- «La latinoamericanización de la inmigración en España». Cuadernos Geográficos de la Universidad de Granada, n. ${ }^{\circ}$ 36, 2006, pp. 51-64.

MARTíNEZ VeIGA, U., «Evolución y clasificación del trabajo doméstico inmigrante», en OFRIM Suplementos, junio 2000, Madrid.

OIT, «Informe II. Medición del tiempo de trabajo», $18 .{ }^{a}$ Conferencia Internacional de Estadísticos del Trabajo, Ginebra, Organización Internacional del Trabajo, 2008.

ONU, Guía para la elaboración de estadísticas sobre el empleo del tiempo para medir el trabajo remunerado y no remunerado, Nueva York, Departamento de Asuntos Económicos y Sociales, División de Estadística, Naciones Unidas, 2006.

PEDRERO, M., «Propuesta metodológica para medir y valorar el cuidado de la salud doméstico no remunerado», en La economía invisible y las desigualdades de género. La importancia de medir y valorar el trabajo no remunerado, Washington DC, Organización Panamericana de la Salud (OPS), 2008.

Pérez Orozco, A., D. Paiewonsky y M. García Domínguez, Cruzando Fronteras II. Migración y desarrollo desde una perspectiva de género, Madrid, Instituto de la Mujer / UN-INSTRAW, 2008.

Pla Julián, I., Informalidad en el empleo y precariedad laboral de las empleadas de hogar, Valencia, Universidad de Valencia y Ministerio de la Igualdad, 2004.

Rogero GarCía, J. y E. MARTín COPPOLA, «Un estudio exploratorio del cuidado provisto por inmigrantes a mayores de 64 años en los hogares», en Index de Enfermería, (en prensa), 2010.

\section{Nota:}

Este trabajo ha sido realizado en el marco del proyecto de investigación «Inmigración y cuidados de personas mayores en Madrid» (CUIMAD), financiado por la Fundación BBVA, dirigido por Vicente Rodríguez Rodríguez, y cuyo equipo de investigación estuvo formado por Silvia Marcu, Gloria FernándezMayoralas Fernández, Fermina Rojo Pérez, Raúl Lardiés Bosque, Santiago Ramos Espina, Eva Martín Coppola y Jesús Rogero García. 



\title{
«LAS OTRAS» CUIDADORAS: MUJERES INMIGRANTES EN EL SERVICIO DOMÉSTICO Y TRASVASES GENERIZADOS EN EL ÁMBITO TERRITORIAL DEL BIENESTAR
}

\author{
"The other» carers: immigrant women in domestic \\ service and genderised transfers in local welfare
}

MARÍA JosÉ AgUILAR IDÁÑEZ*

\begin{abstract}
Resumen
La paulatina incorporación de la mujer al mercado laboral y el éxodo rural femenino producen una nueva serie de necesidades socio-familiares relacionadas con el cuidado. Como no se produce el reparto efectivo de tareas en el seno de los hogares, y las políticas públicas necesarias para conciliar la vida familiar y laboral son muy insuficientes, las familias recurren a la externalización del trabajo de cuidado del hogar. Externalización que se produce siempre entre mujeres: abuelas y mujeres extranjeras principalmente. Por su proximidad con los papeles tradicionales de género, el servicio doméstico se configura como una puerta de entrada naturalizada a la inserción laboral de las mujeres inmigrantes y a la regularización de situaciones de ilegalidad. Este sector presenta unas características y circunstancias especialmente propicias a las condiciones de trabajo precarias, de abuso y explotación, por reproducir la posición de subordinación de género históricamente asignada a las mujeres. En este artículo e presentan los resultados de dos investigaciones en Castilla-La Mancha: la primera, centrada en el análisis de las condiciones de empleo y discriminación de las mujeres migrantes que trabajan en el servicio doméstico, y la segunda, referida a la actividad, ocupación, empleo, usos del tiempo, conciliación y reparto de tareas.
\end{abstract}

\footnotetext{
* María José Aguilar Idáñez

Universidad de Castilla-La Mancha

Escuela Universitaria de Trabajo Social

Edificio Melchor Cano. 16071 Cuenca

Teléfono: 969179100 (extensión 4609) Fax: 969179120

mariajose.aguilar@uclm.es
} 
Palabras clave: usos del tiempo, cuidados, conciliación, mujeres inmigrantes, servicio doméstico.

\begin{abstract}
The gradual incorporation of women into the job market and the female rural exodus has led to a new series of care-related needs in society and in the family. As tasks at home are not divided equally, and the public policies need to conciliate family and work are severely lacking, families resort to outsourcing the work of home-based care. The outsourcing is always for women, mainly foreign women and grandmothers.

Because it is closely linked to traditional gender roles, domestic services acts as a naturalised port of entry for female immigrants to enter the job market and to formalise their legal status. The characteristics and circumstances of this sector contribute to precarious work situations of abuse and exploitation, by reproducing the position of gender subordination historically assigned to women.

This paper presents the results of two studies carried out in Castilla-La Mancha. One analyses the working conditions and discrimination of female migrants working in domestic service. The other deals with the activity, occupation, employment, use of time, conciliation and division of tasks.
\end{abstract}

Keywords: uses of time, care, conciliation, immigrant women, domestic service.

\title{
1. Introducción
}

El cambio de las estructuras familiares y la paulatina incorporación de la mujer al mercado laboral producen una nueva serie de necesidades socio-familiares relacionadas con el cuidado. Esta incorporación de la mujer al mercado laboral no ha supuesto que ésta deje de asumir las tareas propias del ámbito doméstico-familiar, ya que se incorporan al espacio productivo sin que los hombres lo hagan en el reproductivo. Ante esta nueva realidad social, donde no se reproduce el reparto efectivo de tareas en el seno de los hogares, y donde las políticas públicas necesarias para conciliar la vida familiar y laboral son muy insuficientes, las familias recurren a la externalización del trabajo de cuidado del hogar. Tradicionalmente para esta externalización se recurría a otras mujeres de la propia familia, principalmente las abuelas. Actualmente, en el medio rural, ésta sigue siendo la principal estrategia de externalización del cuidado de niños, mientras que la externalización del cuidado de ancianos dependientes se produce mediante la contratación de mujeres extranjeras por parte de las familias. En el medio urbano, para la externalización del cuidado, en ambos casos, se recurre a mujeres migrantes extranjeras que llegan atraídas por esa fuente de demanda. Se producen, de este modo, trasvases generizados de la función de cuidado, siempre entre mujeres, ya sean de la propia familia o ajenas a ella. El servicio doméstico es uno de los sectores de ocupación más relevantes para las mujeres migrantes. Por su proximidad con los papeles 
tradicionales de género y el desempeño asalariado de las tareas domésticas, se configura como una puerta de entrada naturalizada a la inserción laboral de las mujeres y a la regularización de situaciones de ilegalidad. Sin embargo, este sector presenta unas características y circunstancias muy particulares y especialmente propicias a las condiciones de trabajo precarias y/o de abuso y explotación, precisamente por reproducir la posición de subordinación de género históricamente asignada a las mujeres ${ }^{1}$.

\section{Actividad, ocupación y paro según el nivel de formación: diferencias territoriales y de género en Castilla-La Mancha}

En términos generales, cuanto mayor es el nivel de formación mayor es la tasa de actividad y ocupación. Independientemente de la zona que se trate, las tasas son siempre superiores en los hombres que en las mujeres. No obstante, las mayores desigualdades se localizan en la zona intermedia, siendo, en la mayoría de las ocasiones, la diferencia entre sexos relativamente similar en la zona rural y urbana. En todas las zonas los estudios de primaria y la primera etapa de secundaria son los niveles de estudio con mayor desequilibrio entre sexos. Se evidencia así que la tasa de ocupación y el nivel de formación se relacionan positivamente. De esta manera, cuanto más alto es el grado de estudios, mayor es la tasa de ocupación. Hay que señalar que el desequilibrio entre sexos es distinto en cada zona. Específicamente, la zona intermedia es la que registra mayores diferencias, mientras que la zona urbana es donde hay mayor paridad. Los datos relativos a la tasa de paro revelan que el paro en las mujeres es más elevado que en los hombres en todos los niveles de formación. En el caso de los hombres, el paro es relativamente constante a lo largo de los diferentes niveles de formación. Por el contrario, si bien es cierto que el paro en la mujer no decrece a medida que el nivel de formación es mayor, también

1. En este artículo se utilizan, de forma cruzada, los resultados de dos investigaciones realizadas en Castilla-La Mancha: la primera, centrada en el análisis de las condiciones de empleo y discriminación de las mujeres migrantes que trabajan en el servicio doméstico (Aguilar, 2010), y la segunda (como parte de un proyecto europeo I+D más amplio), referida a la actividad, ocupación, empleo, usos del tiempo, conciliación y reparto de tareas en toda la población del mismo territorio, introduciendo el análisis territorial y la perspectiva de género (Aguilar et al., 2010). La metodología utilizada ha sido una combinación triangulada de datos primarios cuantitativos (149 encuestas válidas a mujeres inmigrantes extranjeras empleadas de hogar), datos primarios cualitativos (entrevistas exploratorias, entrevistas en profundidad a empleadas e informantes-clave, grupos de discusión con empleadas y empleadoras e historias de vida). También se ha realizado una exhaustiva explotación de datos secundarios (Censo, EPA, Encuesta Nacional de Usos del Tiempo, Encuesta de Mujeres Rurales, Encuesta de Compatibilización FamiliaEmpleo, entre otros). 
es cierto que el nivel de formación más alto es el que registra menores tasas de paro.

Estos datos, junto con los resultados de las entrevistas realizadas en profundidad, nos muestran que la falta de oportunidades laborales que presenta el mundo rural hace que las mujeres jóvenes opten por emigrar a la ciudad con la finalidad de conseguir un empleo. Una de las principales dificultades para la inserción laboral de las mujeres rurales de mediana edad es su bajo nivel de formación reglada, cuando no es inexistente, a lo que hay que añadir la falta de medios con que suelen contar (no suelen tener carné de conducir, por ejemplo) y la falta de acceso a la información. Las mujeres de mediana edad no suelen estar motivadas en realizar formación ocupacional a menos que sea remunerada. La formación de las mujeres en empleos típicamente masculinos plantea problemas, tanto a la hora de que sea bien recibido por las mujeres, como a la hora de que una vez terminada la formación las mujeres sean contratadas. Por el contrario, la formación en ocupaciones típicamente femeninas tiene una aceptación muy buena por parte de las mujeres y facilita a las mujeres su incorporación en el mercado de trabajo. Uno de los motivos del fracaso en encontrar empleo tras la finalización de la formación ocupacional se debe a que no aporta la suficiente especialización que requiere el mercado laboral. También la dificultad de conciliación entre la vida familiar y laborar es uno de los principales obstáculos que impide a la mujer rural poder acceder a un empleo.

En el ámbito rural existe una mentalidad marcadamente patriarcal donde a los hombres se les ha asignado tareas y responsabilidades relacionadas con el «ámbito productivo». Por el contrario, a las mujeres se les considera responsables del «ámbito reproductivo». Esta mentalidad aleja a la mujer de su integración laboral.

\section{Tiempo de cuidados: diferencias territoriales y de género en Castilla-La Mancha}

Los hombres dedican más horas al trabajo remunerado que las mujeres independientemente de si se encuentran ocupados, parados o inactivos. Sin embargo, el número de horas dedicadas al hogar y la familia es siempre mayor en las mujeres que en los hombres tanto en ocupados, parados, como en inactivos. El tiempo invertido por la mujer al hogar es de 2 horas y 28 minutos mayor que en los hombres cuando se encuentran ocupados y parados, mientras que en situación de inactividad las mujeres emplean 3 horas y 41 minutos más que los hombres. En las mujeres el número de horas dedicadas al hogar es menor cuando están ocupadas que paradas, habiendo una diferencia entre 
Tabla 1. Horas dedicadas al hogar y la familia en ocupados, parados e inactivos según sexo

\begin{tabular}{|c|c|c|c|}
\cline { 2 - 4 } \multicolumn{1}{c|}{} & Ocupado & Parado & Inactivo \\
\hline Hombre & $1 \mathrm{~h} 5 \mathrm{~min}$ & $2 \mathrm{~h} 35 \mathrm{~min}$ & $2 \mathrm{~h} 20 \mathrm{~min}$ \\
\hline Mujer & $3 \mathrm{~h} 33 \mathrm{~min}$ & $5 \mathrm{~h} 03 \mathrm{~min}$ & $6 \mathrm{~h} 01 \mathrm{~min}$ \\
\hline Diferencia entre sexos & $-2 \mathrm{~h} 28 \mathrm{~min}$ & $-2 \mathrm{~h} 28 \mathrm{~min}$ & $-3 \mathrm{~h} 41 \mathrm{~min}$ \\
\hline
\end{tabular}

Fuente: Elaboración propia a partir de la Encuesta de «Empleo del tiempo» 2002-2003.

ambas situaciones de dos horas. Asimismo, la cantidad de horas empleadas en el hogar en las mujeres paradas es menor que en las inactivas. En esta ocasión la diferencia es de una hora. En los hombres, al igual que en la mujer, la menor dedicación al hogar se da cuando se encuentran ocupados. No obstante, a diferencia de las mujeres, la diferencia de número de horas invertidas en el hogar cuando se encuentran parados o inactivos es pequeña y en sentido contrario. Concretamente, los parados e inactivos emplean una hora y 1520 minutos más al hogar. Los datos sobre las horas dedicadas al hogar y al trabajo, en conjunto, parecen indicar que el menor tiempo dedicado al hogar por parte de los ocupados es consecuencia de que tienen que emplear gran cantidad de tiempo a su trabajo.

La suma de las horas dedicadas tanto al hogar como al trabajo revela que son los ocupados los que emplean más tiempo a desarrollar estas dos actividades. Además, la suma de horas de ambas actividades es superior en las mujeres que en los hombres, tanto en los ocupados como parados o inactivos. La diferencia entre sexos es de entorno a una hora y 10 minutos en los ocupados y de casi dos horas en los parados, localizándose la mayor brecha entre sexos en los inactivos, donde la diferencia de tiempo es de aproximadamente 3 horas y 15 minutos. En consecuencia, en cuanto al sexo, de estos datos se desprende que son las mujeres las que sufren una mayor carga de tareas laborales y familiares. Por otro lado, en cuanto a la relación con el empleo, son los ocupados los que tienen que dedicar más horas al hogar y el trabajo. El tiempo empleado al hogar y la familia es directamente inverso al tiempo dedicado al trabajo. Es decir, cuanto mayor tiempo se dedica al trabajo, menor tiempo se emplea al hogar. Este resultado es congruente con el hecho de que sean los ocupados, que por definición emplean más tiempo al trabajo, los que menos horas dediquen al hogar. Por último, es destacable que, en todos los rangos de horas empleadas al trabajo, las mujeres dediquen más tiempo al hogar que los hombres. Las diferencias decrecen gradualmente a medida que aumenta el número de horas empleadas al trabajo, lo que puede indicar una 
Tabla 2. Horas dedicadas al hogar y a la familia en función del número de horas empleadas al trabajo y según sexo

\begin{tabular}{|c|c|c|c|c|}
\cline { 2 - 5 } \multicolumn{1}{c|}{} & De 0 a 3 & De 4 a 6 & De 7 a 9 & De 10 a 12 \\
\hline Hombre & $1 \mathrm{~h} 44 \mathrm{~min}$ & $1 \mathrm{~h} 20 \mathrm{~min}$ & $1 \mathrm{~h} 05 \mathrm{~min}$ & $29 \mathrm{~min}$ \\
\hline Mujer & $5 \mathrm{~h} 27 \mathrm{~min}$ & $4 \mathrm{~h} 16 \mathrm{~min}$ & $2 \mathrm{~h} 23 \mathrm{~min}$ & $1 \mathrm{~h} 4 \mathrm{~min}$ \\
\hline Diferencia entre sexos & $3 \mathrm{~h} 43 \mathrm{~min}$ & $2 \mathrm{~h} 56 \mathrm{~min}$ & $1 \mathrm{~h} 18 \mathrm{~min}$ & $35 \mathrm{~min}$ \\
\hline
\end{tabular}

Fuente: Elaboración propia a partir de la Encuesta de «Empleo del tiempo» 2002-2003.

posible externalización de las tareas de cuidado en el hogar (ya sea dentro de la red familiar o fuera de ella) o un posible reparto de tareas entre el hombre y la mujer en el hogar donde ambos trabajan. Veamos cuál de estas situaciones es la generalizada. Los datos que muestran las tablas relevan claramente que sigue existiendo una «doble jornada» de trabajo para la mujer con respecto a la jornada del hombre debido a la mayor cantidad de horas dedicadas al hogar, tanto si se trabaja fuera del hogar como si no. Esto pone de manifiesto que el reparto de tareas de cuidado familiar entre hombres y mujeres es prácticamente inexistente.

El porcentaje de personas que alegan falta de tiempo para poder cumplir con todas las tareas que tienen que hacer es claramente superior en las mujeres que en los hombres en todas las posibles relaciones con el empleo. Asimismo, en ambos sexos el porcentaje de personas que se quejan de falta de tiempo es mayor en los ocupados que en los parados e inactivos. Sin embargo, si bien en los hombres el porcentaje de parados e inactivos es muy similar, en las mujeres hay un mayor porcentaje en las paradas que en las inactivas. Si se relacionan estos datos con los de la suma de horas empleadas al hogar y al trabajo, se llega a la conclusión de que existe una correspondencia parcial entre ambas. Como se ha apuntado con anterioridad, es en los ocupados donde la cantidad total de horas dedicadas al hogar y al trabajo es mayor. En concordancia con ello, son estos los que más se quejan de disponer de insuficiente tiempo para cumplir con sus tareas. La discordancia se encuentra en las mujeres paradas e inactivas. Como ya se ha puesto de manifiesto, la suma de horas dedicadas al hogar y al trabajo por parte de las inactivas es una hora superior que por parte de las paradas. Esta diferencia es el resultado de que las inactivas emplean al hogar y a la familia una hora más que las paradas. A pesar de esto, son las paradas, y no las inactivas, las que afirman en mayor proporción de disponer de poco tiempo para lo que tienen que hacer. Esta falta de correspondencia puede ser debida a que las inactivas asumen el papel de amas de casa, mientras que las paradas se ven a sí mismas como mujeres 
Tabla 3. Horas dedicadas al hogar y a la familia en hombres y mujeres según nivel de formación y horas empleadas al trabajo

\begin{tabular}{|c|c|c|c|c|c|}
\cline { 3 - 6 } \multicolumn{2}{c|}{} & De 0 a 3 & De 4 a 6 & De 7 a 9 & De 10 a 12 \\
\hline \multirow{3}{*}{$\begin{array}{l}\text { Educación } \\
\text { Secundaria }\end{array}$} & Hombre & $1 \mathrm{~h} 40 \mathrm{~min}$ & $51 \mathrm{~min}$ & $59 \mathrm{~min}$ & $20 \mathrm{~min}$ \\
\cline { 2 - 6 } & Mujer & $5 \mathrm{~h} 35 \mathrm{~min}$ & $5 \mathrm{~h}$ & $2 \mathrm{~h} 33 \mathrm{~min}$ & $1 \mathrm{~h} 12 \mathrm{~min}$ \\
\cline { 2 - 6 } & Diferencia entre sexos & $-3 \mathrm{~h} 55 \mathrm{~min}$ & $-4 \mathrm{~h} 09 \mathrm{~min}$ & $-1 \mathrm{~h} 34 \mathrm{~min}$ & $-52 \mathrm{~min}$ \\
\hline \multirow{3}{*}{$\begin{array}{c}\text { Educación } \\
\text { Superior }\end{array}$} & Hombre & $1 \mathrm{~h} 20 \mathrm{~min}$ & $2 \mathrm{~h} 48 \mathrm{~min}$ & $1 \mathrm{~h} 19 \mathrm{~min}$ & $36 \mathrm{~min}$ \\
\cline { 2 - 6 } & Mujer & $4 \mathrm{~h} 17 \mathrm{~min}$ & $3 \mathrm{~h} 34 \mathrm{~min}$ & $1 \mathrm{~h} 52 \mathrm{~min}$ & $26 \mathrm{~min}$ \\
\cline { 2 - 6 } & Diferencia entre sexos & $-2 \mathrm{~h} 57 \mathrm{~min}$ & $-46 \mathrm{~min}$ & $-33 \mathrm{~min}$ & $10 \mathrm{~min}$ \\
\hline
\end{tabular}

Fuente: Elaboración propia a partir de la Encuesta de «Empleo del tiempo» 2002-2003.

trabajadoras en búsqueda de empleo y les supone más esfuerzo el cumplir con las tareas del hogar. Cruzando todos estos datos con el nivel de formación de hombres y mujeres vemos cómo influye el nivel de formación alcanzado en el número de horas dedicadas al hogar. Dicho nivel se clasifica en dos categorías: estudios de secundaria, que incluye aquellos niveles de formación que alcanzan como máximo los estudios de secundaria, y estudios superiores, que incluye aquellos niveles que alcanzan como máximo los estudios superiores.

El número de horas dedicadas al hogar disminuye a medida que aumenta el número de horas empleadas al trabajo. En términos generales, el número de horas dedicadas al hogar es mayor en las mujeres que en los hombres. En la mayoría de los rangos de horas empleadas al trabajo, el número de horas que los hombres dedican al hogar es mayor en los estudios superiores que en los de secundaria. De modo opuesto, en las mujeres el número de horas es menor en los estudios superiores que en estudios de secundaria. Como consecuencia de esto, la diferencia entre los sexos resulta menor en los estudios superiores que en los estudios de secundaria. De estos resultados se desprende que el nivel de formación influye, de manera determinante, en el número de horas dedicadas al hogar.

\section{Estrategias de conciliación entre la vida laboral y familiar: diferencias territoriales y de género en Castilla-La Mancha}

Las regiones donde se dan los mayores porcentajes de personas ocupadas, con al menos un hijo, que confían el cuidado de sus niños a su cónyuge ${ }^{2}$ son Cantabria (42,9 \%), Andalucía (40,9 \%), Extremadura (40,7\%) y Castilla

2. INE, «EPA. Módulo de conciliación entre la vida laboral y familiar», Notas de Prensa, [en línea], 2006, <http://www.ine.es/prensa/np417.pdf)>. 
La-Mancha (40 \%). Por sexo, cabe decir que más del 56\% de los varones de Extremadura, Castilla-La Mancha y Andalucía confían el cuidado de sus hijos a sus esposas, mientras que en Navarra este porcentaje se reduce al 42,6 \% y en el País Vasco es del 40,6\%. En cuanto a la organización de la vida laboral, el 28,6 \% de los ocupados de Castilla-La Mancha y el 27,8 \% de los trabajadores de Canarias no pueden modificar el inicio o la finalización de su jornada laboral por razones familiares (los valores más altos en este aspecto dentro del ámbito nacional). Analizando los microdatos, este módulo de la EPA para Castilla-La Mancha, desde la perspectiva territorial y de género, resultan relevantes las variables que veremos a continuación.

\subsection{Actitudes ante la organización de la vida en las esferas laboral y familiar}

Tanto hombres como mujeres prefieren dedicar más tiempo a sus hijos y allegados dependientes que al trabajo fuera del hogar, aunque ellas en menor medida. No obstante, se observa menor satisfacción de las segundas con su actual modo de vida, generalmente más orientado a compaginar actividades en las dos esferas. También, es necesario resaltar que únicamente un $61 \%$ de las mujeres ocupadas del medio rural desea mantener su actual situación, que supone un valor muy por debajo de la media que se sitúa en un $78 \%$. Con los datos disponibles podemos afirmar que la mujer en el medio rural está mucho más insatisfecha con la organización de su tiempo. A diferencia de los hombres, que los del medio rural están más satisfechos que la media regional en lo que a organización del tiempo se refiere para conciliar la vida laboral y familiar (son los que menos concilian y los que más satisfechos están con esta situación). Este dato es sumamente preocupante ya que muestra la existencia real de mayores resistencias en los hombres del medio rural ante la posibilidad de reparto de tareas en el seno del hogar. También se aprecian las notables diferencias entre las mujeres paradas de la zona rural, intermedia y urbana: mientras un $38 \%$ de las paradas de la zona urbana desearían trabajar más y cuidar menos, este porcentaje se eleva al $46,3 \%$ de las paradas de zona intermedia y sube a un $64 \%$ en el caso de las mujeres paradas del medio rural. La situación en los hombres es justo a la inversa: sólo un 26,4 \% de los parados y un $0 \%$ de los inactivos del medio rural desearían trabajar más y cuidar menos, mientras que esas cifras suben a medida que aumenta ligeramente el tamaño del municipio. 
Tabla 4. Principal servicio de cuidado a los niños utilizado para cuidar a sus hijos o los de su pareja

\begin{tabular}{|l|l|c|c|c|c|c|c|}
\cline { 3 - 8 } \multicolumn{2}{l|}{} & $\begin{array}{c}\text { Servicios } \\
\text { especiali- } \\
\text { zados }\end{array}$ & Cónyuge & $\begin{array}{c}\text { Familiares, } \\
\text { vecinos o } \\
\text { amigos }\end{array}$ & $\begin{array}{c}\text { No utiliza } \\
\text { asistencia }\end{array}$ & No sabe & $\begin{array}{c}\text { Total } \\
\text { general }\end{array}$ \\
\hline \multirow{2}{*}{ Rural } & Hombres & 13,2 & 55,1 & 5,7 & 24,6 & 1,3 & 100,0 \\
\cline { 2 - 9 } & Mujeres & 22,3 & 9,2 & 26,1 & 38,0 & 4,4 & 100,0 \\
\hline \multicolumn{2}{|l|}{ Total rural } & 15,9 & 41,2 & 11,9 & 28,7 & 2,3 & 100,0 \\
\hline \multirow{2}{*}{ Intermedio } & Hombres & 11,3 & 63,5 & 9,4 & 15,1 & 0,8 & 100,0 \\
\cline { 2 - 9 } & Mujeres & 22,8 & 6,0 & 27,0 & 43,6 & 0,7 & 100,0 \\
\hline \multicolumn{2}{|l|}{ Total intermedio } & 14,9 & 45,4 & 14,9 & 24,1 & 0,7 & 100,0 \\
\hline \multirow{2}{*}{ Urbano } & Hombres & 16,3 & 52,0 & 8,9 & 22,8 & 0,0 & 100,0 \\
\cline { 2 - 8 } & Mujeres & 26,3 & 9,4 & 21,3 & 42,6 & 0,4 & 100,0 \\
\hline \multicolumn{2}{|l|}{ Total urbano } & 20,0 & 36,3 & 13,5 & 30,1 & 0,1 & 100,0 \\
\hline \multicolumn{2}{|l|}{ Total CLM } & 17,7 & 40,1 & 13,7 & 27,9 & 0,7 & 100,0 \\
\hline
\end{tabular}

Fuente: Elaboración propia EPA. Módulo de conciliación entre la vida laboral y familiar.

4.2. Los servicios de apoyo para el cuidado de niños y personas en situación de dependencia

La estrategia dominante entre los hombres continúa siendo la tradicional, es decir, el cuidado dispensado por el cónyuge (siempre la mujer). Para las mujeres ocupadas la estrategia conyugal es minoritaria; lo más habitual es que, aparte de no utilizar ninguna asistencia, recurran a familiares (más común en las zonas rural e intermedia) y a servicios ofrecidos en el mercado (más normal en la urbana). Estos datos ilustran la persistencia del modelo clásico de organización de los hogares en torno al reparto de tareas productivas (hombres) y reproductivas (mujeres), que convive actualmente con la función productiva de las mujeres y que inevitablemente deviene en una multiplicación de las responsabilidades asumidas por aquéllas, con el consiguiente conflicto de compatibilidad entre las dos esferas de la vida cotidiana.

Otro dato que merece la pena analizar es el referido al uso de los servicios especializados: estrategia que se utiliza mucho menos en el medio rural. En todo caso, éste es un problema también de la zona urbana a tenor de la escasa diferencia de cinco puntos entre las zonas. Tanto es así, que una parte importante de quienes querrían dedicar más tiempo al trabajo declaran no poder hacerlo a causa de las condiciones de los servicios de cuidado de niños. Esta situación, confirmada por las entrevistas realizadas a informantes-clave, evidencia las importantes deficiencias que en materia de servicios sociales y 
socio-educativos existen en Castilla-La Mancha para permitir la incorporación de la mujer al trabajo remunerado sin verse obligada a cumplir con «dobles jornadas», o, simplemente, para posibilitar algún atisbo de conciliación entre la vida laboral, social y familiar. El hecho de que mucho más de la mitad de las personas ocupadas recurran a las redes sociales naturales (dentro de la familia nuclear, la familia extensa o el vecindario y amistades) para atender el cuidado de los hijos menores enseña la verdadera situación en la que nos encontramos, más allá de los discursos bienintencionados de turno. La situación nos muestra claramente, más allá de los deseos y declaraciones, que el nuestro es un modelo de bienestar más de tipo familista que verdaderamente social al estilo norte o centroeuropeo. Sin duda la importancia que el vínculo familiar tiene en nuestras sociedades permite que se sostenga, por ahora, dicho modelo, pero ¿qué pasará dentro de unos años cuando las abuelas no vivan en la misma localidad? ¿Qué pasará cuando las mujeres con una formación cada vez mayor no deseen renunciar a su desarrollo profesional y a su derecho al trabajo remunerado? ¿Tendrán las mujeres que seguir renunciando al trabajo remunerado o aceptarlo a costa de una doble jornada? Y otro tanto ocurre con el cuidado de adultos dependientes. Por otro lado, fijándonos en la atención al cuidado de adultos que no pueden valerse por sí mismos, actividad que implica a una parte importante de la población con edades entre 16-64 años y que constituye el gran reto a enfrentar por los servicios de atención a personas dependientes, los datos confirman una mayor dedicación de las mujeres, ya tradicionalmente ocupadas en este tipo de labores no remuneradas. La zona

Tabla 5. Atención de familiares o amigos de 15 o más años que necesitan de cuidado

\begin{tabular}{|c|c|c|c|c|c|c|c|}
\hline & \multicolumn{2}{|c|}{ Ocupados } & \multicolumn{2}{|c|}{ Parados } & \multicolumn{2}{|c|}{ Inactivos } \\
\hline & & Sí & No & Sí & No & Sí & No \\
\hline \multirow{2}{*}{ Rural } & Hombres & 10,5 & 89,5 & 11,7 & 88,3 & 7,7 & 92,3 \\
\hline & Mujeres & 19,1 & 80,9 & 7,9 & 92,1 & 18,9 & 81,1 \\
\hline \multicolumn{2}{|c|}{ Total rural } & 13,0 & 87,0 & 9,2 & 90,8 & 16,3 & 83,7 \\
\hline \multirow{2}{*}{ Intermedio } & Hombres & 6,7 & 93,3 & 0,0 & 100,0 & 4,6 & 95,4 \\
\hline & Mujeres & 10,8 & 89,2 & 11,5 & 88,5 & 18,7 & 81,3 \\
\hline \multicolumn{2}{|c|}{ Total intermedio } & 8,0 & 92,0 & 7,5 & 92,5 & 15,8 & 84,2 \\
\hline \multirow{2}{*}{ Urbano } & Hombres & 6,6 & 93,4 & 8,6 & 91,4 & 10,4 & 89,6 \\
\hline & Mujeres & 10,1 & 89,9 & 7,9 & 92,1 & 17,8 & 82,2 \\
\hline \multicolumn{2}{|l|}{ Total urbano } & 7,9 & 92,1 & 8,1 & 91,9 & 15,5 & 84,5 \\
\hline \multicolumn{2}{|l|}{ Total CLM } & 8,7 & 91,3 & 8,2 & 91,8 & 15,8 & 84,2 \\
\hline
\end{tabular}

Fuente: Elaboración propia EPA. Módulo de conciliación entre la vida laboral y familiar 
Tabla 6. Principal razón, ligada con el cuidado de adultos dependientes, para no trabajar (más)

\begin{tabular}{|l|l|c|c|c|c|c|}
\cline { 3 - 7 } \multicolumn{2}{l|}{} & $\begin{array}{c}\text { Falta de } \\
\text { servicios }\end{array}$ & $\begin{array}{c}\text { Servicios } \\
\text { muy caros }\end{array}$ & $\begin{array}{c}\text { Servicios sin } \\
\text { calidad }\end{array}$ & No sabe & Total general \\
\hline \multirow{2}{*}{ Rural } & Hombres & - & - & - & - & - \\
\cline { 2 - 7 } & Mujeres & 82,3 & 17,7 & 0,0 & 0,0 & 100,0 \\
\hline \multicolumn{2}{|l|}{ Total Rural } & 82,3 & 17,7 & 0,0 & 0,0 & 100,0 \\
\hline \multirow{2}{*}{ Intermedio } & Hombres & 0,0 & 100,0 & 0,0 & 0,0 & 100,0 \\
\cline { 2 - 8 } & Mujeres & 46,5 & 29,0 & 9,9 & 14,6 & 100,0 \\
\hline \multicolumn{2}{|l|}{ Total Intermedio } & 43,9 & 33,0 & 9,4 & 13,7 & 100,0 \\
\hline \multirow{2}{*}{ Urbano } & Hombres & 0,0 & 100,0 & 0,0 & 0,0 & 100,0 \\
\cline { 2 - 8 } & Mujeres & 30,9 & 69,1 & 0,0 & 0,0 & 100,0 \\
\hline \multicolumn{2}{|l|}{ Total Urbano } & 22,3 & 77,7 & 0,0 & 0,0 & 100,0 \\
\hline \multicolumn{2}{|l|}{ Total CLM } & 42,8 & 46,1 & 4,5 & 6,6 & 100,0 \\
\hline
\end{tabular}

Fuente: Elaboración propia EPA. Módulo de conciliación entre la vida laboral y familiar.

rural presenta mayor porcentaje de personas dedicadas al cuidado de adultos dependientes, sin duda debido a su estructura demográfica; la proporción de mujeres dedicadas a cuidados de personas dependientes es mayor que la de los hombres en todas las zonas, siendo el caso de la zona intermedia donde la diferencia relativa entre sexos es mayor.

Según la relación con la actividad que aparece en la Tabla 5, observamos una mayor tendencia de las mujeres inactivas que de los hombres inactivos hacia el cuidado de adultos dependientes, en todas las zonas. Respecto a los desempleados, esa tendencia se invierte en el medio rural y urbano, mientras en el intermedio sólo son mujeres (dentro de los parados) quienes se dedican al cuidado de adultos. Por último, examinando los resultados en la población ocupada, está claro que la conciliación de la vida laboral y el cuidado de adultos es una cuestión que afecta a una mayor proporción de mujeres que de hombres, en todos los tipos de zona. Los motivos por los que algunas de estas personas que cuidan de adultos dependientes no trabajan o no aumentan el número de horas dedicadas a su empleo se muestran en la Tabla 6. En el medio rural no se encuentra a ningún hombre que no trabaje (más) por motivo de cuidado a personas mayores de 15 años; de las mujeres, el 82,3\% apunta como razón principal la falta de servicios y el 17,7 \% que los servicios existentes son muy caros.

En la zona intermedia es también acusada la falta de servicios por parte de las mujeres, ya que un 46,5\% la considera razón principal, un $29 \%$ señala que los servicios de cuidado de adultos dependientes son demasiado caros, un 
9,9\% desconfía de la calidad de esos servicios y un $14,6 \%$ no sabe cuál puede ser la razón; todos los hombres de esta zona coinciden en los altos precios de los servicios como motivo esencial. En el medio urbano, disminuye más la percepción de la falta de servicios como el problema central (sólo un 30,9 \% de las mujeres señala esta opción) y es el hecho de que se consideran muy caros $(69 \%)$ la principal razón para no trabajar más. Tanto mujeres como hombres, coinciden en mayor medida en que la principal razón para no trabajar o trabajar más es que los servicios ligados al cuidado de adultos son muy caros.

\subsection{Flexibilidad laboral y conciliación}

La jornada laboral y su distribución son aspectos determinantes de las posibilidades de compatibilización de la vida laboral y familiar. La falta de coincidencia entre los horarios escolares y los laborales y la necesidad de invertir gran cantidad de tiempo en los desplazamientos a los lugares de trabajo, son algunas de las manifestaciones cotidianas de la dificultad para conciliar las responsabilidades de trabajo y hogar, más allá de la posibilidad de obtener permisos y excedencias para dedicar tiempos específicos a asuntos relacionados con la familia. Centrándonos en los trabajadores por cuenta ajena, la zona en la que más complicado es conseguir esa modificación de la jornada laboral es la rural: un 40,6\% de los asalariados no tiene esa posibilidad. Más de una tercera parte (el $38,9 \%$ ) de los trabajadores por cuenta ajena declara no poder, en ningún caso, disponer de días libres por motivos familiares, siendo poco notable la diferencia entre hombres y mujeres. Estas dificultades parecen mayores en el medio rural, donde el porcentaje en ese caso llega al 44,4\%, mientras la zona intermedia está por debajo de la media regional con un 35,3\%. A la luz de estos datos, la carencia de una red suficiente de servicios e infraestructuras de apoyo para el cuidado de niños y adultos dependientes sigue siendo manifiesta. Asimismo, sigue siendo difícil evaluar los resultados de las medidas tomadas hasta el momento de manera exhaustiva. Sobre el problema específico de la atención a las personas en situación de dependencia es obligado, además, recordar las perspectivas abiertas por el proceso iniciado con la Ley de Promoción de la Autonomía Personal y Atención a la Dependencia, en las que se han depositado grandes expectativas que deberían ayudar a liberar las cargas soportadas por muchas ciudadanas (ya que en su mayoría son mujeres) que atienden habitualmente a familiares con autonomía personal limitada.

La relación que en el orden de las representaciones sociales se realiza entre domesticidad, feminidad y ruralidad, explicaría en parte la persistencia, puesta de manifiesto por muchas investigaciones empíricas, de unos roles de género muy tradicionales que se concretan en una nula implicación de los 
varones en las tareas domésticas ${ }^{3}$, o en la reticencia de las madres a la hora de utilizar servicios como las guarderías infantiles frente al recurso tradicional, las redes de solidaridad informal de parientes y amigas. El cuidado de los nietos, por ejemplo, ofrece a las mujeres mayores una función y un estatus importante en la familia y la comunidad, re-estableciendo de alguna manera su identidad como madres. Las abuelas rurales parecen así mucho más dispuestas a ejercer ese papel que las abuelas urbanas. Los servicios públicos de apoyo a la conciliación no son suficientes o no existen. Pero también se da la paradoja de que, cuando existen, no se aprovechan lo suficiente o no se adecuan a las necesidades de los usuarios por problemas de incompatibilidad horaria, por ejemplo. En todo caso, lo que se constata es una demanda de las mujeres referida a la necesidad del reparto de tareas en el hogar, que de ningún modo se produce en el medio rural. La red familiar y social sigue siendo la estrategia principal de conciliación en el medio rural, independientemente de la existencia o no de servicios de proximidad. La fuerte identificación del rol de género, tradicionalmente asignado y asumido por la mujer como cuidadora principal, junto con el hecho de que los hombres también tienen más fuertemente interiorizado en el medio rural su propio rol tradicional como proveedor (no cuidador), hace que algunas actuaciones realizadas en materia de sensibilización masculina no hayan funcionado. Se termina entendiendo el problema de la conciliación como una cuestión exclusivamente femenina, y no de igualdad entre hombres y mujeres. Por todo esto, más que de conciliación habría que hablar de contradicción (Tobío, 2002) en las madres trabajadoras entre el mundo del trabajo y el de la familia. Las razones individuales, familiares, económicas y sociales que explican la incorporación masiva de la mujer al empleo no parecen indicar la posibilidad de retroceso. Este retraso en la incorporación femenina al empleo en nuestro país se ha hecho con cierta celeridad, lo que seguramente explica la escasa conciencia de la sociedad española ante la magnitud del cambio que está teniendo ya lugar. Pero estos nuevos problemas que ahora «están siendo solucionados de forma callada, privada e informal entre mujeres, a través de una variedad de estrategias de las que es pieza clave la solidaridad intergeneracional» no serán posibles en un futuro próximo: cuando las abuelas inactivas y disponibles vayan desapareciendo o sustituyéndose por abuelas ocupadas y menos proclives a desempeñar este papel de madres sustitutas. El resto de las estrategias no es deseable y

3. Uno de los estudios más detallados sobre la carga y la distribución del trabajo doméstico en las familias rurales fue realizado por Bericat y Camarero en Andalucía, en 1994. En él se muestra cómo la participación de los hombres es muy reducida, no detectándose variaciones significativas en las familias en las que existe una mujer empleada. 
tiene efectos negativos, y la baja tasa de fecundidad española tampoco es ajena a estos problemas.

Aunque al hablar de conciliación casi siempre se hace referencia al cuidado de los hijos, en el medio rural una cuestión central es la atención y el cuidado de las personas mayores dependientes. Este cuidado recae exclusivamente en las mujeres de más de 45 años, que muchas veces no utilizan los escasos recursos residenciales existentes por el «sentimiento de culpa» que ello les produce. Las políticas de desarrollo rural y diversificación de actividades económicas han puesto el acento en la existencia de nuevos «nichos de empleo», que en muchos casos se relacionan con las actividades de cuidado asumidas tradicionalmente por las mujeres (cuidado de niños y ancianos). Si bien es un objetivo importante profesionalizar estas actividades -convirtiéndolas en empleos dignos para las mujeres-, podríamos preguntarnos si no estamos reforzando las representaciones sociales que hacen de estas tareas un ámbito fundamental y exclusivamente femenino. Llegados a este punto, nos encontramos con el viejo dilema de hasta dónde lo «bueno» es enemigo de lo «mejor». Tanto si se trata del cuidado de hijos menores como si se trata del de personas mayores dependientes, una estrategia que suele emplearse si la capacidad económica de la familia lo permite es la externalización, total o parcial, de las tareas del hogar y el cuidado. Esta externalización es el medio rural más utilizado para atender a ancianos dependientes en su propio domicilio (en el régimen de servicio doméstico interno), mientras que en el medio urbano se utiliza indistintamente para atender al cuidado de niños (en régimen de servicio doméstico externo, fijo o por horas en su mayor parte) y para el cuidado de ancianos (en régimen de servicios doméstico interno, principalmente). Veamos a continuación cuál es la situación de las mujeres que trabajan en esta externalización del cuidado del hogar y las personas dependientes.

\section{Situación de las mujeres inmigrantes que trabajan en el servicio doméstico en Castilla-La Mancha}

En los últimos diez años hemos asistido en Castilla-La Mancha a la externalización del cuidado de los niños y mayores dependientes a través de las «otras» cuidadoras: las mujeres inmigrantes, sufrida una triple discriminación como mujeres, trabajadoras e inmigrantes. Es decir, a la marginación que sufren por el tipo de empleo de cuasi-servidumbre desempeñado, tan estigmatizado socialmente como precario e irregular en sus condiciones laborales ${ }^{4}$, se agrega

4. Un análisis exhaustivo de las condiciones laborales y de vida, los mecanismos de acceso al empleo y contratación de las mujeres inmigrantes dedicadas al servicio doméstico en Castilla-La Mancha, puede consultarse en $\mathrm{M}^{\mathrm{a}} \mathrm{J}$. Aguilar, 2010. 
la marginación étnica y la que se sufre sólo por el hecho de ser mujer. Agravándose en muchos casos su infravaloración social por el hecho de que en los pueblos se las visualiza como «malas madres» que abandonan a sus hijos en el país de origen, aunque se les reconoce aquí como «buenas cuidadoras» al proyectar en sus cuidados los que no pueden dispensar a sus propias familias.

Para la gran mayoría de inmigrantes las oportunidades laborales se presentan sólo en aquellos empleos menos deseados por los nacionales, porque están peor pagados, son duros, sucios, inestables, estacionales, inseguros, etc. Las mujeres inmigrantes quedan relegadas a los empleos específicamente femeninos que se externalizan, como es el caso del servicio doméstico. Ocho de las 12 ocupaciones que concentran a más del $71 \%$ del empleo de los extranjeros no comunitarios pertenecen al grupo de «trabajadores no cualificados», siendo la de mayor importancia cuantitativa la de "empleados domésticos y otro personal de limpieza», que aglutina al $30 \%$ de los latinoamericanos, al $20 \%$ de los europeos del este y a menos del $10 \%$ de los africanos, cifras en todos los casos superiores al 4-5\% que registran los distintos grupos de españoles o europeos comunitarios (en los de doble nacionalidad, la cifra es del $7 \%$ ). La situación de precariedad y vulnerabilidad (con el riesgo de exclusión que ello conlleva) es mucho mayor, por tanto, en las mujeres inmigrantes que en los hombres inmigrantes y en las mujeres españolas que trabajan en el mismo sector 5 .

En el caso de Castilla-La Mancha (Aguilar et al., 2007), la mayoría de las trabajadoras extranjeras ${ }^{6}$ en el servicio doméstico está formado por mujeres jóvenes con formación básicamente elemental o secundaria (bachiller), aunque también hay universitarias ${ }^{7}$, sin experiencia previa en servicio doméstico en sus países, que emprenden su proyecto migratorio sin que hubieran hecho anteriormente otras migraciones previas, dirigiendo todas sus expectativas en un país como España donde piensan encontrar un trabajo que les posibilite enviar remesas a sus países de origen para ayudar a sus familias. Una vez llegadas a España, el acceso al empleo está condicionado no tanto por la formación y la experiencia laboral previa, sino por la situación jurídico-admi-

5. En la EPA se constata una tasa global de irregularidad en el mercado laboral nacional del $22 \%$, mientras que esa tasa llega al $44 \%$ en el sector del trabajo femenino en el domicilio.

6. En Castilla-La Mancha alrededor de un $60 \%$ de las empeladas domésticas son extranjeras no comunitarias: el $20 \%$ son europeas del este, el $10 \%$ son africanas, principalmente del Magreb, y el $30 \%$ son latinoamericanas.

7. Menos del $5 \%$ tiene estudios primarios incompletos. Del resto, un $15 \%$ tiene estudios universitarios completos, un $47 \%$ secundarios completos, un $25 \%$ primarios y un $4 \%$ ha completado algún tipo de formación profesional en sus países de origen. 
nistrativa, o las redes sociales con las que las cuenten. Ya que una situación jurídico-administrativa irregular imposibilita el acceso a mercados de trabajo normalizados quedando relegadas a empleos sumergidos, clandestinos, en los que emplean a población inmigrante, como es el servicio doméstico.

Otro condicionante del acceso al empleo es la existencia de redes sociales en el país de destino. Como se muestra en nuestro estudio (Aguilar et al., 2010), las mujeres inmigrantes, con independencia de la situación jurídicoadministrativa, acceden al empleo por amigos, familiares o conocidos que ponen en contacto a los hogares empleadores con estas mujeres. Luego la falta o tenencia de «papeles» determinará las mejores o peores condiciones de empleo dentro del servicio doméstico, ya que una persona en situación administrativa irregular está a merced de la buena o mala fe del empleador, quedando la trabajadora en una situación de vulnerabilidad muy fuerte. Los datos sobre condiciones de trabajo son sólo parcialmente positivos (en la mitad de los casos únicamente) en lo que respecta al cumplimiento del compromiso salarial, asignación de tareas y jornada laboral por parte del empleador; pero son negativos en el resto de las condiciones laborales como: vacaciones pagadas, pagas extras y plus de antigüedad que no se reconocen prácticamente en ningún caso. Además, se constata la existencia de ciertas situaciones de explotación y abuso acontecidas por la situación de vulnerabilidad en que se trabaja. Los hogares empleadores que principalmente contratan servicio doméstico y que cumplen parcialmente con sus obligaciones contractuales son ancianos solos, o parejas con hijos. Estos hogares se ven en la necesidad de contratar a mano de obra extranjera que cubra sus necesidades de limpieza, cocina y cuidados ${ }^{8}$.

Las empleadoras no cumplen todas sus obligaciones legales en las condiciones laborales a que someten a las trabajadoras. Para empezar los sueldos rozan, tirando por lo bajo, el SMI (la mitad cobra menos del Salario Mínimo Interprofesional), cantidad que a muchas de estas mujeres (50\%) no les llega para cubrir sus necesidades básicas, ya que además de tener que pagar vivienda, alimentación, Seguridad Social (un tercio declara pagar ella misma todas las cuotas de la Seguridad Social, incluyendo las que corresponderían al empleador), deben pagar la deuda que contrajeron para poder realizar su proyecto migratorio. A pesar de ello el envío de remesas a sus países continúa siendo el segundo destino de sus ingresos. Además, la mayoría (61 \%) no cobra ningún tipo de retribución como son las pagas extras, las vacaciones

8. El $40 \%$ de las mujeres inmigrantes encuestadas cuida ancianos, el $18 \%$ a niños y el $10 \%$ a enfermos. Además, el $90 \%$ declara limpiar y cocinar en el hogar para el que trabaja. Nos encontramos, por tanto, con un servicio doméstico que incluye todas las tareas del cuidado de personas dependientes en los hogares. 
pagadas o el plus de antigüedad, a pesar de estar contemplado por la ley. Respecto a la jornada laboral habría que decir que, si tenemos en cuenta que la legislación española establece un máximo de 40 horas semanales como jornada de trabajo habitual, la jornada de estas mujeres estaría en 35,75 horas aproximadamente para el $41 \%$ que trabaja de 5 a 8 horas, pero debemos mencionar además el $13 \%$ de mujeres que trabaja de 9 a 12 horas y el $13 \%$ que trabaja más de 12 horas diarias, lo que excede sustancialmente esas 40 horas de las que habla la ley. También hay que decir que respecto a la contratación, a un $47 \%$ de las encuestadas les hicieron contrato en todos los trabajos, y a un 31 \% sólo en algunos. Pero según el análisis cualitativo habría que distinguir entre los primeros trabajos y los consecutivos. No olvidemos que muchas mujeres acceden en situación irregular, por lo que en estos primeros trabajos no tienen ningún tipo de contrato, y cuando lo consiguen es cuando se produce la intención de cambio de trabajo a otro sector o a otro subsector del servicio doméstico. Y es sólo la intención, porque, partiendo de estas condiciones laborales, las mujeres empleadas expresan su deseo de cambiar de trabajo si tuvieran los «papeles» observando en los datos que cuando los consiguen no hacen efectivo dicho deseo. Esto hace que, a pesar de desear cambiar de condiciones laborales, por lo tanto de trabajo, permanecen en este sector desde un año a más de tres, teniendo durante su vida laboral de uno a cuatro trabajos y manteniéndose incluso en el subsector en el que accedieron al empleo, principalmente por horas e internas. Por ello, los principales motivos de desempleo son por decisión personal de la trabajadora al encontrar un trabajo con mejores condiciones, aunque generalmente, como hemos dicho, dentro del servicio doméstico.

En el estudio de las construcciones subjetivas de las mujeres inmigrantes que trabajan en el servicio doméstico, hemos podido constatar la vivencia por parte de las participantes en esta investigación de la llamada triple discriminación: como mujeres, como inmigrantes y como trabajadoras domésticas. El servicio doméstico por su situación en la división sexual del trabajo y la proximidad con los papeles tradicionales de género, donde las mujeres son las responsables del mantenimiento del bienestar en el hogar y el cuidado de las personas dependientes, pero sin reconocimiento social y con derechos laborales muy difusos, se presta también a ser un espacio de exclusión, pues mantiene relaciones de dependencia entre las trabajadoras y las empleadoras, principalmente en lo que respecta a las exigencias legales para la regularización formal de la inmigración y para salir de las habituales situaciones de ilegalidad que viven las inmigrantes. Las/os empleadoras y empleadores ejercen un gran poder sobre las trabajadoras, porque está en sus manos la legalización 
de la permanencia de las inmigrantes en España. En esta relación algunos empleadores/as perciben la legalización de las trabajadoras como un beneficio adicional para ellas y un riesgo, que al disminuir la relación de dependencia, les permitiría romper con el vínculo laboral, y procuran retrasar su tramitación.

Así, las mujeres inmigrantes tienen en el servicio doméstico, su posibilidad de inserción legal en España y los ingresos que les permiten mantenerse, pero también una forma de exclusión, basada en la triple discriminación y en el aislamiento propio del ámbito doméstico, compartido con las amas de casa. Las mujeres inmigrantes describen situaciones de discriminación social, que son vividas en las relaciones laborales y personales. Constatamos que la mayoría de las mujeres encuestadas y entrevistadas manifiesta sentimientos y percepciones ambivalentes en relación a la valoración del trato recibido en el trabajo, relatan ser muy bien tratadas y tener buenas amistades, pero siempre tienen anécdotas de situaciones de discriminación racial o social. Pero las situaciones de discriminación no son exclusivas de las relaciones laborales, sino que son narradas como habituales en las relaciones sociales con la población española. En este contexto, las inmigrantes mantienen frecuentemente relaciones de amistad con otras personas de su misma nacionalidad, y el círculo de amistades con la población española en algunos casos es reducido.

\section{6. ¿Es posible evitar la discriminación de las mujeres cuidadoras extranjeras?}

Las mujeres son discriminadas en el mercado de trabajo de las sociedades occidentales en base a la asunción patriarcal que considera que el rol natural de la mujer está en la esfera reproductiva, por lo que va a ser menos productiva que un hombre en determinados trabajos remunerados y, además, su actividad se va a ver negativamente afectada por sus responsabilidades familiares, en términos de movilidad, estabilidad y eficiencia. Por ello, una de las cuestiones fundamentales a tener en cuenta es la forma en que la mujer compatibiliza la dedicación al trabajo en el mercado laboral y en el hogar: la mayor participación de la mujer española en la esfera productiva en los últimos años ha supuesto una reducción de su presencia horaria en la vida familiar, sin que ello se haya visto acompañado de una reducción paralela en las cargas domésticas. Dado que no se ha producido el deseado reparto de las tareas en el hogar, las mujeres profesionales de clase media han recurrido a la externalización de los trabajos reproductivos, principalmente a través de otras mujeres (tradicionalmente las abuelas o ciertos servicios públicos, y recientemente mediante la contratación de mujeres inmigrantes). Este incremento de la demanda de empleadas domésticas crece al mismo tiempo que disminuye la oferta, lo que 
provoca la aparición de un «nicho laboral» que pasan a ocupar las mujeres autóctonas con menos recursos y, principalmente, las mujeres inmigrantes que llegan atraídas por esta fuerte demanda. Si a ello sumamos el proceso de envejecimiento de la población española, así como la creciente demanda -insuficientemente atendida- de servicios clásicos del Estado de Bienestar -relacionados con el cuidado de niños y de personas adultas dependientes-, no es de extrañar la situación en que nos encontramos.

A la etnoestratificación del mercado de trabajo, debemos añadir que el abanico de posibilidades de las mujeres inmigrantes es mucho más reducido que el de los hombres inmigrantes, ya que son ellas las que ocupan el último escalafón: el servicio doméstico. Así, podemos identificar un trasvase de desigualdades de clase y etnia entre las propias mujeres, por lo que se enmascara el mito del «nuevo igualitarismo dentro de la pareja» y el patriarcado sigue subyaciendo inalterado detrás de las estructuras domésticas y el empleo remunerado. El servicio doméstico es en muchos casos un trabajo muy duro, con muchas horas de trabajo y escaso tiempo libre. Las condiciones de trabajo dependen de la buena voluntad de los empleadores, lo que aumenta considerablemente su vulnerabilidad. Además, las mujeres inmigrantes están expuestas a diferentes formas de violencia, entre ellas la violencia estructural, que son el resultado de los procesos de estratificación social. Se trata de mecanismos cuya consecuencia es que el acceso, reparto o posibilidad de uso de los recursos, es resuelto sistemáticamente a favor de la población autóctona. Estas condiciones estructurales condicionan y limitan las pretensiones de libertad, independencia y autorrealización de las inmigrantes.

El servicio doméstico representa una afirmación del rol tradicional de la mujer: ser ama-de-casa, ser un ser-para-otros. Las empleadas de hogar inmigrantes querían un cambio de vida, y disponer de dinero propio comporta un gran cambio, pero al mismo tiempo su trabajo significa muchas veces reproducir aquello que querían superar. Como se ha identificado en anteriores estudios (Anderson, 2000; Parella, 2003; Stock, 2004), las mujeres inmigrantes que trabajan en el servicio doméstico, sufren una triple discriminación: de género, étnica y de clase social, que configura un complejo entramado de relaciones de poder que dificulta la integración de las mujeres inmigrantes en las sociedades de acogida, así como el hecho de que mantienen situaciones de explotación por la dependencia de las empleadoras para la regularización de sus situaciones de ilegalidad. El servicio doméstico, por su situación en la división sexual del trabajo y la proximidad con los papeles tradicionales de género, donde las mujeres son las responsables por el mantenimiento del bienestar en el hogar y el cuidado de las personas dependientes, pero sin 
reconocimiento social y con derechos laborales muy difusos, se presta a ser un espacio de exclusión, ya que mantiene relaciones de dependencia entre las trabajadoras y las empleadoras, principalmente en lo que respecta a las exigencias legales para la regularización formal de la inmigración y para salir de las habituales situaciones de ilegalidad que viven las inmigrantes. Es urgente replantear las condiciones del trabajo doméstico externalizado, que debe dejar de ser empleo precario. Y al igual que la cotización por un trabajador a la Seguridad Social desgrava al empresario en sus cargas fiscales, la cotización a la Seguridad Social de las empleadas de hogar debería ser objeto de desgravación para las familias que utilizan esta estrategia de conciliación. De este modo, se incentivaría el alta en la Seguridad Social de muchas mujeres que ahora no están dadas de alta, con lo que -también- se blanquearía una parte de la actividad oculta e invisible de la mujer, a la vez que se formalizaría una relación laboral que ahora es de cuasi-servidumbre. Además, es absolutamente necesario que el actual Régimen Especial de Empleadas de Hogar se equipare en prestaciones al Régimen General, ya que las trabajadoras domésticas deben ser consideradas como tales por el propio Estado, y dejar de estar condenadas a una Seguridad Social también precaria, como sus empleos.

\section{Bibliografía}

Aguilar, M. ${ }^{a}$ J. (Dir.), Mujeres inmigrantes en el servicio doméstico. Acceso al empleo y contratación. Problemática ocupacional y condiciones de vida, Albacete, GIEMIC-UCLM, 2010, [en línea], <http://www.giemic.uclm.es/index. php?option=com_docman\&task=doc_view\&grid=1370\&Itemid=9999>.

Aguilar, M. ${ }^{a}$ J. et al., La mujer rural en Castilla-La Mancha. Aspectos demográficos, ocupacionales y de actividad laboral y familiar, desde la perspectiva de género, Albacete, Fondo Social Europeo-EQUAL-CEDERCAMGIEMIC-UCLM, 2010, [en línea], <http://www.giemic.uclm.es/index. php?option=com_docman\&task=doc_view\&grid=1369\&Itemid=9999>.

Anderson, B., Doing the Dirty Work? The global politics of domestic labour, Londres, Zed Books, 2000.

BericAt, E. y M. CAMARERO, Trabajadoras y trabajos en la Andalucía rural, Sevilla, Instituto Andaluz de la Mujer, Serie Estudios no 3, 1994.

PARELLA, S., Mujer. Inmigrante y trabajadora: la triple discriminación, Barcelona, Antrophos, 2003.

STOCK, I., "¿Limpiando El Dorado? Relaciones entre empleadoras españolas y sustrabajadoras domésticas inmigradas», en $4^{\circ}$ Congreso sobre la Inmigración en España, [CD-Rom], Girona, 2004.

Tobío, C., «Conciliación o contradicción: cómo hacen las madres trabajadoras», en REIS, n. ${ }^{\circ}$ 97, Madrid, 2002, pp. 155-186. 


\title{
GESTIÓN DE LOS CUIDADOS, DESNACIONALIZACIÓN Y PRECARIEDAD \\ LABORAL: UNA PERSPECTIVA COMPARADA \\ Care management, denationalisation and precarious
employment: a comparative perspective
}

LUCÍA MARTÍNEZ VIRTO*

\begin{abstract}
Resumen
El objetivo de esta comunicación es analizar cómo un Estado de Bienestar de carácter subsidiario con escasa capacidad de desfamiliarización en las tareas de cuidado ha favorecido la creación de un modelo migratorio complementario y el mantenimiento de un nicho laboral femenino, precario y desvalorizado. En las últimas décadas, el envejecimiento de la población, el acceso de las mujeres autóctonas al mercado laboral y la escasez de servicios de proximidad, han favorecido la demanda de trabajo reproductivo. Ante esta realidad, se observan tres factores en la construcción de este modelo. En primer lugar, se han mantenido los rasgos básicos de la regulación del empleo doméstico. En segundo lugar, se han promovido servicios de atención mercantiles financiados parcialmente con dinero público mediante la gestión privada de servicios con titularidad pública y las ayudas económicas a la dependencia. Y, por último, se ha diseñado una política migratoria muy permisiva, caracterizada por unos flujos muy intensos. Partiendo de que estas actuaciones precarizan las condiciones laborales de los trabajos reproductivos, se comparan y analizan otras experiencias en Europa que han contribuido a mejorar dicho nicho laboral.
\end{abstract}

Palabras clave: gestión de los cuidados, familismo, mercantilismo, precariedad, calidad, empleo doméstico y migración femenina.

\footnotetext{
* Lucía Martínez Virto

Universidad Pública de Navarra

Avd. El salvador, 29,. 31370 Falces (Navarra)

Teléfono: $659150742 / 948714793$

lucia.martinez@unavarra.es
} 


\begin{abstract}
This paper analyses how a subsidy-based welfare state with little capacity for defamilisation in care-related duties has led to a complementary migration model and the continued existence of a devalued and precarious niche for female carers. In recent decades, the ageing of the population, native women's access to the job market and the lack of community services have led to an increase in the demand for reproductive labour. Three factors are observed in how this model is organised. Firstly, the basic features of how home labour is organised remain in place. Secondly, there has been an increase in care provision businesses funded partially by public money by privately managing publicly owned services and dependent care benefits. Finally, a highly permissive migratory policy has been designed, with high levels of movement. Given that these factors jeopardise reproductive labour conditions, this paper compares and analyses other experiences in Europe that have helped to improve this niche in the labour market.
\end{abstract}

Keywords: care management, familism, mercantilism, precariousness, quality, domestic labour and female migration.

\title{
1. Introducción
}

Si hay un rasgo que caracteriza a las migraciones actuales, éste es su feminización. No debemos olvidar que las mujeres siempre han migrado, pero ahora, más que nunca las mujeres tienen un papel activo en los procesos migratorios. Si observamos los datos del INE (2008), el 47 \% de la población extranjera en España son mujeres. Sin embargo, si nos fijamos en el origen de los flujos se ve cómo, exceptuando los países africanos, el resto de flujos extracomunitarios están claramente feminizados, un $54 \%$ en los países del este, un $60 \%$ en América Central y un $54 \%$ en América Latina.

Las mujeres migran, y migran solas, pioneras en sus familias, y esto se debe a que en las sociedades de acogida se han sucedido una serie de cambios sociales y económicos que han convertido a estas mujeres en sujetos demandados como mano de obra barata para los países del norte. En estas dos últimas décadas, han acontecido en dichos países, importantes cambios sociales y económicos que han modificado la estructura social y sus necesidades. Los trabajos reproductivos, desde la sociedad industrial, habían sido realizados por las mujeres, pero con el aumento de la población dependiente y la incorporación de éstas al mercado remunerado, se comienza a demandar atención pública. Una realidad común a todos los países, pero que en España cobra especial relevancia debido a que los cuidados siguen recayendo en la familia y a que la red de servicios de proximidad está escasamente desarrollada.

A lo largo de este artículo, analizaremos cómo se ha gestionado esta realidad. Para ello, se conocerán las primeras actuaciones en materia de gestión 
de los cuidados, la política migratoria y la regulación laboral del empleo doméstico. Procesos serán explorados, considerándolos causas estructurales y coyunturales explicativas de la precariedad del sector y, por tanto, de las mujeres inmigrantes que en él trabajan. Posteriormente, trataremos de conocer qué otras actuaciones en materia de gestión de cuidados se han dado lugar en Europa y expondremos aquellas medidas más efectivas que han contribuido a crear un sistema de gestión de los cuidados basado en la calidad del servicio y en la de las condiciones laborales de las personas prestadoreas de los cuidados.

\section{Características del Estado de Bienestar español}

Actualmente, la gestión de los trabajos reproductivos es una de las necesidades sociales detectadas más potentes debido a los cambios demográficos, sociales, políticos y económicos de las últimas décadas. Hacer frente a estas demandas ha supuesto uno de los mayores retos de los Estados de Bienestar europeos. Pero más todavía, para aquellos estados subsidiarios a la familia con escasa capacidad de desfamiliarización ${ }^{1}$, como es el caso del Estado de Bienestar español. Esto se debe, a que en los países mediterráneos el paso de la asistencia social a la protección social ha sido lento y fragmentado, y, aunque con una tendencia universalista, cuentan con una baja protección social muy desigual entre las categorías contributivas. El tardío crecimiento y la debilidad de la protección pública en estos países han provocado que las familias y la beneficencia religiosa asumieran gran responsabilidad en las tareas de atención y cuidado, impidiendo todo esto el desarrollo de estos ámbitos por parte de la Administración (Pérez Eransus, 2008).

En estos países mediterráneos, el peso de los cuidados personales sigue recayendo en las familias, las cuales son la base sobre la que los Estados de Bienestar de estos países se sostienen. Un modelo de sobreexplotación de los recursos familiares ofrecidos por las mujeres de manera gratuita e invisible.

Por ello, en países como España, donde el papel protector de la familia es más relevante que en otros modelos y donde el Estado no ha desarrollado servicios que alivien de esta responsabilidad atribuida a las mujeres, se hace aún más necesario visibilizar cómo el rol femenino ha sido el encargado de velar por la sostenibilidad de la estructura social.

Debido a la naturaleza familista de la organización social, las tareas que las mujeres realizaban de forma gratuita son ahora exigidas. En este contexto

1. Término introducido por Esping-Andersen (1993), que hace referencia a la capacidad que el Estado tiene de asumir las funciones de cuidado que antes hacía la familia. 
donde la incorporación de las mujeres inmigrantes a estas actividades se demanda desde las políticas migratorias, optando así por un modelo migratorio selectivo, que relaje las tensiones sociales y evada al Estado de crear una red de servicios que satisfaga estas demandas.

\section{Transformaciones sociales y económicas}

En los últimos años el seno de la familia ha sufrido cambios que le han debilitado como estructura protectora debido al descenso de la natalidad y a que las formas de convivencia se han diversificado. Pero sobre todo, la creciente incorporación de las mujeres al trabajo remunerado en una organización social excesivamente familista ha generado la perdida de la capacidad protectora familiar y el reclamo de servicios de proximidad que se encarguen de los cuidados. Estos cambios en la organización familiar se han vuelto más complejos con el envejecimiento progresivo de la población, convirtiendo a esta realidad en una de las necesidades sociales más significativas en las sociedades europeas actuales. A estos cambios se suma otro cambio social, el aumento de flujos migratorios provenientes de países del sur, motivados por la búsqueda de mejores condiciones de vida y ayudados por un mercado laboral que demanda mano de obra para cubrir nichos laborales que desde la población autóctona no son cubiertos.

Estos tres cambios sociales suponen «los nuevos riesgos sociales» ${ }^{2}$ actuales. Una realidad latente en todos los Estados, pero más aún en un Estado de Bienestar mediterráneo y familista como es el español, caracterizado por las grandes responsabilidades de cuidado que asumen las familias y que, por tanto, el estado no desarrolla, y ante la que todos los Estados de Bienestar se han caracterizado por tener unas tendencias de actuación de control del gasto comunes ante la crisis. Pero además, en el caso de nuestro país, a esta restricción del gasto hay que añadir el escaso desarrollo de los servicios de conciliación debido a que los cuidados siguen recayendo en la familia. Por tanto, la necesidad de crear servicios de atención a la dependencia se hace cada vez más visible.

\section{Gestión de los trabajos reproductivos en España}

Ante esta realidad económica, social y política, la gestión de la dependencia se ha convertido en una necesidad para la que ya se están realizando algunas políticas sociales, a través de las cuales, vamos conociendo los primeros

2. Término acuñado por Moreno (2003). 
resultados. Una gestión que no sólo afecta al ámbito social, sino que sus actuaciones se encuentran relacionadas también con el mercado de trabajo y con la gestión de los flujos migratorios actuales. Por ello, el análisis realizado aborda los tres ámbitos. En primer lugar, las primeras actuaciones políticas y sus resultados en materia de atención a los cuidados. En segundo lugar, la relación de éstas con el control de los flujos migratorios y, por último, las características más relevantes del sector laboral en el que se abordan los cuidados.

En las primeras actuaciones en materia de políticas sociales a la dependencia encontramos, por un lado, que ante la necesidad de contener el gasto social y aumentar los servicios sociales para el cuidado, la mercantilización de los cuidados está siendo uno de los efectos más evidentes de estas intervenciones políticas; y por otro, que ante la realidad del aumento de los flujos migratorios a nivel internacional y la necesidad de mano de obra específica para realizar los trabajos reproductivos en España se ha configurado un mecanismo selector y moldeador de los flujos migratorios a través de regulaciones de extranjería y otras actuaciones mercantiles relacionadas con el sector. (Laparra, 2006). Ambas introducen claramente los resultados más visibles de las primeras intervenciones políticas en la atención a la dependencia. A continuación se analizarán en profundidad estos resultados.

\subsection{Primeros intentos y resultados en la atención a la dependencia}

Como bien se ha introducido anteriormente, el contexto económico actual y la orientación de las políticas sociales están marcados por la contención del gasto social. Una tendencia política derivada de la coyuntura económica actual y con especial efecto en el desarrollo de los servicios sociales mercantiles. Así, este contexto, a través de la privatización de los cuidados, se están creando servicios de titularidad pública, financiados con presupuestos públicos, pero con gestión privada o mercantil, como, por ejemplo, la privatización de la gestión del servicio de atención a domicilio de un ayuntamiento. Una medida muy común actualmente, en relación a la dinámica actual del mercado económico, que desde hace unas décadas pide flexibilidad, competitividad y productos al menor coste posible, con la que las empresas compiten por lograr la concesión de concursos públicos para gestionar servicios de cuidado de diferente índole, desde residencias, a guarderías o servicios de conciliación diversos. En esta lucha, la empresa que menor coste ofrece a la Administración a cambio de gestionar su servicio gana el concierto y, por tanto, gestiona ese servicio o prestación que con dinero público se da a la población. Pero estos conciertos ofrecidos a las empresas son limitados en el tiempo, lo cual genera inestabilidad a la empresa porque no sabrá si renovará o no el concierto, 
y para las personas empleadas contratos temporales e inciertos donde no se garantiza continuidad. Todo ello genera situaciones laborales marcadas por la precariedad laboral y el aumento de personas trabajadoras en situación eventual.

Para poder rebajar al máximo posible es necesario disminuir los costes internos, es decir, el presupuesto en mano de obra sin atender a la calidad ni a la formación, los materiales con los que se va a trabajar deben reducir su coste. Sólo así las empresas lograrán ser competitivas entre ellas y podrán luchar para lograr gestionar el servicio.

Por tanto, es verdad que la competitividad empresarial exige siempre estar a la última en tecnología, buscar mecanismos de autoevaluación y, a primera vista, dar un buen servicio. Sin embargo, la realidad es que son tantas las empresas que luchan por gestionar y tan bajas las cuantías que ofrece la Administración que las condiciones laborales de las personas contratadas deben ser más bajas para poder hacer frente a esos límites de coste. (Laparra, 2006) Pero esta vía no es la única que mercantiliza los cuidados, ya que otra opción de mercantilización es la de ofrecer a las familias ayudas económicas para que éstas compren en el mercado, sumergido o no sumergido, el cuidado para sus dependientes. Ambas vías son de la misma naturaleza. Por un lado, el estado, a través de dinero público, contrata servicios de cuidado a las empresas, y, por otro, da el dinero directamente a las familias para que éstas compren los cuidados en el mercado.

Como ejemplo de todo esto tenemos los resultados de la Ley de Promoción de la Autonomía Personal y Atención a las personas en situación de dependencia, la 39/2006, aprobada en diciembre del 2006, la cual busca atender a las personas en situación de dependencia y a sus familiares y dar respuestas a las necesidades antes expuestas mediante la combinación de ayudas económicas y técnicas. Pero es bien conocida la escasez de servicios profesionales, que no cuentan con plazas ni con atención profesional suficiente para dar este tipo de servicio. Por eso, las transferencias económicas son, por el momento, uno de los primeros resultados de dicha ley. Unos resultados que, en un primer momento, generan desigualdades, mercantilizan la atención a la dependencia y financian la precariedad laboral.

Por todo ello, observamos que los primeros resultados de dicha ley y de las políticas sociales en materia de dependencia están relacionados con el aumento de los servicios de atención mercantiles. Para gestionar y mantener todo lo mencionado, es necesaria mano de obra que soporte la precariedad e inestabilidad del mercado de trabajo. Como consecuencia, se ha ido diseñando un modelo migratorio complementario a esta realidad. 


\subsection{Gestión de los flujos migratorios}

En España la inmigración viene motivada por un país en crecimiento, un mercado de trabajo que demanda su fuerza laboral, un reciente desarrollo económico y una ilusión de las personas migrantes de mejorar sus oportunidades vitales y las de sus familias. Ante esta realidad, la inmigración, las políticas sociales, el envejecimiento de la población y los cambios en la familia, se han entrelazado demandando mano de obra extranjera femenina destinada a cubrir, por un lado, las insuficiencias de la red de servicios sociales; por otro, el hueco que las mujeres autóctonas dejan en el hogar debido a su incorporación laboral; y, por último, las carencias y fracasos de las políticas gubernamentales de conciliación de la vida laboral y familiar (Peterson, 2007, en Martínez Buján, 2008).

De este modo, se configura un modelo migratorio capaz de satisfacer las insuficiencias de servicios en el Estado de Bienestar español, de tal forma que se convierte en un modelo migratorio complementario al Estado de Bienestar. (Martínez Buján, 2009) Para ello, se establecen mecanismos de control y selección de flujos migratorios. Por una parte, de forma regular y legal, la creación del contingente y el sistema de cupos. Y, por otro, de forma clandestina, aquellos mecanismos irregulares que atraen, dejan acceder y se regulan a través de ordenaciones extraordinarias o dispositivos ya previstos por la Ley como el arraigo, así como la permisibilidad de los controles y la naturaleza invisible de los trabajos reproductivos.

Pero no sólo el hecho de que sean mujeres es la característica que les hace ser perfil idóneo. Esta elección viene animada por los actuales discursos políticos que fundamentan en la diferencia cultural cualquier tipo de conflicto social. De esta manera, las personas latinoamericanas, por sus lazos históricos con España, poseen unos rasgos físicos y culturales aparentemente similares a los autóctonos: hablan el mismo idioma y son personas de religión católica. Debido a estas similitudes, desde las estructuras políticas, se considera que la integración es más fácil. (Agrela, 2002)

En todo caso, lo mencionado hasta el momento provoca una precariedad que no sólo es producto de la política de privatización de servicios ni de la desvalorización social del sector. La desregulación de la profesión como consecuencia del mantenimiento de un régimen laboral obsoleto, discriminante y precario basado en el paternalismo y la concepción androcéntrica de la profesión, legisla una profesión anclada en el pasado y con grandes diferencias respecto a otros regímenes laborales. 


\subsection{Regulación ambigua y obsoleta}

Desde sus comienzos, el empleo doméstico y de los cuidados ha sido un sector tradicionalmente ligado a las migraciones. Ahora, migraciones transnacionales, y anteriormente, migraciones interiores.

El empleo doméstico y de los cuidados en nuestro país se encuentra regulado por el Real Decreto 1424/1985, y al analizarlo en profundidad se encuentran importantes diferencias con el Estatuto General de los Trabajadores. En primer lugar, el Real Decreto no obliga a que el contrato entre persona empleada y empleadora deba ser por escrito, ya que stablece la posibilidad de que sea verbalmente negociado y acordado. Para la parte empleadora contratar resulta más sencillo, sin embargo, para la persona empleada no da seguridad en el horario, en la duración de los servicios, en el tipo de servicios que va a hacer, así como la retribución de los mismos. Además, la persona empleadora está exenta de entregar un documento de pago a la persona empleada, lo cual no deja constancia de si el salario ha sido pagado o no. En esta línea, y basándose también en la naturaleza paternalista y familista de la profesión, este Real Decreto regula que puede pagarse hasta un $45 \%$ del sueldo en especie, en concepto de alojamiento y comida, mientras que para el resto de empleos el máximo es el $30 \%$. Además, el Real Decreto no regula el derecho de estas trabajadoras al subsidio de desempleo, así como a la baja por enfermedad, que tanto si es profesional como común sólo tienen derecho a cobrarla a partir del día 29.

Sin embargo, hay un aspecto que merece especial mención, la jornada laboral. El máximo de horas diarias de «trabajo efectivo» que se estipula para las personas empleadas de hogar es de 9 horas, una hora más que el general. Pero también estipula, curiosamente, que la persona empleadora se encuentra con derecho a pedir a la empleada que amplíe su jornada diaria hasta un máximo de 3,5 horas de "presencia» en las que sólo realice labores que requieran poco esfuerzo (coger el teléfono, abrir la puerta o vigilar a personas dependientes). Estos «tiempos de presencia» no van incluidos en la jornada habitual de trabajo y pueden o no ser recompensados económicamente.

Dichas menciones son algunas de las diferencias existentes entre ambos regímenes. Aspectos que evidencian que, desde la organización administrativa, económica, social y política, no es considerado un empleo por cuenta ajena normalizado. Su regulación y su consideración social llevan implícito un sistema de relaciones de género y clase basado en el cariño, la afectividad, la esencia familista, de confianza de una profesión que, a pesar de tener una jornada laboral más larga que el resto de trabajos y de aportar económicamente al PIB, no es reconocida como un empleo en igualdad de condiciones al resto. 
Esta antigüedad y desigualdad en el Real Decreto no sólo tiene que ver con lo legislativo. Hay dos aspectos más que merecen mención. Por un lado, el relacionado con las condiciones estructurales y relacionales del trabajo doméstico. Y, por otro, el derivado de la ambigüedad de las relaciones entre empleadora y empleada, las cuales, debido al carácter privado y familista de la profesión están basadas en el acuerdo mutuo, la confianza y la cercanía (Oso, 1998). Una relación ambigua que coloca a la persona empleada en una posición de mayor vulnerabilidad respecto a otros trabajos por cuenta ajena en los que la relación es exclusivamente laboral y distante, y, por tanto, las exigencias laborales no se tiñen de sentimientos afectivos.

\section{Otras formas de gestión: los cuidados de larga duración en Europa}

Tal y como se ha venido diciendo, la atención a la dependencia en nuestro país se encuentra aún en construcción. Por ello, es en este momento cuando se está gestando el modelo de atención a los cuidados, donde resulta útil hacer un ejercicio de comparación y conocer las actuaciones realizadas en otros países europeos. Así, con el objetivo de invitar a la reflexión sobre la creación de un nuevo modelo de atención en España, analizaremos a continuación las principales características en la gestión de la dependencia de los diferentes países europeos, actuaciones orientadas siempre hacia la construcción de un empleo y unos servicios de calidad. El análisis acoge a países como Noruega, Suecia, Finlandia, Dinamarca, Países Bajos, Reino Unido, Alemania, Francia, Austria, Luxemburgo e Italia.

La gestión de los trabajos reproductivos se ha convertido en prioridad política en los diferentes países europeos. Por un lado, dada la magnitud adquirida del fenómeno, y, por otro, por la vinculación afectiva que este ámbito tiene para la ciudadanía. Por ello, más que nunca, se exigen procesos y mecanismos capaces de crear servicios de conciliación de calidad.

Ante esta realidad, el objetivo de fijar la mirada en Europa era encontrar actuaciones políticas que, a diferencia de las ya mencionadas en nuestro país, trazase el camino hacia la creación de servicios de calidad y la mejora de las condiciones laborales de las personas trabajadoras en este sector. Un análisis que podría ampliarse también, en futuros trabajos, al estudio de la gestión de los flujos migratorios en dichos países para encontrar alternativas a su canalización. 


\subsection{Alternativas a la mercantilización de los cuidados}

En otros países europeos, ante un contexto económico similar al nuestro, las respuestas a las demandas de servicios de atención a la dependencia no han sido las mismas. Esto tiene que ver por un lado, con la tradición económica y social del país, y, por otro, con la voluntad y la capacidad política.

También en materia de cuidados, la tradición nórdica se ha caracterizado por una definición más amplia de las políticas de bienestar y se ha mantenido en la línea de crear servicios con intervención pública más activa y directa.

La realidad interna de los países escandinavos no es homogénea, sin embargo, se caracterizan por un mayor desarrollo de los servicios de atención, y éste es precisamente la característica que les diferencia del resto de los países europeos. Un ejemplo del amplio desarrollo de estos servicios de atención a la dependencia es el servicio de atención a domicilio, el cual puede ser de ayuda domiciliaria o de enfermería a domicilio. Paralelamente a estas dos modalidades, se han creado servicios de comidas o accesoria para el apoyo. Son servicios de 24 horas al día, incluidos los fines de semana. Además son gratuitos (en el caso de Dinamarca) o se paga muy poco porcentaje (5-10\% en noruega). A pesar de las diferencias entre países, la tendencia general está siendo la de fortalecer los servicios comunitarios y las viviendas tuteladas respecto a la atención en instituciones. Dinamarca y Suecia tienen el sistema de cuidados domiciliarios más desarrollado de Europa, siendo los servicios principales que prestan: de ayuda doméstica, de enfermería de distrito, comidas a domicilio, y un trabajo coordinado y gestionado por las autoridades locales y financiado a través de impuestos (IMSERSO, 1999).

Otra de las medidas mercantiles analizadas anteriormente es la que abarca las ayudas económicas a la dependencia, la cual no resulta una medida demasiado extendida entre los países escandinavos, sin embargo, en el resto de Europa, sobre todo en Reino Unido, supone una medida base en toda atención a la dependencia. De todos los casos analizados, cabe enunciar que tanto Alemania, España, Países Bajos, Reino Unido, Luxemburgo, Italia, como Francia, con uno u otro objetivo, introducen como medida de atención a la dependencia la dotación de cuantías económicas directas a las familias. Uno de los ejemplos más sorprendentes en esta materia es el referido a las ayudas a la dependencia de Luxemburgo, donde pueden ser tanto económicas como en especie. Los usuarios pueden elegir entre una u otra, sin embargo, la cuantía de la ayuda económica equivale a la mitad del valor de la ayuda en especie y no existe para aquellas personas con un gran nivel de dependencia. Esta medida aumenta la capacidad de elección de las personas, ya que les ofrece los dos tipos de ayuda, sin embargo, anima a optar por las atenciones 
en especie y penaliza a las ayudas dinerarias. Algo que no ocurre en el resto de países, donde la dotación es la misma. (Sanabria, 2003). Pero estas ayudas económicas carecen de sentido si no existe un control de gasto de ese dinero, de justificación de esa necesidad. Ante esta realidad, destacan los sistemas de control de los Países Bajos, en los que existe la obligación de justificar anualmente estas ayudas. Para ello, cuando una familia obtiene una ayuda económica a la dependencia, en el periodo de ocho semanas tras el pago de la ayuda, debe rellenar un formulario en el que especifique cómo va a ser gastado ese dinero, después, al final de cada año natural, en el periodo de declaración en Hacienda, debe detallar cada gasto, excepto un 1,5\% de la ayuda que pueden gastar libremente. Este mecanismo supone la única forma de controlar que esas ayudas a la dependencia han sido o no destinadas para comprar servicios o bienes relacionados con los cuidados. (Ranci y Pavolini, 2009).

\subsection{Intentos por revalorizar el sector}

Otra de las causas que favorecían en nuestro país el mantenimiento del sector de los cuidados en precariedad era la ambigüedad de su decreto, la cual evidenciaba la desvalorización social del sector y de las personas que en él trabajan.

En el análisis legislativo en Europa en materia laboral no se han detectado regulaciones específicas para este sector, lo cual muestra que, en la mayoría de los países, todas las personas trabajadoras se encuentran protegidas bajo unos mínimos por la Ley, pudiendo existir algunas diferencias en las bases de cotización que no suponen diferencias tan marcadas como en España.

Italia es en el único país que hemos encontrado con una regulación específica llamada «Contrato nacional de Trabajo Doméstico». En él hemos encontrado diferencias sustanciales con la regulación española. Mientras que en nuestro país el contrato puede ser acordado verbalmente o por escrito, en Italia sólo puede estar por escrito y firmado por ambas partes. Otra diferencia es que en España, en el caso de maternidad la baja son cuatro meses desde el parto, mientras que en Italia, debido a que consideran que el trabajo tiene riesgo, la baja es de cinco meses, dos antes del parto y tres después. En cuanto a las bajas se refiere, en Italia se considera la baja por accidente laboral, algo que en nuestro país no, y, también, las bajas por enfermedad, donde en Italia se cobra a partir del cuarto día, y en España, a partir del 29.

Pero una de las diferencias que más nos ha sorprendido es que la legislación italiana contempla cuatro categorías de empleadas, mientras que en España no se contempla ninguna. Ellas se dividen en función de formación inexperiencia de las personas contratadas, sin embargo, cuando una persona 
está en la última categoría y lleva 14 meses trabajando, obligatoriamente el empleador debe subirla de categoría. Además de que cada dos años de trabajo es obligatorio ascender el sueldo un $4 \%$ por antigüedad. Todo esto supone un ascenso laboral y, por tanto, ofrece posibilidades de mejora a los trabajadores.

Esta diferencia es otra evidencia más de que la regulación española se encuentra anclada en el pasado y supone una desregulación y una injusticia para las personas que en el trabajan. Incluso Italia, un país mediterráneo cuyo Estado de Bienestar y valores son similares a los nuestros, ha modificado la ley acercando cada vez más a las personas trabajadoras de este sector a unas condiciones laborales más dignas.

A pesar de que sólo en Italia y España se han detectado distinciones en materia de legislación laboral, es evidente que el empleo doméstico y de los cuidados en todas las sociedades ha estado ligado a lo privado, a lo invisible y desregulado. Ello supone un estigma y una desvalorización que sufren todas las trabajadoras que prestan servicios de cuidado y atención. Ante esta realidad, en algunos países se han llevado a cabo actuaciones para revalorizar este sector desde su vinculación a disciplinas sanitarias o pedagógicas encaminadas a la formación y organización de las trabajadoras, así como, a las cuidadoras informales. Por ejemplo, la atención a la dependencia en los Países Bajos y en Alemania se incluyó dentro de las atenciones sanitarias, lo cual introdujo una nueva conceptualización más amplia y valorada de ésta. Por otro lado, en Dinamarca, la orientación ha ido ligada a la pedagogía. Se parte de la necesidad de educar tanto a niños como a mayores en la realización de las actividades básicas de la vida diaria, todo ello desde una conceptualización pedagógica que exige a las personas que trabajan en cuidados estar formadas adecuadamente. Y en Reino Unido, por ejemplo, las medidas más extendidas han sido la creación de centros de formación y orientación para personal cuidador. Medida que genera cohesión y lazos entre las trabajadoras de un mismo sector (IMSERSO, 2005).

Paralelamente a todo esto, la revalorización de la atención informal supone también un gran avance en el reconocimiento y en la visibilidad de las cuidadoras tradicionales. Para ello, por ejemplo, en Alemania, se han creado servicios conocidos como la «sustitución por vacación de los cuidadores». Una medida destinada a las cuidadoras de miembros de su familia, en la que un mes al año, seguido o en periodos cortos, pueden ser sustituidas en su trabajo para poder marchar de vacaciones o tener periodos de descanso. En el caso de Reino Unido, la ley no permite a los beneficiarios de las transferencias monetarias pagar los servicios suministrados por los cuidadores si existe una relación de parentesco entre ellos o si están domiciliados en el mismo hogar. 
Ello anima a la contratación de personal especializado ajeno al hogar, lo cual libera a las cuidadoras tradicionales de la invisibilidad. Aunque esta última afirmación es controvertida dada la necesidad social existente de reconocer a estas trabajadoras informales, tema muy debatido en España al amparo de la ley de la dependencia (Sanabria, 2003).

A pesar de todo, las diferentes medidas y actuaciones que hemos ido mencionando, evidencian los intentos que en algunos países europeos se están dando con el objetivo de revalorizar el empleo de cuidados. Algo que no se consigue sin una voluntad política que lo proteja con una buena legislación y con un marco formativo y profesional adecuado, el cual es inexistente en nuestro país.

\section{Conclusión}

Para finalizar, sólo cabría enumerar aquellas ideas más importantes comentadas a lo largo del texto.

Los cambios sociales de las últimas décadas y la tradición familista del Estado de Bienestar español han convertido a la gestión de los cuidados en un complejo reto para el Estado de Bienestar. En estos años se ha ido tejiendo un modelo de atención a los cuidados que responde a las distintas tendencias, al reciente desarrollo de los Servicios Sociales, a la gestión de los flujos migratorios y a los cambios sociales. Y con ellos encontramos los primeros intentos y los primeros resultados en la construcción del modelo de atención a la dependencia y a los cuidados del Estado español.

Como hemos podido ver en el análisis, estas actuaciones no sólo han tenido acogida en el ámbito de los Servicios Sociales, sino que los cambios en los flujos migratorios y el mercado de trabajo han tenido también su protagonismo.

En primer lugar, se caracteriza por modelo es la mercantilización progresiva de la atención a los cuidados, por el aumento de los Servicios Sociales de gestión privada. En segundo lugar, el mantenimiento de un nicho laboral precario e inestable caracterizado por la regulación obsoleta de las tareas de cuidados. Y, por último, la configuración de una política migratoria complementaria al aumento de la demanda de mano de obra inmigrante para cubrir este nicho laboral. El resultado de todo esto es la creación de unos servicios de atención de baja calidad y de unas condiciones laborales precarias para sus trabajadores.

Por todo esto, es en este momento de construcción de un modelo de atención a los cuidados, cuando resulta necesario mirar hacia Europa, y conocer las medidas más relevantes en el desarrollo de servicios de atención y de 
cuidados a la dependencia. Las referencias más interesantes responden a dos líneas diferenciadas de actuación. Una, con iniciativas que suponen un mayor desarrollo de la atención a domicilio 24 horas pensado en las necesidades de los usuarios y orientado a la atención integral, así como, con un mayor control en la justificación de gasto de las ayudas a dependencia. Y otra con iniciativas relacionadas con la profesionalización del sector de los cuidados, dotándolo de un marco de formación específico, y de una regulación adecuada, además de trabajar por promover la revalorización de un sector que tradicionalmente ha permanecido invisible.

Estas iniciativas que permiten la gestación de un modelo de atención a la dependencia de calidad podrían servir de referencia en la búsqueda del modelo de gestión de cuidados en nuestro país.

\section{Bibliografía}

AGRELA, Belén, «La política de inmigración en España: Reflexiones sobre la emergencia del discurso cultural», en Migraciones internacionales, Vol. 1, n. ${ }^{\circ} 2$, Granada, enero- junio 2002, pp. 93-121.

ESPING-ANDERSEN, Gosta, Los tres mundos del Estado de Bienestar, Valencia, Editorial Alfons el Magnànim, 1993, pp. 25-141.

IMSERSO, Informe-Resumen del Seminario Internacional «Provisión de cuidados en las sociedades que envejecen: cuáles son los retos de las políticas y cómo enfrentarlos», 17-19 mayo de 2005, Malta, [en línea], <http://www.seg-social. es/imserso/documentacion/ses243/243informe.pdf>. [Consulta: 19/06/2009]. Vejez y Protección social a la dependencia en Europa, Observatorio de personas mayores, Madrid, Ministerio de Trabajo y Asuntos Sociales, 1999, pp. 93-319.

LAPARRA, Miguel, «Factores que explican el empleo precario», en La construcción del empleo precario, Madrid, Fundación Foessa, 2006, pp. 55-80.

Ley orgánica 39/2006 de Promoción de la Autonomía y de Atención a las personas en situación de dependencia.

Ley Orgánica 4/2000 de 11 de enero, sobre derechos y libertades de los extranjeros en España y su integración social.

MARTíneZ BujÁn, Raquel, Bienestar y cuidados: El oficio del cariño, mujeres inmigrantes y mayores nativos, tesis doctoral, Universidade da Coruña, La Coruña.

— «Política social, migración internacional y trabajo de cuidados: el caso español», en Inmigración y políticas sociales, Lorenzo Cachón y Miguel Laparra (eds), Barcelona, Ed Bellaterra, 2009, pp. 269-294.

Moreno, Luis, Bienestar mediterráneo y supermujeres, documento de trabajo 0309, Unidad de Políticas Comparadas, Madrid, CSIC, 2003, [en línea], <http:// www.iesam.csic.es/doctrab2/dt-0309.pdf>. [Consulta: 22/04/08]. 
Oso, Laura, La migración hacia España de las mujeres jefas de hogar, Madrid, Ministerio de Trabajo y Asuntos Sociales, Instituto de la mujer, n. ${ }^{\circ}$ 52, 1998, pp. 257-299.

Real Decreto 1424/1985 de 1 de agosto, por el que se regula la relación laboral de caracter especial del servicio del hogar familiar.

PÉREZ ERANSUS, Begoña, Políticas sociales en transformación, materiales docentes sin publicar, Pamplona, Universidad Pública de Navarra, 2008.

RANCI, Costanzo y Enmanuel PAVOlini, «Nuevas tendencias en la política de cuidados de larga duración en Europa Occidental: ¿Hacia un mercado social de cuidados?», en Revista Española del Tercer Sector, [en línea], Fundación Luis Vives, Madrid, n. ${ }^{o}$ 10, sep.-ene. 2009, <http://www.fundacionluisvives.org/ rets/10/articulos/33842/index.html>, [consulta: 4/06/2009].

SANABRIA, Francisco, La protección de la dependencia en la Unión Europea. CEOMA VI Congreso Nacional de Organizaciones de Mayores, [en línea], ponencia 11, Valladolid, <http://www.ceoma.org/vicongreso/ponencias.htm>, [Consulta. 21/10/2003].

\section{Webografía}

Ministerio de Trabajo y Asuntos Sociales de España: http://www.mtas.es Instituto Nacional de Estadística de España: http://www.ine.es http://www.badantibrescia.it/lalegge/guidalavoro_spagnola 



\section{RESEÑAS}

Título: Participación ciudadana y gestión de las políticas sociales municipales Autor: Enrique Pastor Seller

Edita: Ediciones de la Universidad de Murcia, Murcia, 2009, 318 páginas

ISBN: 978-84-8371-828-5

El libro presenta los resultados de una investigación empírica centrada en la participación ciudadana en la gestión de las políticas sociales, especialmente en los Servicios Sociales de ámbito municipal, en la región de Murcia. Para la investigación se han utilizado fundamentalmente técnicas de carácter cualitativo. Por ello, esta obra es de gran interés y actualidad.

El texto está divido en dos partes. En la primera, el autor realiza una revisión teórica de otros estudios e investigaciones sobre el tema tanto en el ámbito nacional como internacional, eligiendo como contexto de análisis el ámbito local. En él analiza los beneficios que tiene la participación ciudadana de base asociativa y de gestión desconcentrada para la dinámica organizacional y comunitaria. Se plantea la participación, no solo de carácter consultivo, sino para participar en la toma de decisiones que lleva consigo la definición y articulación del desarrollo social en el ámbito local, la definición de las políticas, el diseño de servicios, seguimiento y evaluación de los mismos, etc. En esta línea considera la participación ciudadana como un elemento esencial en la construcción de capital social en la comunidad y un indicador de calidad de vida comunitaria. Asimismo, valora las implicaciones de cada modalidad en la gestión de las políticas, en la intervención social y en los propios ciudadanos. En el segundo capítulo de esta primera parte se analizan distintas experiencias participativas desarrolladas a nivel nacional e internacional, así como los métodos y mecanismos utilizados en ellas, realizando una descripción de cada uno de los instrumentos según la modalidad de participación.

En el tercer capítulo lleva a cabo un análisis crítico del contexto sociopolítico y normativo de la participación ciudadana en los Servicios Sociales 
Públicos en el ámbito municipal, para lo que realiza una revisión de las recomendaciones, normativas y/o reglamentaciones que se han ido creando desde Organismos Internacionales para finalizar en la normativa desarrollada desde la Administración Central hasta los mecanismos establecidos en la Administración Regional de la Comunidad Autónoma de Murcia, incluido el planteamiento de la participación en las leyes de Servicios Sociales vigentes.

La segunda parte del libro se centra en la realidad existente sobre la participación en la política de Servicios Sociales municipales de la región de Murcia, comparando distintos casos y contextos. Para ello identifica cuáles son los instrumentos y oportunidades existentes en distintos municipios o mancomunidades para la participación ciudadana. Analiza también las aportaciones de los órganos participativos en la democratización de las políticas sociales municipales, y constata que el desarrollo de los órganos de participación, en general, depende en gran parte de la voluntad política, presentando una cierta inestabilidad y discrecionalidad. Realiza un análisis de los diferentes elementos del desarrollo de la participación: los actores, la representatividad, los objetivos, funciones, temáticas y necesidades abordadas.

Para finalizar, plantea las conclusiones de la investigación y aporta los aspectos que los propios actores sociales implicados consideran importantes para mejorar la participación. Dichas aportaciones resultan relevantes para reflexionar sobre el desarrollo de la participación ciudadana en los municipios y la necesidad de impulsar un mayor protagonismo de los ciudadanos para tomar decisiones relevantes en servicios y programas.

Esta obra resulta interesante por su análisis riguroso y su aportación sobre un tema que siempre ha estado presente en la intervención social y que aporta orientaciones para avanzar en el desarrollo de la participación sustantiva y no solo simbólica de los ciudadanos. Sus aportaciones sirven para profesionales, pero también para políticos, gestores y administradores, entre otros, especialmente del ámbito local.

El autor tiene amplia experiencia como docente universitario y como profesional del Trabajo Social en diferentes administraciones locales y en entidades del Tercer Sector.

Hortensia Redero Bellido

Departamento de Trabajo Social y Servicios Sociales

Instituto Universitario de Desarrollo Social y Paz (IUDESP)

Universidad de Alicante 
Título: Cultura y técnicas de gestión en las ONG

Autor: Borja Vivanco

Edita: Editorial CCS, Madrid, 2009, 244 págs.

ISBN: 978-849842-336-5

Esta publicación, que es el desarrollo y actualización de una tesis doctoral, asume que el desarrollo de la cultura de gestión es un reto que las ONGs deben abordar de forma inmediata. Se evidencia un déficit en el terreno de la gestión, y subsanarlo supone una necesidad por el papel que estas organizaciones han adquirido en los últimos años. Además de estar ya consolidadas en nuestra sociedad, el creciente volumen de sus procesos, y los cada vez más numerosos campos de acción en los que se aplican, obligan a una búsqueda de eficiencia y eficacia en la gestión y en sus resultados.

La necesidad de tener un modelo de gestión lleva a la búsqueda de similitudes y diferencias con dos modelos de referencia en nuestra sociedad: el de la Administración Pública y el de las empresas, y siempre teniendo presente que las ONGs deben huir de la cultura burocrática de la una y del afán lucrativo de las otras. Un valor añadido es analizar, precisamente, qué puntos en común hay en la cultura de la organización entre entidades diferentes, y aprovechar así las sinergias y experiencias de unas como de otras para ser aplicadas en el ámbito propio. Por otra parte, a las diferencias con otros modelos hay que añadir las particularidades propias de las ONGs en la cultura de gestión: la gestión por proyectos y la coordinación. Con la propuesta de desarrollar un modelo de gestión basado en la excelencia, el libro incluye una serie de los elementos más reseñables existentes dentro de la dirección y la organización, subrayando el papel del liderazgo. Y, lo que supone una valiosa aportación, criterios para poder evaluar los procesos y los resultados de dichas organizaciones.

La obra reflexiona también en la financiación y en algunas estrategias de marketing que podrían abordarse, lo que es un aspecto vital para la supervivencia de cualquier organización y, a un tiempo, delicado teniendo en cuenta la cultura propia de las ONGs. Además, se evidencia la dificultad de medir aquellas acciones de marketing destinadas a realizar una labor de 
concienciación. Por último, aborda el tema de las ONGs confesionales, vinculadas formal o informalmente a la Iglesia católica, y analiza su naturaleza diferenciada, sus particularidades y los riesgos específicos que corren, a través de un profuso repaso de sus orígenes y desarrollo.

En suma, esta obra contiene un repaso histórico y aporta una visión novedosa y necesaria de las ONGs pero, lo que es más importante, ofrece pistas para adecuar la heterogénea realidad de estas organizaciones, respetando su idiosincrasia y su cultura, a un patrón de gestión-calidad propio del siglo XXI. Por ello, se antoja de lectura obligada para las personas responsables del sector.

Santiago Pisonero, sociólogo y consultor de CIDEC 
Título: Gestión de caso (y métodos afines) en servicios sanitarios y sociales Autores: VV.AA.

Edita: Resista Políticas Sociales en Europa, 25 y 26, Hacer Editorial, 2009. ISBN: 978-84-96913-23-3

La coordinación entre diferentes servicios en favor de una asistencia más personalizada constituye, sin duda, una exigencia creciente en el ámbito de los Servicios Sociales y Sanitarios. Respondiendo a esta necesidad, este número doble de la revista Políticas Sociales en Europa está dedicado a la gestión de caso y otros métodos similares.

Este conjunto de estrategias responden a dos fenómenos bien conocidos. De un lado, está el incremento de situaciones de dependencia o discapacidad registradas en todos los países occidentales. En efecto, la mejora de las condiciones de vida y los avances médico-sanitarios han permitido el aumento de la población de más edad, la mayor longevidad de las personas con discapacidad y la mayor supervivencia de quienes han sufrido traumatismos graves o presentan alguna enfermedad crónica. Por otro lado, estos cambios demográficos han coincidido con nuevas formas de organización de la asistencia social y sanitaria, terreno donde los formatos totales (hospitales de crónicos, centros psiquiátricos de internamiento permanente, residencias asistidas) han cedido protagonismo a los recursos parciales (hospitales de agudos, de convalecencia o de día; hospitalizaciones domiciliarias, ayuda domiciliaria, centros de día, residencias para estancias temporales), que se combinan en función de las necesidades de cada usuario. Ambas tendencias, la demográfica y la organizativa, han suscitado la necesidad de mejorar la coordinación en múltiples sentidos: entre unos servicios y otros, entre los Servicios Sociales y los Sanitarios, y en el seno de cada uno.

El empleo de la metodología de la gestión de casos en este contexto centró los debates de las VII Jornadas del Seminario de Intervención y Políticas Sociales (SIPOSO) de 2008. Buena parte de las ponencias presentadas, junto a otros materiales, se recogen ahora en este número dobre de la revista, que ha sido coordinado por el director del SIPOSO, Demetrio Casado. 
La gestión de casos no es ajena a nuestros Servicios Sanitarios y, de hecho, ha sido incorporada a la praxis del sector público (véase artículo 12.1 de la Ley 16/2003 de Cohesión y Calidad del Sistema Nacional de Salud). También existen precedentes del uso de este tipo de metodologías en los Servicios Sociales, como muestra la figura del trabajador de referencia, con la que se pretende dar un nuevo impulso al trabajo social comunitario. Sin embargo, en ambas esferas es mucho lo que falta por hacer. Este número doble de la revista aspira, justamente, a difundir en nuestro país la gestión de casos y los métodos afines no sólo profundizando en su vertiente más teórica, sino también dando a conocer algunas experiencias de aplicación de estas herramientas.

La primera de las seis secciones en que se divide este número tiene carácter introductorio. Empieza con un artículo de Demetrio Casado, que, partiendo de la complementariedad entre Servicios Sociales y Sanitarios y de la deseable continuidad entre la atención social y la geriátrica/gerontológica, repasa las principales fórmulas de coordinación y gestión asistencial personalizada. Le sigue un texto de Manuel Aznar López, ex secretario general del Defensor del Pueblo, en el que describe once casos presentados ante dicha entidad que ilustran las dificultades de coordinar intervenciones sociales e intervenciones sanitarias. Cierra la sección una reflexión de las profesoras Pilar Monreal y Arantza del Valle, en la que analizan la experiencia de los usuarios con un problema de salud cuando se dirigen a los servicios de atención comunitaria en Cataluña.

La segunda sección está dedicada a la salud mental, y la abre un texto del psiquiatra José García González sobre los cambios asistenciales que se han producido en este ámbito tras la reforma psiquiátrica iniciada en España en la década de los ochenta. Esta visión general se completa con tres experiencias concretas: una, sobre el tratamiento asertivo comunitario en el área sanitaria de Oviedo, a cargo del psiquiatra Javier Montejo; otra, sobre los equipos de apoyo social comunitario de la Comunidad de Madrid, presentada por su responsable en Alcalá de Henares, Juan Fernández Blanco; y la última, en torno a los pisos supervisados y los programas de apoyo a la reinserción social de personas con enfermedad mental grave y crónica en situación de exclusión social (PRISEMI), desarrollada también en la Comunidad de Madrid, y que expone su coordinador, Fran Recalde.

El ámbito hospitalario sirve de eje a los contenidos de la tercera sección que arranca con la aportación de Dolors Colom, del Institut de Serveis Sanitaris i Socials, que expone las bases del trabajo social sanitario y la planificación del alta sanitaria. Ya desde un punto de vista aplicado, Rosario Suárez Iglesias, jefa del programa de planificación del alta hospitalario en el Complexo Hospitalario Universitario de La Coruña, evalúa este programa desde la perspectiva 
que dan sus diez años de recorrido. Para terminar, Begoña Gutiérrez González, trabajadora social, presidenta y gestora de casos de la Comisión Hospitalaria contra la Violencia del Hospital Ramón y Cajal de Madrid, explica la gestión de casos en el contexto de las comisiones hospitalarias contra la violencia existentes de la Comunidad de Madrid.

La cuarta sección gira en torno a las intervenciones en contextos de marginación social, y en ella se recogen dos experiencias: en primer lugar, el programa de acompañamiento para la inclusión social en la región de Murcia, presentado por los trabajadores sociales de ese programa, Consuelo García Olivares y José Luis Ortega Cañavate; y en segundo lugar, el programa de intervención psicosocial con ancianos aislados en la ciudad de Madrid, de cuya descripción se encargan Berta Ausín y Ana Belén Santos-Olmo, profesionales de dicho programa de la Dirección General de Mayores del Ayuntamiento de Madrid.

El ámbito de la dependencia constituye, sin duda alguna, uno de los ámbitos donde más se han extendido la gestión de casos y las metodologías cercanas, razón por la cual no podía faltar en este número doble. La quinta sección de artículos aborda este campo de actuación, con textos del sociólogo Miguel Montero sobre la gestión de casos en el seguro de dependencia alemán y del consultor Fernando Fantova sobre el acompañamiento social y la autonomía personal.

La última sección reúne un par de trabajos que tienen por objeto la promoción de la gestión de casos en nuestro país. En esta línea, la profesora Cristina Rimbau propone una reflexión sobre el concepto mismo de gestión de casos a partir de diversas experiencias identificadas. Por su parte, la investigadora Alicia Sarabia diserta sobre el perfil que deben tener los profesionales que se dedican a la gestión de casos.

Como broche final, una crónica de las VII Jornadas del Seminario de Intervención y Políticas Sociales, firmada por los consultores Carlos Egea y Fernando Fantova; unas fichas que sintetizan los datos básicos de los servicios y programas presentados en ese marco, recopiladas por la profesora M. ${ }^{a}$ Carmen Sánchez Pérez; y las habituales recensiones del SIIS-Centro de Documentación y Estudios.

En suma, este número doble de Políticas Sociales en Europa ha logrado reunir un interesante conjunto de artículos sobre gestión de casos y métodos afines. Combinando textos analíticos con otros más descriptivos, la revista permite aproximarse a los fundamentos teóricos de estas metodologías, constatar su capacidad para reforzar la coordinación entre servicios y la atención personalizada y dar a conocer algunas experiencias que pueden resultar inspiradoras.

SIIS-Centro de Documentación y Estudios 



\section{INSTRUCCIONES PARA LOS AUTORES ${ }^{1}$}

\section{Información general}

La revista Alternativas. Cuadernos de Trabajo Social con ISSN 1133-0473 es una publicación del Departamento de Trabajo Social y Servicios Sociales de la Universidad de Alicante. Fundada con el mismo título en 1992 por la Escuela Universitaria de Trabajo Social de la Universidad de Alicante, se publica desde el 2009 por el Departamento de Trabajo Social y Servicios Sociales de dicha universidad. Su periodicidad es anual.

Se trata de una revista arbitrada que utiliza el sistema de revisión externa por expertos (peer-review) en el conocimiento de los objetos investigados y en las metodologías utilizadas en las investigaciones. Adopta y se adhiere a las normas de publicación establecidas en el Manual de la $\mathrm{APA}^{2}$. Es preciso recordar que el cumplimiento de los requisitos del Manual de la APA facilita la indización de la revista en las principales bases de datos de la especialidad, con lo que ello supone de beneficio para los autores y sus centros por la mayor difusión que alcanzan los trabajos publicados.

Cada uno de sus números se edita tanto en versión impresa como en versión electrónica, ésta disponible en el Repositorio Institucional de la Universidad de Alicante (http://rua.ua.es/dspace/handle/10045/5269).

Alternativas. Cuadernos de Trabajo Socal está abierta a intercambios con otras publicaciones.

1. De acuerdo con lo elaborado para FECYT por Rafael Ruiz-Pérez, Emilio Delgado LópezCózar y Evaristo Jiménez Contreras. Grupo de Investigación EC3, Universidad de Granada, http://ec3.ugr.es/.

2. Manual de la APA (American Psychological Association, [en línea], http://books.apa. org/books.cfm?id=4200061\&toc=yes). 


\section{Alcance y cobertura}

Alternativas. Cuadernos de Trabajo Social tiene como objeto fundamental contribuir a la difusión de investigaciones, experiencias, trabajos teóricos y metodológicos, tanto de carácter académico como profesional, que se realizan en nuestro país y en el ámbito internacional, relativos al Trabajo Social, a la política social y a los Servicios Sociales, así como a otras disciplinas y profesiones que desde un punto de vista multi e interdisciplinar enriquecen y complementan la disciplina y la acción profesional del Trabajo Social en el ámbito de las Ciencias Sociales.

Los trabajos deben ser originales, no publicados ni estar siendo considerados en otra revista para su publicación, escritos en español y en otras lenguas (inglés y francés). El autor es el único responsable de las afirmaciones sostenidas en su artículo. De manera excepcional, los artículos que no sean inéditos se publicarán bajo la valoración del Consejo Editorial y en función de que su difusión haya sido en algún medio de difícil acceso y de que se consideren de particular relevancia e interés científico profesional.

Serán considerados para su publicación los siguientes tipos de trabajos: investigaciones originales, revisiones bibliográficas, experiencias, reseñas bibliográficas, notas técnicas.

Investigaciones originales: estarán estructuradas de la siguiente manera: resumen, palabras clave, texto (introducción, material y métodos, resultados y discusión), agradecimientos y bibliografía. La extensión máxima del texto será de 6000 palabras (en formato Word), escritas a doble espacio, cuerpo de letra 12, tipo Times New Roman, admitiéndose 4 figuras y 6 tablas. Las tablas y figuras deberán presentarse en hoja aparte numerándose correlativamente e indicando el lugar de colocación en el artículo. Si se utilizan, han de ser aquellas que por su relevancia sean necesarias para apoyar los argumentos recogidos en el texto. Es aconsejable que el número de autores no sobrepase los seis.

Revisiones bibliográficas y experiencias prácticas: las revisiones bibliográficas consistirán en un análisis crítico de temáticas relevantes para el Trabajo Social, la política social y los servicios sociales. Las experiencias prácticas consistirán en una sistematización rigurosa del proceso y resultados de las mismas. Ambas, revisiones y experiencias, deberán incluir un apartado con aportaciones o propuestas de aplicación o transferencia al Trabajo Social, la política social, los servicios sociales o la intervención social. Los textos tendrán una extensión máxima de 4000 palabras (en formato Word) escritas a doble espacio, cuerpo de letra 12 y tipo Times New Roman. Opcionalmente el trabajo podrá incluir tablas y figuras. 
Reseñas bibliográficas: tendrán una extensión máxima de 1000 palabras (en formato Word), escritas a doble espacio, cuerpo de letra 12 y tipo Times New Roman. Deberán estar precedidas del título de la obra, autores, editorial, lugar de edición, año de publicación, número de páginas e ISBN.

Notas técnicas: describirán de forma resumida normativas o políticas, investigaciones en curso, así como crónicas de congresos, seminarios o jornadas relevantes para el Trabajo Social, la política social y los servicios sociales. Tendrán una extensión máxima de 1000 palabras (en formato Word), escritas a doble espacio, cuerpo de letra 12 y tipo Times New Roman.

\section{Presentación y estructura de los trabajos}

Las siguientes normas de publicación están basadas en el Manual de la APA:

a) Los manuscritos deben ser enviados por correo electrónico a la Redacción de la revista Alternativas. Cuadernos de Trabajo Social del Departamento de Trabajo Social y Servicios Sociales a la dirección dtsss@ua.es con copia a masun.martinez@ua.es, a doble espacio, márgenes amplios y con sus páginas numeradas correlativamente en el ángulo superior derecho. Deberán ir acompañados de una carta de presentación (ver modelo facilitado por la revista) pidiendo la consideración del manuscrito, en la que además el autor explicará en 4-5 líneas, cuál es la aportación original del trabajo que presenta y sus novedades, la declaración de que no ha sido publicado anteriormente y que no se ha enviado simultáneamente a otras revistas, así como la confirmación de las autorías firmantes. En esta carta también figurará la cesión de derechos al editor. El autor debe conservar una copia del original para evitar irreparables pérdidas o daños del material.

b) Las citas bibliográficas deben reseñarse en forma de referencias a continuación de la discusión o de los agradecimientos si los hubiere. Las citas bibliográficas, cuyo número ha de ser el suficiente y necesario, se presentarán según el orden de aparición en el texto con la correspondiente numeración correlativa y serán identificadas por autor y año entre paréntesis y separados por una coma (ejemplo: Coob, 1989), con inclusión del número de página o páginas en el caso de citas textuales (ejemplo: Coob, 1989: 25-27). 


\section{Los manuscritos se presentarán de acuerdo al siguiente orden y} estructura

Página de título. Primera página del manuscrito

A modo de portada del manuscrito, esta primera página contendrá:

a) Título del artículo (conciso pero informativo), en español e inglés, conformado con el mayor número de términos significativos posibles (a ser posible tomados de un vocabulario controlado de la especialidad). Si es necesario, se añadirá un subtítulo no superior a 40 letras y espacios, en español e inglés.

b) Nombre y dos apellidos de cada uno de los autores teniendo en cuenta la forma de firma para indexación en bases de datos internacionales (véanse en la sección «¿Sabes qué tienes que hacer para identificar tus publicaciones científicas?» las recomendaciones formuladas en http://www.accesowok.fecyt.es/).

c) Nombre completo del centro de trabajo de cada uno de los autores, el cual tendrá su referencia al lado del nombre del autor con números arábigos entre paréntesis (o en superíndice).

d) Nombre y dirección completa del responsable del trabajo o del primer autor como responsable de correspondencia, incluyendo número de teléfono y del telefax en su caso, así como dirección de correo electrónico si se dispone de ella.

e) Información sobre becas, ayudas o soporte financiero con el que se ha contado (Proyectos de Investigación) para la subvención del trabajo y otras especificaciones, cuando sea el caso.

Para una mejor elaboración de esta página, véase modelo adjunto a estas instrucciones sobre cómo elaborar la hoja de identificación del manuscrito.

Páginas de resumen y palabras-clave. Segunda página del manuscrito

Una segunda página independiente deberá contener los nombres y apellidos de los autores, el título del artículo y el título de la revista, un resumen del contenido del artículo en español y el listado de palabras clave. Tanto el resumen como las palabras clave tendrán una versión en inglés.

a) el resumen del trabajo tendrá una extensión de 150-250 palabras. En el caso de los artículos originales, el contenido del mismo se dividirá en cuatro apartados (resumen estructurado): introducción, material y métodos, resultados y discusión. En cada uno de ellos se describirá de forma concisa, 
respectivamente, el motivo y el objetivo de la investigación, la metodología empleada, los resultados más destacados y las principales conclusiones. Se enfatizarán los aspectos novedosos y relevantes del trabajo. En el caso de las colaboraciones especiales se resumirá el trabajo sin dividirlo en estos cuatro apartados.

b) Palabras clave: a continuación del resumen se especificarán cinco palabras clave o frases cortas que identifiquen el contenido del trabajo para su inclusión en los repertorios y bases de datos nacionales e internacionales. Se procurará poner el mayor número posible hasta un máximo de cinco. Deberán utilizarse términos controlados de referencia.

Texto del manuscrito. Tercera página, que será la del arranque del texto del manuscrito

La tercera página y siguientes serán las que se dediquen al texto del manuscrito, que se ajustará a las especificaciones de las instrucciones indicadas para cada tipo de trabajo. En el caso de las Revisiones y Notas técnicas podrá figurar el manuscrito estructurado en los apartados convenientes para facilitar así su compresión. Sin embargo, los trabajos originales deben ajustarse en la medida de lo posible a los siguientes apartados: introducción, materiales y métodos, resultados y discusión:

Introducción: debe incluir los fundamentos y el propósito del estudio, utilizando las citas bibliográficas estrictamente necesarias. No incluirá datos o conclusiones del trabajo presentado. No debe realizarse una revisión bibliográfica detallada.

Material y métodos: será presentado con la precisión que sea conveniente para que el lector comprenda y confirme el desarrollo de la investigación. Fuentes y métodos previamente publicados deben describirse sólo brevemente y aportar las correspondientes citas, excepto que se hayan realizado modificaciones en los mismos. Se describirá el cálculo del tamaño de la muestra y la forma de muestreo utilizada en cada caso. Se hará referencia al tipo de análisis documental, crítico, estadístico, etc., empleado. Si se trata de una metodología original, será necesario exponer las razones que han conducido a su empleo y describir sus posibles limitaciones.

Cuando se trate de trabajos experimentales en los que se hayan utilizado grupos humanos, se indicará si se han tenido en cuenta los criterios éticos correspondientes. No deben utilizarse los nombres ni las iniciales de las personas que hayan participado formando parte de la muestra estudiada.

Resultados: aparecerán en una secuencia lógica en el texto, tablas o figuras, no debiendo repetirse en todas ellas los mismos datos. Se procurará 
resaltar las observaciones importantes. Se describirán, sin interpretar ni hacer juicios de valor, las observaciones efectuadas con el material y métodos empleados.

Discusión: resumirán los hallazgos, relacionando las propias observaciones con otros estudios de interés y señalando las aportaciones y limitaciones de unos y otros. No deben repetirse con detalle los datos u otro material ya comentado en otros apartados. Se mencionarán las inferencias de los hallazgos y sus limitaciones, incluyendo las deducciones para una investigación futura. Se enlazarán las conclusiones con los objetivos del estudio, evitando las afirmaciones gratuitas y las conclusiones no apoyadas completamente por los datos del trabajo.

Agradecimientos: únicamente se agradecerá su colaboración a aquellas personas que hayan hecho contribuciones sustanciales al estudio pero sin llegar a merecer la calificación de autor, debiendo disponer el autor de su consentimiento por escrito. Así mismo, el Council Science Editors (CSE) recomienda a los autores, en su caso, una declaración explícita de la fuente de financiación de la investigación, y que ésta se encuentre entre los agradecimientos (CSE, 2000) (Conflicts of Interest and the Peer Review Process. Draft for CSE member review, del 03/31/00. http://www.cbe.org/services_DraftPolicies.shtml).

Bibliografía: la bibliografía debe reseñarse a continuación de la discusión o de los agradecimientos si los hubiere, y en la forma antes indicada según el orden alfabético de autores.

Para las referencias bibliográficas se recomienda seguir el estilo que se detallará más adelante con ejemplo, basado en las normas de la APA.

- Los nombres de las revistas deben abreviarse según consenso existente en el área de conocimiento, y siempre que exista una lista de referencia.

- Se mencionarán todos los autores hasta seis, o los seis primeros, y et al. cuando sean siete o más.

La bibliografía debe ser corregida por el autor, comparándola con la copia en su poder. Se evitará utilizar frases imprecisas como citas bibliográficas. No pueden emplearse como tales las que precisen de aclaraciones del tipo «observaciones no publicadas», ni «comunicación personal», aunque sí podrán citarse dentro del texto entre paréntesis. Los trabajos aceptados, pero aún no publicados, se incluirán en las citas bibliográficas especificando el nombre de la revista, seguido por la expresión «en prensa».

Las citas bibliográficas deberán extraerse de los documentos originales, indicando siempre la página inicial y la final del trabajo del que proceden. A fin de asegurar la coherencia, en cualquier momento del proceso editorial, la 
dirección de la revista podrá requerir a los autores el envío de la primera página (fotocopia) de cada uno de los artículos citados en su bibliografía.

Para las revistas, dada su trascendencia para los índices de citas y los cálculos de los factores de impacto, se citarán: a) autor(es), con su(s) apellido(s) e inicial(es) de nombre(s), separando los apellidos del nombre con una coma. Si hay más de un autor, entre ellos se pondrá una coma. Todos hasta un máximo de seis, y cuando sean más de seis se pondrán sólo los seis primeros y se añadirá et al. Tras el último autor se pondrá el año entre paréntesis y un punto; b) título del artículo en su lengua original, y con su grafía y acentos propios. Tras el título se pondrá un punto; c) nombre correcto de la revista; d) número de volumen ( . $^{\circ}$ ) (la separación entre este apartado y el siguiente se hará con coma); y e) páginas primera y última, separadas por un guión.

A continuación se dan ejemplos de citas bibliográficas correctamente referenciadas.

\section{Publicaciones periódicas}

Artículo de revista, un autor

Bekerian, D. A. (1992). In search of the typical eyewitness. American Psychologist, 48, 574-576.

Artículo de revista, dos autores

Klimowski, R., Palmer, S. (1993). The ADA and the hiring process in organizations. Consulting Psychology Journal: Practice and Research, 45(2), 10-36.

Artículo de revista, de tres a cinco autores

Borman, W. C., Hanson, M. A., Oppler, S. H., Pulakos, E. D., y White, L. A. (1993). Role of early supervisory experience in supervisor performance. Journal of Applied Psychology, 78, 443-449.

Artículo de revista, seis autores

Kneip, R. C., Delamater, A. M., Ismond, T., Milford, C., Salvia, L., y Schwartz, D. (1992). Self- and spouse ratings of anger and hostility as predictors of coronary heart disease. Health Psychology, 12, 301-307.

Artículo de revista, en prensa

Bekerian, D. A. (en prensa). In search of the typical eyewitness. American Psychologist. 
Bekerian, D. A. (en prensa-a). Role of early supervisory experience in supervisor performance. American Psychologist.

Bekerian, D. A. (en prensa-b). Self- and spouse ratings of anger and hostility as predictors of coronary heart disease. American Psychologist.

Artículo de revista no inglesa, con el título traducido al inglés

Zajonc, R. B. (1992). Bischofs gefühlvolle Verwirrunggen über die Gefühlle [Bischof's emotional fluster over the emotions]. Psychologische Rundschau, 40, 574-576.

\section{Libros y capítulos de libro}

Referencias a libros completos

Bekerian, D. A. (1992). People in organizations: An introduction to organizational behavior (3. ${ }^{\mathrm{a}}$ ed.). New York: McGraw-Hill.

Libro, autor en grupo (agencia gubernamental) como editor

Australian Bureau of Statistics (1992). Estimated resident population by age and sex in statistical local areas, New South Wales, June 1990 (No 3209.1). Australian Capital Territory: ABS

Libro editado

Bekerian, D. A. (Ed.). (1992). People in organizations: An introduction to organizational behavior. New York: McGraw-Hill.

Libro sin autor o editor

Merriam-Webster's Collegiate Dictionary (10. ${ }^{a}$ ed.). Springfield, MA: Merriam-Webster.

Enciclopedia o diccionario

Bekerian, D. A. (1992). The new Grove dictionary of music and musicians (3. ed., Vols. 1-20). New York: McGraw-Hill.

Traducción inglesa de un libro

Laplace, P. -S. (1951). A philosophical essay on probabilities (Trads., F. W. Truscott y F. L. Emory). New York: McGraw-Hill. (Trabajo original publicado en 1814). 
Capítulo en un volumen de una serie

Maccoby, E. E. (1992). Socialization in the context of the family. En P. M. Musen (Ed. Serie) y M. J. Martin (Ed. Vol.). Handbook of child psychology: Vol. 4. Socialization, personality, and social development (3. ${ }^{a}$ ed., pp. 1-101). New York: McGraw-Hill.

\section{Informes técnicos y de investigación}

Informe disponible en la GPO (Government Printing Office), instituto gubernamental como autor

National Institute of Mental Health (1992). Clinical training in serious mental illnes (Publicación DHHS N. .o ADM 90-1679). Washington, DC: Government Printing Office.

Reuniones científicas (congresos, simposios, etc.)

Actas de congreso publicadas, contribución publicada a un simposio, artículo o capítulo en libro editado

Bekerian, D. A. (1992). A motivational approach to the self. En R. DeMaier (Ed.), Nebraska Symposium of Motivation: Vol. 38. Perspectives on motivation (pp. 574-596). Lincoln: University of Nebraska Press.

Actas publicadas regularmente

Bekerian, D. A. (1992). In search of the typical eyewitness. Proceedings of the National Academy of Sciences, USA, 89, 574-576.

Trabajo no publicado presentado a un congreso

Bekerian, D. A. (1992, Enero). Early data on the Trauma Symptom Checklist for Children (TSC-C). Comunicación presentada al Congreso de la American Professional Society on the Abuse of Children, San Diego, CA.

\section{Tesis doctorales y de máster}

Tesis doctoral no publicada

Bower, D. L. (1993). Employee assistant programs supervisory referrals: Characteristics of referring and nonreferring supervisors. Tesis doctoral no publicada. University of Missouri, Columbia.

Tesis de máster no publicada, universidad no estadounidense Saldaña, P. (1992). Actitudes de los padres hacia la integración escolar. Tesis de máster no publicada, Universidad de Salamanca, Salamanca, España. 


\section{Revisiones}

Revisión de un libro

Baumeister, R. F. (1993). Exposing the self-knowledge myth [Revisión del libro The self-knower: A hero under control]. Contemporary Psychology, 38, 466-467.

\section{Medios audiovisuales}

Película, circulación limitada

Bekerian, D. A. (productor), y Smith, J. N. (director). (1992). Changing our minds [película]. (Disponible en Changing Our Minds, Inc., 170 West End Avenue, Suite 35R, New York, NY 10023).

\section{Medios electrónicos}

Artículo de revista on-line, acceso limitado a suscriptores

Central Vein Occlusion Study Group. (1993, 2 Octubre). Central vein occlusion study of photocoagulation: Manual of operations [675 párrafos]. Online Journal of Current Clinical Trials [Serie on-line]. Disponible en: Doc. N. ${ }^{\circ} 92$.

\section{Referencias de fuentes electrónicas (Internet)}

Sitios web

Tilton, J. (1995). Composing good HTML (Vers. 2.0.6). http://www.cs.cmu. edu/ tilt/cgh/ (13 Jan. 1997).

Tablas: deben presentarse en hojas independientes numeradas según su orden de aparición en el texto con números arábigos. Se emplearán para clarificar puntos importantes, no aceptándose la doble documentación bajo la forma de tablas y figuras. Los títulos o pies que las acompañen deben explicar perfectamente el contenido de las mismas.

Figuras: serán consideradas figuras todo tipo de fotografías, gráficas o dibujos. Se les asignará un número arábigo según orden de aparición en el texto, siendo identificadas por el término abreviado fig.(s). Los pies o leyendas de cada una deberán ir mecanografiados y con el número correspondiente en una hoja aparte. El texto en las figuras irá en mayúsculas. Deben ser diseñadas presentando un buen contraste, de forma que no pierdan calidad con la reducción. Las microfotografías presentarán también un buen contraste de forma que puedan ser publicadas sin reducción. 
La publicación figuras en color especificarse previamente. Corriendo los gastos de fotomecánica a cargo del autor.

Las figuras deben clarificar de forma importante el texto y su número estará reducido al mínimo necesario.

Abreviaturas: sólo deberán ser empleadas abreviaturas estándar universalmente aceptadas (consultar Units Symbols and Abbreviations). Cuando se pretenda acortar un término empleado frecuentemente en el texto, su abreviatura, entre paréntesis, deberá acompañarse la primera vez que aparezca. No serán usados los números romanos en el texto, empleándose para los decimales el punto a la derecha del cero en lugar de la coma. Los nombres comerciales no serán utilizados salvo necesidad, en cuyo caso la primera vez que se empleen irán acompañados del símbolo.

\section{Proceso editorial}

Los trabajos se remitirán acompañados de una carta de presentación, en la que se solicitará la evaluación de los mismos para su publicación en alguna de las secciones de la revista, con indicación expresa de tratarse de un trabajo que no ha sido difundido ni publicado anteriormente, ser enviado únicamente a la revista Alternativas. Cuadernos de Trabajo Social para su evaluación y publicación si procede, así como las aportaciones en cuanto a originalidad y novedad que, a juicio de los autores, plantea el trabajo.

La carta de presentación deberá ir firmada por todos los autores. Incluirá la autorización escrita de todas las personas que aparezcan en los agradecimientos o de aquellas que hayan sido estudiadas durante la investigación y cuya identificación sea esencial para presentar los resultados. Así mismo, se declarará aceptar, si procede, la introducción de cambios en el manuscrito por parte de la Redacción de la revista.

La Redacción de la revista acusará recibo a los autores de los trabajos que le lleguen y posteriormente informará de su aceptación o rechazo.

La Redacción pasará a considerar el trabajo para su publicación por el Comité Editorial, comprobando si se adecua a la cobertura de la revista y cumple las normas de publicación. En tal caso se procederá a su revisión externa.

Los manuscritos serán revisados de forma anónima (ciego o doble ciego) por dos expertos en el objeto de estudio y/o metodología empleada. La Redacción de la revista, a la vista de los informes externos, se reserva el derecho de aceptar/rechazar los artículos para su publicación, así como el de introducir modificaciones de estilo y/o acortar los textos que sobrepasen la extensión permitida, comprometiéndose a respetar el contenido del original. El protocolo utilizado por los revisores de la revista se hace público como anexo a estas 
normas y publicado en la web de la Revista en el Departamento de Trabajo Social y Servicios Sociales (http://www.ua.es/dpto/dtsss/publicaciones.htm).

En el caso de juicios dispares entre los dos evaluadores, los trabajos se remitirán a un tercer evaluador. Serán sometidos a revisión pareada externa las investigaciones, las revisiones bibliográficas y las experiencias. Los trabajos que sean revisados y pudieran ser considerados para publicación previa modificación, deberán ser devueltos en el plazo de 30 días tanto si se solicitan correcciones menores como mayores. Cuando sea necesario, la nueva versión del texto será enviada otra vez a los revisores externos, procedimiento que se seguirá hasta la aceptación definitiva del trabajo por la revista. Los autores recibirán los informes de evaluación de los revisores (de acuerdo con el protocolo de evaluación de la revista), de forma anónima, para que éstos puedan realizar (en su caso) las correcciones o réplicas oportunas.

En general, una vez vistos los informes externos, los factores en los que se funda la decisión sobre la aceptación-rechazo de los trabajos por parte de la Redacción de la revista son los siguientes: a) originalidad: totalmente original, información valiosa, repetición de resultados conocidos; b) actualidad y novedad; c) relevancia: aplicabilidad de los resultados para la resolución de problemas concretos; d) significación: avance del conocimiento científico; e) fiabilidad y validez científica: calidad metodológica contrastada; y f) presentación: buena redacción, organización (coherencia lógica y presentación material).

Los autores de artículos aceptados recibirán las pruebas de imprenta para su corrección por correo electrónico en formato PDF. Deberán devolverlas corregidas a la Redacción de la revista mediante fax o PDF dentro de las 72 horas siguientes a su recepción. Únicamente se pueden realizar mínimas correcciones sobre el contenido del manuscrito original sin incurrir en un coste extra.

En su caso, el autor o primer firmante recibirá un ejemplar de la revista en papel después de su publicación.

\section{Responsabilidades éticas}

Es responsabilidad y deber de la Redacción de la revista Alternativas. Cuadernos de Trabajo Social recordar a sus colaboradores los siguientes extremos:

- Cuando se describen experimentos realizados en seres humanos debe indicarse si los procedimientos seguidos son conformes a las normas éticas del comité de experimentación humana responsable (institucional o regional) y a la Declaración de Helsinki de 1975 revisada en el 2000. No se deben utilizar nombres, iniciales u otros datos de identificación de los centros donde se ha realizado. 
- Contar con permiso de publicación por parte de la institución financiadora de la investigación, cuando proceda.

- La revista no acepta material previamente publicado. Los autores son responsables de obtener los oportunos permisos para reproducir parcialmente material (texto, tablas o figuras) de otras publicaciones y de citar su procedencia correctamente.

Conflicto de intereses: la revista espera que los autores declaren cualquier asociación comercial que pueda suponer un conflicto de intereses en conexión con el artículo remitido.

Autoría: en la lista de autores firmantes deben figurar únicamente aquellas personas que han contribuido intelectualmente al desarrollo del trabajo. Haber ayudado en la colección de datos o haber participado en alguna técnica no son, por sí mismos, criterios suficientes para figurar como autor. En general, para figurar como autor deben cumplirse los siguientes requisitos: a) haber participado en la concepción y realización del trabajo que ha dado como resultado el artículo en cuestión, b) haber participado en la redacción del texto y en las posibles revisiones del mismo y c) haber aprobado la versión que finalmente va a ser publicada.

La revista declina cualquier responsabilidad sobre posibles conflictos derivados de la autoría de los trabajos a publicar.

Consentimiento informado: los autores deben mencionar en la sección de métodos que los procedimientos utilizados con los participantes han sido realizados tras obtención de un consentimiento informado.

Transmisión de derechos de autor: se incluirá junto al manuscrito, o formando parte de la carta de presentación, una Hoja de Identificación y Cesión de Derechos (facilitada por la revista) firmada por todos los autores.

\section{Información adicional}

La revista acusa recepción de todos los trámites realizados para tener informados a los autores de la situación en la que se encuentra su manuscrito.

Los juicios y opiniones expresados en los artículos y comunicaciones publicados en la revista son del autory no necesariamente del Comité Editorial.

Tanto el Comité Editorial como la empresa editora declinan cualquier responsabilidad sobre el material publicado. Ni el Comité Editorial ni la empresa editora garantizan o apoyan ningún producto que se anuncie en la revista, ni garantizan las afirmaciones realizadas por el fabricante sobre dicho producto o servicio. 


\section{Protocolos destinados a los autores ${ }^{3}$}

\section{Listado de comprobaciones}

Tiene por objeto el exigir al autoruna revisión final del manuscrito en cuanto a sus aspectos fundamentales de carácter formal y metodológico.

\section{Listado de comprobaciones}

Para facilitar la labor del Comité de Lectura, la entrada en proceso de su manuscrito y la rapidez en su posible publicación, se exige que el autorrealice una revisión final del manuscrito, comprobando las cuestiones enumeradas en la presente lista, que una vez marcadas, será remitida junto al manuscrito. Se recuerda que el incumplimiento de alguno de los ítems puede ser motivo de devolución del manuscrito.

1. Se envía el manuscrito vía correo electrónico, en ficheros en formato Word, escritos a doble espacio, incluidas las citas bibliográficas, tablas y figuras

2. Se incluye el título completo del manuscrito en español e inglés

3. Se incluye el resumen del manuscrito y las palabras clave, en español e inglés

4. El resumen se ajusta a las normas de publicación en cuanto a número de palabras, y en él constan objetivos, diseño o material y métodos, resultados, conclusiones y/o discusión

5. Se envía el resumen y las palabras clave traducidos al inglés y, a ser posible, revisados por un experto en este idioma

6. Se incluyen las filiaciones institucionales y/o profesionales de cada uno de los autores

7. Se incluye la dirección del autor principal o responsable de correspondencia, número de teléfono, fax y dirección de correo electrónico

8. En su caso, se declaran becas, ayudas o soporte financiero y su procedencia

9. El manuscrito responde a la estructura exigida en las normas de publicación y a las especificaciones de la sección a la que se dirige

10. El manuscrito describe todas las fuentes, materiales, equipo y elementos usados, tanto en términos de grupos investigados como la globalidad del estudio

11. Un experto en el contenido del manuscrito podría reproducir su estudio, experimento, análisis, etc., a partir de la metodología descrita

12. Las conclusiones se apoyan en los resultados obtenidos

13. En su caso, se han utilizado análisis estadísticos, y éstos han sido revisados por un experto en la materia

14. Se han revisado las referencias bibliográficas, y éstas se ajustan en su estilo y formato a las normas internacionales exigidas por la revista

15. En su caso, las figuras y tablas aportan información adicional y no repetida en el texto

16. En su caso, se ha revisado el sistema de unidades empleado

3. De acuerdo con lo elaborado para FECYT por Rafael Ruiz-Pérez, Emilio Delgado LópezCózar y Evaristo Jiménez Contreras. Grupo de Investigación EC3, Universidad de Granada (http://ec3.ugr.es/). 


\begin{tabular}{|l|c|}
\hline 1. Listado de comprobaciones \\
\hline 17. Se detallan las abreviaturas tras su primera cita en el texto & $\bullet$ \\
\hline 18. En su caso, se citan las normas éticas utilizadas & $\bullet$ \\
\hline $\begin{array}{l}\text { 19. En su caso, se adjuntan o se da fe en el manuscrito consentimientos de los } \\
\text { informados de experimentación con personas, así como de los permisos de } \\
\text { reproducción }\end{array}$ & $\bullet$ \\
\hline $\begin{array}{l}\text { 20. Se adjunta una lista de comprobación y una carta de presentación indicando } \\
\text { originalidad, novedad del trabajo y sección de la revista a la que se dirige }\end{array}$ & $\bullet$ \\
\hline $\begin{array}{l}\text { 21. La carta de presentación debe incluir un anexo firmado por los autores } \\
\text { responsabilizándose de la autoría y cediendo los derechos de autor al editor }\end{array}$ & $\bullet$ \\
\hline
\end{tabular}

\section{Cómo confeccionar la primera página del manuscrito}

También llamada hoja de identificación o página de título, este protocolo tiene la intención de facilitar al autor el formato adecuado para la elaboración de los datos de identificación del manuscrito. Estos datos no sólo son importantes para la propia versión del manuscrito que finalmente será publicada, sino también para la indexación en las bases de datos.

\section{Cómo confeccionar una hoja de identificación}

Dada la importancia de los datos de identificación del manuscrito (Primera página del manuscrito o página de título), debe seguirse la estructura del siguiente modelo

\section{Título:}

Competencia profesional en Trabajo Social...

Professional competence in Social work...

\section{Autores:}

Roberto A. XXXX-XXXX ${ }^{1}$, Luis A. DE XXX-XXXX², José XXXXX-XXXX

Filiación profesional/institucional

1. Universidad XXXXX, Dpto. de XXXXXXX, Madrid, España

2. Consejo Superior de Investigaciones Científicas, Instituto de XXX, Granada, España

3. Hospital XXX, Servicio de XXX, Unidad de XXX, Madrid, España

(no hacer referencia a la condición de «residente», «profesor», «catedrático», etc.)

Responsable de la correspondencia

Roberto A. XXXX-XXXX

Universidad XXXXX, Dpto. de XXXXXXX, Madrid, España

Av. MMMMMMM, 273

28007 Madrid, España

E-mail: xxx@internet.com

Institución responsable que soporta la investigación y/o soporte financiero (en su caso)

Instituto Oftalmológico XXX, Universidad de XXX, Madrid, España

Proyecto subvencionado FIS-78/2-1993 del Ministerio de Sanidad

Antecedentes de difusión (en su caso)

Presentado parcialmente como comunicación al «XX Congreso XXX»,

Helsinki, Finlandia, celebrado el xxx 


\section{Cómo confeccionar una hoja de identificación}

Sección a la que se dirige el artículo

(especificar)

3. Carta de presentación, de cesión de derechos y de declaración de conflicto de intereses

La carta de presentación tiene la finalidad de ayudar a que el proceso de revisión del manuscrito y la toma de decisiones sobre el mismo sea más rápida y eficiente, y ello en la medida en que informa y adelanta aquellos aspectos y detalles más importantes requeridos por la revista para la toma en consideración de un trabajo, tales como justificación de la elección de la revista, aportaciones del trabajo, declaración de autoría y originalidad, responsabilidades éticas y conflictos de intereses, etc.

\begin{tabular}{l} 
3. Carta de presentación y cesión de derechos de copyright \\
\hline Sr./Sra. director/a de la revista Alternativas. Cuadernos de Trabajo Social: \\
Leídas atentamente las instrucciones a autores y analizada la cobertura de la revista, \\
considero que la publicación que Vd. dirige es la adecuada para la difusión de nuestro \\
trabajo, por lo que le ruego someta a la consideración de su posible publicación en la \\
sección de \\
el manuscrito que adjunto le remito titulado \\
cuyos autores son \\
de los cuales \\
será el encargado de la correspondencia. \\
Las aportaciones originales y novedades que en nuestra opinión el referido manuscrito \\
aporta al estudio de \\
son, en síntesis, las siguientes: \\
\hline \\
\hline Los autores certifican que este trabajo no ha sido publicado ni en todo ni en parte por \\
cualquier otro medio, ni está en vías de consideración para publicación en otra revista. \\
Los autores se responsabilizan de su contenido y de haber contribuido a la concepción, \\
diseño y realización del trabajo, análisis e interpretación de datos, y de haber participado \\
en la redacción del texto y sus revisiones, así como en la aprobación de la versión que \\
finalmente se remite. \\
Así mismo, aceptamos la introducción de cambios en el contenido si hubiere lugar tras la \\
revisión y de cambios en el estilo del manuscrito por parte de la redacción de la revista.
\end{tabular}


3. Carta de presentación y cesión de derechos de copyright

Cesión de derechos y declaración de conflicto de intereses

Los autores abajo firmantes transfieren los derechos de propiedad (copyright) del presente trabajo al Servicio de Publicaciones de la Universidad de Alicante, como organización editora patrocinadora de la revista Alternativas. Cuadernos de Trabajo Social. Declaramos además estar libres de cualquier asociación personal o comercial que pueda suponer un conflicto de intereses en conexión con el artículo remitido, así como el haber respetado los principios éticos de investigación.

Firmado:

Roberto A. XXX-XXX

Luís A. de XXX

José XXX-XXX

Alternativas, 17, 2010, pp. 245-261 - ISSN 1133-0473 



\section{INSTRUCTIONS FOR THE AUTHORS ${ }^{1}$}

\section{General Information}

The Journal Alternativas. Cuadernos de Trabajo Social, with ISSN 1133-0473, is a publication of the Department of Social Work and Social Services of Alicante University. Originally founded under the same title in 1992 by the University School of Social Work at the University of Alicante, but since 2009 it has been published by the Department of Social Work and Social Services at the same University. The journal is published annually.

It is a refereed journal, using the peer-review system for external revision by experts in the field and methodology of the research. The publication standards adopted and applied are those detailed in the APA Publication Manual $^{2}$.

It should be noted that indexing of the journal in the leading social work databases is facilitated by compliance with the requirements of the APA Manual; such compliance is therefore of benefit to authors and their centers as it ensures widespread dissemination of the research published.

Each issue of the journal is published in both a printed version and an electronic version; the latter is available on RUA of Alicante University (http://rua.ua.es/dspace/handle/10045/5269)

The journal is open to collaboration with other publications.

\section{Scope and Policy}

The primary objective of the Journal Alternativas. Cuadernos de Trabajo Social is to contribute towards the dissemination of research, experiences, and theoretical and methodological studies, of both an academic and professional

1. FECYT Rafael Ruiz-Pérez, Emilio Delgado López-Cózar, Evaristo Jiménez Contreras. EC3 Research Group. University of Granada. (http://ec3.ugr.es/t).

2. APA (American Psychological Association (http://books.apa.org/books.cfm?id=4200061 \&toc=yes). 
practice nature, carried out in Spain or internationally. Such studies may deal specifically with social work, social policies and the social services or come from other disciplines and professions in the area of the Social Sciences, which from a multi- or interdisciplinary perspective serve to enrich and complement the discipline and professional practice of social work.

Submissions must represent original, previously unpublished work which is not being considered for publication in another journal, written in Spanish, English or French. The author carries sole responsibility for the claims made in the article. Under special circumstances, previously published research may be published following consideration by the Editorial Board, when the following condition applies: publication has been through channels which are not easy to access, and the article is of particular professional relevance or scientific interest.

The following are considered for publication: original research, literature reviews, experiences, book reviews and technical notes.

Original. They must have the following structure: summary, key words, text (introduction, material and methods, results and discussion), thanks and bibliography. The maximum length of the text will be 6000 words, (in Word format), double-spaced, font size 12, font Times New Roman, with a maximum of 4 figures and 6 tables. Tables and Figures must be submitted on a separate page, numbered sequentially and indicating where they are to be inserted in the article. Only those Tables and Figures necessary to support the arguments presented in the text should be included. It is recommended that the number of authors does not exceed six.

Literature reviews and practical experience. Literature reviews should comprise a critical analysis of subjects relevant to social work, social policy and the social services. Practical experiences should consist of a rigorous systemization of the process and corresponding results. Both literature reviews and experiences should include a section detailing the contribution made, or a proposal for application or transfer to social work, social policy the social services or social intervention. Texts will be no longer than 4000 words in Word format, and should be double spaced in Times New Roman font size 12. Optionally, the text may include Tables and Figures.

Book reviews. These will be no longer than 1000 words in Word format, and should be double spaced in Times New Roman Font size 12. The heading should include the book title, authors, publishing house, place of publication, year of publication, number of pages and ISBN.

Technical notes: These should comprise a brief description of regulations or policies, research in progress, or reports of conferences, seminars or study 
days of relevance to social work, social policy or the social services. They will be no longer than 1000 words in Word format, and should be double spaced in Times New Roman font size 12.

\section{Presentation and structure of the works}

The following publication standards are based on APA http://books.apa.org/ books.cfm?id=4200061\&toc=yes:

a) The manuscripts must be sent to the Department of Social Work and Social Services (dtsss@ua.es) with copy to masun.martinez@ua.es, doublespaced, wide margins and with the pages numbered sequentially in the upper right-hand corner. The manuscript shall be accompanied by a cover letter (use template provided by the journal) asking that the manuscript be taken into consideration, with the author explaining in 4-5 lines what the original contribution of the work presented is and its new developments, a statement of non-simultaneous submission to other journals and confirmation of the undersigned authors. This letter must also transfer the copyright to the publisher. The author must keep a copy of the original to avoid irreparable loss or damage to the material.

b) Bibliographic quotations must be marked as references following the discussion or thanks, if any. An adequate number of relevant references should be used, and these should be listed in order of appearance in the text, with the corresponding reference number. References should be given as author and year between brackets, separated by a comma (for example, Coob, 1989). Page number or numbers should be included for textual quotes (for example, Coob, 1989: 25-27).

The manuscripts must be presented according to the following order and structure

Title Page. First page of the manuscript

As the cover of the manuscript, this first must contain:

a) Title of the article (concise, yet informative), in Spanish and English, made up of the greatest number of significant terms possible (taken when possible from a controlled specialty glossary). If necessary, a subtitle may be added, not to exceed 40 letters and spaces, in Spanish and English.

b) First name and two last names of each of the authors, taking into account the signature format for indexing in international databases (see section «Do 
you know how to reference scientific publications?» the recommendations provided in http://www.accesowok.fecyt.es/)

c) Full name of the work center of each of the authors, which is referenced beside the name of the author with Arabic numerals in parentheses (or superscript).

d) Name and full address of the person responsible for the work of the lead author as responsible for correspondence, including the phone number and fax number, when appropriate, as well as the e-mail address, if any.

e) Information on grants, aid or financial support provided (Research Projects) to subsidize the work and other specifications, when applicable.

To better prepare this page, see the template (provided by the journal) attached to these instructions on how to prepare the manuscript identification sheet.

\section{Summary and Key-Word Pages. Second page of the manuscript}

A second, separate page must contain the first and last names of the authors, the title of the article and the abbreviated title of the journal, article content summary in Spanish and the list of key words. Both the summary and the key words must have an English version.

- The Summary of the work must be between 150 and 250 words. In the case of the original articles, the content shall be divided into four sections (structured summary): Introduction, Material and Methods, Results and Discussion. Each of them must describe, concisely, the purpose and objective of the research, the methodology used, the most important results and the main conclusions, respectively. The novel and relevant aspects of the work must be emphasized. In the case of Special Collaborations, the work will be summarized, without dividing it into these four sections.

- Key words: Beneath the summary, 5 key words or short phrases shall be specified to indicate the content of the work, for inclusion in collections and national and international databases. As many as possible should be provided, up to a maximum of five. The controlled reference terms must be used.

Manuscript text. Third page, which is where the manuscript text begins

The third and following pages are dedicated to the manuscript text, which will comply with the specifications detailed in the instructions above for all 
submissions. In the case of Reviews and notes, the structured manuscript may be included in the appropriate sections to facilitate comprehension. However, the Original works must include, to the extent possible, the following sections: Introduction, Material and Methods, Results and Discussion.

Introduction: You must include the foundation and purpose of the study, using the bibliographic citations that are strictly necessary. Do not include data or conclusions of the work presented. Do not proved a detailed bibliographic review.

Material and Methods: It must presented with sufficient precision so that the reader can understand and confirm the development of the research. Sources and methods published previously should be described just briefly, providing the corresponding quotes, except when they have been modified. The sample size calculation and the sampling method used must be described, when appropriate. Reference must be made to the type of documentary, critical and statistical analysis, etc. used. If it is an original methodology, the reasons for using it must be explained, describing any possible limitations.

When dealing with experimental works in which groups of humans have been used, indicate whether the ethical criteria approved. Neither the names nor the initials of the people participating in the study sample must be used.

Results: These shall appear in a logic sequence in the text, tables or figures, without repeating the same data included in each of them. Try to highlight the important observations. Describe, without interpreting or judging, the observations made with the material and methods used.

Discussion: Summarize the findings, relating the observations of this study with those of other studies of interest, highlighting the contributions and limitations of each. Do not repeat the data or other material already commented in other sections in detail. Mention the inferences from the findings and their limitations, including the deductions for future research. Link the conclusions to the study objectives, avoiding gratuitous affirmations and conclusions that are not fully supported by the study data.

Thanks: Thank only those who have made substantial contributions to the study, but who do not warrant the status of author; the author must obtain their consent in writing. Likewise, the Council Science Editors (CSE) recommend that authors, when appropriate, provide an explicit statement of the source of their research funding, placing it among the thanks (CSE 2000) (Conflicts of Interest and the Peer Review Process. Draft for CSE member review, posted 3/31/00. http://www.cbe.org/services_DraftPolicies.shtml). 
Bibliography: The bibliography must be placed after the discussion or the thanks, if any, in the format indicated above, based on the alphabetical order of authors.

The recommended style for the references is indicated below in the examples; it is based on the APA standards.

- The names of the journals must be abbreviated in accordance with the consensus reached in the area of knowledge, whenever there is a reference list.

- All authors must be mentioned, up to six, or the first six plus «et al» when there are seven or more.

The bibliography must be corrected by the author, correcting it with the copy in his or her possession. Avoid using vague phrases as bibliographical quotations. Do not use those that require clarifications such as «unpublished observations» or "personnel correspondence», although they may be cited in the text in parentheses. Works that have been accepted, but not yet published, shall be included in the bibliography, specifying the name of the journal, followed by the expression «pending publication».

The bibliographic quotes must be taken from the original documents, always indicating the starting and ending page number of the work from which they are taken. To ensure consistency, at any time during the publishing process, the journal editors may require authors to send the first page (photocopy) of each of the articles quoted in the bibliography.

For journals, given the their importance for quotation indexes and Impact Factor calculations, the following shall be cited: a) author(s), with their last name(s) and first name(s). If there is more than one author, they must be separated by a comma. All of them, up to a maximum of six; if there are more than six, the first six shall be indicated, followed by «et al». Place the year, in parentheses and a period after the final author, b) title of the article in the original language, with the appropriate spelling and accents. Place a period after the title, c) correct name of the journal, d) issue number (no.). A comma shall be used to separate this section and section e, e) first and last pages, separated by a hyphen.

The following are examples of properly referenced bibliographic quotations:

\section{Periodical Publications}

Journal article, one author

Bekerian, D. A. (1992). In search of the typical eyewitness. American Psychologist, 48, 574-576. 
Journal article, two authors

Klimowski, R., Palmer, S. (1993). The ADA and the hiring process in organizations. Consulting Psychology Journal: Practice and Research, 45(2), 10-36.

Journal article, three to five authors

Borman, W. C., Hanson, M. A., Oppler, S. H., Pulakos, E. D., and White, L. A. (1993). Role of early supervisory experience in supervisor performance. Journal of Applied Psychology, 78, 443-449.

Journal article, six authors

Kneip, R. C., Delamater, A. M., Ismond, T., Milford, C., Salvia, L., and Schwartz, D. (1992). Self- and spouse ratings of anger and hostility as predictors of coronary heart disease. Health Psychology, 12, 301-307.

Journal article, pending publication

Bekerian, D. A. (pending publication). In search of the typical eyewitness. American Psychologist.

Bekerian, D. A. (pending publication-a). Role of early supervisory experience in supervisor performance. American Psychologist.

Bekerian, D. A. (pending publication-b). Self- and spouse ratings of anger and hostility as predictors of coronary heart disease. American Psychologist.

Non-English journal article, with the title translated into English

Zajonc, R. B. (1992). Bischofs gefühlvolle Verwirrunggen über die Gefühlle [Bischof's emotional fluster over the emotions]. Psychologische Rundschau, 40, 574-576.

\section{Books and Book Chapters}

References to entire books

Bekerian, D. A. (1992). People in organizations: An introduction to organizational behavior (3rd ed.). New York: McGraw-Hill.

Book, group authorship (governmental agency) as publisher

Australian Bureau of Statistics (1992). Estimated resident population by age and sex in statistical local areas, New South Wales, June 1990 (No. 3209.1). Australian Capital Territory: ABS

Published book

Bekerian, D. A. (Ed.). (1992). People in organizations: An introduction to organizational behavior. New York: McGraw-Hill. 
Book without author or publisher

Merriam-Webster's Collegiate Dictionary (10th ed.). Springfield, MA: Merriam-Webster.

Encyclopedia or dictionary

Bekerian, D. A. (1992). The new Grove dictionary of music and musicians (3rd ed., Vols. 1-20). New York: McGraw-Hill.

English translation of a book

Laplace, P. -S. (1951). A philosophical essay on probabilities (Trans., F. W. Truscott and F. L. Emory). New York: McGraw-Hill. (Original work published in 1814).

Chapter in one volume of a series

Maccoby, E. E. (1992). Socialization in the context of the family. En P. M. Musen (Ed. Serie) and M. J. Martin (Ed. Vol.). Handbook of child psychology: Vol. 4. Socialization, personality, and social development (3rd ed., pgs. 1-101). New York: McGraw-Hill.

\section{Technical and Research Reports}

Report available in the GPO (Government Printing Office), governmental institution as author

National Institute of Mental Health (1992). Clinical training in serious mental illness (Publication DHHS No. ADM 90-1679). Washington, DC: Government Printing Office.

Scientific Meetings (Congresses, symposiums, etc.)

Published congress minutes, contribution published in a symposium, article or chapter in published book

Bekerian, D. A. (1992). A motivational approach to the self. En R. DeMaier

(Ed.), Nebraska Symposium of Motivation: Vol. 38. Perspectives on motivation (pgs. 574-596). Lincoln: University of Nebraska Press.

Regularly published minutes

Bekerian, D. A. (1992). In search of the typical eyewitness. Proceedings of the National Academy of Sciences, USA, 89, 574-576. 
Unpublished work presented at a congress

Bekerian, D. A. (1992, January). Early data on the Trauma Symptom Checklist for Children (TSC-C). Presentation given at the Congress of the American Professional Society on the Abuse of Children, San Diego, CA.

\section{Doctoral and Master's Theses}

Unpublished doctoral thesis

Bower, D. L. (1993). Employee assistant programs supervisory referrals: Characteristics of referring and nonreferring supervisors. Unpublished doctoral thesis. University of Missouri, Columbia.

Unpublished Master's thesis, non-American university

Saldaña, P. (1992). Actitudes de los padres hacia la integración escolar. Unpublished Master's thesis, Universidad de Salamanca, Salamanca, Spain.

\section{Reviews}

Review of a book

Baumeister, R. F. (1993). Exposing the self-knowledge myth [Review of the book The self-knower: A hero under control]. Contemporary Psychology, $38,466-467$.

\section{Audiovisual Media}

Film, limited distribution

Bekerian, D. A. (Producer), and Smith, J. N. (Director). (1992). Changing our minds [Film]. (Available from Changing Our Minds, Inc., 170 West End Avenue, Suite 35R, New York, NY 10023).

\section{Electronic Media}

Online journal article, access limited to subscribers

Central Vein Occlusion Study Group. (1993, 2 October). Central vein occlusion study of photocoagulation: Manual of operations [675 paragraphs]. Online Journal of Current Clinical Trials [Online series]. Available in: Doc. No. 92. 


\section{References to electronic sources (INTERNET)}

www sites

Tilton, J. (1995). Composing good HTML (Vers. 2.0.6). http://www.cs.cmu. edu/ tilt/cgh/ (13 Jan. 1997).

Tables: These must be presented on separate pages, numbered according to their order of appearance in the text with Arabic numerals. They are used to clarify important points; double documentation by means of tables and figures shall not be accepted. The titles or footers that accompany them must perfectly explain their content.

Figures: All types of photographs, graphs or drawings are considered figures. They are assigned an Arabic numeral according to their order of appearance in the text, identified by the abbreviated term fig.(s). The footers or legends of each one must be typed, with the corresponding number on a separate sheet. The text in the figures must be in uppercase. They must be designed presented with good contrast so that quality is not lost in the reduction. Micro-photographs will be accepted in these proportions for publication without reduction.

The publication of figures in color must be specified in advance. The author shall be responsible for the photomechanical expenses.

The figures must clarify the text in a major way, and they must be used in the minimum amount necessary.

Abbreviation: Only standard, universally accepted abbreviations shall be used. See Units, Symbols and Abbreviations. When a term that is used frequently in the text is to be shortened, the corresponding abbreviation must accompany it (in parentheses) the first time it appears. No Roman numerals shall be used in the text; periods shall be used to the right of the zero for decimals, not commas. Trademarks shall not be used except as needed, in which case the first time they are used they shall be accompanied by the symbol.

\section{Editorial process}

The works shall be submitted together with a cover letter which requests evaluation of the same for publication in one of the sections of the Journal, expressly indicating that it is a work that has not been disseminated or published previously, sent only to the Journal Alternativas. Cuadernos de Trabajo Social for evaluation and publication, if appropriate, as well as the contributions regarding originality and novelty that, according to the authors, the work contains. 
The cover letter must be signed by all authors. It shall include written authorization from all people appearing in the section of thanks or from those studied during the research whose identification is essential in presenting the results. It shall also include a statement, when appropriate, accepting the introduction of changes to the manuscript by the journal editors.

The Journal's editorial staff shall acknowledge receipt to the authors of the works they receive, subsequently notifying them of their acceptance or rejection.

The editorial staff shall pass the work under consideration for publication to the Editorial Board, verifying that it suits the journal's coverage and complies with the publication standards. If it does, it will be reviewed externally.

The manuscripts shall be reviewed anonymously (blind or double blind) by two experts in the study subject and/or methodology used. Based on the external reports, the Journal's editorial staff reserves the right to accept / reject the articles for publication, as well as to make style modifications and/ or shorten texts that surpass the established limit, committing to respect the original content. The protocol used by the journal reviewers shall be made public as annexes to these standards published on the journal's website: http://www.ua.es/dpto/dtsss/publicaciones.htm

In the event of differences of opinion between the two evaluators, the works shall be sent to a third evaluator. External paired review will be applied to research, literature reviews, and experiences. Works that are reviewed and considered for publication following modification shall be returned within a period of 30 days regardless of whether minor or major corrections are requested. Where necessary, the new version of the text will be submitted again to external review, and this process will be repeated until the text is definitively accepted by the Journal. The authors will receive the evaluation reports from the reviewers, anonymously, so that they may make (when appropriate) any necessary corrections or replies.

In general, once the external reports have been seen, the factors on which the Journal's editorial staff bases its decision on accepting/rejecting the works are the following: a) originality: completely original, valuable information, repetition of known results; b) timeliness and novelty; c) relevance: applicability of the results in resolving specific problems; d) significance: advancement of scientific knowledge; e) reliability and scientific validity: verified methodological quality; f) presentation: good writing, organization (logical coherence and material presentation).

The author(s) of accepted articles will receive printing proofs for correction by e-mail in PDF format. These must be returned corrected to the 
editorial staff of the journal by fax or PDF within 72 hours of receipt. Only minimal corrections may be made to the content of the original manuscript without an extra charge applying.

The author or the lead signatory will receive 1 copy of the Journal after it has been published.

\section{Ethical responsibility}

It is the responsibility and duty of the editorial staff of the Journal Alternativas. Cuadernos de Trabajo Social to remind its collaborators of the following:

- When describing the experiments carried out on human beings, indicate whether the procedures followed are in compliance with the ethical standards of the responsible human experimentation committee (institutional or regional) and the 1975 Declaration of Helsinki, revised in 2000. No names, initials or other information should identify the centers where the research was conducted.

- The institution financing the research must grant permission for publication.

- The journal does not accept previously published material. The authors are responsible for obtaining the appropriate permission for partially reproducing material (text, tables or figures) from other publications and for citing their source correctly.

Conflict of Interest. The Journal expects the authors to declare any commercial association that may represent a conflict of interest as regards the article submitted.

Authorship. The list of signing authors must include only those who have contributed intellectually to the development of the work. Having assisted in the collection of data or participated in a technique are not in and of themselves sufficient criteria for listing as an author. In general, being listed as an author requires fulfilling the following requirements: a) participation in the conception and drafting of the work leading to the article in question, b) participation in drafting the text and in any revisions, c) having approved the final version to be published.

The Journal waives any liability due to possible conflicts derived from the authorship of the works published in the Journal.

Informed Consent. The authors must mention, in the methods section, that the procedures and controls used with participants were carried out after obtaining an informed consent form.

Copyright Transfer. The manuscript or the cover letter shall include a Rights Identification and Transfer Sheet (provided by the journal) signed by all authors. 


\section{Additional Information}

The Journal confirms receipt all formalities carried out to keep the authors abreast of the status of their manuscript.

The judgments and opinions expressed in the articles and notices published in the Journal are those of the authors and not necessarily of the Editorial Board.

Both the Editorial Board and the publishing company waive all liability for the material published. Neither the Editorial Board nor the publishing company guarantee or support any product advertised in the Journal, nor do they guarantee the claims made by the manufacturer of said product or service.

\section{Protocols for the authors ${ }^{3}$}

\section{Checklist}

(Its purpose is to require the author(s) to review the manuscript one last time as regards its fundamental formal and methodological aspects.)

\section{Checklist}

To facilitate the Reading Committee's work, acceptance of the manuscript for processing and speeding up its possible publication, the author(s) must carry out a final review of the manuscript, verifying the issues included on this list. Once completed, the list must be submitted together with the manuscript. Remember that failure to complete any of the items may be cause for the manuscript to be returned.

\begin{tabular}{l|c|}
\hline $\begin{array}{l}\text { 1. Attached are complete copy of the manuscript by e-mail files, in word for- } \\
\text { mat, double-spaced, including the bibliographic quotations, and figures. }\end{array}$ & $\bullet$ \\
\hline \begin{tabular}{l} 
2. The full title of the manuscript is included in Spanish and English. \\
\hline $\begin{array}{l}\text { 3. The abbreviated title of the manuscript and the key words are included in Spanish } \\
\text { and English. }\end{array}$
\end{tabular} & $\bullet$ \\
\hline $\begin{array}{l}\text { 4. The summary complies with the publication standards as regards the number of } \\
\text { words, and it includes objectives, design or material and methods, results, conclu- } \\
\text { sions and/or discussion. }\end{array}$ & $\bullet$ \\
\hline $\begin{array}{l}\text { 5. The summary and key words has been translated into English or Spanish and, } \\
\text { when possible, reviewed by an expert in that language. }\end{array}$ & $\bullet$ \\
\hline $\begin{array}{l}\text { 6. The institutional and/or professional affiliations of each author are included } \\
\text { 7. The address, telephone number, fax number and e-mail address of the main au- } \\
\text { thor or the person responsible for correspondence are included. }\end{array}$ & $\bullet$ \\
\hline 8. When applicable, grants, aid or financial support have been stated. Source. & $\bullet$ \\
\hline
\end{tabular}

3. (c) Drafted for FECYT by Rafael Ruiz-Pérez, Emilio Delgado López-Cózar, Evaristo Jiménez Contreras. EC3 Research Group. University of Granada. http://ec3.ugr.es/ 


\begin{tabular}{|l|l|}
\hline 1. Checklist \\
\hline $\begin{array}{l}\text { 9. The manuscript follows the structured required in the publication standards and } \\
\text { the specifications from the section to which it is addressed. }\end{array}$ & $\bullet$ \\
\hline $\begin{array}{l}\text { 10. The manuscript describes all sources, materials, equipment and elements used, } \\
\text { both in terms of research groups and in the whole of the study. }\end{array}$ & $\bullet$ \\
\hline $\begin{array}{l}\text { 11. An expert in the subject matter covered by the manuscript could reproduce the } \\
\text { study, experiment, analysis, etc. based on the methodology described. }\end{array}$ & $\bullet$ \\
\hline 12. The conclusions are based on the results obtained. & $\bullet$ \\
\hline 13. When appropriate, statistical analyses were used, reviewed by an expert. & $\bullet$ \\
\hline $\begin{array}{l}\text { 14. The Bibliographic References have been reviewed and they comply with the style } \\
\text { and format in the international standards required by the journal. }\end{array}$ & $\bullet$ \\
\hline $\begin{array}{l}\text { 15. When applicable, the figures and tables provide additional information, not re- } \\
\text { peated in the text. Their graphical quality has been verified. }\end{array}$ & $\bullet$ \\
\hline $\begin{array}{l}\text { 16. When appropriate, the units system used has been reviewed. } \\
\text { 17. Abbreviations are detailed the first time they are mentioned in the text. }\end{array}$ & $\bullet$ \\
\hline \begin{tabular}{l} 
18. When appropriate, the ethical standards used are cited. \\
\hline $\begin{array}{l}\text { 19. When appropriate, the informed consent forms for experimentation with hu- } \\
\text { mans or animals, as well as reproduction permission, are attached to the manuscript. }\end{array}$ \\
\hline $\begin{array}{l}\text { 20. The checklist and cover letter are attached, indicating originality, novelty of the } \\
\text { work and the section of the journal to which it is addressed. }\end{array}$
\end{tabular} & $\bullet$ \\
\hline $\begin{array}{l}\text { 21. The cover letter includes an annex signed by the authors, taking responsibility } \\
\text { for authorship and transferring the copyright to the publisher. }\end{array}$ & $\bullet$ \\
\hline
\end{tabular}

\section{Writing the first page of the manuscript}

Also known as the Identification Sheet or Title Page, this protocol provides the author with the appropriate format for providing the manuscript identification data. These data are important not only for the final version of the manuscript that is to be published, but also for indexing in the databases.

\section{Preparing an identification sheet}

Given the importance of the identification data for the manuscript (First page of the manuscript or Title Page), follow the structure in the following template.

Title: spanish and english

Competencia profesional en Trabajo Social...

Professional competence in Social work...

Authors:

Roberto A. XXX-XXX11, Luís A. de XXX-XXX², José XXX-XXX

Professional/Institutional affiliation

1. XXX University. XXX Dept., Madrid, Spain

2. Higher Council for Scientific Research. Institute of XXX, Granada, Spain

3. XXX Hospital. XXX Service. XXX Unit, Madrid, Spain

(Do not reference status as «resident», «professor», «department head», etc.) 


\begin{tabular}{|l|}
\hline 2. Preparing an identification sheet \\
\hline Correspondence coordinator \\
Roberto A. XXX-XXX \\
XXX University. XXX Dept., Madrid, Spain \\
Av. MMMMMMM 273 \\
28007 Madrid, Spain \\
$\quad$ E-mail: xxx@internet.com \\
\hline Institution responsible for research support and/or financial support (when \\
applicable) \\
XXX Ophthalmology Institute, XXX University, Madrid, Spain. \\
Subsidized project FIS-78/2-1993 by the Ministry of Health \\
\hline Dissemination history (when applicable) \\
Presented in part as a speech to the «20th XXX Congress», Helsinki, Finland, held on \\
XXX \\
\hline Section to which the article is addressed \\
Original Articles \\
\hline
\end{tabular}

\section{Cover letter, rights transfer and conflict of interests statement}

The purpose of the Cover Letter is to help make the manuscript review and decision-making process as quick and efficient as possible, in that it provides information and summarizes the most important aspects and details, required by the journal to take the work into consideration, such as justification for choosing the journal, work contributions, authorship and originality statement, ethical and conflict of interest responsibilities, etc. 


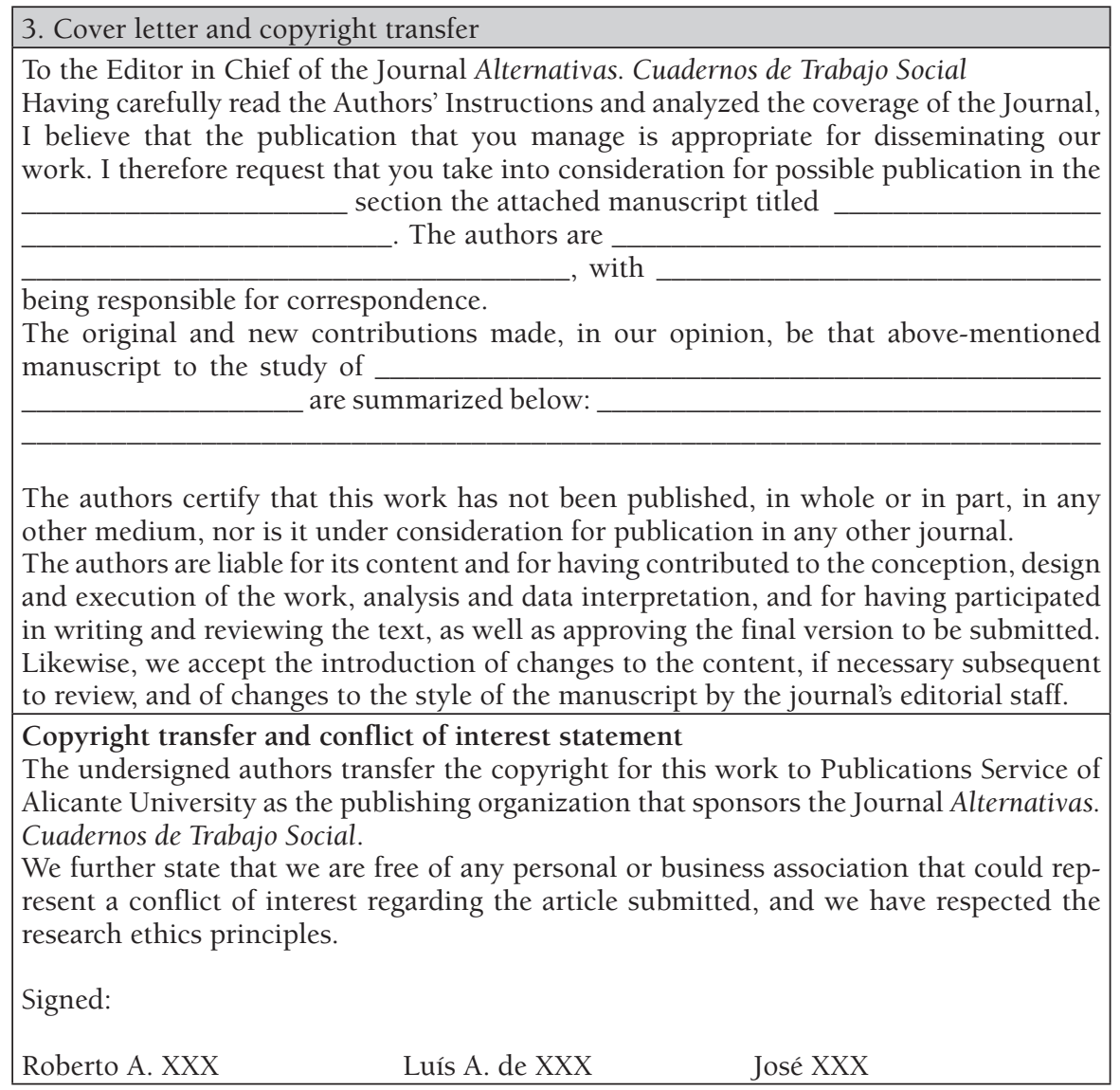




\section{PROTOCOLO REVISORES EXTERNOS}

Estimado revisor:

El modelo que se adjunta pretende ser una ayuda orientada para la realización de su valoración, y no una limitación a la misma. A este protocolo el evaluador puede añadir aquellos aspectos que considere oportunos, a ser posible, en la línea de uno de los fundamentos del Peer Review (revisión por pares), esto es, mejorar la presentación formal y los contenidos científicos del manuscrito cuando éste le merezca una valoración favorable.

Junto a este protocolo, se le remiten las instrucciones para los autores de la revista, si bien, también podrá localizarlas en http://www.ua.es/dpto/dtsss/ publicaciones.htm.

Una vez realizada la evaluación, remitir vía e-mail a Yolanda Doménech López(dtsss@ua.es),con copia a masun.martinez@ua.es.

Revista: Alternativas. Cuadernos de Trabajo Social Directora: M. ${ }^{a}$ Asunción Martínez Román

Manuscrito n. ${ }^{\circ}$ ref.:

Título manuscrito:

Evaluador:

Fecha envío evaluador: Fecha devolución: 


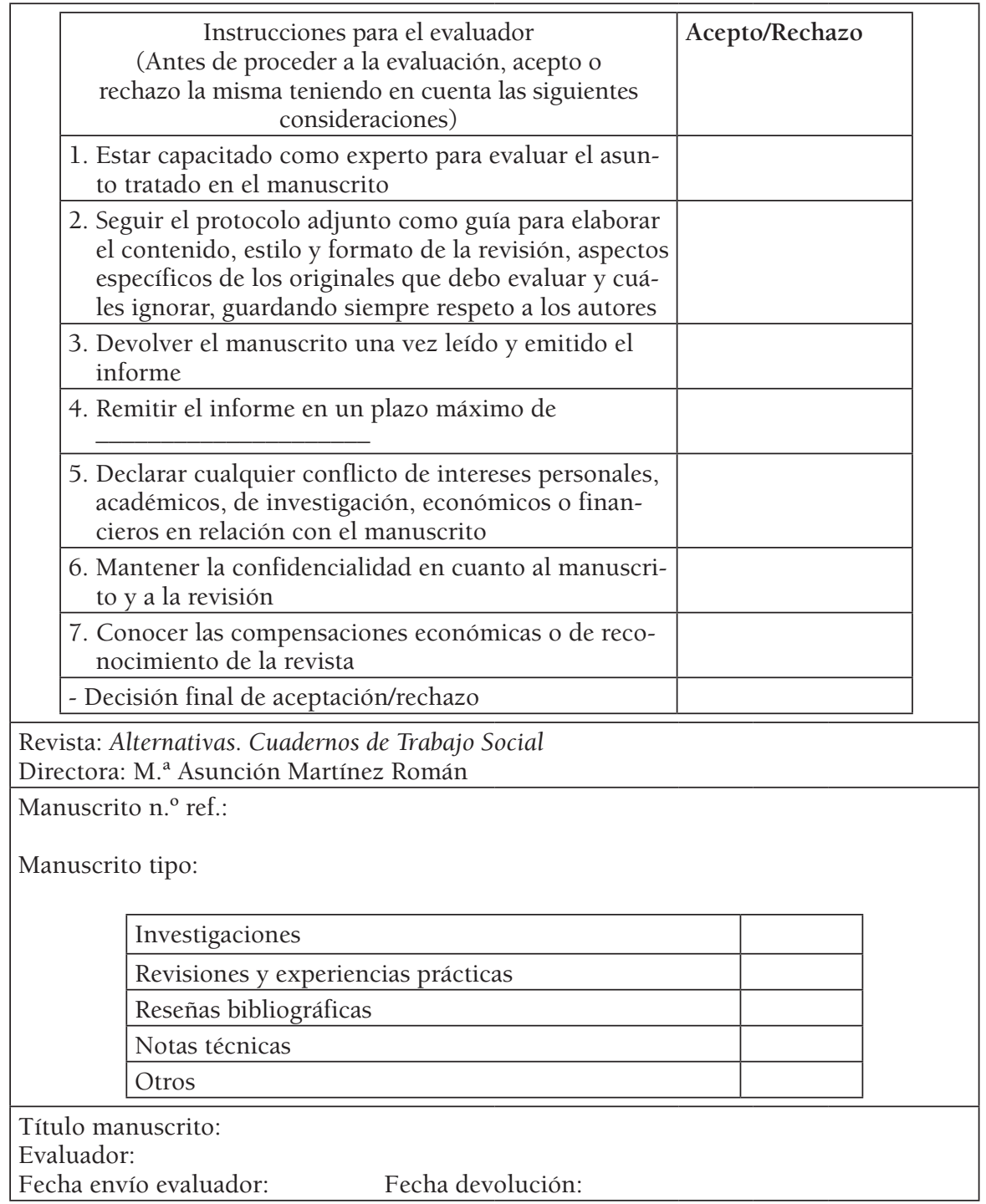




\section{Cumplimentar como conclusión final de la evaluación}

1. Recomendación:

\begin{tabular}{|l|l|}
\hline Aceptar & \\
\hline Aceptar con correcciones menores & \\
\hline $\begin{array}{l}\text { Aceptar con correcciones mayores } \\
\text { (Nuevo proceso de revisión) }\end{array}$ & \\
\hline Rechazar & \\
\hline Prioridad de publicación & \\
\hline
\end{tabular}

2. Valoración global de la calidad del trabajo

\begin{tabular}{|l|l|}
\hline Máxima & \\
\hline Buena & \\
\hline Media & \\
\hline Baja & \\
\hline
\end{tabular}

3. Valoración de originalidad y relevancia (respecto de la información científica que contiene el artículo: a) nueva y valiosa, b) resultados ya conocidos, c) irrelevante)

\begin{tabular}{|l|l|}
\hline Máxima & \\
\hline Media & \\
\hline Baja & \\
\hline
\end{tabular}

4. Aspectos técnicos y científicos:

\begin{tabular}{|l|l|l|l|}
\hline 4.1. Estructura y estilo: & Sí & No & $\begin{array}{c}\text { Mejorar o } \\
\text { cambiar }\end{array}$ \\
\hline 4.1.1. Título adecuado (claro, conciso e informativo) & & & \\
\hline Español & & & \\
\hline Inglés & & & \\
\hline $\begin{array}{l}\text { 4.1.2. Resumen correcto (es claro e incluye los objetivos, } \\
\text { el diseño, los métodos, las variables consideradas, } \\
\text { los principales resultados y las conclusiones más } \\
\text { relevantes) }\end{array}$ & & & \\
\hline Español & & & \\
\hline Inglés & & No & $\begin{array}{c}\text { Mejorar o } \\
\text { cambiar }\end{array}$ \\
\hline $\begin{array}{l}\text { 4.1.3. La estructura del discurso es adecuada } \\
\text { 4.1.4. El estilo es apropiado (claro, conciso y sigue una se- } \\
\text { cuencia lógica) }\end{array}$ & & & \\
\hline $\begin{array}{l}\text { 4.2. Fundamentación, metodología, } \\
\text { resultados y discusión }\end{array}$ & & & \\
\hline $\begin{array}{l}\text { 4.2.1. El tema, asunto o problema general ise identifica de } \\
\text { forma inmediata y clara? }\end{array}$ & & & \\
\hline $\begin{array}{l}\text { 4.2.2. El tema(s), asunto o problema específico ise delimita } \\
\text { y define con claridad? }\end{array}$ & & & \\
\hline
\end{tabular}




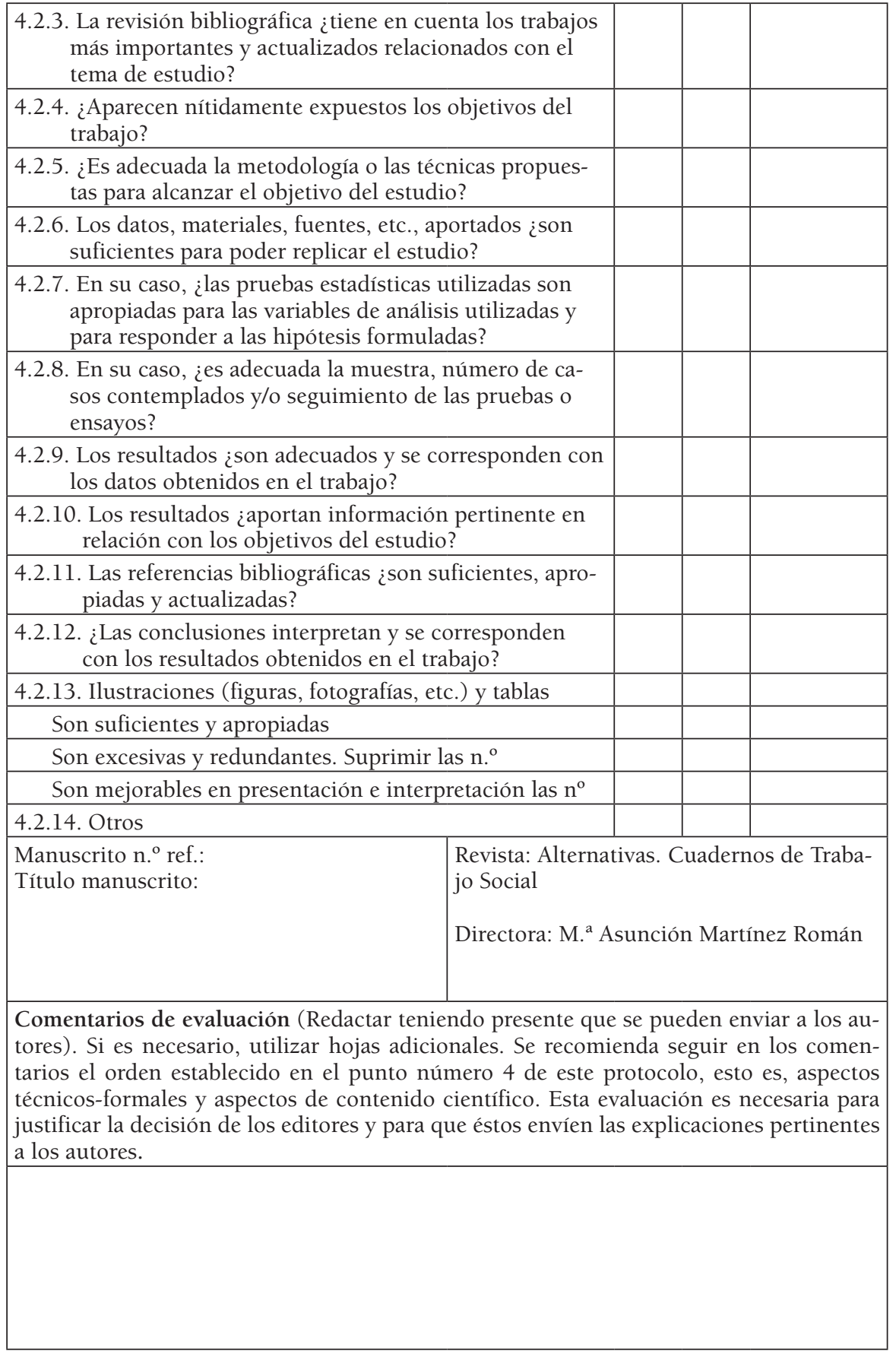




\begin{tabular}{|l|l|}
\hline $\begin{array}{l}\text { Manuscrito } \mathrm{n}^{\circ} \text { : } \\
\text { Manuscrito Título: }\end{array}$ & $\begin{array}{l}\text { Revista: Alternativas. Cuadernos de Traba- } \\
\text { jo Social }\end{array}$ \\
\hline Evaluador: & Directora: Ma Asunción Martínez Román \\
\hline $\begin{array}{l}\text { Comentarios confidenciales (Comentarios sólo con respecto a la aceptabilidad del ma- } \\
\text { nuscrito, sólo para el editor) }\end{array}$ & \\
\hline
\end{tabular}

Tras revisar el artículo, declaro: Que no tengo interés financiero ni intelectual, ni personal en relación con el mismo y que no difundiré la información obtenida a través de su revisión previamente a su publicación

Nombre y apellidos:

Lugar y fecha:

Firmado: 



\section{EXTERNAL REVIEWERS' PROTOCOL}

Dear reviewer, The attached template is intended as a guideline for conducting the assessment, but not a limitation to the same. The evaluator may add any aspects to this protocol deemed to be appropriate, in line, when possible, with one of the principles of the Peer Review; that is, to improve the formal presentation and scientific content of the manuscript when it is worthy of a favorable assessment.

The Instructions for the Authors for the journal are also included, although they can also be found on the website http://www.ua.es/dpto/dtsss/ publicaciones.htm

Once completed, send the evaluation by e-mail to Yolanda Domenech López(dtsss@ua.es),with copy to masun.martinez@ua.es

Journal: Alternativas. Cuadernos de Trabajo Social

Editor in Chief: M. ${ }^{a}$ Asunción Martínez Román

Manuscript Ref. No.:

Manuscript Title:

Evaluator:

Date sent to evaluator: Date returned: 


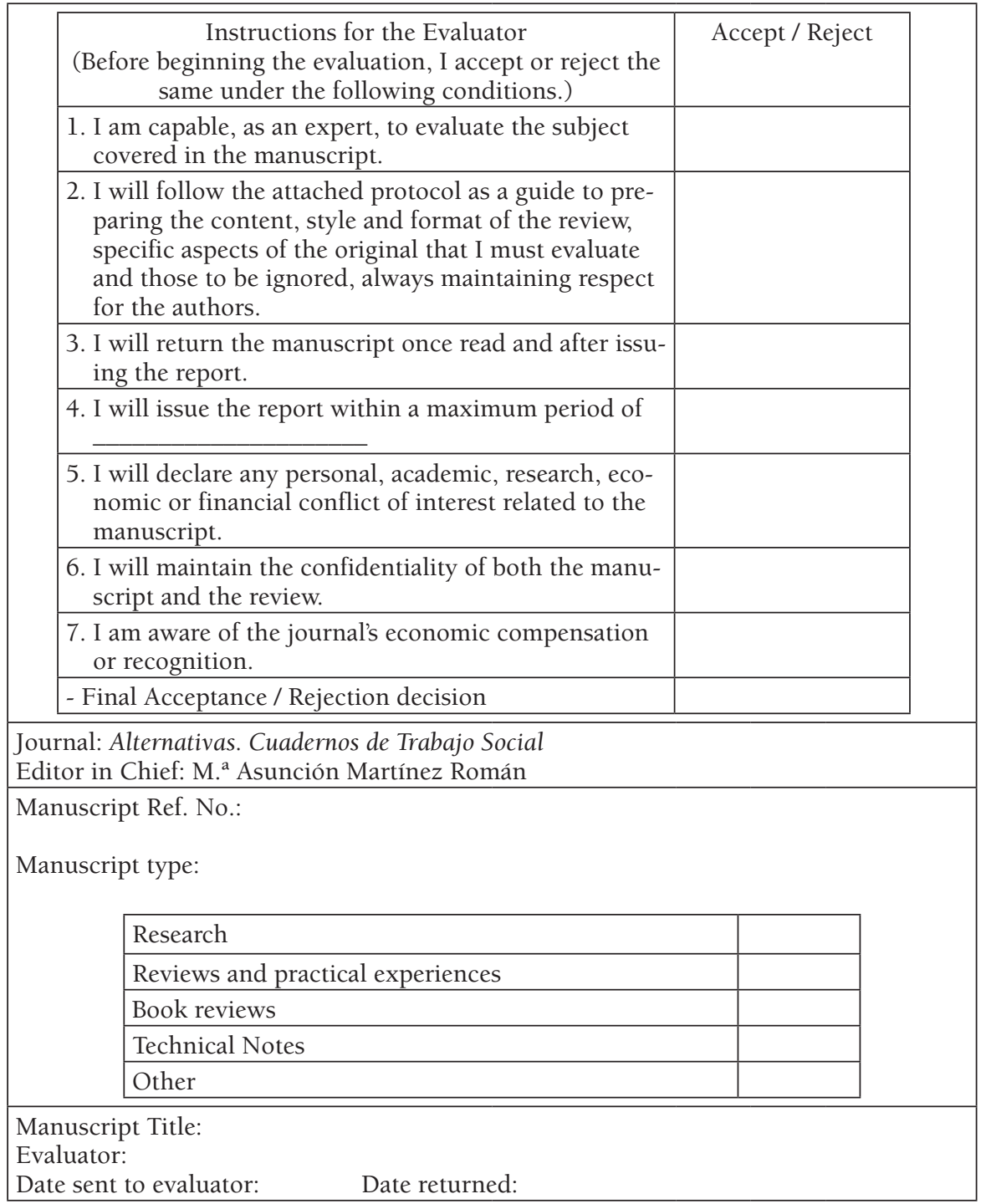




\section{Complete as final evaluation conclusion}

1. Recommendation:

\begin{tabular}{|l|l|}
\hline Accept & \\
\hline Accept with minor corrections & \\
\hline $\begin{array}{l}\text { Accept with major corrections } \\
\text { (New review process) }\end{array}$ & \\
\hline Reject & \\
\hline Publication priority & \\
\hline
\end{tabular}

2. Overall assessment of the quality of the work:

\begin{tabular}{|l|l|}
\hline Highest & \\
\hline Good & \\
\hline Average & \\
\hline Low & \\
\hline
\end{tabular}

3. Originality and relevance assessment (regarding the scientific information contained in the article: -new and valuable, -results already known, - irrelevant):

\begin{tabular}{|l|l|}
\hline Highest & \\
\hline Average & \\
\hline Low & \\
\hline
\end{tabular}

4. Technical and scientific aspects:

\begin{tabular}{|c|c|c|c|}
\hline 4.1. Structure and style & Yes & No & $\begin{array}{c}\text { Improve or } \\
\text { Change }\end{array}$ \\
\hline \multicolumn{4}{|l|}{ 4.1.1. Appropriate title (clear, concise and informative) } \\
\hline \multicolumn{4}{|l|}{ Spanish } \\
\hline \multicolumn{4}{|l|}{ English } \\
\hline \multicolumn{4}{|l|}{$\begin{array}{l}\text { 4.1.2. Correct summary (it is clear and includes the objec- } \\
\text { tives, design, methods, variables considered, primary } \\
\text { results and most relevant conclusions) }\end{array}$} \\
\hline \multicolumn{4}{|l|}{ Spanish } \\
\hline \multicolumn{4}{|l|}{ English } \\
\hline \multicolumn{4}{|l|}{ 4.1.3. The structure of the discussion is appropriate } \\
\hline \multicolumn{4}{|l|}{$\begin{array}{l}\text { 4.1.4. The style is appropriate (clear, concise and following } \\
\text { a logical sequence) }\end{array}$} \\
\hline 4.2. Foundation, methodology, results and discussion & Yes & No & $\begin{array}{c}\text { Improve or } \\
\text { Change }\end{array}$ \\
\hline \multicolumn{4}{|l|}{$\begin{array}{l}\text { 4.2.1. Is the theme, subject or general problem identified } \\
\text { immediately and clearly? }\end{array}$} \\
\hline \multicolumn{4}{|l|}{$\begin{array}{l}\text { 4.2.2. Are the theme(s), subject or specific problem } \\
\text { outlined and defined clearly? }\end{array}$} \\
\hline $\begin{array}{l}\text { 4.2.3. Does the bibliographic review take into consideration } \\
\text { the most important and up-to-date works related to } \\
\text { the study theme? }\end{array}$ & & & \\
\hline
\end{tabular}

Alternativas, 17, 2010, pp. 285-289 - ISSN 1133-0473 


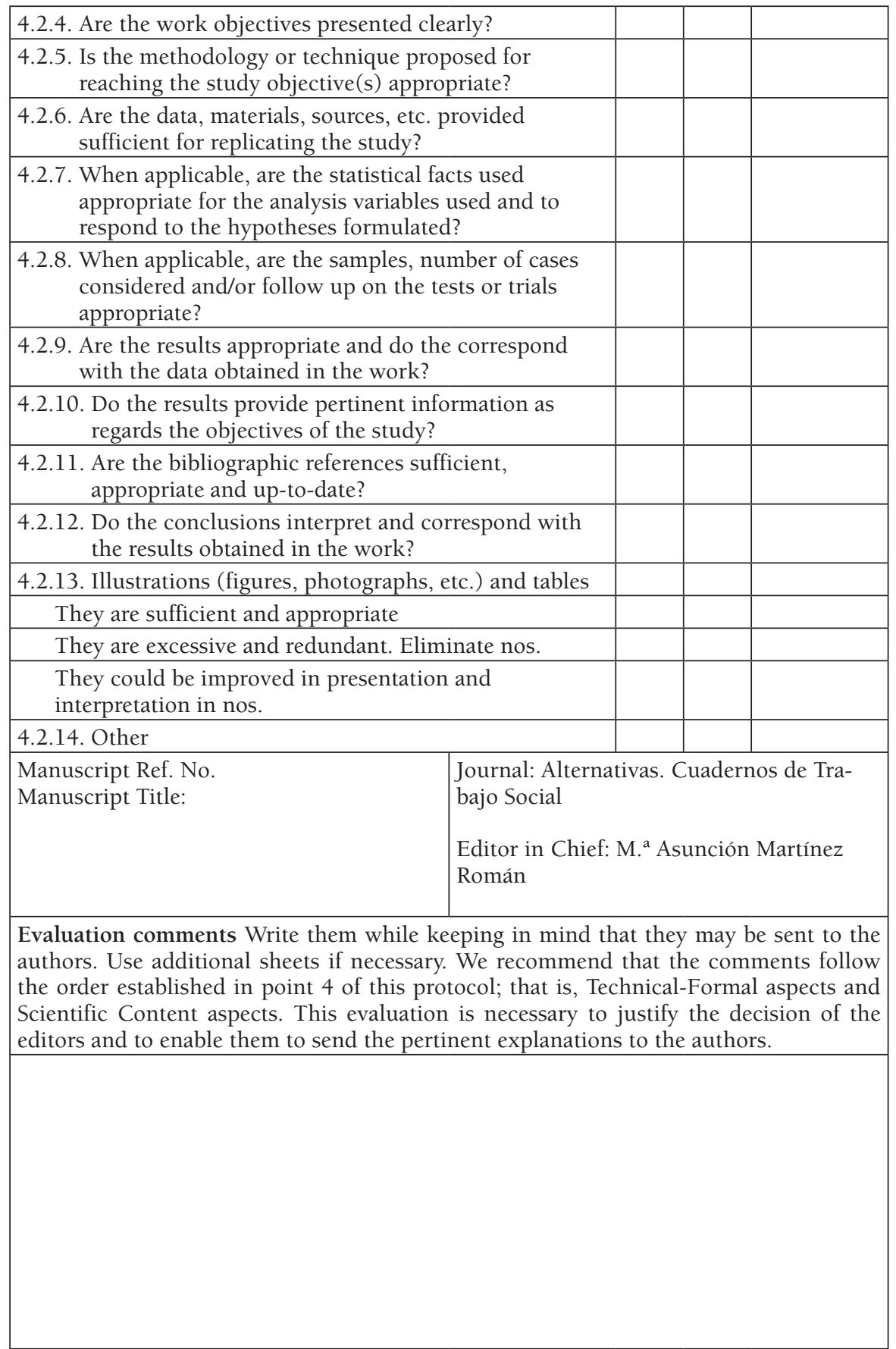




\begin{tabular}{|l|l|}
\hline $\begin{array}{l}\text { Manuscript } \mathrm{N}^{\circ} .: \\
\text { Manuscript Title: }\end{array}$ & $\begin{array}{l}\text { Journal: Alternativas. Cuadernos de Tra- } \\
\text { bajo Social } \\
\text { Editor in Chief: M. }{ }^{a} \text { Asunción Martínez } \\
\text { Román }\end{array}$ \\
\hline Evaluator: & C (Comments on the acceptability of the manuscript only; for the Editor only). \\
\hline
\end{tabular}

I have reviewed the article and hereby declare: that I have no financial, intellectual or personal interest in this article and that I will not disseminate the information obtained through the review of the article prior to its publication.

Name:

Location and date:

Signed.

Alternativas, 17, 2010, pp. 285-289 - ISSN 1133-0473 


